NATASCHA CARDOSO DA FONSECA

\title{
Estudo do perfil serotoninérgico no hipocampo de pacientes com epilepsia do lobo temporal
}

Tese apresentada à Faculdade de Medicina da Universidade de São Paulo para obtenção do título de Doutor em Ciências

Programa de Psiquiatria

Orientadora: Profa. Dra. Kette Dualibi Ramos Valente

São Paulo 2018 
Dados Internacionais de Catalogação na Publicação (CIP)

Preparada pela Biblioteca da

Faculdade de Medicina da Universidade de São Paulo

Creprodução autorizada pelo autor

Fonseca, Natascha Cardoso da

Estudo do perfil serotoninérgico no hipocampo de pacientes com epilepsia do lobo temporal /

Natascha Cardoso da Fonseca. -- São Paulo, 2018.

Tese (doutorado)--Faculdade de Medicina da

Universidade de São Paulo.

Programa de Psiquiatria.

Orientadora: Kette Dualibi Ramos Valente.

Descritores: 1.Serotonina 2.Receptores de serotonina 3.Epilepsia do lobo temporal 4.Hipocampo 5.Western blotting 6.Cromatografia líquida de alta pressão

$\mathrm{USP} / \mathrm{FM} / \mathrm{DBD}-297 / 18$

Responsável: Eidi Raquel Franco Abdalla - CRB-8/4901 


\section{DEDICATÓRIA}


Aos meus pais, Márcia e Dimas (in memoriam), fonte de inspiração e base do que eu sou.

Aos meus filhos, Giovana e Gabriel, que me motivam e dão um sentido especial ao meu viver.

Ao meu esposo, Fabrício, companheiro e cúmplice desta caminhada. 
AGRADECIMENTOS 
Uma tese nasce de uma ideia e um esforço e ganha forma através da persistência e dedicação. Mas ela não é resultado do trabalho de apenas um, pois muitos são os que contribuem para a sua realização. Gostaria de agradecer a todos os envolvidos, que participaram, de forma direta ou indireta neste trabalho.

A minha orientadora, Prof. Dra. Kette Dualibi Ramos Valente, um exemplo de dedicação e competência no que faz. Obrigada pelo carinho, atenção e disponibilidade, me orientando e corrigindo (inúmeras vezes), sempre com muita paciência. Por ter sido mais que uma orientadora e professora, sempre compartilhando experiências profissionais e pessoais, com momentos agradáveis de conversas, conselhos, almoços e cafezinho.

A Helena, pelos ensinamentos, colaboração, disponibilidade e muita paciência comigo, mesmo nos momentos de total descoordenação. Pelo socorro e direcionamento, quando me aventurei neste mundo laboratorial, completamente diferente do rotineiro. Sua ajuda foi fundamental para o desenvolvimento deste trabalho.

A Leda Talib, chefe do Laboratório (LIM 27), pela receptividade, ao receber uma intrusa no seu ambiente de trabalho; por todo o apoio e orientação no mundo laboratorial e da neurociência básica.

A toda a equipe e alunos do LIM27, local onde pude realizar este trabalho, por todo o aprendizado, e suporte necessário. Em especial, a Vanessa e Tamires, pelo auxílio nos momentos necessários; a Edivani, por ajudar a manter o laboratório em ordem após a minha bagunça.

A Silvia de Vincentiis, pela sabedoria e pelo suporte, ao compartilhar suas experiências e me ajudar, até em questões burocráticas, e pela generosidade de ceder seu banco de dados.

Aos amigos do Laboratório de Neurofisiologia Clínica: aos colegas e companheiros, Karenina Goldberg, Emanoella Faro e Rudá Alessi, pelas conversas e risadas, trazendo leveza e diversão aos momentos de aprendizado; a dra. Rosa Hassan e dra. Stella Tavares, pelos ensinamentos e companhia nos almoços; às funcionárias do Laboratório de Neurofisiologia Clínica Marly, Michelle e Célia, por todo o carinho e ajuda. Obrigada também a 
amiga Karenina Goldberg, por, além do descrito, ter cedido suas atualizações ao banco de dados muito útil para este trabalho.

A Eliza Fukushima e Isabel Ataíde, secretárias da pós-graduação, pelo apoio e suporte administrativo.

Ao Bernardo dos Santos, pelas análises estatísticas e colaboração com minhas dúvidas de estatística.

Aos pacientes, por terem cedido um pouco de si, com a esperança de avanços no conhecimento científico, tornando possível a execução deste trabalho.

A minha família e amigos.

A Giovana e Gabriel, filhos maravilhosos, que me mostraram como amar e cuidar incondicionalmente. Obrigada pela paciência com os momentos ausentes pelo trabalho, por tornarem os meus dias mais felizes, a minha vida mais completa e por serem uma incrível razão de viver.

A Fabrício, marido e pai dedicado. Obrigada pelo amor e pela compreensão, por me estimular, apoiar e ajudar na realização deste trabalho; pela paciência e suporte nos momentos necessários de ausência pelo trabalho, cuidando dos nossos filhos e ajudando-os a compreender estes momentos.

A Márcia, por ser uma mãe dedicada e carinhosa, um referencial de mulher forte, dinâmica e competente. Obrigada por estar sempre presente e disponível (mesmo quando longe), me ajudando nos momentos mais difíceis; pelos conselhos e, também, pelas críticas, que sempre visaram o meu crescimento; por todo o amor incondicional, amor de mãe, que pude compreender melhor depois de ter me tornado uma.

A Dimas (in memoriam), por ter sido um pai presente e amoroso, um exemplo de honestidade e ética; por todos os conselhos, cuidado e proteção, por ter sido o porto seguro da família. Obrigada por instigar a fagulha do conhecimento, através de toda a sua curiosidade e interesse pela leitura e estudo; por me incentivar, mesmo nas decisões arriscadas. A falta é grande, mas sua presença será eterna em meu coração. 
A meu irmão Tiago, por dar o exemplo e estímulo, ao ser o primeiro de "nós" a terminar uma pós-graduação. Obrigada a você, Dani e minha afilhada Bia, pelos momentos de alegria, descontração e muito amor.

A todos da família que sempre fizeram parte da minha vida: minha madrinha Ila, meus avós: Alice, Celina (in memoriam), Florêncio (in memoriam), João (in memoriam), tios, tias e primos. Obrigado a todos por todo carinho, amor e cuidado.

Aos meus sogros, Bernadete e Delírio, por compreenderem minhas escolhas e pela ajuda com as crianças, enquanto escrevia esta tese.

Aos amigos, distantes ou próximos, antigos ou novos; pelos momentos de lazer, desabafos e fuga da rotina. 
"O sucesso nasce do querer, da determinação e persistência em se chegar a um objetivo. Mesmo não atingindo o alvo, quem busca e vence obstáculos, no mínimo fará coisas admiráveis."

(José de Alencar) 
NORMATIZAÇÃO ADOTADA 
Esta Tese está de acordo com as seguintes normas, em vigor no momento de sua publicação:

Referências: adaptado de International Committee of Medical Journals Editors (Vancouver).

Universidade de São Paulo. Faculdade de Medicina. Divisão de Biblioteca e Documentação. Guia de apresentação de dissertações, teses e monografias. Elaborado por Anneliese Carneiro da Cunha, Maria Julia de A. L. Freddi, Maria F. Crestana, Marinalva de Souza Aragão, Suely Campos Cardoso, Valéria Vilhena. $3^{a}$ ed. São Paulo: Divisão de Biblioteca e Documentação; 2011.

Abreviaturas dos títulos e periódicos de acordo com List of Journals Indexed in Index Medicus. 
SUMÁRIO 
Lista de abreviaturas e siglas.

Lista de Figuras.

Lista de Tabelas

Lista de Gráficos

Resumo.

Summary.

1.0 INTRODUÇÃO

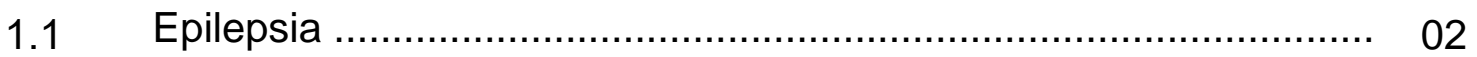

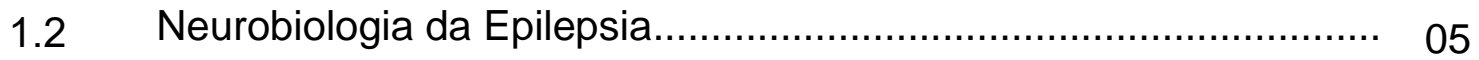

1.3 Epilepsia do Lobo Temporal e Esclerose Hipocampal................... 06

$1.4 \quad$ Epilepsia Temporal e Transtornos Psiquiátricos......................... 09

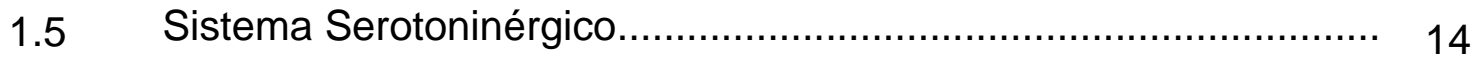

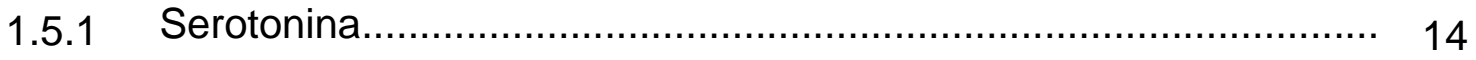

1.5.2 Receptores Serotoninérgicos........................................... 16

1.5.3 Transportador Serotoninérgico......................................... 19

1.5.4 Interação das vias monoaminérgicas..................................... 19

1.6 Atividade Serotoninérgica na Epilepsia................................. 21

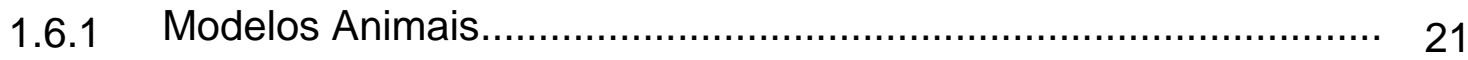

1.6.2 Estudos com Neuroimagem Funcional ................................ 28

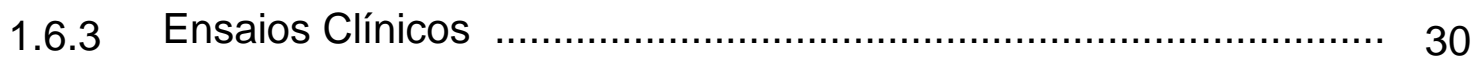

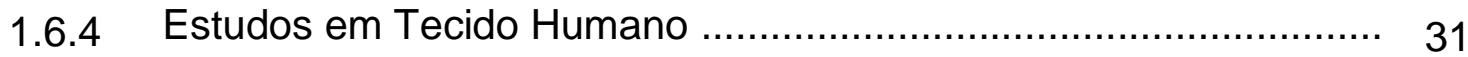

1.7 Atividade Serotoninérgica nos Transtornos Psiquiátricos nos Pacientes com Epilepsia

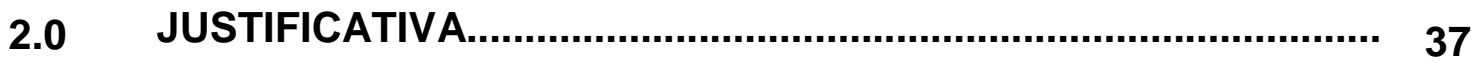

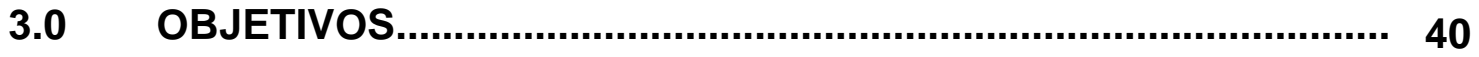

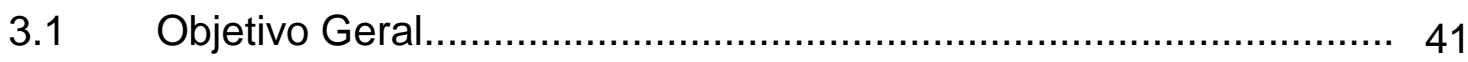




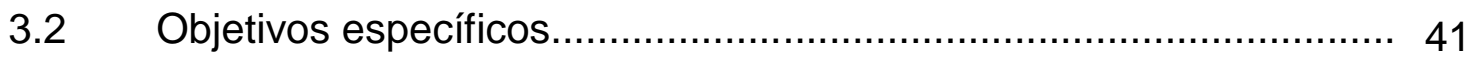

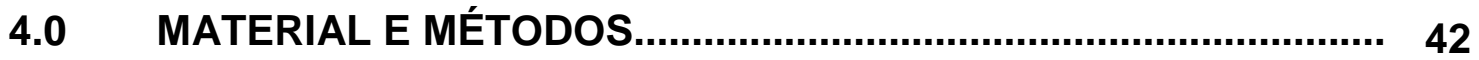

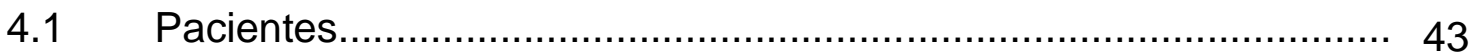

4.1.1 Critérios de Inclusão............................................................ 43

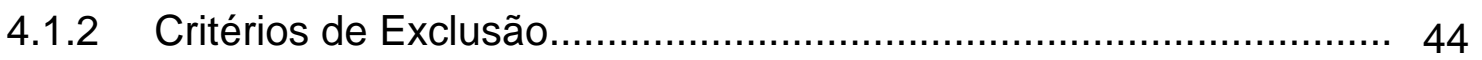

4.1.3 Caracterização dos Pacientes...................................................... 44

4.2 Cromatografia Líquida de Alta Pressão................................... 47

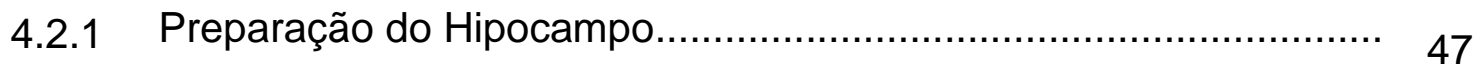

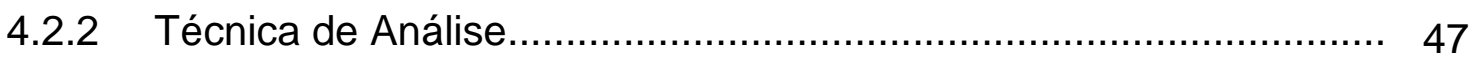

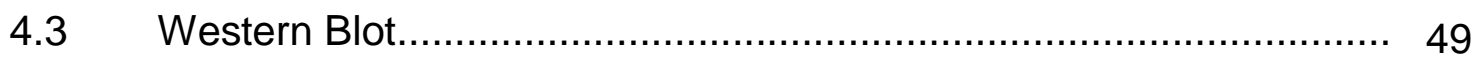

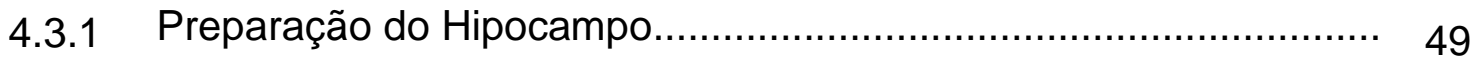

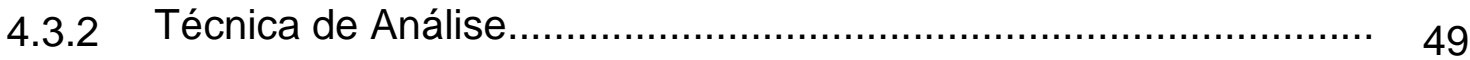

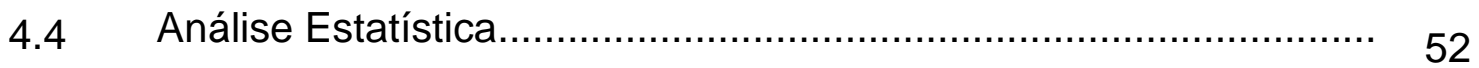

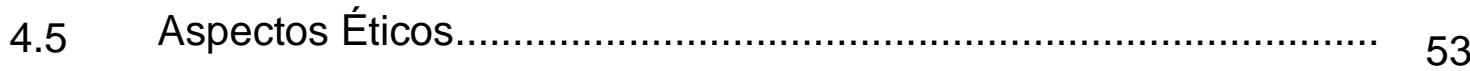

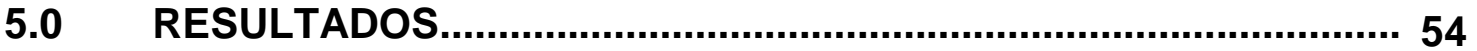

5.1 Concentração de Serotonina............................................. 55

5.2 Densidade Receptores Serotoninérgicos............................... 58

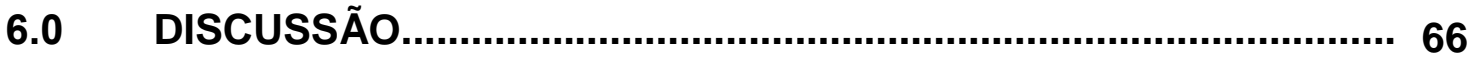

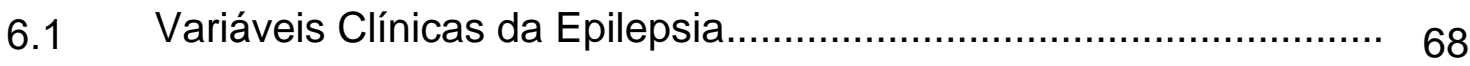

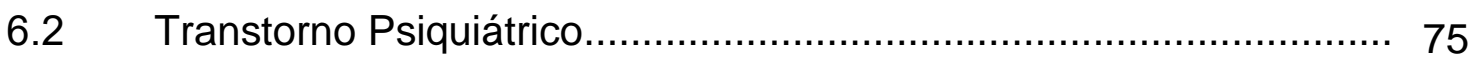

6.3 Limitações do estudo.................................................... 77

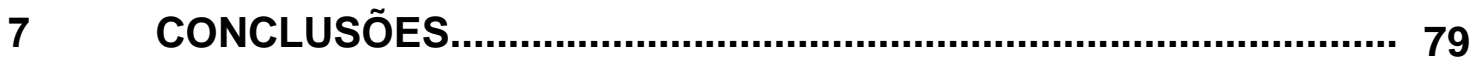

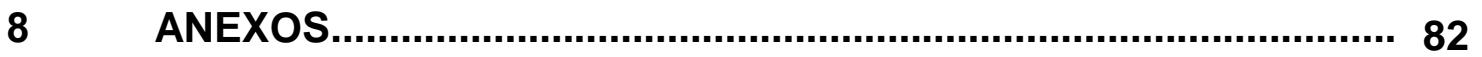

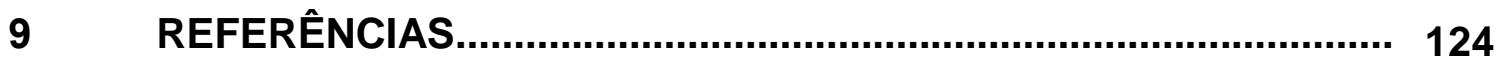
APÊNDICE. 
LISTAS 


\section{LISTA DE ABREVIATURAS E SIGLAS}

5-HT

5-HTT

$\left[{ }^{11} \mathrm{C}\right] \mathrm{WAY} 100635$

${ }^{18}$ F-FCWAY

([18F]MPPF)

BZD

CA

CBZ

CTCG

DA

DC

DSM

DBA

EH

ELT

ELT-EH

EME

FAE

FLAIR

FLX

GEPR

GLM

$\mathrm{HAL}$

$\mathrm{HClO} 4$

HPLC

HS serotonina

transportador de serotonina

[carbonyl- $\left.{ }^{11} \mathrm{C}\right] \mathrm{WAY}-100635$

${ }^{18}$ F-trans-4-fluoro-N-2-[4-(2-methoxyphenyl)piperazin-1-

yl]ethyl-N(2-pyridyl)cyclohexanecarboxamide

4-(2'-methoxyphenyl)-1-[2'-(N-2"-pyridinyl)-p-[18F]

fluorobenzamido]ethylpiperazine

benzodiazepínico

Corno de Amon

carbamazepina

crise tônico-clônico generalizada

dopamina

detergent compatible

diagnostic and statistical manual of mental disorders

Dilute Brown Non-Agouti

esclerose hipocampal

epilepsia do lobo temporal

epilepsia do lobo temporal por esclerose hipocampal

estado de mal epiléptico

fármaco antiepiléptico

fluid attenuation inversion recovery

fluoxetina

genetic epilepsy prone rats

modelo linear generalizado

haloperidol

ácido perclórico

high pressure liquid chromatography

hippocampal sclerosis 
ILAE

IRSN

ISRS

LMT

MPPF

fluorobenzamido]
International League Against Epilepsy

inibidor de recaptação da serotonina e noradrenalina

inibidor seletivo de recaptação da serotonina

lamotrigina

4-(2'-methoxyphenyl)-1-[2'-(N-2-pirydynyl)-p-

-ethyl-piperazine

MSO

metionina-sulfoximina

mTOR

NE

mammalian target of rapamycin

norepinefrina

OXC

oxcarbazepina

PET-CT

PHT

PB

RISP

SCID-4

SER

SNC

SUDEP

$\mathrm{T}$

TBS

TBS-T

TCG

TLE

TP

TPM

VPA positron emission tomography computerized tomography

fenitoína

fenobarbital

risperidona

structured clinical interview for the DSM-IV

sertralina

sistema nervoso central

sudden unexpected death syndrome

Tesla

tris-buffered saline

tris-buffered saline - tween (polysorbate 20)

tônico-clônico generalizada

temporal lobe epilepsy

transtorno psiquiátrico

topiramato

ácido valpróico 


\section{LISTA DE TABELAS}

Tabela 1 Caracterização dos pacientes.............................................. 45

Tabela 2 Média de 5-HT nos pacientes com e sem história de CTCG. 55

Tabela 3 Modelo linear com distribuição gama analisando interferência do uso de antipsicóticos e duração da epilepsia na densidade do receptor 5 -HT1A.................................... 60

Tabela 4 Análise de densidade receptor 5-HT6 nos pacientes com e sem história de EME............................................................ 62 


\section{LISTA DE FIGURAS}

Figura 1 Membrana de nitrocelulose após utilização do Ponceau...... 50

Figura 2 Amostra de membrana incubada com 5-HTT....................... 52

Figura 3 Cromatograma de paciente com e sem história de CTCG. Acima: paciente com história de CTCG. Acima: paciente sem história de CTCG. Pico de 5-HT em 5,4 minutos e pico de padrão externo de 7,6 minutos. Concentração de $5-\mathrm{HT}$ (área preenchida em verde) no primeiro de $0,173 \mathrm{ng} / \mathrm{mg} \mathrm{e}$, no segundo, de $0,256 \mathrm{ng} / \mathrm{mg}$.

Figura 4 Amostras de membranas incubadas com anticorpo antireceptor 5-HT1A, comparando paciente com diferentes

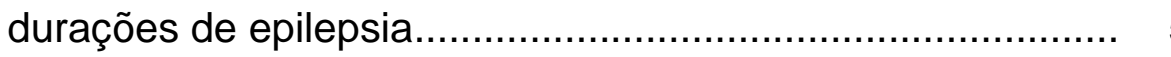

Figura 5 Amostras de membranas incubadas com anticorpo antireceptor 5-HT6, comparando a densidade do receptor entre pacientes com e sem história de EME. 


\section{LISTA DE GRÁFICOS}

Gráfico 1 Caracterização dos pacientes............................................. 47

Gráfico 2 Níveis de dispersão da concentração de serotonina.............. 55

Gráfico 3 Concentração de 5-HT entre pacientes com e sem história

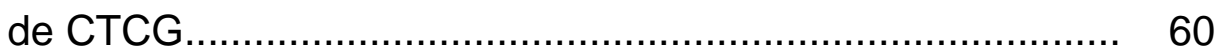

Gráfico 4 Gráfico de dispersão entre o receptor 5-HT1A e a duração da epilepsia.......................................................................... 62 


\section{RESUMO}

Fonseca NC. Estudo do perfil serotoninérgico no hipocampo de pacientes com epilepsia do lobo temporal [tese]. São Paulo: Faculdade de Medicina, Universidade de São Paulo; 2018.

A epilepsia é a condição crônica mais prevalente dentre as doenças neurológicas, associada com taxas significativas de morbidade e mortalidade. Pacientes com epilepsia farmacorresistente possuem uma taxa de mortalidade 2 a 3 vezes maior que indivíduos sem epilepsia. A epilepsia do lobo temporal (ELT) é a principal causa de epilepsia farmacorresistente nos adultos e também o protótipo da epilepsia cirurgicamente tratável, portanto, com uma maior acessibilidade para estudo de possíveis mecanismos epileptogênicos. Esclerose hipocampal (EH) é o achado neuropatológico mais comum em pacientes com ELT. Evidências, baseadas em experimentos animais e estudos em humanos, sugerem que as vias serotoninérgicas desempenham um importante papel na epileptogênese. Pacientes com ELT, causadas pela EH, apresentam uma maior prevalência de transtornos do humor e psicose contribuindo para uma pior qualidade de vida, com consequente impacto negativo nas respostas terapêuticas farmacológicas e cirúrgicas. Além disso, alguns estudos sugerem a existência de um mecanismo patogênico operante comum entre estas condições. Portanto, esta é um importante variável para análise. O objetivo desse estudo foi correlacionar as variáveis clínicas da epilepsia e a presença de transtornos psiquiátricos coexistentes com a concentração de serotonina $(5-\mathrm{HT})$, a densidade dos receptores serotoninérgicos e a densidade do transportador serotoninérgico (5-HTT) no hipocampo dos pacientes com ELT-EH, que foram submetidos à cirurgia devido à presença de epilepsia farmacorresistente. Foram avaliadas amostras de 44 hipocampos de pacientes cirurgicamente tratados para ELT-EH. A concentração de 5-HT foi avaliada por cromatografia líquida de alta pressão 
(HPLC) com detecção por fluorescência. 5-HTT e os receptores serotoninérgicos 5-HT1A, 5-HT2A, 5-HT6 e 5-HT7 foram avaliados por Western Blot. Níveis mais baixos de concentração de $5-\mathrm{HT}$ estiveram associados com a presença de crises TCG (Wilcoxon-Mann-Whitney; $\mathrm{p}=0.019$ ). A densidade aumentada do receptor 5-HT1A esteve associada com maior duração da epilepsia (coeficiente de correlação de Spearman: $p=0.040$ ) e a densidade diminuída do receptor 5-HT6 esteve associado com presença de EME (Wilcoxon-Mann-Whitney: $p=0.0027$ ). A densidade dos receptores 5 -HT2A e 5-HT7 e do 5-HTT não estiveram associadas com variáveis clínicas da epilepsia. A concentração de $5-\mathrm{HT}$, a densidade dos receptores e a densidade de 5-HTT não estiveram associadas à presença dos transtornos psiquiátricos neste grupo de pacientes. Nossos achados sugerem que as vias serotoninérgicas estão associadas com mecanismos de epileptogênese. Não foi evidenciado associações entre as vias serotoninérgicas e a presença de comorbidades psiquiátricas neste grupo de pacientes com ELT-EH.

Descritores: serotonina; receptores de serotonina; epilepsia do lobo temporal; hipocampo; western blotting; cromatografia líquida de alta pressão. 


\section{SUMMARY}

Da Fonseca NC. Study of serotonergic profile in temporal lobe epilepsy patients' hippocampus [thesis]. São Paulo: "Faculdade de Medicina, Universidade de São Paulo"; 2018.

Epilepsy is the most prevalent neurological condition and it is associated with significative morbidities and mortalities rates. Patients with refractory epilepsy have a 2- to 3-fold higher mortality rate than people without epilepsy. Temporal lobe epilepsy (TLE) is the most common form of adult drug-resistant epilepsy. It is also the prototype of a surgically treatable epilepsy and because of that it is the most accessible for studies focused in epileptogenesis. Hippocampal sclerosis (HS) is the most common neuropathological finding in patients with TLE. Evidences from experimental, clinical and image studies suggest that the serotonergic system play an important role in epileptogenesis. Patients with TLE-HS have a higher prevalence of mood disorder and psychosis contributing for a worse quality of life with and consequent negative impact in pharmacological and surgical responses. Furthermore, studies suggest a common pathogenic mechanism operant in both conditions. Therefore, this is an important analytical variable. The objective of this study was to correlate clinical variables of epilepsy and the presence of psychiatric disease with serotonin $(5-\mathrm{HT})$ concentration, serotonergic receptor density and serotonergic transporter (5-HTT) density in the hippocampus of TLE-HS patients submitted for surgery due to refractory epilepsy. It was analyzed 44 hippocampal tissue samples from surgical treated TLE-HS patients. 5-HT concentration was assessed by high pressure liquid chromatography (HPLC) with fluorescence detection. 5-HTT and serotonergic receptors 5-HT1A, 5-HT2A, 5-HT6 and 5HT7 were assessed by Western Blotting. Lower levels of $5-\mathrm{HT}$ concentration were associated with the presence of generalized tonic-clonic seizures (Wilcoxon-Mann-Whitney; $\mathrm{p}=0.019$ ). A higher 5 -HT1A receptor density was associated with longer epilepsy duration (Spearman correlation coefficient: $p=$ 0.040). Lower $5-\mathrm{HT} 6$ receptor density was associated with the presence of 
status epilepticus (Wilcoxon-Mann-Whitney: $\mathrm{p}=0$ 0.0027). 5-HT2A receptor, 5HT7 receptor and 5-HTT densities were not associated with clinical variables of epilepsy. 5-HT concentration, serotonergic receptors and transporter densities were not associated with the presence of psychiatric disease in this group of patients. Our findings suggest that the serotonergic pathways are associated with epileptogenesis mechanisms. It was not evidenced any association between serotonergic pathways and psychiatric comorbidities in this group of TLE-HS patients.

Descriptors: serotonin; receptors, serotonin; epilepsy, temporal lobe; hippocampus; blotting, western; chromatography, high pressure liquid. 
1. INTRODUÇÃO 
"A condição médica da Epilepsia é tão antiga quanto a existência humana" (Magiorkinis et al., 2010).

As crises epilépticas e a epilepsia já foram descritas desde a Antiguidade, com relatos de até 2.000 anos antes de Cristo (Magiorkinis et al., 2010). Entretanto, somente com os avanços da medicina, a partir do século 18 e 19, as crenças e superstições religiosas foram abandonadas e deu-se o início do desenvolvimento da neurobiologia e das pesquisas sobre epilepsia (Magiorkinis et al., 2014). Hughlings Jackson (1835 - 1911) introduziu a base científica da epileptogênese e do conceito moderno de epilepsia, caracterizando a crise epiléptica como um evento desencadeado por uma descarga elétrica excessiva e súbita proveniente do córtex cerebral (Magiorkinis et al., 2014).

\section{$1.1 \quad$ Epilepsia}

A epilepsia é a condição crônica mais prevalente dentre as doenças neurológicas, associada com taxas significativas de morbidade e mortalidade. Apresenta uma prevalência aproximada de 4.3 a 7.2 para 1.000 em relação à população geral; com taxas mais elevadas, entre 10 para 1.000, nos países de baixa renda; e uma incidência entre 43 a 47 para 100.000 pessoas/ ano (Ablah et al., 2014; Giussani et al., 2014; Steer et al., 2014; Moshé et al., 2015). A taxa de mortalidade nos países de alta renda varia de 2 a 5 vezes em relação à 
população geral, sendo maior nos primeiros anos após o diagnóstico da epilepsia (taxa de mortalidade prematura); chegando a aproximadamente 11 comparada à população geral. Além disto, nos países de baixa renda, essa taxa pode aumentar significativamente (até 37 vezes) (Moshé et al., 2015). Nos pacientes com epilepsia, a taxa de mortalidade é maior nos pacientes que apresentam crises tônico-clônicas generalizadas com início focal (Rakitin et al., 2011).

O diagnóstico de epilepsia, de acordo com a proposta atual da International League Against Epilepsy - ILAE (Fisher et al., 2014), é definido por um dos seguintes critérios: 1. Pelo menos duas crises epilépticas não provocadas ou reflexas ocorrendo com uma diferença de tempo > 24 horas; 2. Uma crise epiléptica não provocada ou reflexa e uma probabilidade de novas crises epilépticas semelhante ao risco geral de recorrência (pelo menos de $60 \%$ após duas crises não provocadas; 3. Diagnóstico de uma síndrome epiléptica.

A epilepsia é considerada farmacorresistente quando não houver controle das crises epilépticas, isto é, uma ou mais crises por mês, após tratamento com dois ou mais fármacos antiepilépticos (FAEs), adequadamente escolhidos e em doses máximas toleradas, seja em monoterapia ou de forma combinada (Beleza, 2009; Kwan e Sperling, 2009; Kwan et al., 2010).

Os pacientes com epilepsia farmacorresistente possuem uma taxa de mortalidade 2 a 3 vezes maior do que os indivíduos sem epilepsia, sendo o fenômeno da morte súbita e inesperada na epilepsia (SUDEP) a principal causa de morte nesses pacientes, representando 7,5 a $17 \%$ de todas as mortes em epilepsia (Scorza e Tucci, 2015) e estando associada com um 
aumento de 20 vezes do risco de morte súbita e inesperada nos pacientes com epilepsia (Kanner, 2013).

Pacientes que não são responsivos ao tratamento com dois FAEs apropriados têm uma chance de resolução das crises com uma futura medicação em torno de 5 a 10\% ao ano, sendo que esta remissão ainda pode não ser duradoura. Em contrapartida, nos pacientes apropriadamente indicados, mais de $70 \%$ apresentam uma resolução duradoura das crises epilépticas com o tratamento cirúrgico (Kwan e Sperling, 2009). Sendo assim, nos casos de epilepsia farmacorresistente confirmada, deve-se avaliar se a condição epiléptica se enquadra como cirurgicamente tratável e considerar as opções cirúrgicas disponíveis para o caso (Schmidt, 2009).

A cirurgia de epilepsia parece ser um tratamento igualmente eficaz para pacientes com epilepsia farmacorresistente de diferentes idades, sexo e lateralidade do foco epiléptico; com idade variando de 10 a 60 anos e com incidências semelhantes entre os sexos e a lateralidade (Englot et al., 2013; Gonçalves-Ferreira et al., 2013; Josephson et al., 2013; Vannemreddy et al., 2013). É observado um resultado satisfatório de longo prazo no controle das crises epilépticas nos pacientes com epilepsia farmacorresistente submetidos ao procedimento cirúrgico, incluindo pacientes com ELT-EH (Dorfer et al., 2017; Krucoff et al., 2017; Holm et al., 2018), além de redução do risco de mortalidade prematura (Seymour et al., 2012). 


\subsection{Neurobiologia da Epilepsia}

A epileptogênese se refere ao desenvolvimento da epilepsia, ou seja, a sequência de eventos que culminam na predisposição de um cérebro para apresentar crises epilépticas (Scharfman, 2007). Está relacionado com um processo crônico, no qual ocorrem uma série de mudanças bioquímicas e estruturais no tecido nervoso (Sendrowski e Sobaniec, 2013). É o processo que associa injúrias cerebrais ou outros fatores de risco a um subsequente aparecimento da epilepsia (Goldberg e Coulter, 2013). Na epilepsia, assume-se que um grupo de neurônios se tornam hiperexcitáveis, favorecendo o aparecimento de descargas anormais (Scharfman, 2007).

A epileptogênese é constituída por três fases: a primeira caracterizada por um insulto inicial ou uma lesão cerebral aguda; a segunda caracterizada por um período de maturação do foco epiléptico e a última fase caracterizada pela instalação da epilepsia. Estes mecanismos epileptogênicos resultam em uma redução do limiar convulsivo, até que a crise epiléptica ocorre em resposta a fatores precipitantes (Engel et al., 2013; Sendrowski e Sobaniec, 2013).

Acredita-se que os mecanismos responsáveis pelo desenvolvimento da epilepsia sejam multifatoriais, e que a epileptogenicidade, ou seja, a probabilidade de uma crise epiléptica ocorrer, não seja estática, sendo que o grau de epileptogenicidade pode variar com o tempo (Engel et al., 2013). 


\subsection{Epilepsia do Lobo Temporal e Esclerose Hipocampal}

A ELT é o tipo mais frequente de epilepsia sintomática do adulto. O lobo temporal é a estrutura mais epileptogênica do cérebro, sendo a maioria das crises temporais originados das estruturas mesiais e envolvendo predominantemente uma desregulação hipocampal, gerada por uma hiperexcitabilidade neuronal (Fisher et al., 1998; Tatum, 2012). Na ELT-EH, as crises se caracterizam por início com sensações víscero-sensoriais (em especial mal-estar epigástrico), medo, ansiedade, sensações dismnésticas, como deja $v u$ ou jamais $v u$, ou mais raramente alucinações gustativas e olfativas. Em seguida, se observa uma parada comportamental e alterações variáveis da perceptividade; podendo o paciente apresentar olhar fixo e perda parcial ou completa da responsividade. Os automatismos orofaciais e manuais são comumente observados, com ocasional postura distônica contralateral ao hemisfério de origem das crises epilépticas; não sendo comum a generalização secundária destas. Outras características comuns são crises com duração prolongada e presença de algum grau de disfunção cognitiva e de linguagem pós-ictal (Andrade-Valença et al., 2006; Malmgren e Thom, 2012)).

Aproximadamente $60 \%$ dos casos de ELT são causados pela esclerose de hipocampo $(E H)$, com elevada proporção de pacientes com crises fármacorresistentes (Andrade-Valença et al., 2006). Dos casos com ELT submetidos à cirurgia de epilepsia, a incidência de EH é de aproximadamente 33 a 48\% (Blümcke, 2009; Blümcke et al., 2012; Blümcke et al., 2013).

A etiologia da $\mathrm{EH}$ ainda não está bem esclarecida. Acredita-se que ela seja multifatorial; possivelmente ocorrendo secundária a uma susceptibilidade 
genética, associado a outros fatores. A ELT-EH é tipicamente considerada como um transtorno adquirido, resultado de insulto a um cérebro previamente normal (Goldberg e Coulter, 2013). A ELT-EH induzida pode ser causada por crises febris prolongadas, entretanto, esta evolução com atrofia hipocampal ocorre na minoria dos casos. Além disto, há a forma familiar de ELT, cuja etiologia é presumidamente genética (Goldberg e Coulter, 2013). Portanto, este ainda é um assunto controverso (Thom, 2014).

A formação hipocampal é uma estrutura anatômica com três camadas de alocórtex com uma organização lamelar, compreendendo o giro denteado, o hipocampo propriamente dito e o subículo. O hipocampo faz parte do sistema límbico, com um papel fundamental nos processos emocionais, comportamentais e de memória. O hipocampo, propriamente dito, também conhecido como corno de Amon (CA), está localizado na face mesial do lobo temporal e pode ser dividido em cabeça, corpo e cauda. Histologicamente, seu córtex pode ser dividido em quatro setores: CA1 a CA4 (Sendrowski e Sobaniec, 2013). O setor CA1 corresponde a maior parte da camada de células piramidais, com seus neurônios amplamente distribuídos, estando em continuidade com o subículo. O setor CA2 é o mais estreito e com neurônios densamente distribuídos. O setor CA3 apresenta neurônios em arranjo radial formam a curva do hipocampo e o setor CA4 se localiza dentro da concavidade do giro denteado, compreendendo neurônios grandes, como as células ovoides. As regiões CA3 e CA4 recebem numerosos axônios das células granulares do giro denteado, chamadas fibras musgosas (Malmgren e Thom, 2012). 
O achado característico da EH é uma perda segmentar dos neurônios piramidais, associada com um padrão grave de gliose dos astrócitos. De acordo com a ILAE (Blümcke et al., 2013) ela pode ser dividida em 3 diferentes subtipos histopatológicos:

- Tipo I: o segmento CA1 do hipocampo é mais gravemente afetado, com perda neuronal em $>80 \%$. Outros segmentos também apresentam perdas neuronais significativas, afetando 30 a 50\% dos neurônios piramidais do segmento CA2; 30 a 90\% dos neurônios no segmento CA3 e 40 - 90\% no segmento CA4. Além disto, o giro denteado geralmente apresenta uma perda em torno de 50 - $60 \%$ de células granulares. Este é o tipo mais comum de $\mathrm{EH}$, presente em 60 - 80\% dos casos de ELT cirurgicamente tratados.

- Tipo II: perda neuronal predominante no segmento CA1, em torno de $80 \%$, com os outros segmentos demonstrando uma perda celular leve, apenas evidenciada por análise qualitativa; sendo no segmento CA2 e CA3 $<20 \%$ e no segmento CA4 < 25\%. Este tipo é incomum, sendo observado em 5 a $10 \%$ dos casos de ELT.

- Tipo III: perda neuronal predominante no segmento CA4, de aproximadamente $50 \%$, e no giro denteado, em torno de $35 \%$. Os demais segmentos demonstram uma perda de: CA $1<20 \%$, CA2 $<25 \%$ e CA3 $<30 \%$. Também um tipo raro de EH, evidenciada em cerca de $4-7.4 \%$ dos casos.

O diagnóstico de EH é realizado através da avaliação com ressonância magnética de encéfalo, sendo caracterizado predominantemente pela atrofia hipocampal nas imagens ponderadas em T1 e hipersinal hipocampal nas 
imagens ponderadas em T2 (Camacho e Castillo, 2007; Menzler et al., 2010; Blümcke et al., 2013).

Embora alguns casos de ELT-EH evoluam com crises epilépticas controladas ou pouco frequentes, muitos dos pacientes são farmacorresistentes. Nestes pacientes, o tratamento cirúrgico pode ser uma boa opção terapêutica, com relatos do controle das crises epilépticas em 2/3 dos pacientes, nos 2 a 3 primeiros anos e $57 \%$ em 5 anos (Thom, 2014).

O sucesso cirúrgico depende da remoção da área epileptogênica no lobo temporal (Sagher et al., 2012); sendo o objetivo cirúrgico que isso ocorra sem causar déficits neurológicos permanentes (Beleza, 2009). Já foram desenvolvidas diferentes abordagens para acesso à região mesial temporal, sendo a lobectomia temporal anteromesial e a amigdalohipocampectomia seletiva as técnicas preferencialmente utilizadas (Sagher et al., 2012).

A lobectomia temporal anteromesial consiste na ressecção limitada da porção anterior e neocortical do lobo temporal e a ressecção mais extensa das estruturas temporais mesiais (amígdala, hipocampo e giro parahipocampal). Alternativamente, pode ser realizada uma cirurgia mais seletiva denominada amigdalohipocampectomia, preservando ao máximo o neocórtex temporal (Sagher et al., 2012; Gonçalves-Ferreira et al., 2013; Josephson et al., 2013).

\subsection{Epilepsia Temporal e Transtornos Psiquiátricos}

A prevalência dos transtornos psiquiátricos nos pacientes com epilepsia varia amplamente, com taxas entre 19 a $80 \%$. A maior prevalência é observada nos pacientes em avaliação pré-cirúrgica referidos aos centros 
terciários e a menor nos estudos populacionais. A grande variabilidade pode ser explicada pela grande heterogeneidade dos estudos. Entretanto, apesar disso, há um consenso de que os distúrbios psiquiátricos são mais prevalentes nos pacientes com epilepsia (García-Morales et al., 2008).

Em um estudo populacional, realizado no Canadá, foi identificada uma prevalência da presença de transtorno psiquiátrico nos pacientes com epilepsia de $23.5 \%$ em 12 meses e 35,5\%, ao longo da vida, sendo as prevalências ao longo da vida de $24,4 \%$ para transtornos do humor, $17,4 \%$ para transtorno depressivo maior, 22,8\% para distúrbios de ansiedade e 6,6\% de síndrome do pânico ou agorafobia; além de uma taxa de ideação suicida de 25\%, para pacientes com epilepsia e $13.3 \%$ naqueles sem epilepsia (Tellez-Zenteno et al., 2007).

Num estudo de revisão não sistemática da literatura, os transtornos depressivos representaram a comorbidade psiquiátrica mais frequente nos pacientes com epilepsia (30\%), seguido por transtornos de ansiedade (10 25\%), transtornos psicóticos (2 - 7\%) e transtornos de personalidade (1 $2 \%$ )(Gaitatzis et al., 2004).

As comorbidades psiquiátricas são mais frequentes nas epilepsias focais, em especial na ELT, com taxas de prevalência de depressão, ansiedade e psicose significativamente maiores, quando comparadas a outros tipos de epilepsia (Perini et al., 1996; Matsuura et al., 2003).

Pacientes com ELT- EH apresentam uma maior prevalência de transtornos do humor e psicose (Briellmann et al., 2007; D'alessio et al., 2009; 
Gonçalves e Cendes, 2011) com consequente impacto negativo nas respostas terapêuticas farmacológicas e cirúrgicas.

Segundo Hitiris et al. (2007), a presença de transtorno psiquiátrico pode ser um fator preditivo de farmacorresistência. A depressão representou 85\% dos diagnósticos psiquiátricos, em pacientes com epilepsia seguidos por 20 anos, e foi associada, por si só, como um fator de risco para pior resposta.

Kanner et al. (2009) demonstraram que o histórico de depressão crônica foi um preditivo de pior resposta ao tratamento cirúrgico considerandose a remissão das crises epilépticas, após o seguimento de 100 pacientes com ELT-EH submetidos à lobectomia temporal anterior, com um período de acompanhamento médio de $8.3 \pm 3.3$ anos.

Koch-Stoecker et al. (2017) encontraram que as taxas de controle das crises nos pacientes submetidos à ressecção do lobo temporal, para tratamento da epilepsia, foram significativamente maiores nos pacientes com epilepsia sem transtornos psiquiátricos associados, quando comparados com pacientes com epilepsia e à presença de transtornos psiquiátricos (depressão, psicose e/ou transtornos de personalidade).

A presença de transtornos psiquiátricos representa um fator de risco independente para uma pior qualidade de vida nos pacientes com epilepsia (Anhoury et al., 2000; Aydemir et al., 2004; Pugh et al., 2005). Além disso, as comorbidades psiquiátricas associadas com maior risco de suicídio são relativamente frequentes nos pacientes com epilepsia, sendo o suicídio responsável por 12\% das mortes prematuras desse grupo (Kanner, 2013).

Fazel et al. (2013), em um estudo populacional realizado na Suécia, observou que a mortalidade prematura era aproximadamente 11 vezes mais 
frequente nos pacientes com epilepsia, quando comparados com a população geral e com irmãos saudáveis. As chances de morte prematura por causas externas, que incluíam suicídio e acidentes, foi 3 vezes maior nos pacientes com epilepsia. Nos pacientes com epilepsia que tiveram morte prematura por causas externas, comorbidades psiquiátricas foram documentadas em aproximadamente $75 \%$, sendo a depressão e o abuso de substâncias as principais comorbidades encontradas.

Os transtornos psiquiátricos frequentemente se apresentam de forma diferenciada nos pacientes com epilepsia quando comparados a pacientes sem epilepsia, apresentando uma estreita relação entre o aparecimento dos sintomas psiquiátricos com a ocorrência de crises epilépticas. Por conta disto, os sintomas psiquiátricos podem ser classificados em relacionados ao evento ictal (pré-ictais, ictais e pós ictais) e interictais. Os sintomas pré-ictais são aqueles que aparecem precedendo uma crise epiléptica em até 2 dias; os sintomas interictais são aqueles que estão presentes independente da presença de crises; os ictais são aqueles que aparecem como manifestação da crise epiléptica e os pós ictais os que ocorrem dentro dos cinco dias após uma crise epiléptica (García-Morales et al., 2008; Kanner, 2009).

A etiologia das comorbidades psiquiátricas nos pacientes com epilepsia é multifatorial, envolvendo fatores neurobiológicos e psicossociais (Kanner, 2005; 2009).

Os determinantes neurobiológicos incluem a idade de início da epilepsia, a frequência e a gravidade das crises epilépticas, o tipo de epilepsia, a localização do foco epiléptico e as medicações em uso, tendo em consideração tanto o tipo, quanto o número (Kanner, 2005; 2008). 
Os possíveis fatores psicossociais incluem estigma percebido, número elevado de eventos estressores prévios, não aceitação da epilepsia, estresse financeiro, problemas profissionais e início precoce da epilepsia (Kanner, 2008; 2009).

Vários estudos mais demonstram uma relação bidirecional entre epilepsia e os transtornos psiquiátricos (Kanner, 2005; Pineda et al., 2010; Kanner, 2011). Os transtornos depressivos não são restritos aos pacientes com crises epilépticas farmacorresistentes e, frequentemente, precedem o início das crises (Forsgren e Nyström, 1990; Hesdorffer et al., 2000). Além disto, não somente pessoas com epilepsia têm maior risco de desenvolver transtornos depressivos, mas pacientes com transtornos depressivos têm chances 3 a 7 vezes maiores de desenvolver epilepsia (Forsgren e Nyström, 1990; Hesdorffer et al., 2000; Hesdorffer et al., 2006).

Estudos com modelos animais, neuroimagem funcional e post-mortem em humanos sugerem a existência de um mecanismo patogênico operante comum entre estas condições (Cheetham et al., 1990; Stockmeier et al., 1998; Toczek et al., 2003; Savic et al., 2004; Lothe et al., 2008; Kandratavicius et al., 2013). Os mecanismos patológicos comuns incluem anormalidades no potencial de ligação de receptores de diversos neurotransmissores do sistema nervoso central (SNC), especialmente os de serotonina e anormalidades funcionais nos lobos temporais e frontais, incluindo diminuição de receptores de 5-HT nas estruturas mesiais, núcleo da rafe, tálamo e giro cíngulo (Drevets et al., 1999; Sargent et al., 2000; Kanner, 2005; Hasler et al., 2007; Kanner, 2009; 2011). 


\subsection{Sistema Serotoninérgico}

O sistema de neurotransmissão serotoninérgica é constituído por grupos morfologicamente heterogêneos de neurônios localizados no tronco encefálico, predominantemente nos núcleos da rafe, e apresentam um sistema axonal complexo, que inerva virtualmente todas as regiões do SNC; formando um sistema com projeções difusamente organizados (Törk, 1990).

Esse sistema difuso de inervação do sistema serotoninérgico, explica porque a 5-HT e seus receptores são importantes na regulação de virtualmente todas as funções cerebrais e, também, porque as alterações na regulação das suas vias já foram associadas à patogênese de diversos transtornos neurológicos e psiquiátricos (Mann, 1999; Berger et al., 2009).

\subsubsection{Serotonina}

A 5-HT é uma indolamina massivamente sintetizada no trato gastrointestinal, predominantemente pelas células enterocromafins, com uma pequena porcentagem sintetizada no SNC. Apesar disto e do fato de também exercer um papel na agregação plaquetária, motilidade intestinal, dentre outras possíveis funções, a sua função primordial é a de neurotransmissão (Mann, 1999; Charnay e Léger, 2010; Lv e Liu, 2017). A 5-HT é um neurotransmissor monoaminérgico sintetizado no núcleo da rafe do tronco encefálico, a partir do aminoácido essencial triptofano (Alenina e Klempin, 2015). Aproximadamente 
30 a $80 \%$ dos neurônios do núcleo da rafe sintetizam 5-HT (Hecimovic et al., 2001).

Após sua síntese, a 5-HT é armazenada em vesículas sinápticas e carreadas, pelas fibras serotoninérgicas ascendentes para regiões corticais, límbicas e do tronco encefálico, incluindo a formação hipocampal (Berger et al., 2009; Alenina e Klempin, 2015). O hipocampo, assim como todo o sistema límbico, é o principal alvo das vias aferentes serotoninérgicas (Berumen et al., 2012). As vias serotoninérgicas da rafe-hipocampo desempenham um papel importante na regulação do humor (Carr e Lucki, 2011). A principal teoria neurobiológica da depressão, a clássica "hipótese monoaminérgica da depressão", associa uma alteração da neurotransmissão monoaminérgica, com depleção de serotonina, noradrenalina e dopamina, como uma das principais causas os sintomas depressivos (Köhler et al., 2016; Ferrari e Villa, 2017).

A liberação da 5-HT pelos neurônios da rafe é regulada por mecanismos intrínsecos e extrínsecos. O mecanismo mais eficiente consiste na alça curta (feedback) auto inibitória que envolve receptores somatodendríticos 5-HT1A. A ativação dos autorreceptores 5-HT1A da rafe pela liberação local de 5-HT inibe a descarga de neurônios serotoninérgicos e posterior liberação do neurotransmissor (Carr e Lucki, 2011).

As monoaminas, como a 5-HT, produzem seus efeitos induzindo mudanças bioquímicas complexas nos neurônios pós-sinápticos do SNC, através da interação com proteínas sinalizadoras - proteína G - dentro da membrana celular pós-sináptica (Carr e Lucki, 2011). 


\subsubsection{Receptores Serotoninérgicos}

Todas as regiões encefálicas expressam múltiplos receptores serotoninérgicos, sendo que cada neurônio pode expressar múltiplos tipos de receptores serotoninérgicos (Berger et al., 2009). Todas famílias de receptores serotoninérgicos estão expressas no hipocampo (Berumen et al., 2012).

Os receptores serotoninérgicos são os mais numerosos e diversos do sistema dos receptores de transmissão monoaminérgica. Atualmente, sete famílias distintas de receptores serotoninérgicos já foram identificadas (5-HT1, 5-HT2, 5-HT3, 5-HT4, 5-HT5, 5-HT6 e 5-HT7) e inúmeras subpopulações já foram descritas. Os receptores 5-HT1A, 5-HT1B, 5-HT2A, 5-HT2C, 5-HT4, 5HT6 e 5-HT7 já foram associados à regulação do humor e relacionados a transtornos psiquiátricos (Pytliak et al., 2011).

Os receptores 5-HT1 são subdivididos em 5 subgrupos: 5-HT1A, 5HT1B, 5-HT1D, 5-HT1E e 5-HT1F. Eles são, em sua maioria, porém não exclusivamente, associados com proteínas Gi/G0 e inibem a produção de AMPc (Pytliak et al., 2011).

Os receptores 5 -HT1A são os mais amplamente distribuídos de todos os receptores serotoninérgicos. No SNC, os receptores 5-HT1A estão presentes em maior densidade no córtex cerebral, hipocampo, septo, amígdala e núcleo da rafe. No SNC, eles agem como autorreceptores e receptores polissinápticos. No córtex, estes agem como autorreceptores, bem como receptores polissinápticos. Estes receptores estão envolvidos na inibição da descarga de neurônios, regulação da produção de ACTH e regulação do 
comportamento e fome (Wang et al., 2009), sendo que, possivelmente, desempenham um papel importante no desenvolvimento da ansiedade (Klemenhagen et al., 2006), o que é corroborado pelo uso de antagonistas do receptor 5-HT1A no tratamento da ansiedade e depressão.

Os receptores 5-HT2 são subdivididos em 3 classes: 5-HT2A, 5-HT2B e 5-HT2C. Estes são os principais subtipos de receptores excitatórios entre os receptores acoplados à proteína G para 5-HT. Entretanto, o receptor 5-HT2A pode ter um efeito inibitório em certas áreas, como o córtex visual e orbitofrontal (Pytliak et al., 2011).

Os receptores 5-HT2A são expressos em muitos tecidos centrais e periféricos. No SNC, os receptores 5-HT2A estão presentes principalmente no córtex, claustro e gânglios da base (Pytliak et al., 2011). Sua ativação no córtex pré-frontal, região cujo metabolismo está alterado nos pacientes com esquizofrenia, modula a liberação de dopamina e GABA (Feng et al., 2001; Bortolozzi et al., 2005). Antagonistas do receptor 5-HT2A, com diferentes sítios de afinidade (como risperidona, seroquel, olanzapina), são utilizados no tratamento da esquizofrenia, e já foram relacionados com a presença de sintomas obsessivos compulsivos nestes pacientes (Kim et al., 2009).

O receptor 5-HT6 está localizado predominantemente no encéfalo, onde está acoplado ao estímulo de uma adenil ciclase (Carr e Lucki, 2011). Duas variantes do receptor 5-HT6 já foram descritas. A variante completa é composta por 440 aminoácidos e predomina nas áreas límbicas e nas zonas cerebrais extrapiramidais. A segunda variante possivelmente resulta de uma deleção da primeira, contendo 286 aminoácidos e predominando no caudado e substância negra. A importância clínica exata dos receptores 5-HT6 permanece 
ainda incerta (Pytliak et al., 2011). Existem evidências que este receptor regula a liberação de inúmeros neurotransmissores, como a acetilcolina, norepinefrina, ácido gaba-aminobutírico e dopamina, que proveem um mecanismo adicional para sua possível efetividade no tratamento de transtornos psiquiátricos. Inúmeros antidepressivos (amitriptilina, imipramina, doxepina) e alguns antipsicóticos atípicos (olanzapina, quetiapina, clozapina) agem como antagonistas dos receptores 5-HT6, embora sem seletividade, sugerindo uma possível associação entre estes receptores e certos transtornos psiquiátricos.

Os receptores 5-HT7 são compostos por 445 aminoácidos e aumentam a ativação da Adenil ciclase via proteína Gs. Ele também ativa a AMP quinase. Existem 5 isoformas do receptor (5-HT7A-D), que diferem entre si pelo seu terminal C (Pytliak et al., 2011). Três destas variantes foram identificadas em humanos, designadas como 5-HT7a, 5-HT7b e 5-HT7c (Leopoldo et al., 2011). Todos exibem as mesmas propriedades farmacológicas e são expressos em vasos, músculos lisos extravasculares e SNC. Antipsicóticos atípicos, como a clozapina, e antidepressivos possuem grande afinidade por receptores 5-HT7. Antagonistas dos receptores 5-HT7 mimetizam efeitos dos inibidores seletivos de recaptação da 5-HT e podem ser aplicados no tratamento da depressão e transtornos do sono (Mnie-Filali et al., 2007). No estudo de Witkin et al. (Witkin et al., 2007), realizado com ratos deficientes de receptor 5-HT7, os autores demonstraram que estes ratos possuíam uma redução do limiar para crises epilépticas, quando comparados a ratos selvagens. 


\subsubsection{Transportador Serotoninérgico}

O transportador serotoninérgico $(5-\mathrm{HTT})$ age como o primeiro mecanismo de remoção de 5-HT da fenda sináptica, ação essa dependente de ATP (Veenstra-Vanderweele et al., 2000; Charnay e Léger, 2010). No SNC, o 5-HTT é o mecanismo controlador predominante da intensidade e duração da neurotransmissão serotoninérgica (Daws e Gould, 2011). Ele se localiza nos terminais pré-sinápticos de células do SNC, bem como em axônios e corpos celulares de células serotoninérgicas da rafe. Os antidepressivos tricíclicos e os inibidores de recaptação de 5-HT desempenham como um de seus mecanismos de ação a inibição do transportador de 5-HT, efeito corroborado por estudo com Tomografia Computadorizada por Emissão de Pósitrons (PETCT) nos pacientes com transtorno depressivo maior (Lundberg et al., 2012).

O gene humano do 5-HTT está localizado no cromossoma 17q11.1-q12 e consiste em 14 exons. Diversos polimorfismos do gene do 5-HTT já foram relatados como associados com transtornos psiquiátricos, além de ELT (Manna et al., 2007; Charnay e Léger, 2010).

\subsubsection{Interação das vias monoaminérgicas}

Estudos demonstram evidências de que as vias de neurotransmissão monoaminérgica que envolvem a 5-HT, norepinefrina (NE) e a dopamina (DA) exercem um papel na regulação da cognição, do humor, das emoções, dentre 
outros. Essas vias formam sistemas individuais, com núcleos distintos, que, entretanto, possuem uma neuroanatomia consistente com interconexões e interações funcionais robustas, através de suas projeções para o prosencéfalo, formando uma rede complexa de inervações sobrepostas. Além disso, existem conexões entre os núcleos monoaminérgicos do prosencéfalo, propiciando uma coordenação entre suas atividades neuronais (Hamon e Blier, 2013; Hensler et al., 2013).

Interações funcionais entre essas vias também já foram relatadas, com demonstrações do 5-HT exercendo um uma influência negativa nos sistemas da NE e DA, através de mecanismos mediados pelos receptores 5-HT2A e 5HT2C, respectivamente. Além de influências complexas, positivas e negativas, do sistema da NE sobre neurotransmissão serotoninérgica, através dos receptores adrenérgicos a1 e $\alpha 2$ (Hamon e Blier, 2013).

Evidências sugerem que neurônios dopaminérgicos na substância negra parte compacta, na área tegmental ventral, além de terminações dopaminérgicas, incluindo o núcleo accumbens, córtex pré-frontal medial, amígdala, corpo estriado e tubérculo olfatório, são inervados por células contendo 5-HT, que controlaria a atividade do sistema dopaminérgico, predominantemente de forma fásica e excitatória, excetuando-se pelo receptor 5-HT2C, que parece ter uma ação tônica, e, como descrito anteriormente, inibitória (De Deurwaerdère e Di Giovanni, 2017). 


\subsection{Atividade Serotoninérgica na Epilepsia}

Há evidências, baseadas em experimentos animais e estudos em humanos, envolvendo neuroimagem funcional, ensaios clínicos ou experimentos em tecido cortical, de que as vias serotoninérgicas desempenham um importante papel na epileptogênese.

\subsubsection{Modelos Animais}

Estudos com modelos animais são fundamentais para um maior conhecimento sobre as patologias humanas. Esses estudos têm contribuído significativamente para uma maior compreensão dos mecanismos de epileptogênese e de ação de fármacos antiepilépticos (Avanzini, 1995).

O modelo de ratos geneticamente propensos à epilepsia (GEPR) é um modelo animal de estudo da epilepsia, no qual a predisposição para crises é induzida através de estímulo sonoro. Além disso, eles também exibem limiares diminuídos para indução de crises epilépticas por uma variedade de outros métodos, incluindo hipertermia, eletrochoque, drogas convulsivas, e kindling. Observam-se duas linhagens com diferentes expressões de gravidade e manifestações: a linhagem GEPR-3, de gravidade moderada, na qual a resposta ao estímulo sonoro ocorre através de crises clônicas generalizadas; e a linhagem GEPR-9, com crises graves e que responde ao estímulo sonoro através de crises tônicas extensoras (Faingold, 1988; Dailey et al., 1989; Jobe et al., 1995). Esse modelo animal, possui uma depleção de 5-HT no sistema nervoso central que parece desempenhar um importante papel na 
susceptibilidade às crises epilépticas (Jobe et al., 1982; Jobe et al., 1986; Dailey, Mishra, et al., 1992; Kumar et al., 2016). Foi demonstrado que a administração de medicações, que diminuem ainda mais estas concentrações, levam à maior gravidade das crises epilépticas (Jobe et al., 1981; Mishra et al., 1988).

Estudos em linhagens de GEPR evidenciaram um efeito anticonvulsivante dos fármacos inibidores seletivos de recaptação da 5-HT, com evidências sugerindo que esta ação está relacionada com mecanismos serotoninérgicos (Dailey, Yan, et al., 1992; Yan et al., 1994). Browning et al. (1997) demonstraram que o aumento extracelular de 5-HT observado após a administração concomitante do ISRS com um antagonista do receptor 5-HT1A tem um papel importante para o efeito anticonvulsivante da fluoxetina. Além disso, um fator importante associado com o efeito anticonvulsivante da carbamazepina, em ambas as linhagens de GEPR, está associado com a liberação de 5-HT, com subsequente aumento de 5-HT extracelular, evidenciando uma relação da 5-HT na supressão de crises epilépticas (Yan et al., 1992; Dailey et al., 1997).

Outro importante modelo animal de ELT, o modelo da pilocarpina, também evidencia o papel das vias serotoninérgicas na epileptogênese. A pilocarpina é um potente agonista muscarínico, sendo que a sua administração sistêmica em ratos e camundongos promove uma série de alterações que reproduzem as características principais da ELT. O desenvolvimento do modelo ocorre em três fases distintas: na fase aguda observam-se crises límbicas que evoluem para estado de mal epiléptico (EME); uma fase silenciosa, onde ocorre normalização progressiva das alterações 
comportamentais e eletroencefalográficas; e uma fase crônica, caracterizada por crises espontâneas recorrentes (Cavalheiro, 1995; Scorza et al., 2009). Cavalheiro et al. (1994) demonstraram que na fase aguda ocorre um aumento dos níveis de 5-HT. Este achado foi corroborado por Lin et al. (2013), que além do aumento de 5-HT na fase aguda, observaram uma diminuição significativa destes níveis, comparado aos controles, na fase crônica. A depleção de 5-HT na fase crônica foi, posteriormente, corroborada por Kumar et al. (2016).

Ainda no modelo da pilocarpina, a depleção da 5-HT e as alterações de receptores serotoninérgicos esteve relacionada em diferentes estudos às variáveis clínicas. Trindade-Filho et al. (2008) avaliaram os efeitos da depleção de 5-HT, induzida por injeção de 5,7-dihidroxitriptamina. Estes autores observaram que após a administração desta substância, durante a fase aguda do desenvolvimento do modelo da pilocarpina, há uma maior facilitação da indução do EME. Quando a administração é realizada na fase crônica, ocorre um aumento significativo da frequência das crises espontâneas; sugerindo que a depleção da 5-HT está relacionada com uma piora da atividade epileptiforme.

Os estudos de Wang et al. (2015) e Yang et al. (2012) utilizaram modelos de epilepsia pela pilocarpina para avaliar as expressões dos receptores 5-HT6 e 5-HT7 respectivamente, através de técnicas imunológicas.

Wang et al. (2015), através da técnica de Western Blot, avaliou a expressão do receptor 5-HT6 no hipocampo e neocórtex de ratos, modelos de epilepsia pela administração da pilocarpina, encontrando um aumento da expressão do receptor, em ambos os tecidos. O aumento foi evidenciado a partir do terceiro dia de administração da pilocarpina, se mantendo elevado até 30 dias após a administração, último momento que foi realizado o Western Blot. 
Também observaram que os ratos que eram submetidos à administração de um antagonista seletivo do receptor 5-HT6 (SB399885), previamente à administração da pilocarpina, evoluíam com uma maior latência de início das crises epilépticas e apresentavam uma menor gravidade das crises, com uma menor expressão do receptor 5-HT6 e diminuição da atividade de mammalian target of rapamycin (mTOR).

Yang et al. (2012), através da técnica de imunohistoquímica, demonstraram um aumento da expressão do receptor 5-HT7 no lobo temporal de ratos, modelos de epilepsia pela pilocarpina, comparados com grupos de ratos não epilépticos. Foi avaliado também a atividade eletroencefalográfica e comportamental dos ratos epilépticos, tratados com um antagonista seletivo do receptor 5-HT7 (SB269970) ou com um agonista seletivo do receptor 5-HT7 (AS19), encontrando que o agonista dos receptores 5-HT7 poderia aumentar o número de crises epilépticas, as quais poderiam ser reduzidas pelo antagonista dos receptores 5 - $\mathrm{HT7}$.

Yang et al. (2014) associaram o receptor 5-HT1A com um efeito inibitório de EME em camundongos com epilepsia induzida pela pilocarpina e lítio. A administração subcutânea de um agonista do receptor 5-HT1A nesses camundongos, antes da administração da pilocarpina, aumentou o tempo de latência da primeira descarga epileptiforme, do estado de mal eletrográfico e das manifestações da crise generalizada e, com doses mais elevadas, também foi observada uma diminuição da duração da crise generalizada. Sendo que todos esses efeitos foram inibidos pela administração combinada de um antagonista do receptor 5-HT1A. 
No estudo de Buchanan et al. (2014), camundongos com redução > 99\% de neurônios serotoninérgicos no sistema nervoso central e camundongos controles foram induzidos à epilepsia pela pilocarpina ou por eletrochoque. $\mathrm{O}$ grupo com depleção dos neurônios serotoninérgicos apresentou um limiar epileptogênico menor e um aumento da mortalidade induzida por crises, quando comparado com controles. Além disso, a administração prévia de agonista do receptor 5-HT2A foi relacionada com redução da taxa de mortalidade nos dois grupos. Estes achados sugerem que as vias serotoninérgicas têm um papel importante na regulação do limiar epileptogênico, na gravidade das crises epilépticas e na proteção à morte súbita na epilepsia.

Os camundongos DBA 1 e DBA 2 são modelos de morte súbita em epilepsia, geneticamente propensos a crises induzidas por estímulo auditivo. Esses camundongos desenvolvem uma insuficiência respiratória, levando à insuficiência cardíaca e morte súbita, provocada por crises generalizadas audiogênicas. Os modelos DBA diferem quanto à suscetibilidade à insuficiência respiratória. O modelo DBA 1 tem uma baixa susceptibilidade à insuficiência respiratória após 30 dias de estímulos auditivos iniciais. Entretanto, esta incidência pode chegar a aproximadamente $100 \%$ e durar meses, após 3 a 4 dias consecutivos de preparação (exposição ao estímulo). O modelo DBA 2 tem uma incidência de insuficiência respiratória de aproximadamente $75 \%$ após estímulos iniciais, diminuindo após 28 dias pós-natais. Ambos os modelos têm se mostrado relevantes no estudo da SUDEP (Feng e Faingold, 2017). 
Existem evidências de que as vias serotoninérgicas estejam envolvidas na epileptogênese desse modelo animal. Estudos avaliando a expressão de receptores serotoninérgicos, através de Western Blot, no tronco encefálico de camundongos DBA, evidenciaram alterações nas expressões desses receptores. Nos camundongos DBA 1, as expressões dos receptores 5-HT2B, 5-HT2C, 5-HT3B estavam reduzidas e a do receptor 5-HT4 aumentada. Nos camundongos DBA/2, as expressões dos receptores 5-HT2C, 5-HT3C e 5-HT4 estavam reduzidas e do receptor 5-HT2C aumentada (Uteshev et al., 2010; Faingold, Randall, et al., 2011). Uteshev et al. (2010) sugeriram que uma das causas de susceptibilidade do modelo DBA/2 à insuficiência respiratória seria por uma expressão alterada dos receptores de 5-HT. A administração de fluoxetina, um inibidor seletivo de recaptação da 5-HT, previne a insuficiência respiratória sem bloquear as crises epilépticas, nos camundongos DBA (Faingold, Tupal, et al., 2011; Zeng et al., 2015). Faingold et al. (2016) demonstraram que agonistas do receptor 5-HT3 bloqueiam o desenvolvimento de insuficiência respiratória em camundongos DBA 1 e que antagonistas do receptor 5-HT3, coadministrados com fluoxetina abolem o efeito de bloqueio da insuficiência respiratória pela fluoxetina.

Witkin et al. (2007) compararam o limiar de crises epilépticas induzidas por estímulo elétrico ou químico, pentilenotetrazol (antagonista do GABA) ou cocaína (inibidor de recaptação da noradrenalina, 5-HT e dopamina) entre ratos deficientes de receptor 5-HT7 e ratos selvagens. Ratos deficientes do receptor 5-HT7, exibem um limiar reduzido para crises epilépticas induzidas por pentilenotetrazol e por cocaína e para crises tônicas, mas não clônicas, induzidas por eletrochoque. 
As injeções crônicas de metionina-sulfoximina (MSO), um inibidor da glutamina-sintetase, nos hipocampos de animais estão associadas com 0 desenvolvimento de um modelo animal de epilepsia-induzida caracterizado por crises espontâneas e recorrentes; em alguns casos com desenvolvimento de características semelhantes à esclerose hipocampal, com atrofia por perda neuronal hipocampal (Eid et al., 2008). Foi demonstrado que após a administração de MSO em hipocampos de camundongos, os níveis de $5-\mathrm{HT}$ sofrem uma redução significativa (Cloix, Tahi, Boissonnet, et al., 2010; Picard et al., 2011); a administração concomitante de 5-HT atrasa o início das crises induzidas por MSO (Picard et al., 2011). Nesses camundongos, linhagens de latência curta de início de crises possuem níveis basais de 5-HT mais elevados que linhagens de latência longa, além disso, ambas as linhagens apresentam diminuições dos níveis de 5- HT após início das crises epilépticas (Cloix, Tahi, Boissonnet, et al., 2010). Os autores propuseram que os camundongos de linhagens de latência curta conseguem metabolizar 5-HT na presença de MSO, ajudando assim a atrasar o início das crises, enquanto os camundongos de linhagens curtas são incapazes de metabolizar o 5-HT, justificando seus níveis mais elevados de 5-HT. Estes achados sugerem o envolvimento das vias serotoninérgicas com o desenvolvimento de crises epilépticas e a regulação de sua latência. 


\subsubsection{Estudos com Neuroimagem Funcional}

Diversos estudos com PET-CT já evidenciaram uma redução significativa da afinidade de ligação dos receptores 5-HT1A no lobo temporal ipsilateral à zona epileptogênica nos pacientes com ELT (Giovacchini et al., 2005; Didelot et al., 2008; Liew et al., 2009; Assem-Hilger et al., 2010).

Assem-Hilger et al. (2010), utilizando antagonista do receptor 5-HT1A, [carbonyl- $\left.{ }^{11} \mathrm{C}\right]$ WAY-100635 ([ $\left.\left.{ }^{11} \mathrm{C}\right] \mathrm{WAY} 100635\right)$, realizaram PET-CT em 13 pacientes com epilepsia do lobo temporal e observaram que o potencial de ligação do receptor 5-HT1A estava diminuído no hipocampo, giro parahipocampal e amígdala do lobo epileptogênico de pacientes com ELT, quando comparados ao grupo controle. Além disso, observaram uma assimetria interhemisférica significativa nos pacientes com ELT.

Ito et al. (2007) realizaram um estudo semelhante ao anterior, utilizando PET-CT com $\left[{ }^{11}\right.$ C]WAY100635 em 13 pacientes com ELT e observaram uma diminuição de ligação do receptor 5-HT1A no lobo temporal, hipocampo e amígdala ipsilateral ao foco epileptogênico, mas também na amígdala contralateral.

Giovacchini et al. (2005) realizaram um estudo com PET-CT em 22 pacientes com ELT, utilizando outro antagonista do receptor $5-\mathrm{HT} 1 \mathrm{~A},{ }^{18} \mathrm{~F}$-trans4-fluoro-N-2-[4-(2-methoxyphenyl)piperazin-1-yl]ethyl-N(2-

pyridyl)cyclohexanecarboxamide $\left({ }^{18} \mathrm{~F}-\mathrm{FCWAY}\right)$, e demonstraram que a redução do potencial de ligação do receptor 5-HT1A, nos pacientes com ELT, se mantém nas estruturas mesio-temporais e ínsula, mesmo após a correção de 
efeito parcial de volume, realizado para corrigir interferências da atrofia hipocampal nos resultados de PET-CT.

Merlet et al. (2004), através do estudo de PET-CT, com o antagonista do receptor 5-HT1A, 4-(2'-methoxyphenyl)-1-[2'-(N-2"-pyridinyl)-p[18F]fluorobenzamido]ethylpiperazine([18F]MPPF), associado com implantação de eletrodos intracerebrais e monitorização videoeletroencefalográfica das crises epilépticas, em nove pacientes com ELT, demonstraram que, além da redução da afinidade de ligação do receptor 5-HT1A no lobo temporal epileptogênico, quando comparado à pacientes controle, esta redução de ligação do receptor 5-HT1A estava relacionada com o grau de epileptogenicidade das áreas corticais.

Liew et al. (2009) realizaram estudo de PET-CT com ${ }^{18} \mathrm{~F}$-FCWAY em 12 pacientes com ELT, sem alterações compatíveis na RM. Foi evidenciado que a relação entre a diminuição do potencial de ligação do receptor 5-HT1A coincide com a região da atividade epileptiforme, demonstrada através da combinação de eletroencefalografia com eletrodos de superfície e eletrodos subdurais ou intra-operatórios, mesmo nesses pacientes sem lesões temporais identificadas pela ressonância magnética encefálica.

O estudo de Didelot et al. (2008), utilizou PET-CT com o antagonista do receptor 5-HT1A, 4-(2'-methoxyphenyl)-1-[2'-(N-2-pirydynyl)-pfluorobenzamido]-ethyl-piperazine (MPPF), em 42 pacientes com ELT, sendo 32 pacientes com ELT mesial. Ao combinar os resultados da PET-CT com dados e resultados pós--cirúrgicos, foi observado que todos os pacientes com ELT, que apresentaram uma diminuição do potencial de ligação ao antagonista do receptor 5-HT1A no hipocampo, amígdala e polo temporal, 
simultaneamente, foram bons candidatos cirúrgicos, evoluindo com resolução das crises após lobectomia temporal anterior.

\subsubsection{Ensaios Clínicos}

Diversos estudos experimentais com modelos animais evidenciaram o papel anticonvulsivante dos ISRS. Além disso, alguns ensaios clínicos obtiveram resultados semelhantes em humanos. Um ensaio clínico com 17 pacientes com crises focais, com ou sem crises generalizadas associadas, avaliou o efeito da fluoxetina na frequência das crises epilépticas. Em seis pacientes, houve remissão completa das crises epilépticas após 8 meses de tratamento. Nos onze pacientes restantes, houve uma redução de aproximadamente $30 \%$ na frequência das crises epilépticas (Favale et al., 1995). Em um ensaio preliminar com onze pacientes com epilepsia farmacorresistente, sem depressão associada, foi administrado citalopram por um período de 8 a 10 meses. Houve uma redução da média de frequência das crises epilépticas em 55,6\%, com nove pacientes melhorando pelo menos $50 \%$ (Favale et al., 2003).

Semelhantemente a esses estudos, um recente estudo observacional retrospectivo em 100 pacientes com epilepsia, que iniciaram ISRS ou inibidores de recaptação da serotonina e norepinefrina (IRSN) para tratamento de depressão ou ansiedade, observou que estas drogas poderiam estar relacionadas com uma redução na frequência das crises epiléticas (Ribot et al., 2017)c. 


\subsubsection{Estudos em Tecido Humano}

Poucos estudos foram realizados com tecido cerebral humano, correlacionando as vias serotoninérgicas com a epilepsia. Estes dados são ainda mais escassos quando analisamos somente o hipocampo (Broderick et al., 2000).

A concentração de 5-HT foi avaliada previamente no tecido cerebral humano de pacientes com ELT (Mori et al., 1987; Pintor et al., 1990; NaffahMazzacoratti et al., 1996; Broderick et al., 2000; Pacia et al., 2001), incluindo pesquisa através da cromatografia líquida de alta pressão (HPLC)(Mori et al., 1987; Pintor et al., 1990; Naffah-Mazzacoratti et al., 1996), como será detalhado a seguir.

Naffah-Mazzacoratti et al. (1996) avaliaram os níveis de monoaminas, através da HPLC com detecção eletroquímica, no líquor e no tecido temporal de seis pacientes com crises focais fármacorresistente, submetidos ao tratamento cirúrgico para controle das crises epilépticas, que foram monitorados com eletrocorticografia durante o procedimento cirúrgico. Os níveis de 5-HT e seu metabólito, o ácido 5-hidróxi-indol-acético, estavam aumentados nas áreas temporais de maior atividade epileptogênica, quando comparado com áreas não epileptogênicas. Pintor et al. (1990), através de HPLC com detecção eletroquímica, acharam resultados semelhantes no tecido temporal neocortical de 20 pacientes com epilepsia farmacorresistente.

Mori et al. (1987) analisaram os níveis de monoaminas, através de HPLC com detecção eletroquímica, no tecido cerebral de 12 pacientes com 
epilepsia fármacorrresistente. Não foi encontrada diferença significativa entre os níveis de $5-\mathrm{HT}$ dos pacientes com epilepsia e os pacientes controle. Entretanto, neste estudo, a etiologia da epilepsia dos pacientes analisados era predominantemente pós-traumática ou tumoral, com um caso de ELT geneticamente determinada.

Broderick et al. (2000) realizaram um estudo de monoaminas em camadas do hipocampo através da microvoltametria, proveniente de 13 pacientes com ELT farmacorresistente, nove pacientes com ELT mesial e quatro com ELT neocortical. O $5-\mathrm{HT}$ foi achado em todas as camadas estudadas do hipocampo, com maior concentração nas células granulares do giro denteado e na camada piramidal do hipocampo dos pacientes com ELT neocortical, quando comparado ao tecido proveniente de pacientes com ELT mesial.

Trottier et al. (1996) avaliaram a inervação serotoninérgica, através de imunoquímica, no tecido cortical de quatro pacientes com epilepsia focal de etiologia indeterminada e causada por displasia, submetidos a avaliação eletroencefalográfica com eletrodos profundos seguido de procedimento cirúrgico. Foi evidenciado uma maior inervação serotoninérgica no tecido cortical dos pacientes com epilepsia por displasia, mas não nos de etiologia indeterminada, quando comparados com controles.

Os receptores serotoninérgicos e o 5 -HTT foram avaliados no tecido pós-operatório de pacientes com ELT. Palomero-Gallagher et al. (2012) e Graebenitz et al. (2011) avaliaram a densidade de receptores, através de autorradiografia, nas biópsias de pacientes com ELT fármacorresistente, comparado com autópsias de controles. O primeiro estudo, realizado na 
amostra neocortical de 36 pacientes com epilepsia focal fármacorresistente, encontrou uma maior densidade do receptor 5-HT1A nos tecidos epilépticos neocortical, comparado aos controles e nenhuma alteração nos receptores 5HT2A. O segundo estudo, realizado em amostra de amígdala de 26 pacientes com ELT fármacorresistente, encontrou uma diminuição da densidade do receptor 5-HT1A, quando comparado ao controle.

Nos estudos de Wang et al. (2015) e Yang et al. (2012), descritos previamente, em modelos de pilocarpina, também foram avaliados a densidade dos receptores $5-\mathrm{HT} 6$ e $5-\mathrm{HT} 7$, respectivamente, em tecidos corticais humanos. Wang et al. (2015), através da técnica de Western Blot, encontrou uma maior expressão do receptor 5-HT6 no neocórtex temporal de 25 pacientes operados por epilepsia temporal lateral fármacorresistente, comparado com pacientes controles, operados por hipertensão intracraniana pós-traumática. Yang et al. (2012) demonstrou, através de imunohistoquímica, que a expressão de receptores 5 -HT7 no córtex temporal anterior de 28 pacientes operados por epilepsia farmacorresistente era maior do que nos do córtex dos pacientes controles, operados por hipertensão intracraniana póstraumática. Ambos os estudos encontraram aumento da expressão de receptores serotoninérgicos, tanto em modelo animal, quanto em tecido humano, quando comparados com controles, sugerindo que esses receptores podem estar associados com uma modulação da atividade epiléptica e/ou patogênese da epilepsia.

O estudo de Rocha et al. (2007) avaliou a afinidade de ligação serotoninérgica, avaliando a 5-HT, receptores e transportador serotoninérgico, através da técnica de autorradiografia, em tecido temporal neocortical de 15 
pacientes com ELT mesial, quando comparados com controles de tecido de vítimas fatais de acidente de automobilístico ou de câncer de pulmão, sem acometimento neurológico. No estudo, foi demonstrado uma diminuição da afinidade de ligação do 5-HTT em todas as camadas corticais dos pacientes com ELT mesial. Além de uma associação entre as alterações de receptores 5HT7 e 5-HT4 com a idade de início da epilepsia, a duração da epilepsia e o uso de FAEs. Uma menor afinidade de ligação do receptor 5-HT7 foi encontrada em todas as camadas de pacientes com idade precoce de início da epilepsia e, em algumas camadas (III-IV, V-VI), de pacientes com maior duração da epilepsia ou uso prolongado de FAEs. Já a afinidade de ligação do receptor 5HT4 foi encontrada diminuída em algumas camadas (III - IV) de pacientes com maior duração da epilepsia ou do uso prolongado de FAEs ou aumentada em outras camadas $(\mathrm{V}-\mathrm{VI})$ nos pacientes com uso prolongado de FAEs.

Cuellar-Herrera et al. (2014) avaliaram a ativação funcional dos receptores 5-HT1A acoplados à proteína G, através de um ensaio de ligação, utilizando 8-OH-DPAT (um antagonista do receptor 5-HT1A), no tecido hipocampal de 8 pacientes com ELT mesial fármacorresistente, comparados com tecido hipocampal controle proveniente de autópsias de indivíduos sem relato de condições neurológicas. Foi observado uma maior ativação desses receptores, nos pacientes com ELT mesial.

\subsection{Atividade Serotoninérgica nos Transtornos Psiquiátricos nos Pacientes com Epilepsia}


Diversos estudos clínicos e experimentais já demonstraram que na depressão ocorre um aumento na regulação dos receptores 5-HT1A localizados na rafe, com consequente auto-inibição aumentada da liberação de 5-HT. Este mecanismo também pode estar envolvido nos pacientes com depressão associado à epilepsia.

Em um estudo com PET-CT, realizado nos pacientes com ELT e depressão, foi demonstrado que a afinidade de ligação dos receptores 5 -HT da rafe estava aumentada e positivamente relacionada com a gravidade dos sintomas depressivos (Lothe et al., 2008). Outros estudos em humanos, com neuroimagem funcional, tendo como alvo os receptores serotoninérgicos 5HT1A, sugerem um papel fisiopatológico comum da 5-HT na depressão e epilepsia (Hasler et al., 2007). Nos dois estudos, foi demonstrada uma diminuição da ligação de 5-HT em estruturas comuns das duas patologias: nas regiões temporais mesiais, giro do cíngulo e núcleo da rafe (Hasler et al., 2007; Lothe et al., 2008).

Martinez et al. (2013) demonstraram uma assimetria de afinidade de ligação do 5-HTT na ínsula e no giro fusiforme, entre os lados ipsilateral e contralateral à zona epileptogênica, nos pacientes com ELT e depressão associada, quando comparados com pacientes com ELT isolada, sugerindo uma diminuição da atividade do 5-HTT nestes pacientes, compensatória a uma perda do receptor 5-HT1A, que também estava alterado neste estudo.

Usando modelos animais de estado de mal induzido por lítio e pilocarpina (modelo animal de epilepsia temporal), Mazarati et al. (2008) encontraram sintomas de depressão nos ratos pós EME. Este estudo demonstrou uma transmissão interictal serotoninérgica rafe-hipocampal 
diminuída nos ratos pós EME induzido. Estudos posteriores evidenciaram que a depressão associada com a epilepsia é acompanhada por hipersensibilização dos receptores 5-HT1A, em ratos pós EME induzido, quando comparados aos controles saudáveis (Pineda et al., 2010; Pineda et al., 2011). 
2. JUSTIFICATIVA 
Há evidências provenientes de estudos animais e de neuroimagem funcional associando as vias serotoninérgicas com a epileptogênese. Além disto, sugere-se que estas vias poderiam estar envolvidas nos mecanismos fisiopatológicos comuns da epilepsia e dos transtornos psiquiátricos. Entretanto, estudos em tecido cerebral humano são escassos, principalmente em grupos com etiologia homogênea, e diferem muito da região cerebral utilizada.

Dentre esses estudos, os que mensuram a concentração de 5-HT utilizaram amostras pequenas de pacientes com etiologia heterogênea e não avaliaram variáveis clínicas da epilepsia, bem como a presença dos transtornos psiquiátricos. Aqueles que abordaram os receptores serotoninérgicos e o transportador serotoninérgico $(5-\mathrm{HTT})$ utilizaram pacientes com ELT determinada por diferentes etiologias, ou seja, grupos heterogêneos etiologicamente. Além disso, diferentes regiões cerebrais foram avaliadas, sendo que poucos abordaram as variáveis clínicas e nenhum avaliando as comorbidades psiquiátricas.

A ELT, protótipo das epilepsias cirurgicamente tratáveis e frequentemente reproduzida nos modelos animais para estudo, tem como principal causa a $\mathrm{EH}$, sendo este um excelente modelo para estudo em humanos, permitindo uma seleção etiologicamente mais homogênea dos pacientes. Além disto, sendo o hipocampo o local acometido nesta patologia, é muito importante a avaliação das possíveis alterações neurobiológicas desta região.

Este é o primeiro estudo avaliando as vias serotoninérgicas em tecido hipocampal humano de pacientes homogênenos quanto à etiologia, ou seja, 
com ELT-EH. Além disso, é o primeiro que correlaciona a concentração de 5HT e a densidade dos receptores serotoninérgicos e do 5-HTT com as variáveis clínicas da epilepsia dentro deste grupo, bem como, compararam, nestes pacientes, a presença ou ausência de transtornos psiquiátricos associados. Espera-se que os presentes achados possam contribuir para melhor delimitar os mecanismos serotoninérgicos que podem ser responsáveis pela gravidade da epilepsia, assim como, dos mecanismos envolvendo a correlação entre epilepsia e comorbidades psiquiátricas. 
3. OBJETIVO 


\subsection{Objetivo Geral}

Este estudo tem como objetivo primário avaliar se existe associação entre a concentração de 5-HT ou a densidade dos receptores serotoninérgicos e do 5-HTT, avaliados no hipocampo de pacientes com ELT-EH, com fatores associados com a gravidade da epilepsia. O objetivo secundário é o de avaliar se existe relação entre a atividade serotoninérgica no tecido hipocampal dos pacientes com ELT-EH e a presença de transtornos psiquiátricos

\subsection{Objetivos Específicos}

Este estudo tem como objetivos específicos:

1. Avaliar a concentração de 5-HT através da técnica de HPLC.

2. Avaliar a densidade de receptores de 5-HT no hipocampo, através da técnica de Western-Blot.

3. Avaliar a densidade do 5-HTT no hipocampo, através da técnica de Western-Blot.

4. Analisar se as concentrações de 5-HT, assim como a densidade dos receptores serotoninérgicos e do 5-HTT estão associadas com variáveis clínicas da epilepsia.

5. Verificar se as concentrações de 5-HT, assim como a densidade dos receptores serotoninérgicos e do 5-HTT estão associadas com a presença de transtorno psiquiátrico. 
4. MATERIAL E MÉTODOS 


\subsection{Pacientes}

\subsubsection{Critérios de Inclusão}

Foram incluídos os pacientes submetidos a procedimento neurocirúrgico caracterizado por lobectomia temporal anterior, por indicação clínica, que preenchiam os seguintes critérios:

- Investigação e diagnóstico prévio de ELT-EH unilateral e fármacorresistente, com indicação de tratamento cirúrgico.

- Diagnóstico de epilepsia baseado na proposta mais atual da ILAE (Fisher et al., 2014) e a epilepsia considerada farmacorresistente na ausência de controle das crises epilépticas, isto é, uma ou mais crises por mês, após tratamento com dois ou mais FAEs adequadamente escolhidos e nas doses máximas toleradas (Beleza, 2009; Kwan e Sperling, 2009; Kwan et al., 2010).

- A avaliação prévia com ressonância magnética demonstrando diminuição do volume hipocampal nas imagens ponderadas em T1 e aumento do hipersinal em T2 e flair foi critério absoluto (Camacho e Castillo, 2007; Menzler et al., 2010; Blümcke et al., 2013).

- Pacientes nos quais a amostra de tecido hipocampal dissecada foi armazenada $\mathrm{a}-80^{\circ} \mathrm{C}$, logo após procedimento cirúrgico, até homogeneização.

As comorbidades psiquiátricas foram avaliadas através da Entrevista Clínica Estruturada para Transtornos de Eixo I do DSM-IV - SCID-4 (Structured Clinical Interview for DSM-IV AXIS Disorders). 
Durante a análise dos dados foram divididos grupos em monoterapia e politerapia para avaliação quanto a possíveis interferências nos resultados.

\subsubsection{Critérios de Exclusão}

Os critérios de exclusão foram: 1. Não consentimento na pesquisa após a apresentação do termo de consentimento livre e esclarecido (ANEXO 1) ou ao termo de assentimento (para crianças ou adolescentes); 2. Pacientes na qual a amostra de tecido humano, após o procedimento cirúrgico, não era suficiente para análise

\subsubsection{Caracterização dos Pacientes}

O tecido hipocampal avaliado foi proveniente de uma amostra constituída por 44 pacientes, sendo 24/44 (54.5\%) do sexo feminino, com idade média de início da epilepsia de 8,9 anos (DP $\pm 7,4)$ e duração média da epilepsia de 26 anos (DP $\pm 12,0$ ). História de CTCG estava presente em $65.9 \%$ dos pacientes (29/44); história de EME em 13.6\% (6/44), história de crises febris em 20.5\% (9/44) (Gráfico 1).

Transtornos psiquiátricos foram diagnosticados em 54.5\% (24/44) dos pacientes, incluindo os seguintes diagnósticos: transtorno depressivo em $34.0 \%(15 / 44)$, transtorno de ansiedade em $2.2 \%(1 / 44)$ e psicose em $18.2 \%$ (8/44) (Gráfico 1). 
Todos os pacientes estavam em uso de FAEs no momento da cirurgia, como monoterapia ou politerapia. Com exceção de um paciente em monoterapia com fenitoína, todos os outros pacientes em monoterapia estava em uso de carbamazepina ou oxcarbazepina. Os FAEs utilizados em associação foram topiramato, fenobarbital, ácido valpróico e benzodiazepínicos (Tabela 1).

Tabela 1- Caracterização dos pacientes

\begin{tabular}{|c|c|c|c|c|c|c|c|c|c|c|c|c|}
\hline Paciente & Sexo & $\begin{array}{c}\text { Idade na } \\
\text { cirurgia } \\
\text { (anos) }\end{array}$ & $\begin{array}{l}\text { Idade } \\
\text { início } \\
\text { epilepsia } \\
\text { (anos) }\end{array}$ & $\begin{array}{l}\text { Duração } \\
\text { da } \\
\text { epilepsia } \\
\text { (anos) }\end{array}$ & $\begin{array}{l}\text { Frequência } \\
\text { das crises }\end{array}$ & $\begin{array}{c}\text { História } \\
\text { de } \\
\text { crises } \\
\text { febris }\end{array}$ & $\begin{array}{l}\text { História } \\
\text { de CTCG }\end{array}$ & $\begin{array}{l}\text { Frequência } \\
\text { CTCG }\end{array}$ & $\begin{array}{l}\text { História } \\
\text { de EME }\end{array}$ & FAEs & $\begin{array}{c}\text { ISRS/ } \\
\text { Antipsicóti- } \\
\text { cos }\end{array}$ & TP \\
\hline 1 & $\mathrm{Fe}$ & 13 & 5 & 7 & $\mathrm{~s}$ & + & + & $E$ & - & OXC/BZD & - & De \\
\hline 2 & $\mathrm{Fe}$ & 19 & 0.9 & 18 & D & - & + & $\mathrm{Me}$ & - & $\mathrm{CBZ} / \mathrm{PB} / \mathrm{BZD}$ & - & De \\
\hline 3 & $\mathrm{Fe}$ & 47 & 6 & 41 & $\mathrm{Me}$ & + & + & $\mathrm{Me}$ & - & OXC/BZD & - & $\mathrm{De}$ \\
\hline 4 & $\mathrm{Fe}$ & 40 & 5 & 35 & Me & - & + & $\mathrm{E}$ & - & LMT/TPM/PB & - & De \\
\hline 5 & $\mathrm{Fe}$ & 35 & 12 & 23 & $\mathrm{Me}$ & - & + & $\mathrm{E}$ & - & CBZ/LMT/PB & - & De \\
\hline 6 & $\mathrm{Fe}$ & 39 & 9 & 30 & Me & - & + & E & - & CBZ/PHT & - & De \\
\hline 7 & M & 29 & 16 & 13 & $\mathrm{~s}$ & + & + & E & - & $\mathrm{CBZ} / \mathrm{VPA} / \mathrm{PB} / \mathrm{BZD}$ & SER/RISP & De \\
\hline 8 & $\mathrm{Fe}$ & 41 & 3 & 38 & $\mathrm{~s}$ & - & + & E & + & PHT/PB & SER/HAL & De \\
\hline 9 & $\mathrm{Fe}$ & 45 & 10 & 35 & $\mathrm{~s}$ & - & + & $E$ & - & $\mathrm{OXC} / \mathrm{PB}$ & - & A \\
\hline 10 & M & 37 & 20 & 17 & Me & - & + & E & - & CBZ & - & $P$ \\
\hline 11 & M & 27 & 5 & 22 & $\mathrm{Me}$ & + & + & E & - & $\mathrm{VPA} / \mathrm{PB}$ & - & $\mathrm{P}$ \\
\hline 12 & $\mathrm{Fe}$ & 43 & 8 & 35 & $\mathrm{Me}$ & - & + & E & - & $\mathrm{CBZ} / \mathrm{PB}$ & HAL & $P$ \\
\hline 13 & $\mathrm{Fe}$ & 41 & 18 & 23 & $\mathrm{D}$ & - & + & $\mathrm{Me}$ & - & PHT/BZD & - & $\mathrm{P}$ \\
\hline 14 & $\mathrm{Fe}$ & 45 & 1 & 44 & Me & - & + & $\mathrm{E}$ & - & PHT/LMT/BZD & RISP & $\mathrm{P}$ \\
\hline 15 & M & 44 & 21 & 23 & $\mathrm{~s}$ & - & + & $\mathrm{E}$ & - & CBZ/BZD & RISP & $\mathrm{P}$ \\
\hline 16 & $\mathrm{Fe}$ & 53 & 1 & 52 & Me & - & + & E & - & $\mathrm{PHT} / \mathrm{PB}$ & HAL & $\mathrm{P}$ \\
\hline 17 & M & 35 & 9 & 26 & $\mathrm{D}$ & - & + & E & - & CBZ/BZD & - & $P$ \\
\hline 18 & M & 22 & 1 & 21 & $\mathrm{~s}$ & - & + & E & + & $\mathrm{CBZ/PB/BZD}$ & - & $\mathrm{N}$ \\
\hline 19 & M & 24 & 4 & 20 & D & - & + & E & + & CBZ/BZD & - & $\mathrm{N}$ \\
\hline 20 & M & 10 & 0.75 & 10 & $\mathrm{~s}$ & - & + & $\mathrm{Me}$ & - & CBZ & RISP & $\mathrm{N}$ \\
\hline 21 & $\mathrm{Fe}$ & 44 & 29 & 15 & $\mathrm{Me}$ & - & + & $\mathrm{Me}$ & - & CBZ & - & $\mathrm{N}$ \\
\hline 22 & M & 24 & 0.4 & 24 & Me & - & + & $\mathrm{Me}$ & + & CBZ & - & $\mathrm{N}$ \\
\hline 23 & M & 52 & 24 & 28 & $\mathrm{D}$ & - & + & $\mathrm{Me}$ & + & CBZ & - & $\mathrm{N}$ \\
\hline 24 & $\mathrm{Fe}$ & 51 & 8 & 43 & $\mathrm{~s}$ & + & + & $\mathrm{E}$ & - & $\mathrm{PHT} / \mathrm{TPM} / \mathrm{PB} / \mathrm{BZD}$ & - & $\mathrm{N}$ \\
\hline 25 & $\mathrm{Fe}$ & 38 & 0.75 & 37 & Me & + & + & $\mathrm{Me}$ & - & $\mathrm{CBZ} / \mathrm{BZD}$ & - & $\mathrm{N}$ \\
\hline
\end{tabular}


Tabela 1- Caracterização dos pacientes (continuação)

\begin{tabular}{|c|c|c|c|c|c|c|c|c|c|c|c|c|}
\hline Paciente & Sexo & $\begin{array}{l}\text { Idade na } \\
\text { cirurgia } \\
\text { (anos) }\end{array}$ & $\begin{array}{c}\text { Idade } \\
\text { início } \\
\text { epilepsia } \\
\text { (anos) }\end{array}$ & $\begin{array}{l}\text { Duração } \\
\text { da } \\
\text { epilepsia } \\
\text { (anos) }\end{array}$ & $\begin{array}{l}\text { Frequência } \\
\text { das crises }\end{array}$ & $\begin{array}{l}\text { História } \\
\text { de } \\
\text { crises } \\
\text { febris }\end{array}$ & $\begin{array}{l}\text { História } \\
\text { de CTCG }\end{array}$ & $\begin{array}{l}\text { Frequência } \\
\text { CTCG }\end{array}$ & $\begin{array}{l}\text { História } \\
\text { de EME }\end{array}$ & FAEs & $\begin{array}{c}\text { ISRS/ } \\
\text { Antipsicóti- } \\
\text { cos }\end{array}$ & TP \\
\hline 26 & M & 28 & 3 & 25 & S & - & + & $\mathrm{Me}$ & - & $\mathrm{CBZ} / \mathrm{PB}$ & - & $\mathrm{N}$ \\
\hline 27 & M & 42 & 1 & 41 & $\mathrm{Me}$ & - & + & $E$ & + & OXC/LMT/BZD & - & $\mathrm{N}$ \\
\hline 28 & M & 47 & 12 & 35 & $\mathrm{Me}$ & - & + & Me & - & $\mathrm{CBZ} / \mathrm{PB}$ & - & $\mathrm{N}$ \\
\hline 29 & $\mathrm{Fe}$ & 33 & 21 & 12 & $\mathrm{~s}$ & - & + & $E$ & - & CBZ/BZD & - & $\mathrm{N}$ \\
\hline 30 & $\mathrm{Fe}$ & 41 & 14 & 27 & $\mathrm{~s}$ & - & - & - & - & PHT/TPM/PB & SER & De \\
\hline 31 & M & 15 & 3 & 12 & $\mathrm{~s}$ & + & - & - & - & CBZ & SER & De \\
\hline 32 & $\mathrm{Fe}$ & 34 & 11 & 23 & $\mathrm{~s}$ & - & - & - & - & CBZ/VPA & SER & De \\
\hline 33 & $\mathrm{Fe}$ & 43 & 12 & 29 & $\mathrm{Me}$ & + & - & - & - & $\mathrm{CBZ} / \mathrm{PB} / \mathrm{BZD}$ & SER & De \\
\hline 34 & $\mathrm{Fe}$ & 37 & 21 & 16 & $\mathrm{Me}$ & - & - & - & - & CBZ/BZD & FLX & De \\
\hline 35 & $\mathrm{Fe}$ & 41 & 14 & 27 & $\mathrm{~s}$ & - & - & - & - & CBZ/LMT/BZD & FLX & De \\
\hline 36 & M & 17 & 1 & 16 & $\mathrm{Me}$ & - & - & - & - & CBZ/TPM/BZD & $\begin{array}{c}\text { SER/RISP/HA } \\
L\end{array}$ & De \\
\hline 37 & $\mathrm{Fe}$ & 69 & 9 & 60 & $\mathrm{Me}$ & - & - & - & - & $\mathrm{CBZ} / \mathrm{PB}$ & - & $\mathrm{N}$ \\
\hline 38 & $\mathrm{Fe}$ & 20 & 3 & 17 & $\mathrm{~s}$ & - & - & - & - & CBZ & - & $\mathrm{N}$ \\
\hline 39 & $\mathrm{Fe}$ & 13 & 5 & 8 & $\mathrm{Me}$ & - & - & - & - & CBZ & - & $\mathrm{N}$ \\
\hline 40 & M & 46 & 12 & 34 & $\mathrm{~s}$ & + & - & - & - & $\mathrm{PXC} / \mathrm{PB}$ & - & $\mathrm{N}$ \\
\hline 41 & M & 20 & 10 & 10 & $\mathrm{~s}$ & - & - & - & - & $\mathrm{CBZ} / \mathrm{PB}$ & - & $\mathrm{N}$ \\
\hline 42 & M & 29 & 5 & 24 & $\mathrm{Me}$ & - & - & - & - & CBZ/VPA/BZD & - & $\mathrm{N}$ \\
\hline 43 & M & 50 & 16 & 34 & Me & - & - & - & - & CBZ/LMT/PB/PHT & - & $\mathrm{N}$ \\
\hline 44 & M & 18 & 1 & 17 & Me & - & - & - & - & $\mathrm{CBZ}$ & - & $\mathrm{N}$ \\
\hline
\end{tabular}

CTCG: crise tônico-clônico generalizada; EME: estado de mal epiléptico; TP: transtorno psiquiátrico; Fe: feminino; M: masculino; D: diário; S: Semanal; Me: mensal; E: esporádico; De: depressão; A: ansiedade; P: psicose; N: nenhum; BZD: benzodiazepínico; CBZ: carbamazepina; LTG: lamotrigina; OXC: oxcarbazepina; PB: fenobarbital; PHT: fenitoína; TPM: topiramato; VPA: ácido valpróico; FLX: fluoxetina; HAL: haloperidol; SER: sertralina; RISP: risperidona 
Gráfico 1- Caracterização dos pacientes

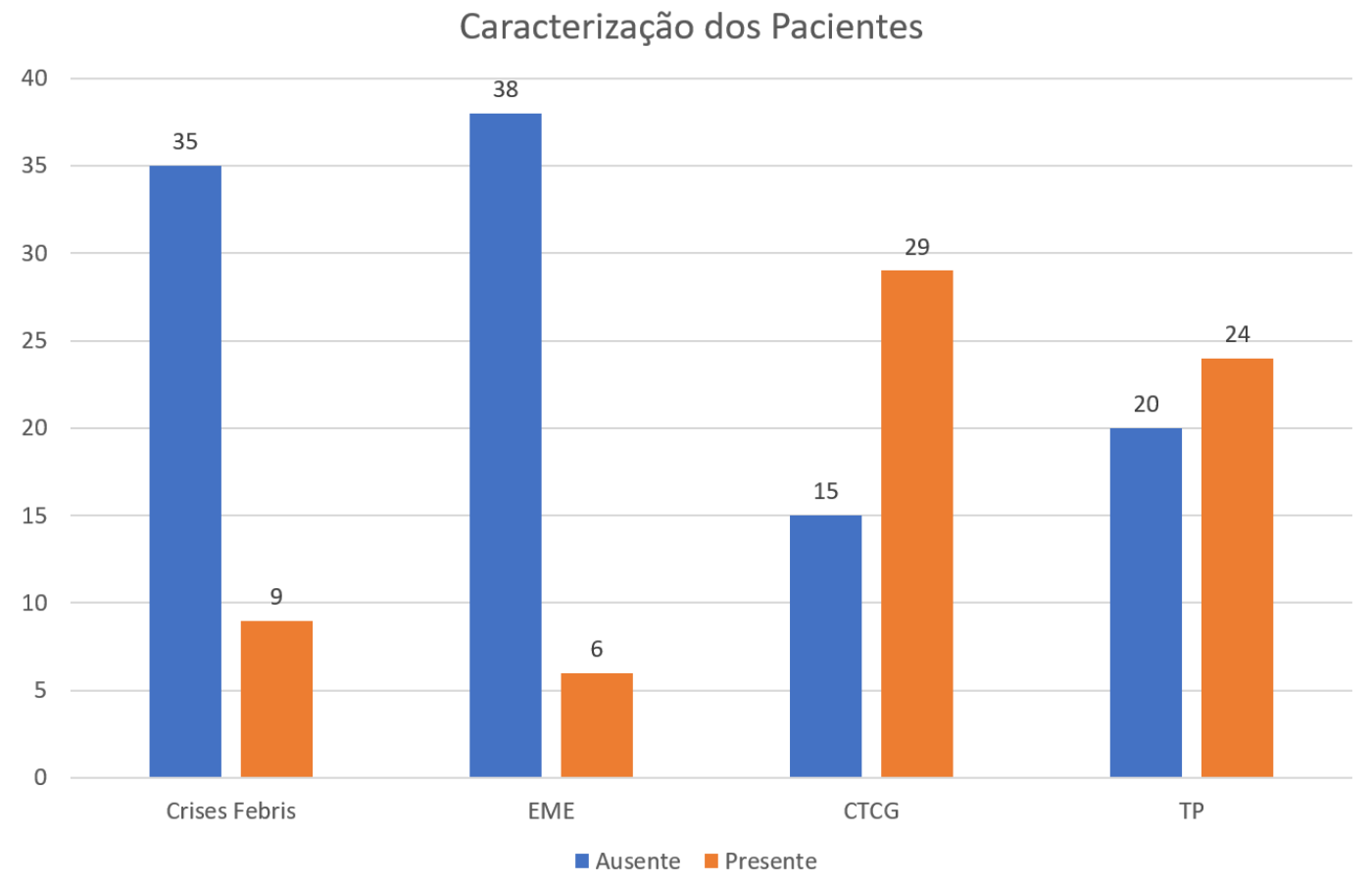

EME: estado de mal epiléptico; CTCG: crises tônico-clônico generalizadas; TP: transtorno psiquiátrico

\subsection{Cromatografia Líquida de Alta Pressão}

\subsubsection{Preparação do Hipocampo}

O tecido cerebral humano dissecado e armazenado, foi homogeneizado com ácido perclórico 3,4M em potter (Potter S, B. Braun da Biotech International®) para uma concentração final de $25 \mathrm{mg} / \mathrm{ml}$. Em seguida, sonicado por 30 segundos para lise de membranas (Biotech International囚, VirSonic 100 da Virtis ${ }^{\circledR}$ ), centrifugado $14000 \mathrm{~g}$ a 4ํㅡ por 20 minutos (Centrífuga Himac CF ISC2 da Hitachi $\left.{ }^{\circledR}\right)$ e armazenado a $-80^{\circ} \mathrm{C}$ até uso. 


\subsubsection{Técnica de Análise}

A metodologia de quantificação de 5-HT através da cromatografia líquida de alta pressão foi desenvolvida baseada em protocolos previamente estabelecidos pelo grupo em plaquetas humanas e em estudos prévios da literatura (Baumann et al., 1998; Alvarez et al., 1999; Noguchi et al., 2000; Umeda et al., 2005; Talib et al., 2011).

A 5-HT foi diluída em uma solução de fosfato de sódio da Merck (Darmstadt, Germany). O dodecil sulfato de sódio utilizado foi da Aldrich-Sigma (Steinheim, Germany). Ácido Perclórico (HClO4), metanol e acetonitrila foram obtidos da Merck (Darmstadt, Germany).

A fase móvel foi composta por uma mistura de solução ácida (contendo fosfato de sódio $0,1 \mathrm{M}$ e dodecil fosfato de sódio $10 \mu \mathrm{M})$, acetonitrila e metanol (70:15:15 v/v/v) A fase móvel foi ajustada para $\mathrm{pH} 2.5$ com ácido perclórico 37\%, filtrada com filtro de 0.45-mm e degaseificada antes do uso. A fase móvel foi usada em temperatura ambiente com fluxo de $0,8 \mathrm{ml} / \mathrm{min}$ (pressão aproximada de 150 bar).

Foram preparados padrões com solução de fosfato de sódio, que armazenados em frascos âmbar nas seguintes concentrações: $1 \mathrm{mg} / \mathrm{mL}$, $0,1 \mathrm{mg} / \mathrm{mL}, 0,01 \mathrm{mg} / \mathrm{mL}, 0,001 \mathrm{mg} / \mathrm{ml}$ e $0.0001 \mathrm{mg} / \mathrm{ml}$ de $5-\mathrm{HT}$. O padrão externo foi o 5- metoxitriptamina preparado em uma solução de fosfato de sódio $30 \mathrm{mM}$, pH 7,4 e armazenado em frasco âmbar a $4^{\circ} \mathrm{C}$.

A cromatografia foi realizada pelo sistema Shimadzu. A coluna (250 x $4.0 \mathrm{~mm}$ i.d.) utilizada foi a Lichrospher $5 \mathrm{~mm} 100 \mathrm{C} 8$ (Varian) e a detecção realizada por fluorescência (Shimadzu), ideal para compostos que fluorescem 
devido a sua alta sensibilidade, ajustada em $330 \mathrm{~nm}$ para excitação e 450nm para emissão.

Para a curva de calibração foi utilizado $200 \mu \mathrm{L}$ de ácido perclórico, também utilizado para homogeneizar o tecido cerebral humano e, o qual é livre de substâncias potencialmente interferentes no comportamento da 5-HT. As soluções padrões foram preparadas semanalmente.

\subsection{Western Blot}

\subsubsection{Preparação do Hipocampo}

O tecido hipocampal foi dissecado e armazenado $-80^{\circ} \mathrm{C}$, sendo posteriormente homogeneizado no tampão de lise (RIPA buffer) com inibidores de fosfatase e protease, para uma concentração final de $200 \mathrm{mg} / \mathrm{ml}$. As alíquotas homogeneizadas foram armazenadas a $-80^{\circ} \mathrm{C}$.

\subsubsection{Técnica de Análise}

Os níveis de proteína total foram determinados utilizando o kit de dosagem de proteína DC (detergent compatible) Protein Assay (Bio-Rad, Life Sciences Group, Hercules, California, USA) e o método espectofotométrico utilizado para esta quantificação foi o de Lowry modificado (Lowry et al., 1951; Peterson, 1977).

Para fracionar $25 \mathrm{mg}$ de proteína de cada amostra, foi utilizada a eletroforese em gel de poliacrilamida com dodecil sulfato de sódio (SDS) a 10\%. O marcador de peso molecular utilizado foi da Bio-Rad. A corrida da eletroforese foi de $160 \mathrm{~V}$ por 90 minutos. 
Após a corrida, foi realizado a fase de transferência das proteínas do gel para uma membrana de nitrocelulose. Foi realizada uma transferência eletroforética, com $250 \mathrm{~mA}$, por 60 minutos.

Após a transferência, foi utilizado o corante Ponceau para confirmar a transferência das proteínas para a membrana (Figura 1).

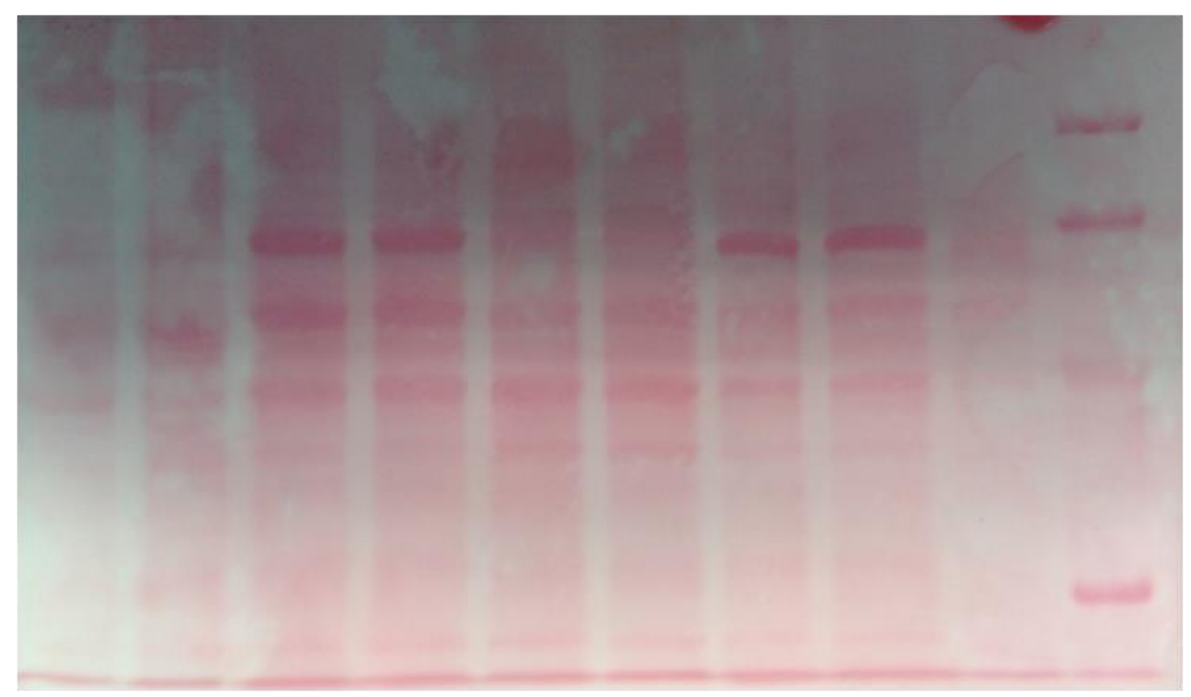

Figura 1- Membrana de nitrocelulose após utilização do Ponceau

Antes da detecção da proteína de interesse, as membranas foram bloqueadas com leite desnatado $5 \%$ em solução salina tamponada com Tris (TBS), acrescida de polissorbato 20 ou tween 20 (T) a 0,02\%, com o objetivo de impedir ligações inespecíficas nas membranas. As membranas que seriam reagidas com os receptores 5-HT1A, 5-HT2A e 5-HT6 permaneceram em bloqueio com leite durante 1 hora em temperatura ambiente. As membranas que seriam reagidas com o receptor 5-HT7 e o 5-HTT permaneceram em bloqueio com leite durante uma noite à uma temperatura de $4^{\circ} \mathrm{C}$.

Após o bloqueio, as membranas foram lavadas com solução de TBS-T 0,02\% e então incubadas com anticorpo monoclonal primário: Os anticorpos 
dos receptores 5-HT1A (anticorpo policlonal de coelho anti 5-HT1A, ab64994, Abcam, Cambridge, MA, USA); 5-HT2A (anticorpo policlonal de coelho anti 5HT2A, ab85496, Abcam, Cambridge, MA, USA) e 5-HT6 (anticorpo policlonal de coelho anti 5-HT6, ab101911, Abcam, Cambridge, MA, USA) foram diluídos em solução de TBS-T $0.02 \%$, com uma proporção de 1:1000 e incubados durante a noite, em temperatura de $4^{\circ} \mathrm{C}$.

Os anticorpos do receptor 5-HT7 (anticorpo policlonal de coelho anti 5HT7, ab28892, Abcam, Cambridge, MA, USA) e do 5-HTT (anticorpo policlonal de coelho anti 5-HTT, ab102408, Abcam, Cambridge, MA, USA) foram diluídos em solução de TBS-T 0.02\%, com uma proporção de 1:3000 e 1:1000, respectivamente, e incubados por 1 hora, em temperatura ambiente.

As membranas foram lavadas com TBS-T 0,02\% e, então, incubadas com anticorpo secundário (anticorpo secundário anti-coelho da Sigma-Aldrich, Saint Louis, MO, USA), por 1 hora, em temperatura ambiente. A diluição do anticorpo secundário em TBS-T $0.02 \%$ foi de 1:20000 nas membranas de receptores 5-HT1A, 5-HT7 e 5-HTT; e de 1: 10000 nas membranas dos receptores 5-HT2A e 5-HT6.

As membranas foram novamente lavadas com TBS-T $0.02 \%$ e levadas para revelação. Para este processo, foi utilizado um reagente quimioluminescente (Enhanced chemiluminescence ECL Select; GE Life Sciences, Marlborough, MA, USA), que foi aplicado nas membranas. As membranas foram imediatamente inseridas no aparelho detector (Chemilmager 4000 systems). Neste aparelho, a luz é capturada, fotografada e convertida em uma imagem digital. A análise da densitometria das diferentes bandas protéicas foi realizada através do software v5.5 da Alpha Innotech (San 
Leandro, CA, USA). Cada amostra foi analisada em duplicata. Como o método é semi-quantitativo, foram comparadas as intensidades de densidade entre as diferentes amostras (Figura 2).
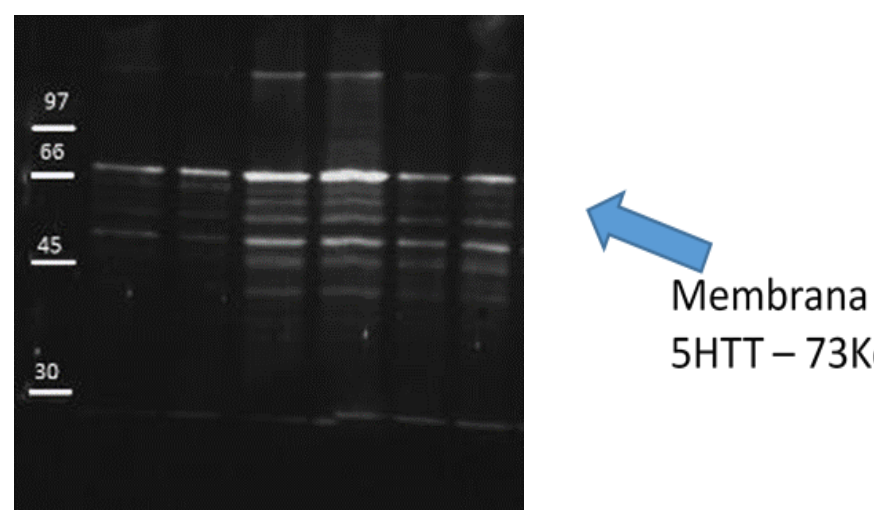

$5 \mathrm{HTT}-73 \mathrm{Kda}$

Figura 2- Amostra de membrana incubada com 5-HTT

\subsection{Análise Estatística}

Foram analisadas as seguintes variáveis: idade de início da epilepsia, duração da epilepsia, presença de crises febris, presença de EME, presença e frequência de crises epilépticas, presença e frequência das CTCG, FAEs (monoterapia versus politerapia). Também foram avaliados o uso de ISRS e de drogas antipsicóticas e a presença e tipo de transtorno psiquiátrico.

O desfecho primário foi identificar a associação entre variáveis clínicas da epilepsia e concentração de 5-HT ou densidade dos receptores serotoninérgicos e do 5-HTT. O resultado clínico secundário foi a presença de transtorno psiquiátrico.

Primeira análise: A relação entre a concentração de 5-HT, a densidade dos receptores serotoninérgicos ou do 5-HTT e as variáveis clínicas 
foram acessadas com os seguintes testes: 1. Teste de Wilcoxon-Mann-Whitney ou teste de Kruskal-Wallis para variáveis independentes, dependendo do número de grupos ou teste de Jonckheere-Terpstra para variáveis independentes ordinais e 2. Coeficiente de correlação de Spearman para variáveis contínuas e ordinais.

A associação entre crises TCG e as variáveis confusionais foi analisada pelo teste exato de Fischer.

Segunda análise: Para acomodar fatores confusionais, a associação entre a concentração de 5-HT, a densidade dos receptores serotoninérgicos ou a densidade do 5-HTT com variáveis independentes foi acessada com o modelo linear de distribuição gama. Para a distribuição normal, foi avaliado através do gráfico quantil quantil.

As análises estatísticas foram realizadas com o programa Statistical Package for the Social Sciences, versão 4.0 (SPSS Inc., Chicago, IL, USA). Todos os testes foram bicaudais e, em todos eles, foi adotado um nível de significância estatística de 5\%.

\subsection{Aspectos Éticos}

O projeto de pesquisa foi aprovado pelo Comitê de Ética em Pesquisa do HC-FMUSP e enquadrado como APROVADO, sob o número CAAE: 56797513.4.0000.0068; número do parecer 1.633.093. 
5. RESULTADO 


\subsection{Concentração de Serotonina}

Os resultados sobre a concentração de 5-HT que serão apresentados abaixo, encontram-se no artigo Fonseca, NC et al. Epilepsy Research 2015; 111:18-25. (ANEXO 2)

A determinação da concentração de 5-HT foi realizada em 44 amostras de hipocampo, sendo que os níveis variaram entre 0.0916 a 0.7323 ng/mg, com uma média de concentração de 0.3366 ng/mg (Gráfico 2). Níveis séricos mais baixos de 5-HT foram associados com presença de crises TCG (Wilcoxon-Mann-Whitney; $p=0.019$ ). (Tabela 2, Figura 3, Gráfico 3).

Gráfico 2- Níveis de dispersão da concentração de serotonina

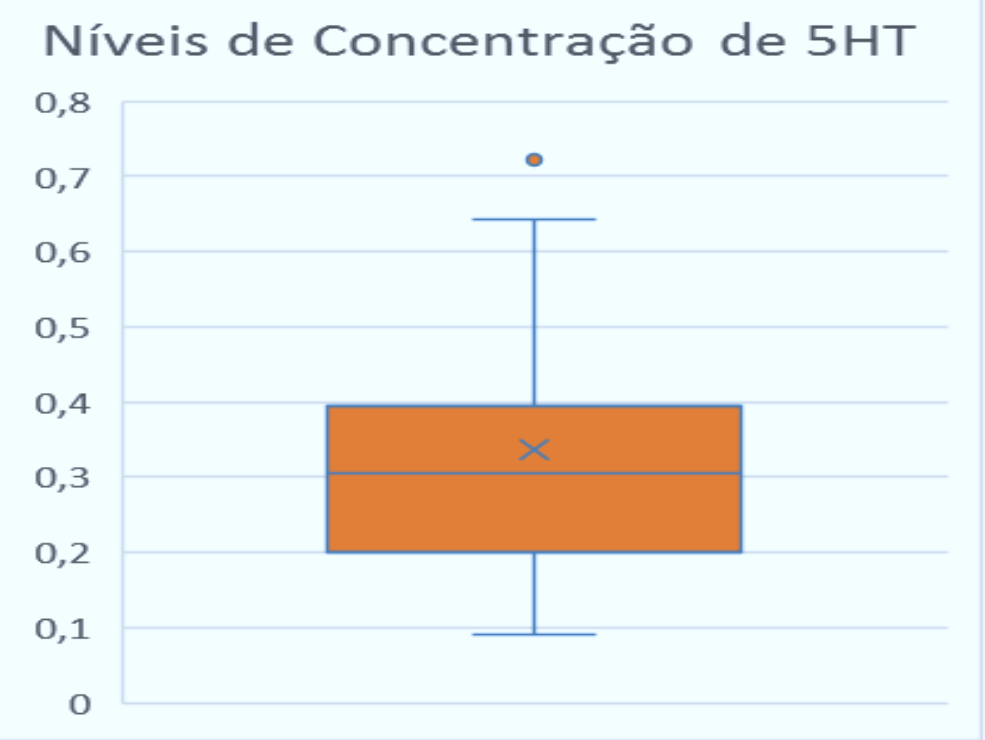

Tabela 2- Média de 5-HT nos pacientes com e sem história de CTCG.

\begin{tabular}{|c|c|c|c|}
\hline História de CTCG & $\mathbf{N}$ & Média 5-HT & Desvio Padrão \\
\hline Ausente & 20 & 0.4084 & 0.16127 \\
\hline Presente & 16 & 0.2995 & 0.16359 \\
\hline Total & 44 & 0.3366 & 0.16919 \\
\hline
\end{tabular}




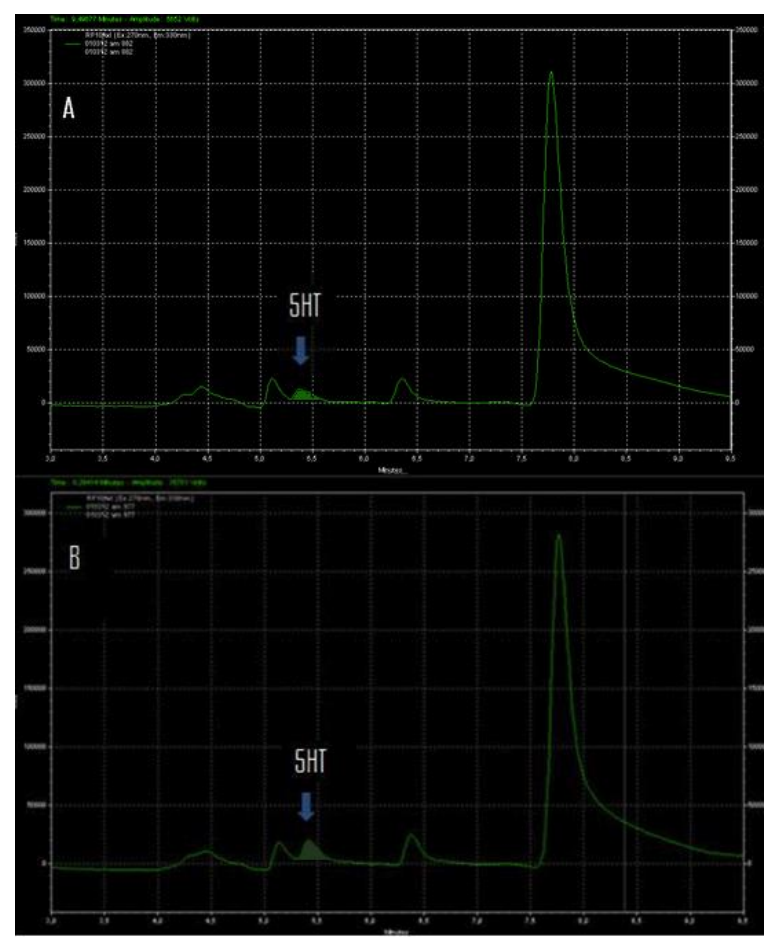

Figura 3 - Cromatograma de paciente com e sem história de CTCG. Acima: paciente com história de CTCG. Acima: paciente sem história de CTCG. Pico de 5-HT em 5,4 minutos e pico de padrão externo de 7,6 minutos. Concentração de 5-HT (área preenchida em verde) no primeiro de $0,173 \mathrm{ng} / \mathrm{mg}$ e, no segundo, de $0,256 \mathrm{ng} / \mathrm{mg}$.

Gráfico 3 - Concentração de 5-HT entre pacientes com e sem história de CTCG.

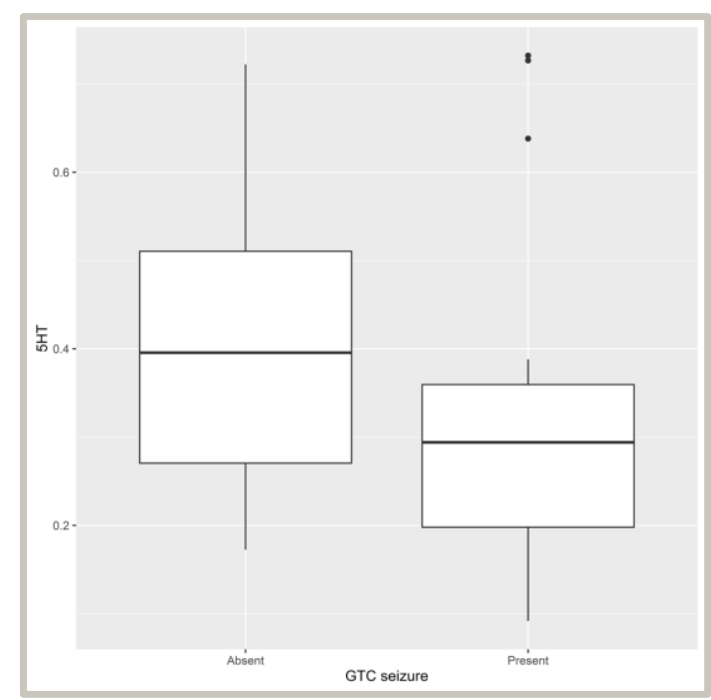


Não houve diferenças significativas entre os níveis de 5-HT e outras variáveis clínicas.

No subgrupo de pacientes com crises TCG, não houve diferenças significativas entre pacientes em politerapia ou monoterapia (teste exato de Fisher; $p=0.464)$; também não houve diferenças significativas com o uso de antipsicóticos (teste exato de Fisher; $p=0.226$ ), com histórico de crises febris (teste exato de Fisher; $p=1.000$ ) ou de EME (teste exato de Fisher; $p=0.134$ ). Transtornos psiquiátricos estiveram igualmente distribuídos entre os pacientes com e sem crises TCG (teste exato de Fisher; $p=0.532$ ). Os pacientes usando ISRS apresentaram menos crises TCG (teste exato de Fisher; $p=0.004$ ).

Para analisar se as crises TCG e os ISRS interferiam na concentração de 5-HT simultaneamente, foi utilizado o Modelo Linear Generalizado (GLM) com distribuição gama, com fator de interação. O resultado foi significativo indicando que no grupo de pacientes com crises TCG, o uso de ISRS altera significativamente a concentração de 5-HT $(p=0.011)$.

Os níveis de 5-HT não foram correlacionados com outras variáveis clínicas, incluindo a idade de início da epilepsia (coeficiente de Correlação de Spearman; $p=0.938$ ), a duração da epilepsia (coeficiente de correlação de Spearman; $p=0.745$ ), a frequência de crises epilépticas (Kruskal-Wallis; $p=$ 0.211), o histórico de EME (Wilcoxon-Mann-Whitney; p 0.657) e o histórico de crises febris (Wilcoxon-Mann-Whitney; $p=0.250$ ). Não houve diferenças significativas com a presença ou tipo de transtorno psiquiátrico (WilcoxonMann-Whitney; $p=0.334$ ), assim como entre os pacientes com monoterapia e politerapia (Wilcoxon-Mann-Whitney; $p=0.302$ ). 


\subsection{Densidade Receptores Serotoninérgicos}

\section{- Receptor 5-HT1A}

Os resultados sobre a densidade do receptor 5-HT1A que serão apresentados abaixo, encontram-se no artigo Fonseca, NC et al. European Journal of Neurology 2017; 24(4):602 - 608 (ANEXO 3).

A análise da densidade dos receptores 5-HT1A foi realizada em 34 amostras de tecido hipocampal. As características demográficas e clínicas desses pacientes encontra-se no ANEXO 4.

Foi encontrada uma associação entre a maior densidade do receptor 5HT1A e maior duração da epilepsia (coeficiente de correlação de Spearman: $p$ = 0.040) (Gráfico 4; Figura 4); sendo que cada ano de epilepsia aumentou a densidade do receptor 5-HT1A em 2.1\% (GLM: $p=0.026)$. Além disso, o uso de antipsicóticos interferiu na densidade do receptor 5-HT1A (Wilcoxon-MannWhitney: $p=0.028$, diminuindo em $55.9 \%$ o seu nível de densidade (GLM: $p=$ 0.003) (Tabela 3). 


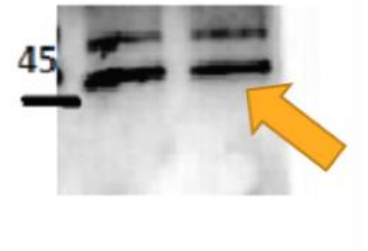

\section{Paciente I}

Duração epilepsia: 60 anos

Densidade: 329.238

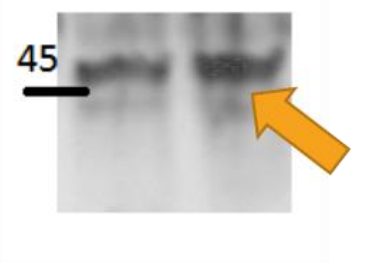

Paciente 2

Duração epilepsia: 37 anos

Densidade: | 30.22 |

Figura 4 - Amostras de membranas incubadas com anticorpo anti-receptor 5HT1A, comparando paciente com diferentes durações de epilepsia

Gráfico 4 - Gráfico de dispersão entre o receptor 5-HT1A e a duração da epilepsia

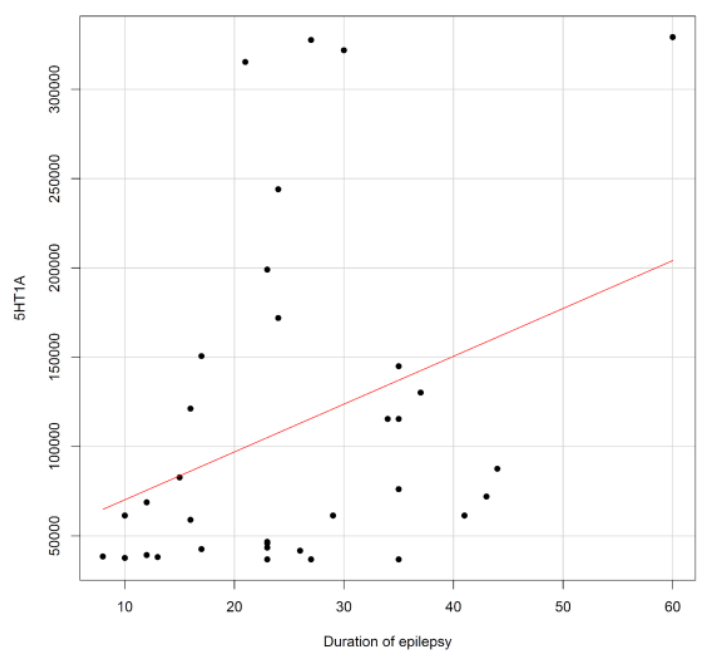


Tabela 3 - Modelo linear com distribuição gama analisando interferência do uso de antipsicóticos e duração da epilepsia na densidade do receptor 5-HT1A.

\begin{tabular}{r|l|l|l|} 
5-HT1A & $\operatorname{Exp}(\mathrm{B})$ & $95 \% \mathrm{Cl}$ & $\mathbf{P}^{1}$ \\
\hline Antipsicóticos & 0.431 & $0.267-0.724$ & 0.003 \\
\hline Duração da Epilepsia & 1.021 & $1.003-1.042$ & 0.026 \\
\cline { 2 - 4 } & &
\end{tabular}

${ }^{1}$ GLM (modelo linear com distribuição gama)

Não houve diferença entre a duração da epilepsia e o uso de ISRS (Wilcoxon-Mann-Whitney: $p=0.200$ ), o uso de antipsicóticos (Wilcoxon-MannWhitney: $p=0.476$ ) ou o tipo de transtorno psiquiátrico (Kruskal-Wallis: $p=$ 0.586). Para avaliar a interferência de fatores confusionais, foi utilizado o Modelo Linear Generalizado. Através dessa análise, nós encontramos que a densidade do receptor 5-HT1A está ligada à duração da epilepsia, havendo um aumento em $2.1 \%$ a cada ano de epilepsia $(p=0.026)$.

A densidade do receptor 5-HT1A não foi associada com a presença de transtornos psiquiátricos (Wilcoxon-Mann-Whitney: $p=0.267$ ) ou outras variáveis clínicas, incluindo a idade de início da epilepsia (coeficiente de correlação de Spearman: $p=0.265$ ), a idade na cirurgia (coeficiente de correlação de Spearman: $p=0.347$ ), a frequência das crises epilépticas (Kruskal-Wallis: $p=0.268$ ), a frequência das crises TCG (Kruskal-Wallis: $p=$ 0.485), a presença de crises TCG (Wilcoxon-Mann-Whitney: $p=0.321$ ), o histórico de EME (Wilcoxon-Mann-Whitney: $p=0.153$ ) ou o histórico de crises febris (Wilcoxon-Mann-Whitney: $p=0.258$ ). Além disto, não houve associação com o tipo de transtorno psiquiátrico (Kruskal-Wallis: $p=0.177$ ) ou com o uso de ISRS (Wilcoxon-Mann-Whitney: $p=0.626$ ). 
Não houve diferenças estatísticas na densidade do receptor 5-HT1A entre pacientes com monoterapia ou politerapia (Wilcoxon-Mann-Whitney: $p=$ 0.406).

\section{- Receptor 5-HT2A}

A análise da densidade dos receptores 5-HT2A foi realizada em 30 amostras de tecido hipocampal. As características demográficas e clínicas desse grupo de pacientes encontra-se no ANEXO 5.

A densidade do receptor 5-HT2A não esteve associada a nenhuma das variáveis clínicas da epilepsia, à presença ou tipo de transtorno psiquiátrico e ao uso de medicação psicotrópica, como detalhado a seguir.

Não houve diferença entre densidade do receptor 5-HT2A e a idade de início da epilepsia (coeficiente de correlação de Spearman: $p=0.363$ ), a idade na cirurgia (coeficiente de correlação de Spearman: $p=0.574$ ), a duração da epilepsia (coeficiente de Spearman: $p=0.724$ ), a frequência das crises epilépticas (Kruskal-Wallis: $p=0.761$ ), a frequência das crises TCG (KruskalWallis: $p=0.452$ ), a presença de crises TCG (Wilcoxon-Mann-Whitney: $p=$ 0.723), o histórico de EME (Wilcoxon-Mann-Whitney: $p=0.252$ ) e o histórico de crises febris (Wilcoxon-Mann-Whitney: $p=0.908$ ). Também não houve diferença em relação à presença de transtorno psiquiátrico (Wilcoxon-MannWhitney: $p=0.614$ ), ao tipo de transtorno psiquiátrico (Kruskal-Wallis: $p=$ 0.440), ao uso de ISRS (Wilcoxon-Mann-Whitney: $p=0.400$ ) e ao uso de medicação antipsicótica (Wilcoxon-Mann-Whitney: $p=0.590$ ).

Não houve diferenças na densidade do receptor 5-HT2A entre os pacientes com monoterapia e politerapia (Wilcoxon-Mann-Whitney: $p=0.686$ ). 


\title{
- Receptor 5-HT6
}

A análise da densidade dos receptores 5-HT6 foi realizada em 15 amostras de tecido hipocampal. As características demográficas e clínicas desse grupo de pacientes encontra-se no ANEXO 6.

Foi encontrada uma associação entre a menor densidade do receptor 5HT6 e a história de EME (Wilcoxon-Mann-Whitney: $p=0.0027$ ) (Tabela 4, Figura 5).

Tabela 4 - Análise de densidade receptor 5-HT6 nos pacientes com e sem história de EME

\begin{tabular}{c|c|c|c|}
$\begin{array}{c}\text { História de } \\
\text { EME }\end{array}$ & N & $\begin{array}{c}\text { Média de } \\
\text { 5-HT6 }\end{array}$ & Desvio Padrão \\
\hline $\begin{array}{c}\text { Ausente } \\
\text { Presente }\end{array}$ & 13 & 284438 & 26052 \\
\hline & 2 & 181594 & 8618 \\
\hline
\end{tabular}

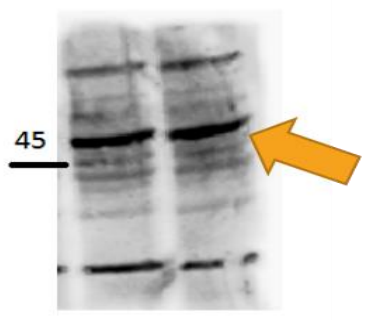

\author{
Paciente I \\ EME ausente \\ Densidade: 313.625
}

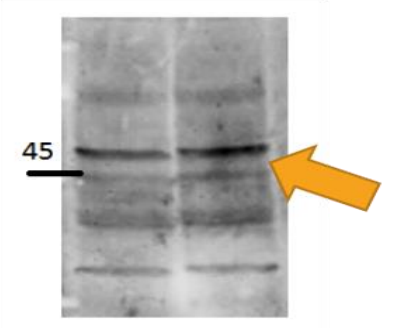

\author{
Paciente 2 \\ EME presente \\ Densidade: 187.688
}

Figura 5 - Amostras de membranas incubadas com anticorpo anti-receptor 5HT6, comparando a densidade do receptor entre pacientes com e sem história de EME. 
A densidade do receptor 5-HT6 não foi associada a nenhuma das outras variáveis clínicas da epilepsia, à presença ou tipo de transtorno psiquiátrico e ao uso de medicação psicotrópica, como detalhado a seguir.

Não houve diferença significativa entre a densidade do receptor 5-HT6 e a idade de início da epilepsia (coeficiente de correlação de Spearman: $p=$ 0.363), a idade na cirurgia (coeficiente de correlação de Spearman: $p=0.325$ ), a duração da epilepsia (coeficiente de Spearman: $p=0.775$ ), a frequência das crises epilépticas (Teste de Jonckheere-Terpstra: $p=0.176$ ), frequência das crises TCG (Teste de Jonckheere-Terpstra $p=0.589$ ), a presença de crises TCG (Wilcoxon-Mann-Whitney: $p=0.358$ ) e o histórico de crises febris (Wilcoxon-Mann-Whitney: $p=0.885)$. Também não houve diferença em relação à presença de transtorno psiquiátrico (Wilcoxon-Mann-Whitney: $p=0.105$ ), ao tipo de transtorno psiquiátrico (Kruskal-Wallis: $p=0.318$ ), ao uso de ISRS (Wilcoxon-Mann-Whitney: $p=0.279$ ) e ao uso de medicação antipsicótica (Wilcoxon-Mann-Whitney: $\mathrm{p}=0.516$ ).

Não houve diferenças na densidade do receptor 5-HT6 entre os pacientes com monoterapia e politerapia (Wilcoxon-Mann-Whitney: $p=0.665$ ).

\section{- Receptor 5-HT7}

A análise da densidade dos receptores 5-HT7 foi realizada em 31 amostras de tecido hipocampal. As características demográficas e clínicas desse grupo de pacientes encontra-se no ANEXO 7. 
A densidade do receptor 5-HT7 não foi associada a nenhuma das variáveis clínicas da epilepsia, à presença ou tipo de transtorno psiquiátrico e ao uso de medicação psicotrópica, como detalhado a seguir.

Não houve diferença significativa entre a densidade de 5-HT7 e a idade de início da epilepsia (coeficiente de correlação de Spearman: $p=0.067$ ), a idade na cirurgia (coeficiente de correlação de Spearman: $p=0.074$ ), a duração da epilepsia (coeficiente de correlação de Spearman: $p=0.439$ ), a frequência das crises epilépticas (Kruskal-Wallis Test: $p=0.066$ ), a frequência das crises TCG (Jonckheere-Terpstra: $p=0.136$ ), a presença de crises TCG (Wilcoxon-Mann-Whitney: $p=0.320$ ), o histórico de EME (Wilcoxon-MannWhitney: $p=0.469$ ) e o histórico de crises febris (Wilcoxon-Mann-Whitney: $p=$ 0.133). Também não houve diferença em relação à presença de transtorno psiquiátrico (Wilcoxon-Mann-Whitney: $p=0.857$ ), ao tipo de trastorno psiquiátrico (Kruskal-Wallis: $p=0.306$ ), ao uso de ISRS (Wilcoxon-MannWhitney: $p=0.333$ ) e ao uso de medicação antipsicótica (Wilcoxon-MannWhitney: $p=0.943)$.

Não houve diferenças na densidade do receptor 5-HT7 entre os pacientes com monoterapia e politerapia (Wilcoxon-Mann-Whitney: $p=0.464$ ).

\section{Densidade do Transportador Serotoninérgico}

A análise da densidade do 5-HTT foi realizada em 24 amostras de tecido hipocampal. As características demográficas e clínicas desse grupo de pacientes encontra-se no ANEXO 8. 
A densidade do 5-HTT não foi associada a nenhuma das variáveis clínicas da epilepsia, à presença ou tipo de transtorno psiquiátrico e ao uso de medicação psicotrópica, como detalhado a seguir.

Não houve diferença significativa entre a densidade de 5-HTT e a idade de início da epilepsia (coeficiente de correlação de Spearman: $p=0.10$ ), a idade na cirurgia (coeficiente de correlação de Spearman: $p=0.927$ ), a duração da epilepsia (coeficiente de Spearman: $p=0.738$ ), a frequência das crises epilépticas (Teste de Jonckheere-Terpstra: $p=0.250$ ), a frequência das crises TCG (Teste de Jonckheere-Terpstra: $p=0.871$ ), a presença de crises TCG (Wilcoxon-Mann-Whitney: $p=0.128$ ), o histórico de EME (Wilcoxon-MannWhitney: $p=0.174$ ) e o histórico de crises febris (Wilcoxon-Mann-Whitney: $p=$ 0.614). Também não houve diferença em relação à presença de transtorno psiquiátrico (Wilcoxon-Mann-Whitney: $p=0.602$ ), ao tipo de transtorno psiquiátrico (Kruskal-Wallis: $p=0.128$ ), ao uso de ISRS (Wilcoxon-MannWhitney: $p=0.434$ ) e ao uso de medicação antipsicótica (Wilcoxon-MannWhitney: $p=0.374)$.

Não houve diferenças na densidade do 5-HTT entre os pacientes com monoterapia e politerapia (Wilcoxon-Mann-Whitney: $p=0.571$ ). 
6. DISCUSSÃO 
Esse estudo analisou o tecido hipocampal de pacientes com epilepsia focal do lobo temporal farmacorresistente, em um grupo etiologicamente homogêneo, composto somente por pacientes com $\mathrm{EH}$, com o objetivo de avaliar o perfil serotoninérgico e buscar possíveis associações com variáveis clínicas da epilepsia ou com a presença de transtornos psiquiátricos nestes pacientes.

O estudo pode ser dividido em duas etapas, sendo a etapa inicial a dosagem da concentração de serotonina, através do método de HPLC, avaliada no tecido hipocampal de 44 pacientes com ELT-EH farmacorresistente.

A segunda etapa, realizada através do método de Western Blot, consistiu na análise da densidade do 5-HTT em 24 amostras hipocampais, dos receptores 5-HT1A em 34 amostras hipocampais, 5-HT2A em 30 amostras hipocampais, 5-HT6 em 15 amostras hipocampais e 5-HT7 em 31 amostras hipocampais. Todas essas amostras provenientes do grupo de 44 pacientes com ELT-EH farmacorresistente, que tiveram os níveis de concentração de serotonina dosados. Não foi possível a realização da análise da densidade de todos os receptores em todas as amostras hipocampais, pois a análise dependia do tamanho da amostra hipocampal viável, ou seja, tamanho da ressecção cirúrgica e a viabilidade do tecido; que por ser uma amostra de tecido de sistema nervoso central era limitada em tamanho e acesso. Além disso, outro fator interferente foi a viabilidade da análise, por vezes, com necessidade de repetição, por algum erro ou falha nas etapas analíticas. 
Diversos estudos tentam demonstrar o papel das vias serotoninérgicas na epileptogênese, bem como a associação da epilepsia com os transtornos psiquiátricos. Entretanto, os dados em tecido cerebral humano são escassos sendo realizados com amostras heterogêneas quanto à sua etiologia.

\subsection{Variáveis Clínicas da Epilepsia}

\section{I) Concentração de 5-HT}

Este foi o primeiro estudo de concentração de serotonina no hipocampo humano, associado com variáveis clínicas da epilepsia e realizado em uma amostra etiologicamente homogênea de epilepsia.

No nosso estudo encontramos que níveis mais baixos de serotonina estavam associados com a presença de CTCG anteriores ou atuais. Esses achados são condizentes com evidências em modelos animais que demonstram que diminuições dos níveis de serotonina estão associados com a fisiopatologia de CTCG.

O modelo animal de epilepsia-induzida por MSO demonstra um envolvimento hipocampal, por vezes, com características semelhantes à esclerose hipocampal humana (Eid et al., 2008). Neste modelo, a administração de MSO induz a CTCG (Cloix, Tahi, Martin, et al., 2010) e a uma redução significativa dos níveis de 5-HT (Cloix, Tahi, Boissonnet, et al., 2010). Além disso, a administração concomitante de 5-HT e MSO, atrasa o início das 
crises epilépticas (Picard et al., 2011). Evidenciando o importante papel do 5HT na predisposição à CTCG.

Nos modelos GEPR foi demonstrado que depleções de 5-HT estão associadas com a predisposição à crise epiléptica (Dailey, Mishra, et al., 1992; Jobe et al., 1995). A linhagem GEPR-9, que possui crises de maior gravidade, mimetizando de forma muito aproximada as crises TCG em humanos, exibe uma redução significativa nas concentrações de 5-HT (Statnick et al., 1996). Nessa linhagem, a destruição de terminações serotoninérgicas, com subsequente diminuição da concentração de 5-HT, bloqueia o efeito supressor de CTCG exercido pela fluoxetina (Yan et al., 1994; Merrill et al., 2007; Lin et al., 2013). Além disso, a maioria das crises TCG são TCG bilaterais, ou seja, ocorrem secundariamente em resposta a crises límbicas (Jobe e Dailey, 2000).

No modelo da epilepsia induzido pela pilocarpina, modelo que cursa com alterações que reproduzem uma ELT humana, já foi demonstrado que os níveis de 5-HT estão diminuídos na fase crônica da epilepsia (Lin et al., 2013; Kumar et al., 2016). Além disso, agentes que facilitam a liberação de 5-HT hipocampal diminuem a gravidade das crises epilépticas, indicativos, pela escala utilizada, de menor chance de CTCG ou EME (Smolders et al., 2008).

Estudos usando HPLC em tecido cortical humano evidenciaram que os níveis de 5-HT estavam aumentados ou inalterados nas áreas epileptogênicas, quando comparado a áreas não epileptogênicas de pacientes com epilepsia focal (Pintor et al., 1990; Naffah-Mazzacoratti et al., 1996; Broderick et al., 2000). Estudos utilizando microvoltametria encontraram que níveis de $5-\mathrm{HT}$ estavam diminuídos no tecido hipocampal, mas não no tecido neocortical de pacientes com ELT mesial, quando comparado com pacientes com epilepsia 
temporal neocortical (Broderick et al., 2000). Os achados desses estudos não podem ser comparados com os nossos dados, visto que diferem quanto ao desenho de estudo, tamanho e caracterização amostral, ou por não fazer associação com variáveis clínicas da epilepsia. Porém, enfatizam a importância da homogeneidade referente à etiologia da epilepsia quanto aos dados encontrados.

Nos nossos resultados, foram realizadas análises para descartar a interferência de fatores confusionais. Observamos que, na nossa amostra, os FAEs foram igualmente distribuídos entre os grupos de pacientes, sem diferenças significativas entre os pacientes com ou sem CTCG, assim como os psicotrópicos não alteraram nossos resultados. Entretanto, o uso de ISRS esteve associado com uma redução no número de CTCG e alteraram os níveis de 5-HT nos pacientes com CTCG. Diversos estudos sugerem que os ISRS estão relacionados com uma diminuição na frequência das crises epilépticas (Dailey, Yan, et al., 1992; Vermoesen et al., 2012), com evidências desta ação relacionada com mecanismos serotoninérgicos (Dailey, Yan, et al., 1992; Yan et al., 1994; Browning et al., 1997; Merrill et al., 2007). Podemos inferir dos nossos resultados que, nos pacientes com epilepsia apresentando crises TCG, o tratamento com ISRS poderia ser benéfico.

\section{II) Receptor 5-HT1A}

No nosso estudo foi demonstrado que uma maior duração da epilepsia esteve associada com uma maior densidade do receptor 5-HT1A. Apesar de sua ampla distribuição no cérebro, com uma maior densidade no sistema 
límbico, particularmente no hipocampo, são escassos os estudos que estudam o papel do receptor 5-HT1A com variáveis clínicas da epilepsia, sendo este o primeiro estudo avaliando a densidade deste receptor, com variáveis clínicas da epilepsia, no hipocampo de uma amostra etiologicamente homogênea de pacientes com ELT-EH.

Os achados da literatura avaliando o receptor 5-HT1A em tecido cortical humano possuem resultados divergentes quando áreas ou etiologias distintas são analisadas. Nos pacientes com epilepsia farmacorresistente, com etiologia heterogênea, quando comparados com pacientes controles, foi demonstrada uma diminuição da densidade do receptor 5-HT1A na amígdala (Graebenitz et al., 2011) e um aumento da sua densidade no tecido temporal neocortical (Palomero-Gallagher et al., 2012). Em outro estudo, também realizado em tecido temporal neocortical, porém, em pacientes com ELT-EH, foi encontrada uma menor densidade dos receptores 5-HT1A no tecido neocortical, quando comparado aos controles (Rocha et al., 2007). Este último estudo foi o único a pesquisar associações com variáveis clínicas, não encontrando nenhuma relação com a expressão do receptor $5-\mathrm{HT} 1 \mathrm{~A}$. Os achados são importantes para evidenciar que diferenças na região cortical estudada ou na etiologia da epilepsia podem gerar resultados opostos. Ressaltando o fato de que não podemos compará-los com os nossos achados, por divergências da região proveniente do tecido cortical estudado, da etiologia da epilepsia, no desenho do estudo ou metodologia utilizada para análise.

A nossa hipótese para o nosso achado é que o aumento da densidade do receptor 5-HT1A seria secundário a uma tentativa de compensar uma diminuição da sua atividade. Essa hipótese estaria em concordância com 
diversos estudos de neuroimagem funcional, que demonstraram uma diminuição da afinidade de ligação do receptor 5-HT1A ipsilateral à área epileptogênica de pacientes com ELT (Merlet et al., 2004; Giovacchini et al., 2005; Ito et al., 2007; Didelot et al., 2008; Liew et al., 2009; Assem-Hilger et al., 2010). Neste caso, quanto maior a duração da epilepsia, maior o tempo que a região hipocampal estaria sendo submetida a uma diminuição da atividade dos receptores 5-HT1A e maior o tempo de efeito compensatório, com aumento da densidade dos receptores.

\section{III) Receptor 5-HT6}

Nosso estudo encontrou que a presença de EME esteve associada com uma densidade diminuída do receptor 5-HT6.

No modelo animal de epilepsia pela pilocarpina, na fase aguda, quando as crises límbicas estão mais propensas à evolução para EME, estudos demonstraram que os níveis de 5-HT se encontram elevados (Cavalheiro et al., 1994; Lin et al., 2013). O que poderia explicar uma diminuição por efeito compensatório dos receptores 5-TH6. Entretanto, neste modelo, na fase crônica, ocorre uma diminuição da concentração de 5-HT (Lin et al., 2013; Kumar et al., 2016), o que poderia explicar um aumento compensatório dos receptores serotoninérgicos, ao contrário de uma diminuição. Baseado nesta explicação, na nossa amostra, esperaríamos ter encontrado um aumento da densidade, tendo em vista que os nossos pacientes já estavam em uma fase crônica da epilepsia. Estudos em tecido cerebral humano, que mostraram um aumento da concentração de serotonina nas áreas epileptogênicas, podendo explicar um efeito compensatório do receptor, não possuíam uma amostra 
homogênea quanto à etiologia (Pintor et al., 1990; Naffah-Mazzacoratti et al., 1996) o que, como já foi descrito previamente, interferiria nos resultados esperados.

Estudos que avaliaram o receptor 5-HT6, mostraram dados contrários aos nossos. Lin et al. (2017) demonstraram, em camundongos, que o EME induzido pela pilocarpina gerava um aumento na expressão do receptor 5-HT6. Similarmente, Wang et al. (2015) que, através da técnica de Western Blot, avaliaram a expressão do receptor 5-HT6 no hipocampo e neocórtex de ratos modelos de epilepsia pela administração da pilocarpina, encontraram que crises epilépticas induziram o aumento do receptor 5-HT6, sendo esta expressão maior durante a fase de recorrência das crises epilépticas. Este mesmo estudo comparou o tecido temporal neocortical de 25 pacientes com ELT farmacorresistente com controles e encontrou um aumento da densidade do receptor 5 -HT6.

A discordância entre os nossos resultados e estudos anteriores pode ser decorrente do tipo de epilepsia estudada, como também do maior fator limitante desta parte do estudo - o tamanho da amostra (15 pacientes). Estudos posteriores com maior número de pacientes com ELT-EH poderão corroborar nossos resultados.

\section{IV) Receptores 5-HT2A e 5-HT7}

As análises dos receptores 5-HT2A e 5-HT7 não evidenciaram nenhuma associação com variáveis clínicas da epilepsia.

Há dois estudos associando o receptor 5-HT2A ou o receptor 5-HT7 com variáveis clínicas da epilepsia (Yang et al., 2012; Buchanan et al., 2014). 
Entretanto, essas associações foram realizadas através do uso de drogas, antagonistas ou agonistas de receptores, em modelos animais, e sem determinar exatamente o local de ação desse efeito. O estudo em tecido humano - temporal neocortical - evidenciou uma associação entre a expressão do receptor 5-HT7 e a duração da epilepsia (Rocha et al., 2007). Nossos resultados não podem ser comparados ao estudo citado dada a região analisada.

Uma possível explicação para os nossos achados negativos seria de que alterações nestas vias serotoninérgicas em outras regiões do sistema nervoso possam estar associadas a variáveis clínicas da epilepsia. Estudos com GEPR evidenciaram que alterações serotoninérgicas em diferentes regiões estão associadas com variáveis clínicas distintas da epilepsia (Jobe et al., 1986). Alterações serotoninérgicas no colículo superior foram associadas com diminuição ou supressão das crises epilépticas (Dailey, Mishra, et al., 1992; Merrill et al., 2007) e o padrão de deficiência serotoninérgica no estriado, que na linhagem GEPR-9 difere do padrão da linhagem GEPR-3, já foi implicado na gravidade das crises epilépticas (Dailey, Mishra, et al., 1992). Além disso, acreditamos que a presença de outros mecanismos, incluindo diferentes vias de ação, também agem contribuindo para alterações de variáveis clínicas da epilepsia (Peixoto-Santos et al., 2012; Kandratavicius, Rosa-Neto, et al., 2013).

\section{V) Transportador de 5-HT}

No estudo de Rocha et al. (2007) a afinidade de ligação do 5-HTT em tecido humano de pacientes com ELT-EH estava diminuída em todas as 
camadas do neocórtex temporal, quando comparado com controles, entretanto, as alterações no 5-HTT não estiveram relacionadas com variáveis clínicas da epilepsia, assim como no nosso estudo. Não há, no entanto, nenhum estudo anterior ao nosso avaliando o hipocampo desses pacientes e regiões distintas podem levar a resultados diferentes.

Acreditamos que a possível explicação para os nossos achados, em relação ao 5-HTT, seria semelhante às dos receptores 5-HT2A e 5-HT7.

\subsection{Transtorno Psiquiátrico}

No nosso estudo, a concentração de serotonina, a densidade dos receptores e do transportador não estiveram associados com a presença ou ausência de transtornos psiquiátricos, nos pacientes com ELT-EH.

$\mathrm{Na}$ literatura, dados evidenciam o importante papel das vias serotoninérgicas na gênese dos transtornos psiquiátricos (Parsey et al., 2010; Mulinari, 2012; Dayer, 2014; Donaldson e Hen, 2015). Baseado em evidências clínicas e experimentais, estudos sugerem mecanismos patogênicos comuns entre epilepsia e transtorno psiquiátrico, incluindo alterações das vias serotoninérgicas (Jobe et al., 1999; Kanner, 2005; 2009). Entretanto, como enfatizado anteriormente, não existem estudos em tecido hipocampal humano que tenham avaliado a associação das vias serotoninérgicas nos pacientes com ELT-EH.

Uma limitação do nosso estudo, em relação à análise dos dados relacionados com a presença de transtornos psiquiátricos, foi a falta da comparação com tecido hipocampal de controles. Já foi demonstrada uma redução dos níveis de $5-\mathrm{HT}$ em camundongos submetidos à injeção de 
pilocarpina, que evoluíam com epilepsia e sintomas de depressão, quando comparados a camundongos controle (Mazarati et al., 2008). Em tecido cerebral humano post mortem, Dekker et al. (2018) avaliaram, através do método HPLC, concentrações monoaminérgicas no hipocampo de pacientes com síndrome de Down ou doença de Alzheimer e pacientes controles pacientes sem doenças neurológicas ou psiquiátricas. Nos pacientes controles foi encontrada uma concentração média de $5-\mathrm{HT}$ de $87.8 \mathrm{ng} / \mathrm{g}$, valor muito acima da média dos nossos pacientes de $0.3366 \mathrm{ng} / \mathrm{mg}$ ou aproximadamente $0.00033 \mathrm{ng} / \mathrm{g}$. Ao comparar estes níveis com os encontrados no nosso estudo, poderíamos extrapolar e inferir a possibilidade de que se tivéssemos um grupo controle, teríamos encontrado níveis mais elevados de concentração de 5-HT.

Uma hipótese para nossos achados negativos seria a de que alterações nas vias serotoninérgicas poderiam ocorrer tanto na fisiopatologia da epilepsia, como na dos transtornos psiquiátricos, sendo necessário a associação com outros fatores para diferenciação na presença de um ou outro. Ou seja, diferentes padrões de interações com outras vias determinando a presença de transtorno psiquiátrico isolado, epilepsia isolada ou ambos conjuntamente.

No estudo anteriormente citado de Mazarati et al. (2008), após administração do inibidor de recaptação da serotonina, a fluoxetina, observa-se uma diminuição da degradação de serotonina, porém, sem melhora dos sintomas depressivos. Outros estudos já demonstraram esta falta de resposta dos ISRS na depressão de modelos animais de epilepsia (Pineda et al., 2012; Kumar et al., 2016). Estes achados sugerem que as manifestações psiquiátricas, nos pacientes com epilepsia, possuem mecanismos 
fisiopatogênicos distintos, possivelmente com o envolvimento de outras vias na modulação do transtorno psiquiátrico associado com epilepsia, como já descritos por outros estudos (Gattaz et al., 2011; Rocha et al., 2012; Kandratavicius, Monteiro, Assirati, et al., 2013; Kandratavicius, Monteiro, Hallak, et al., 2013). Além disso, deve-se levar em consideração que outras regiões do sistema nervoso central possam estar associadas (Briellmann et al., 2007).

\subsection{Limitações do estudo}

Além das limitações previamente relatadas, como falta de grupo controle e subgrupos de tamanhos heterogêneos, outro ponto importante e limitante dos nossos dados, seria uma possível interferência do uso crônico de FAEs e psicotrópicos, que agem na neurotransmissão serotoninérgica, através dos receptores serotoninérgicos, tanto ao nível pré-sináptico, quanto póssináptico.

Em todas as análises, foram realizados testes para afastar a interferência destes fatores. Quanto ao uso de FAEs, acreditamos que não foi um fator de interferência significativo nos nossos achados, visto que os subgrupos possuíam distribuições semelhantes. Quanto aos psicotrópicos, foram observadas alterações nos nossos resultados. $\mathrm{Na}$ análise da concentração de 5-HT, foi evidenciado uma interferência do uso de ISRS na frequência das CTCG, como discutido previamente. Além disto, nas análises dos achados do receptor 5-HT1A, foi evidenciado que o uso de antipsicóticos interferiu na densidade do receptor 5-HT1A, através da diminuição da densidade. Os antipsicóticos, agem de forma direta ou indireta nos receptores 
5-HT1A, entretanto, a literatura descreve este efeito através de uma estimulação destes receptores (Assié et al., 2005; Meltzer e Massey, 2011). Embora deva-se considerar que este achado possa ser devido interferência de uma análise entre subgrupos de tamanhos heterogêneos, entre pacientes com e sem uso de antipsicóticos ( $n=26$ e $n=8$, respectivamente), também não devemos ignorar o fato de que o uso de drogas psicoativas possa ter interferido nos nossos achados. 


\section{CONCLUSÕES}


Este estudo demonstrou que níveis mais baixos de concentração de 5HT estiveram associados com a presença de CTCG, em 44 hipocampos de pacientes com ELT-EH; sugerindo que uma depleção do 5-HT poderia estar associado com a gênese de CTCG e consequentemente, com uma maior gravidade da epilepsia. Além disso, demonstrou que a densidade aumentada do receptor 5-HT1A esteve associada com maior duração da epilepsia, em 34 hipocampos. Resultado que postulamos se tratar de um efeito compensatório aos níveis cronicamente baixos da concentração de 5-HT.

A análise de 15 hipocampos de pacientes com ELT-EH demonstrou que a densidade diminuída do receptor 5-HT6 esteve associado com presença de EME. Achado que acreditamos não ser representativo, devido diferenças no tamanho amostral entre os grupos, com número de pacientes com história de EME muito reduzido.

A análise de 30, 31 e 24 hipocampos demonstrou que a densidade do receptor 5-HT2A, do receptor 5-HT7 e do 5-HTT, respectivamente, não estiveram associadas com variáveis clínicas da epilepsia. Achados que acreditamos ser devido mecanismos serotoninérgicos agindo em diferentes regiões do sistema nervoso ou diferentes mecanismos e diferentes vias interagindo entre si na gênese da epilepsia e de suas variáveis clínicas.

Nossos achados reforçam a importância das vias serotoninérgicas na epileptogênese, através dos achados associados com algumas variáveis clínicas da epilepsia. Mais estudos são necessários para melhor elucidação desses mecanismos, em especial em tecido cortical humano. 
A análise da concentração de 5-HT e da densidade dos receptores 5HT1A, 5-HT2A, 5-HT6 e 5-HT7, além do 5-HTT, não estiveram associados com a presença de transtornos psiquiátricos. Achados que acreditamos ser por conta de mecanismos fisiopatológicos operantes em comum envolvendo as vias serotoninérgicas na gênese da epilepsia e dos transtornos psiquiátricos, com diferenças na interação com outras vias levando a presença ou ausência de cada um deles. Sendo necessário, mais estudos, para definição desta hipótese. 
8. ANEXOS 


\section{ANEXO 1. TERMO DE CONSENTIMENTO LIVRE E ESCLARECIDO \\ HOSPITAL DAS CLÍNICAS DA FACULDADE DE MEDICINA DA UNIVERSIDADE DE SÃO PAULO-HCFMUSP \\ TERMO DE CONSENTIMENTO LIVRE E ESCLARECIDO}

\section{DADOS DE IDENTIFICAÇÃO DO SUJEITO DA PESQUISA OU RESPONSÁVEL LEGAL}

1. NOME:

DOCUMENTO DE IDENTIDADE №: SEXO: $M$

DATA NASCIMENTO: .......................

ENDEREÇO № APTO: .......

BAIRRO:

CIDADE

CEP: TELEFONE: DDD(. ..)

2.RESPONSÁVEL LEGAL

NATUREZA (grau de parentesco, tutor, curador etc.)

DOCUMENTO DE IDENTIDADE : SEXO: $M \square \quad F \square$ DATA NASCIMENTO:

ENDEREÇO: № APTO:

BAIRRO: CIDADE:

CEP: TELEFONE: DDD

\section{DADOS SOBRE A PESQUISA}

1. TÍTULO DO PROTOCOLO DE PESQUISA: Atividade serotoninérgica em hipocampos de pacientes com epilepsia do lobo temporal com e sem transtornos psiquiátricos

2. PESQUISADOR: Dra. Kette Dualibi Ramos Valente CARGO/FUNÇÃO: Diretora Técnica do Laboratório de Neurofisiologia Clínica do Instituto de Psiquiatria do HCFMUSP.

UNIDADE DO HCFMUSP: Instituto de Psiquiatria

3. AVALIAÇÃO DO RISCO DA PESQUISA: 


\section{HOSPITAL DAS CLÍNICAS DA FACULDADE DE MEDICINA DA UNIVERSIDADE DE SÃO PAULO-HCFMUSP}

1 - Desenho do estudo e objetivo(s):

$\mathrm{O}$ (A) Sr(a) participará em um estudo muito importante para que possamos compreender melhor a sua doença - epilepsia de lobo temporal - e para que no futuro possamos ajudar pacientes com esta doença. Este estudo somente será realizado com pacientes como o (a) $\operatorname{Sr}(a)$ ou seja que já tem cirurgia agendada para tratamento da sua epilepsia. Por isso, é importante que o (a) Sr(a) entendam o que vai ser explicado sobre este estudo para que eu saiba se concorda em participar. Há no seu cérebro, assim como em todos os cérebros, uma substância chamada serotonina que é muito importante. Se esta substância diminui, os pacientes podem apresentar depressão. Nós acreditamos, tendo como base estudos que foram feitos no passado com cérebros de animais, que esta substância possa estar diminuída no cérebro dos pacientes com epilepsia e em especial naqueles que tem depressão e epilepsia mais grave. As pessoas com epilepsia do lobo temporal têm mais depressão que pessoas da população que não tem epilepsia. Até hoje ninguém estudou o cérebro de pessoas com epilepsia para obter esta informação. Portanto, este é o primeiro estudo que será feito desta forma. Durante a cirurgia, a qual o (a) Sr(a) será submetido para tratar ou curar a sua epilepsia, 
como foi indicado pela equipe clínica que o acompanha, a parte doente do cérebro que causa as crises chamada hipocampo é removida. Nós iremos estudar esta parte que já foi removida durante a cirurgia para qual o (a) senhor (a) tem que ser submetido (a) para controle de suas crises, portanto este estudo nada altera a conduta e o tratamento que o (a) senhor (a) recebe na rotina da sua avaliação diagnóstica e terapêutica.

\section{2 - Descrição dos procedimentos que serão realizados, com seus} propósitos e identificação dos que forem experimentais e não rotineiros:

Se o Sr.(a) decidir participar, faremos uma entrevista para conhecermos seu histórico e da sua família. Durante a cirurgia para melhora da epilepsia, iremos pegar uma amostra da parte doente do seu cérebro, aquela que seria tirada de qualquer forma para o controle das suas crises. Esta amostra (tecido) não seria utilizada para nenhum outro fim. A única diferença é que uma amostra que seria desprezada será utilizada para o estudo. Estas amostras serão guardadas em uma geladeira, chamada freezer, em uma temperatura muito baixa. Estas amostras serão usadas para estudar a substância que acreditamos estar baixa, a serotonina. Todo o material será identificado por códigos, para que ninguém possa saber o nome da pessoa que aceitar participar da pesquisa. A parte não utilizada neste estudo não será utilizada em estudos futuros.

\section{3 - Relação dos procedimentos rotineiros e como são realizados:}

1. A entrevista será feita com o(a) Sr (a) no dia que for melhor para o (a) Sr(a) e que seja uma data na qual o(a) Sr(a) tenha que vir ao hospital para consulta ou realização de exames, assim não alteraremos o seu dia-a-dia ou a 
sua rotina. Nesta entrevista que dura 30 a 40 minutos, iremos perguntar algumas informações do $\operatorname{Sr}(a)$ e de sua família. As informações são a data que suas crises começaram, quantas e quais crises epilépticas o(a) $\operatorname{Sr}(a)$ tem, quais os medicamentos que já foram usados e quais está usando agora. Também será perguntado sobre tratamento com psiquiatra que já tenha acontecido ou que esteja acontecendo, qual a doença que está sendo tratada e qual o remédio que está sendo usado para esta doença.

2. Quando a cirurgia acabar, iremos pegar uma amostra do cérebro que está doente, hipocampo. Nossa equipe não terá contato algum com o procedimento cirúrgico de rotina. Este tecido será dado para nossa equipe e será levado para o freezer do Laboratório de Pesquisa.

3. Iremos guardar a parte do cérebro doente em uma geladeira de temperatura muito baixa, freezer, no Laboratório de Neurociências do Instituto de Psiquiatria - HCFMUSP. Seu nome não estará na sua parte doente, mas sim um código, para ninguém saiba que aquela parte doente é sua.

4. Serão usadas técnicas de laboratório com nomes - HPLC e Western Blot - que servem para medir a quantidade de serotonina na amostra de hipocampo que nós guardamos. Esta fase do estudo, que é a mais importante para nós e que leva mais tempo, não precisa de sua participação. $O(A) \operatorname{Sr}(a)$ não mais será incomodado após a entrevista inicial pela nossa equipe, 
devendo manter o seu tratamento aqui como o que geralmente faz, com os seus médicos e cirurgião responsável pela cirurgia.

5. Caso o (a) Sr. (a) decida depois da cirurgia que nós não podemos usar a amostra de tecido que foi coletada, simplesmente deve nos avisar para que não façamos as análises.

\section{4 - Descrição dos desconfortos e riscos esperados nos procedimentos:}

Não há desconforto que seja causado por esta pesquisa, exceto da sua entrevista que como já dito será realizada em dia da sua conveniência, ou seja, em um dia no qual o $\mathrm{Sr}(\mathrm{a})$ venha ou HC ou mesmo durante o período que já estiver internado para ser operado. Desta forma, não haverá necessidade de transporte extra até o Hospital. A entrevista não tem risco.

A amostra coletada não trará desconforto ou risco para o(a) $\operatorname{Sr}(a)$ pois como já expliquei não interfere na sua cirurgia. $O(A) \operatorname{Sr}$.(a) seria operado de qualquer forma e este seria o pedaço de tecido a ser removido. Portanto, está dentro do procedimento de rotina da sua cirurgia. Nenhum exame a mais é necessário e nada muda na sua cirurgia.

O contato na entrevista será feito com o (a) $\mathrm{Sr}(\mathrm{a})$, somente para responder as perguntas que o (a) $\operatorname{Sr}(\mathrm{a})$ concordar. O contato na hora de pegar a parte doente do cérebro será feito somente com o neurocirurgião e após a sua 
cirurgia, não atrapalhando ela, Iremos guardar o material com código para ninguém saber de quem ele é.

Rubrica do sujeito de pesquisa ou

responsável

Rubrica do pesquisador

\section{HOSPITAL DAS CLÍNICAS DA FACULDADE DE MEDICINA DA UNIVERSIDADE DE SÃO PAULO-HCFMUSP}

\section{5 - Benefícios para o participante:}

No trabalho, não há benefício direto para o participante.

É possível, mas não garantido, que os pacientes com algumas destas doenças possam beneficiar-se dos resultados deste estudo no futuro, bem como seus familiares. O nosso estudo pretende dar um maior esclarecimento das causas da epilepsia e da depressão. Com estes conhecimentos, esperamos conseguir um melhor tratamento das doenças citadas.

6 - Relação de procedimentos alternativos que possam ser vantajosos, pelos quais o paciente pode optar:

Não há.

7 - Garantia de acesso: em qualquer etapa do estudo, você poderá entrar em contato com os profissionais responsáveis pela pesquisa para esclarecimento de eventuais dúvidas. O principal investigador é a Dra. Kette Dualibi Ramos 
Valente que pode ser encontrada no endereço Instituto de Psiquiatria, térreo,setor de Eletrencefalografia - Rua Dr.Ovídio Pires de Campos,785 Cerqueira César - SP. Telefone(s): 2661-6518 ou 2661-7921. Se você tiver alguma consideração ou dúvida sobre a ética da pesquisa, entre em contato com o Comitê de Ética em Pesquisa (CEP) - Rua Ovídio Pires de Campos, 225 - 5aandar tel: 2661-6442 ramais 16, 17, 18 - e-mail: cappesq@hcnet.usp.br.

8 - É garantida a liberdade da retirada de consentimento a qualquer momento e deixar de participar do estudo, sem qualquer prejuízo à continuidade de seu tratamento na Instituição.

09 - As informações obtidas serão analisadas em conjunto com outros pacientes, não sendo divulgada a identificação de nenhum paciente.

10 - Você tem o direito de ser mantido atualizado sobre os resultados parciais das pesquisas, quando em estudos abertos, ou de resultados que sejam do conhecimento dos pesquisadores.

11 - Não haverá despesas pessoais para o participante em qualquer fase do estudo, incluindo exames e consultas. Também não haverá compensações financeiras relacionada à sua participação. 


\section{HOSPITAL DAS CLÍNICAS DA FACULDADE DE MEDICINA DA UNIVERSIDADE DE SÃO PAULO-HCFMUSP}

12 - Os dados obtidos e o material coletado serão utilizados somente para esta pesquisa.

Acredito ter sido suficientemente informado a respeito das informações que li ou que foram lidas para mim, descrevendo o estudo "Atividade serotoninérgica em hipocampos de pacientes com epilepsia do lobo temporal com e sem transtornos psiquiátricos".

Eu discuti com a Dra. Kette Dualibi Ramos Valente sobre a minha decisão em participar nesse estudo. Ficaram claros para mim quais são os propósitos do estudo, os procedimentos a serem realizados, seus desconfortos e riscos, as garantias de confidencialidade e de esclarecimentos permanentes. Ficou claro também que minha participação é isenta de despesas e que tenho garantia do acesso a tratamento hospitalar quando necessário. Concordo voluntariamente em participar deste estudo e poderei retirar o meu consentimento a qualquer momento, antes ou durante o mesmo, sem penalidades ou prejuízo ou perda de qualquer benefício que eu possa ter adquirido, ou no meu atendimento neste Serviço. 
(Para casos de pacientes menores de 18 anos, analfabetos, semianalfabetos ou portadores de deficiência auditiva ou visual).

Declaro que obtive de forma apropriada e voluntária o Consentimento Livre e Esclarecido deste paciente ou representante legal para a participação neste estudo. Data

Rubrica do sujeito de pesquisa ou responsáve

Rubrica do pesquisador 
ANEXO 2. ARTIGO PUBLICADO: EPILEPSY RESEARCH (2015), 18 - 25

Epilepsy Research (2015) 111, 18-25

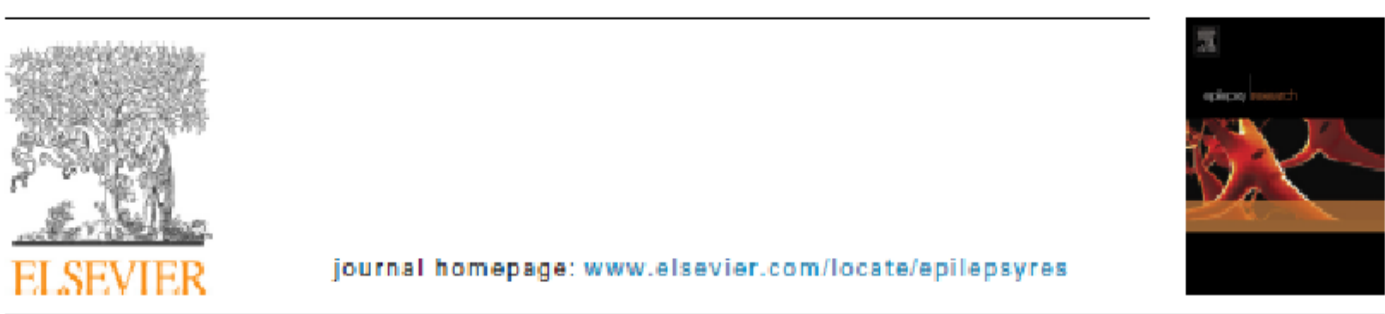

\title{
Hippocampal serotonin depletion is related to the presence of generalized tonic-clonic seizures, but not to psychiatric disorders in patients with temporal lobe epilepsy
}

\author{
Natascha C. da Fonseca ${ }^{a, *}$, Helena P.G. Joaquim ${ }^{b}$, \\ Leda L. Talib ${ }^{\mathrm{b}}$, Silvia de Vincentiis ${ }^{\mathrm{a}, \mathrm{c}}$, Wagner F. Gattaz ${ }^{\mathrm{b}}$, \\ Kette D. Valente ${ }^{\mathrm{a}, c, d}$
}

\footnotetext{
"Laboratory of Clinical Neurophysiology, Institute of Psychiatry, University of Säo Paulo School of Medicine Hospital das Clinicas, Säo Paulo, SP, Erazil

${ }^{b}$ Laboratory of Neuroscience, Institute of Psychiatry, University of Sāo Paulo School of Medicine Hospital das Clinicas, Säo Paulo, SP, Brazil

'Laboratory of Neuroimaging, Institute of Psychiatry, University of Säo Paulo School of Medicine Hospital das Clinicas, Säo Paulo, SP, Brazil

${ }^{d}$ Center for the Support of Research in Applied Neurascience, University of Säo Paula, Säo Paula, SP, Brazil
}

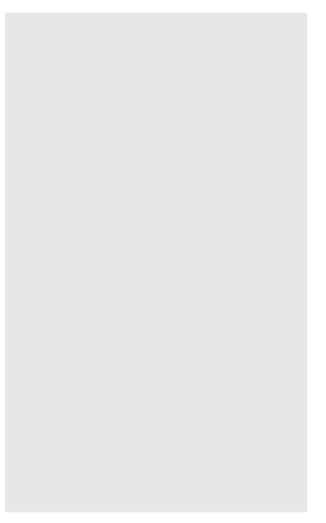

Summary

Objective: Previous studies suggest that concentration of serotonin $([5 \cdot \mathrm{HT}])$ plays a pathogenic role in various types of epilepsy inhibiting seizures. However, most have not considered the clinical variables of epilepsy, and all of these studies included small and heterogeneous samples with refractory epilepsy, regardless of etiology In this work; we measured [5-HT]s in hippocampal tissues from a large series of patients with refractory temporal lobe epilepsy caused by hippocampal sclerosis who undenwent epilepsy surgery and evaluated the relationship between [5HT] and epilepsy-related clinical variables and psychiatric disorders.

Methods: We included 44 patients with refractory unilateral TLE-HS who underwent surgical treatment for epilepsy Hippocampal samples were collected, and serotonin concentrations were measured with high-pressure liquid chromatography (HPLC).

Results: Lower [5-HT]s were correlated with a history of GTC seizures (Student's t-test: p 0.041).

There were no differences in $[5 \cdot \mathrm{HT}] \mathrm{s}$ according to the other clinical variables and the presence of psychiatric disorders.

\footnotetext{
"Corresponding author. Tel.: +55 4291285656.

E-moil address: nataschafonsecagegmail.com (N.C. da Fonseca).
} 
ANEXO 2. ARTIGO PUBLICADO: EPILEPSY RESEARCH (2015), 18 - 25 Hippocampal serotonin depletion is related to the presence of generalized tonic-clonic seizures

Significance: Our findings demonstrated that serotonin depletion in the hippocampus play an important role in some aspects of the severity of epilepsy (i.e., the presence of GTC seizures) in a homogeneous sample of patients with refractory temporal lobe epilepsy determined by hippocampal sclerosis, but not with the presence of psychiatric disorders.

Q 2015 Elsevier B.V. All rights reserved.

\section{Introduction}

Depletion of serotonin (5-HT) and the consequent upregulation of its postsynaptic receptors have been associated with epilepsy in a genetically epilepsy-prone rat (GEPR) mode (Dailey et al., 1992; Jobe and Dailey, 2000).

Agents that elevate extracellular 5.HT levels inhibit facal and generalized seizures (Bagdy et al., 2007). 5-HT plays a pathogenic role in various types of epilepsy in genetically epilepsy-prone rat (GEPR) models. In GEPR models, certain strains with innate noradrenergic and serotonergic pre- and post-synaptic transmission deficits and those with abnormal serotonergic innervations with in the brain are associated with low postsynaptic 5-HT1A receptor densitie in the hippocampus. Additionally, further reductions in serotonin concentration are correlated with epilepsy severity (Clough et al., 1998; Dailey et al., 1992; Ryu et al., 1999 Therefore, there is evidence, particularly from animal mod els, that suggests that [5HT] is associated with epilepsy and epilepsy severity.

Temporal lobe epilepsy (TLE) caused by hippocampal sclerosis (HS) is the leading cause of focal refractory epilepsy in adults (Beleza, 2009; Veriano et al., 2010), and most patients with this condition are referred for epilepsy surgery patients with this condition are referred for epilepsy surgery
because current treatments with anti-epileptic drugs are

ineffective.

Although TLE-HS represents an excellent model for the study of the role of $[5 \mathrm{HT}] \mathrm{s}$ in humans, scarce data from human brain tissue, particularly the hippocampal tissue of patients with epilepsy, are available (Broderick et al., 2000; Louw et al., 1989. Mori et al., 1987. Naffah-liamacorat et al., 1996; Pacia et al., 2001; Pintor et al., 1990)

Earlier studies (Broderick et al., 2000; Louw et al., 1989 Mori et al., 1987; Pacia et al., 2001) have not considered the clinical variables of epilepsy, and all of these studies included small and heterogeneous samples with refractory epilepsy, regardless of etiology.

In the present study, we measured [5-HT]s in hippocampa tissues from a large series of patients with refractory TLE-H who underwent epilepsy surgery and eyaluated the relationship between [5HT] and epilepsy-related clinical variables. We also studied the relationship between [5HT] and the presence of psychiatric comorbidities.

\section{Methods}

Patients

We included patients with refractory unilateral TLE-HS (Kwan et al., 2010). The study sample comprised 44 patients (24 female; mean age of $35.0 \pm 13.1$ years) : All 44 patient had previously been evaluated with 3-Tesla MRI. In all cases, the imaging studies revealed decreased hippocampal volumes on $\mathbf{T} 1$-weighted images and increased hippocampal signal intensities on T2-weighted fluid-attenuated inversion recovery seques. studios what studies were performed at the Laboratory of physiology of the University of Sao Paulo.

Due to refractory epilepsy, these patients underwent standard anterior temporal lobectomies. Samples of the hippocampi were collected during the surgeries and stored at $-80^{\circ} \mathrm{C}$ for subsequent analyses.

The mean age of these patients at the onset of epilepsy was 8.9 years ( $(S D \pm 7.4)$, and the mean duration of epilepsy was 26.0 years $(5 D \pm 12.0)$. Psychiatric comorbidities were present in $45.4 \%(20 / 44)$ of the patients and included the following: mood disorders only following: mood disorders only in $36.4 \%$ (16/44: 15 with depression and ane with anxiety), and psychosis only in $18.2 \%(8 / 44)$. The clinical characteristics of these patients are shown in Table 1.

All patients were taking antiepileptic drugs (AEDS), either as monotherapy or polytherapy, at time of surgery. With the exception of one patient on monotherapy with phenytoin, all of the patients on monotherapy were using carbamazepine or oxcarbazepine. The AEDs that were associated with the polytherapy were topiramate, phenobarbital, valproate and benzodiazepines.

Materials

HPLC-grade methanol, HPLC-grade acetonitrile, sodium phosphate and perchloric acid were purchased from merck phosphate (Darmstadt, Germany) Serotonin (5-HT), external standar (5-methoxytryptamine) and sodium dodecyl sulfate were purchased from Sigma (Steinheim, Germany).

\section{Procedures}

Liquid chromatography

High-pressure liquid chromatography (HPLC) was performed on a Shimadzu system (LC 10AD VP; Shimadz Corporation, Kyoto, Japan) equipped with a fluores. cence detector (RF-10AXL; Shimadzu Corporation, Kyoto, Japan) on a Lichrospher $100 \mathrm{C8} 5$ - $\mu \mathrm{m}$ reversed-phase column $(250 \mathrm{~mm} \times 4.0 \mathrm{~mm}$; Varian, Sunnwwale, CA, USA). The mobile phase contained $0.1 \mathrm{M}$ sodium phosphate and $10 \mathrm{um}$ sodium dodecyl sulfate in water, acetonitrile and methanol ). Elution was performethano (70:15:15 v/VH). Elution was performed by a single gradient, and flow rate was maintained at $0.8 \mathrm{ml} / \mathrm{min}$. The excitation and emission wawelengths of the fluorescence
detector were set to 330 and $450 \mathrm{~nm}$, respectively. The injection volume was $50 \mu \mathrm{l}$. The acquisition and integration of the chromatograms were performed using Shimadzu Class-VP software. 
ANEXO 2. ARTIGO PUBLICADO: EPILEPSY RESEARCH (2015), 18 - 25

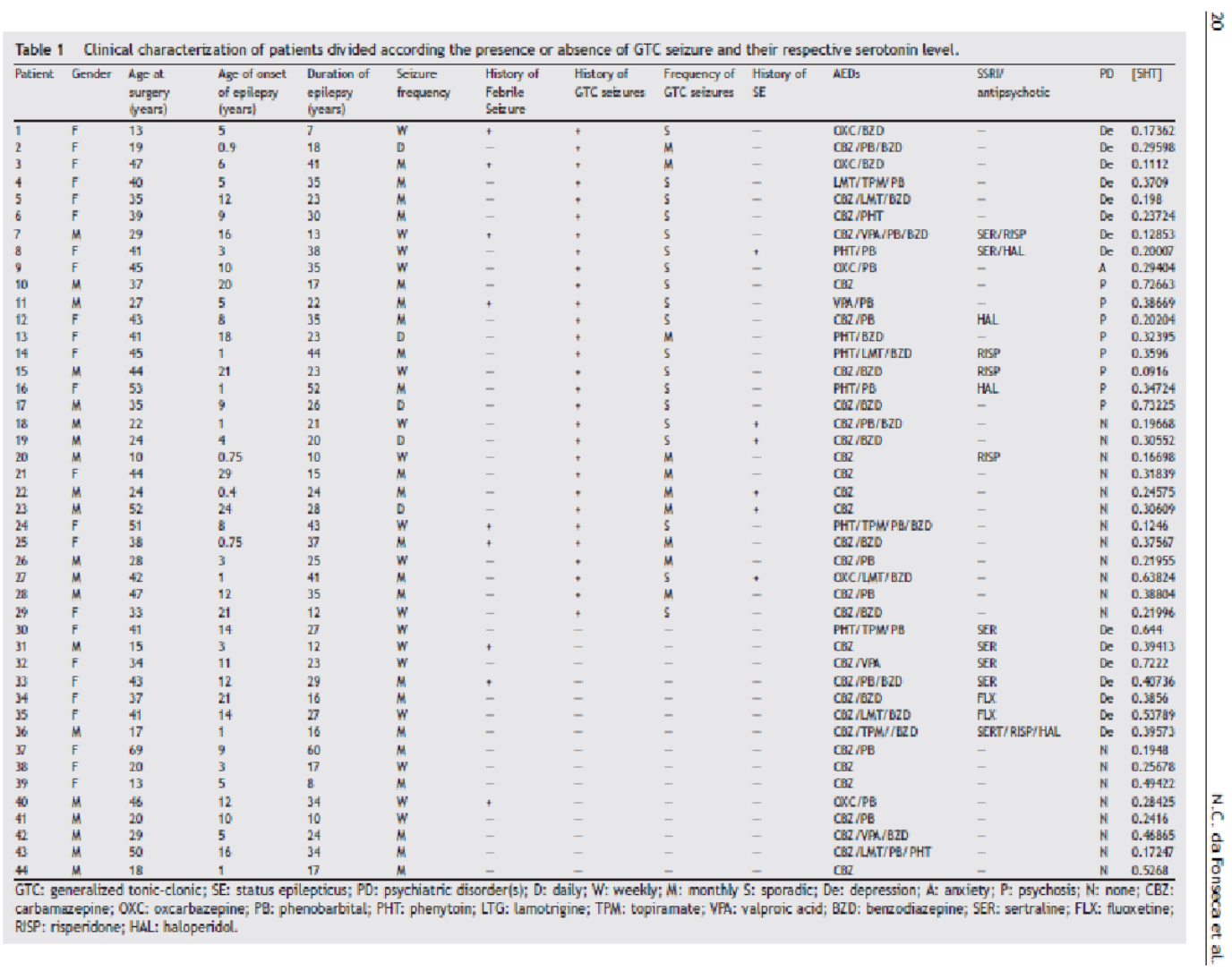


ANEXO 2. ARTIGO PUBLICADO: EPILEPSY RESEARCH (2015), 18 - 25

\begin{tabular}{llll} 
Table 2 & Serotonin (5HT) mean and standard deviation. \\
\hline Psychiatric disorder & N & 5HT mean & Std. deviation \\
\hline None & 20 & 0.3060 & 0.13624 \\
Depression & 16 & 0.3451 & 0.17669 \\
Psychosis & 8 & 0.3963 & 0.22729 \\
Total & 44 & 0.3366 & 0.16919 \\
\hline
\end{tabular}

\section{Calibration standards}

A $1-\mathrm{mg} / \mathrm{ml}$ stack solution of 5 HT was prepared in sodium phosphate buffer. Working calibrators were prepared by dilution of the stock to concentrations of $50.0 \mathrm{ng} / \mathrm{ml}$, $25.0 \mathrm{ng} / \mathrm{ml}, 10.0 \mathrm{ng} / \mathrm{ml}, 5.0 \mathrm{ng} / \mathrm{ml}$, and $2.5 \mathrm{ng} / \mathrm{ml}$. Stock solutions of external standard were prepared in $30 \mathrm{~mm}$ sodium phosphate buffer at $\mathrm{pH} 7.4$, and the working external standard solution was $1 \mu \mathrm{g} / \mathrm{ml}$.

\section{Tissue preparation}

The hippocampal samples were dissected and homogenized with $3.4 \mathrm{M}$ perchloric acid in a Potter $S$ homogenizer (B. Braun Biatech International, Melsungen, Germany) to a final concentration of $25 \mathrm{mg} / \mathrm{ml}$. The homogenized samples were then sonicated for 30 s to lyse the membranes NirSonic 100 ; Virtis, Gardiner, NY, USA), centrifuged at $14,000 \times \mathrm{g}$ at $4^{\circ} \mathrm{C}$ for 20 min (Himac CR22F-Hitachi, Tokyo, Japan), and stored at $-80^{\circ} \mathrm{C}$ until use. The supernatants $(250 \mu \mathrm{H})$ were mixed with $50-\mu l$ external standard solution and vortexed. The clear solutions were transferred to autosampler vials for analysis.

\section{Serotonin concentrations}

The 5HT peaks in each sample were identified according to their retention times and compared with the standard solutions. The retention time for the $5 \mathrm{HT}$ peak was $5.4 \mathrm{~min}$. The concentrations are given in ng/mg. Calculus was applied to the area of the peak to determine the serotonin concentration (Table 2).

\section{Statistical analyses}

The following clinical variables were analyzed: age at epilepsy onset; epilepsy duration; presence and frequency of febrile sezure; presence and frequency of status epilepticus; frequency of generalized tonic-clonic [GTC] seizures; frequency of complex partial seizures; anti-epileptic drugs (mono-versus polytherapy); and the presence and type of psychiatric disorder (PD; Table 1).

The primary outcome measure was to studly the association between GTC and 5-HT levels. Secondary clinical autcome was the presence of psychiatric disorders. For this reason, in the first analysis, we categorized patient in two groups: $G T C+$ ( 29 patients) and $G T C-(15$ patients) (Table 1).

We also categorized patients in PD + (24 patients) and PD - (20 patients).

First analysis

The relationships between [5-HT] and the clinical variables were assessed with the following tests: (1)
Wilcoxon-Mann-whitney test or Kruskall-wallis test for independent variables depending on the number of groups; and (2) Spearman correlation coefficients for continuous variables. The association between GTC seizures and confounding variables was measured with Fisher's exact test.

\section{Second analysis}

To accommodate confounding factors, 5HT concentration association with independent variables was assessed with a gamma distributed generalized linear model.

The normality of the distributions of the values was veri. fied via examination of quantile-quantile plots. Significance was set at $5 \%$, and all tests were two-tailed.

The statistical analyses were performed with the Statistical Fackage for the Social Sciences, version 14.0 (SFSS Inc. (hicago, IL, USA).

\section{Results}

In the hippocampal samples that were collected during the surgical procedures, the concentrations of 5-HT ranged from 0.0916 to $0.7323 \mathrm{ng} / \mathrm{mg}$, and the mean concentration was $0.3366 \mathrm{ng} / \mathrm{mg}$ (Table 2)

We found that lower lewels of 5-HT were correlated with a history of GTC seizures (Wilcoxon-Mann-whitney test; p 0.019) as illustrated in Fig. 1. Na differences in 5-HT levels were significantly associated with the other clinical variables.

Within the subgroup of patients with GTC seizures, there was no significant difference of the patients on polytherapy and those on monothera py, considering benz odiazepines (Fisher's exact test; $p$ 0.271) or not (Fisher's exact test; $p$ $0.464)$; also no significant difference of the patients using antipsychotics (Fisher's exact test; $p \quad 0.226$ ), with the presence of febrile seizure (Fisher's exact test; $p$ 1.000) or status epilepticus (Fisher's exact test; p 0.134). PSychiatric dis. orders were equally represented in the patients with and without GTC seizures (Fisher's exact test; $p$ 0.532).

The patients using selective serotonin reuptake inhibitors (SSRIs) had fewer GTC seizures (Fisher"s exact test; $p$ 0.004). We analyzed if GTC and SSRI interfered in [5HT] at the same time, using GLM igeneralized linear model with gamma distribution) with an interaction effect. The result is sig. nificant, indicating that in the group of patients with GTC seizures the use of SSRI alters significantly the [5HT] ( $P$ 0.011 ).

The 5-HT levels were not correlated with other clinical variables, including the presence or type of PD in TLE-HS (Wilcoxon-Mann-Whitney; $p$ 0.334), the age at the onset of epilepsy (Spearman correlation coefficient; p 0.938), the duration of epilepsy (Spearman correlation coefficient; $p 0.745$ ), the frequency of seizures (Kruskal-Wallis; p 0.211), histary of status epilepticus (Wilcoxon-Mann-Whitney; $p 0.657$ ) and history of febrile seizures (Wilcoxon-Mann-Whitney; $p 0.250$ ).

There were no differences in serotonin concentrations between the patients on monotherapy and those on polytherapy considering benzodiazepines (WilcoxonMann-Whitney; p 0.179) or not (Wilcoxon-Mann-Whitney; p 0.302). 
ANEXO 2. ARTIGO PUBLICADO: EPILEPSY RESEARCH (2015), 18 - 25

22

N.C. da Fonseca et al.

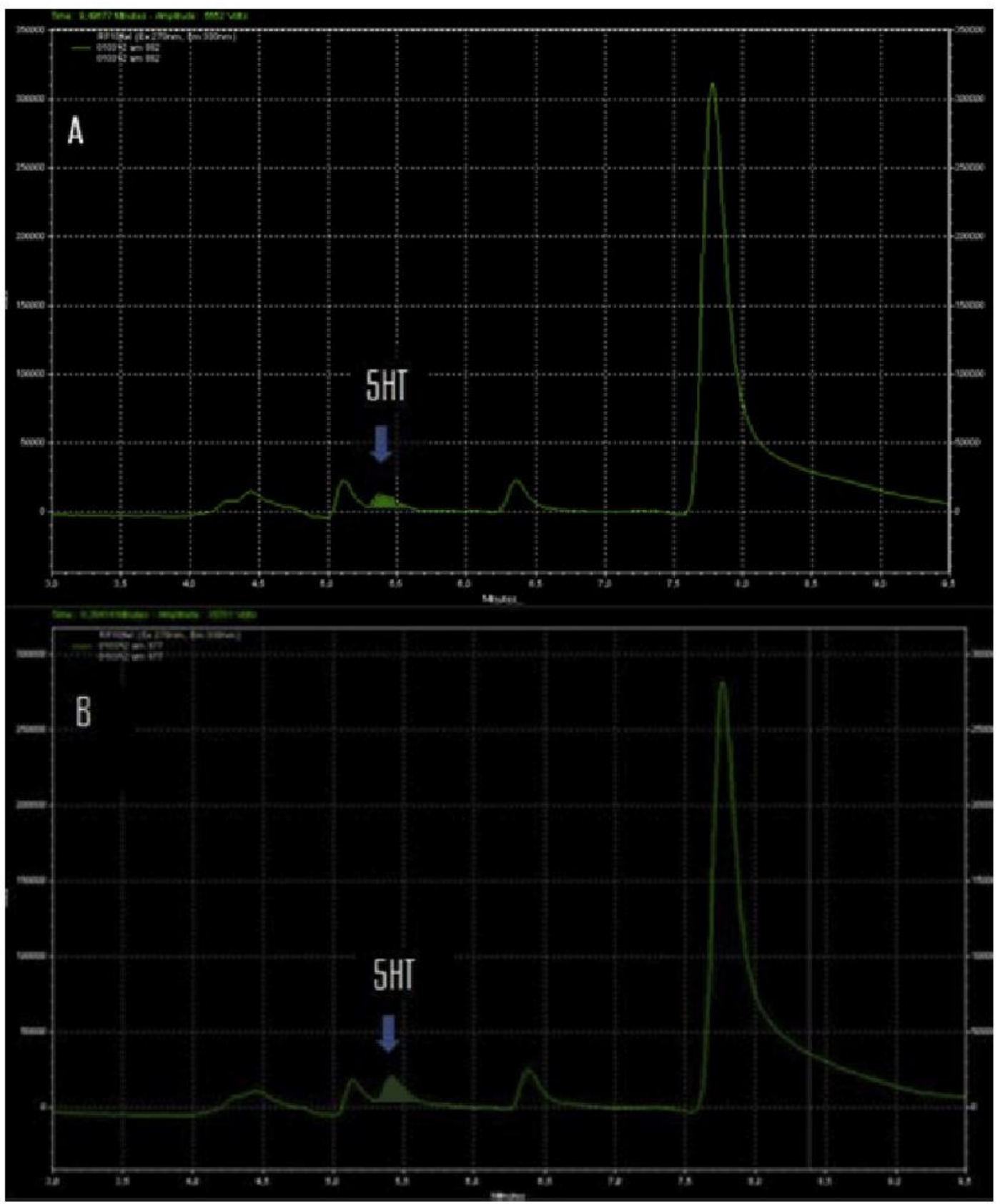

Fig. 1 Chromatograms of patient with GTC seizures (above) and patient without GTC seizures (below) history showing peak of 5HT at $5.4 \mathrm{~min}$ and of external standard at $7.6 \mathrm{~min}$. In the first case the concentration of $5 \mathrm{HT}$ is $0.17362 \mathrm{ng} / \mathrm{mg}$ and the second case is $0.25678 \mathrm{ng} / \mathrm{mg}$. Concentration of $5 \mathrm{HT}$ is represented by the filled in green area. 


\section{ANEXO 2. ARTIGO PUBLICADO: EPILEPSY RESEARCH (2015), 18- 25}

\section{Discussion}

This study analyzed hippocampal tissue from patients with refractory TLE-HS and showed a reduced concentration of 5HT in the patients with past or current history of GTC seizures: These results agree with evidence from animal models that has demonstrated the role of 5-HT in the physiopathology of GTC seizures. In the methionine sulfoximine (MOS)-induced rat madel seizures that mimic GTC seizures, Clois et al. (2010) found that 5-HT is involved in the control of the latency to seizures and that cortical 5HT levels are decreased at the onset of seizures. Ficand et al. (2011) used the same model and also found that defective serotonergic neurotransmission could trigger increases in glycogen and seizure genesis. Classical studies with GEPRs strains (i.e., GEPR-3 and GEPR-9) also suggest a potential role of serotonin in epileptogenesis (Dailey et al., 1989, 1992; Jobe et al., 1986, 1995; Jobe and Dailey, 2000). GEPR-9s were shown to have a marked genetically determined predisposition to seizures that closely mimics GTCSs in humans (Jobe et al., 1995; Jobe and Dailey, 2000). Interestingly, in most GEPR-9S; GTCSs occur secondarily in response to limbic seizures (Caffey et al., 1996; Jobe and Dailey, 2000). These studies have provided a basis for the tentative identification of areas of the brain in which monoaminergic abnormalities regulate setzure severity and susceptibility. In GEPR-9s and GEPR-35, monoaminergic defects in areas such as the thalamus might regulate both the susceptibility to and severity of seizures. In other areas, such as the limbic system, defects might regulate only the severity or susceptibility. There is evidence supporting the concept that noradrenergic and serotonergic innervation act as determinants of seizure predisposition in GEPRS (Dailey et al., 1989, 1992; Jobe and Dailey, 2000).

Additionally, experimental data from the pilocarpine model of epilepsy in rats has shown that agents that facilitate hippocampal 5HT release decrease seizure severity, which is indicative of fewer GTC seizures or status epilepticus episodes (Smolders et al., 2008). Moreover, agents that decrease the content of serotonin in the raphe nuclei and hippocampus facilitate the induction of pilocarpine-induced status epilepticus during the acute period and increase the frequency of spontaneous seizures in the chronic phase (Trindade-Filho et al., 2008).

In our study, serotonin depletion was not associated with ather epilepsy-related clinical variables, with the exception of the presence of GTC seizures. A possible explanation for this finding is that serotonin depletion in the hippocam. pus might be involved in the genesis of GTC seizures from limbic epilepsies, but the susceptibility to seizures might involve serotonin depletion in other regions, such as the superior colliculus (Merrill et al., 2007), and other serotonergic mechanisms. Focha et al. (2012) evaluated the temporal neocortical tissues of patients with TLE-HS by autoradiography, finding that the patients in whom epileptic setzures began at young ages presented with reduced 5-HT7 binding. Similarly, patients with langer duration of the epilepsy and those with long-term history of antiepileptic drug administration exhibited reduced 5-HT4 and 5-HT7 binding. Different neurotransmitters and receptors might also be associated with epilepsy-related clinical variables
(Kandratavicius et al. 2013a; Li et al. 2014, PalomeroGallagher et $\mathrm{al}_{2}$, 2012; Rocha et al., 2012). This analysis is part of an ongoing study.

The effects of bath antiepileptic and SSRI drugs on our results remain outstanding questions. In our group of patients with GTC, we found no differences related to the patients therapies (i.e., monotherapy or polytherapy). The same analy sis was performed for those with PD and produced similar results. Therefore, $\mathrm{AED}$ use was equally distributed across our groups (i.e., those with and withour PD and those with and without GTC seizures). In contrast, SSRI use was associated with a reduced number of GTC seizures and also altered serotonin levels. Indeed, distinct studies have suggested that SSRIs significantly decrease spontaneous seizure frequency (Smolders et al., 2008; Vermoesen et al., 2012) and that one possible mechanism by which their produce anticonvulsant effects might be due to serotanergic incre. ments (Browning et al., 1997; Favale et al., 1995; Favale et al. 2003; Merrill et al., 2007; Specchio et al., 2004; Vermoesen et al., 2012; ran et al., 1994). We can infer from our results that an increase of hippocampal 5-HT levels could be correlated with a reduction of GCT seizures frequency. Therefore, treatments with SSRls could bene. fit patients with GCT seizures. However, we cannot ignore that GCT+ and GCT- subpopulations $N=29$ and 15, respectively), are not homogeneous in terms of numbers; which may have interfered in our results. Nevertheless our study shows the importance of further work on the topic.

Studies using HPLC in human tissue have shown that $5 \mathrm{HT}$ and 5-hydroxyindoleacetic acid levels are increased (Loum et al, 1989: Naffah-Mazzacoratti et al, 1996; Pintor et al. 1990) or unaltered (Mori et al., 1987) in the spiking compared to non-spiking temporal cortices of patients with complex partial seizures. However, these previous studies evaluating serotonin concentrations in humans are not suitable for comparison with ours because the correlations of the serotonin levels with clinical variables were not examined or the study designs and sample sizes were quite different. Specifically, these ather studies did not distinguish between distinct etiologies and were not restricted to HS.

Broderick et al. $(2000)$, Pacia et al. (2001) studied small samples (<15 patients) to evaluate serotonin levels via microvoltammetry and found that 5HT levels are decreased in the hippocampi but not neocortical tissues of patients with TLE-HS compared to thase with neocortical TLE (NTLE); these findings suggest that hippocampal sclerosis might cause 5HT depletion. These findings emphasize the importance of etiology and the study of homogeneous samples. It is possible that the serotonin levels we observed are decreased relative to those of non-epileptic patients and patients with epilepsies with other etiologies. The lack of controls for comparison is a limitation of our study.

we believe that decreased serotonergic function plays an important role in the pathophysiology of depression and that such a decrease might be a common mechanism that links epilepsy and mood disorders. In the present study, this correlation was negative. The heterogeneity of the group in terms of the type of PD might have interfered with our results. However, it is also possible that other mechanisms that are related to 5-HT are correlated with the presence of PD, such as altered serotonin receptor or transporter functions (Drevets et al., 1999; Hasler et al., 2007; Hung et al., 
ANEXO 2. ARTIGO PUBLICADO: EPILEPSY RESEARCH (2015), 18- 25

2011; Sargent et al., 2000; Schenkel et al., 2011). Nonetheless, other mechanisms (Gattaz et al.., 2011; Kandratâvicius et al., $2013 \mathrm{~b})$ are also probably related to these findings.

\section{Conclusions}

In conclusion, our findings suggest that serotomin deple. tion in the hippocampus is associated with the presence of GTC seizures. We postulate that the epilepsy-related clinical variables and comorbidities are multifaceted and that different mechanisms are involved in the pathogenesis of epilepsy. Studies of the receptors and transporters might help to elucidate the roles of 5 HT and other clinical variables, such as mood disorders.

\section{Conflict of interest statement}

The authors state that they have no conflict of interest.

\section{Acknowledgments}

or. valente is the recipient of a grant from the $C M P Q$ (National Council for Scientific and Technological Development - 307262/2011) and FAPESP (Agency of the Sao Paulo Research Foundation - 2013/11361-4). Drs. valente and Fonseca are recipients of a grant from the FAPESP (Agency of the Sao Paulo Research Foundation - 05/56464-9)

\section{References}

Bagdy, G., Kecskemeti, V., Riba, P., Jakus, R., 2007. Serotonin and epilepsy. J. Weurochem. 100 (4), 857-873.

Beleza, P, 2009. Refractory epilepsy: a clinically oriented review. Eur. NeunoL. 62 (2), 65-71.

Broderick, P.A., Pacia, S.V., Doyle, W.K., Devinsky, D., 2000. Monoamine neurotranamitters in resected hippocampal subparcellations from neocortical and mesial temporal lobe epilepsy; patients: in situ microvoltammetric studies. Brain Res. 878 (1-2), 48-63.

Browning, R.A. Wood, A.V., Merrill, M.A., Dailey, J.W., Jobe, P.C. 1997. Enhancement of the anticonyulsant effect of fluoxetine following blockade of $5 \mathrm{HT}$ ia receptors. Eur. J. PharmacoL 336 (1), 1-6.

Cloix, J.F., Tahi, Z., Boissonnet, A., Hévor, T., 2010. Brain glycogen and neurotransmitter levels in fast and slo methionine sulfoximine-selected mice. Exp. Neurol. 225 (2), 274-283.

Clough, R.W., Peterson, B.R., Steenbergen, J. L., Jobe, P.C., Browning, R.A., Mishra, P.K., 1998. Neurite extension of developing noradrenergic neurons is impaired in genetically epilepsy-prone rats (GEPR-3is): an in vitro study in locus coeruleus. Epilepsy Res. $29(2), 135-146$.

Coffey, L.L., Reith, M.E., Chen, N.H., Mishra, P.K., Jobe, P.C., 1996 Amygdala kindling of forebrain seizures and the occurrence of brainstem seizures in genetically epilepsy-prone rats. Epilepsis 37 (2), 189-197.

Dailey, J.W., Reigel, C.E., Mishra, P.K., et al., 1989. Neurology of seizure predisposition in the genetically epilepay-pone rat. Epilepsy Res $3,3-17$

Dailey, J.W., Mishra, P.K., Ko, K.H., Penny, J.E., Jobe, P.C., 1992 Serotoninergic abnommalities in the central inervous system of seizure-naive genetically epilepsy prone rats. Life Sci. 50 (4) $319-326$.
Drevets, W.C., Frank, E., Price, J., Kupfer, D.J., Holt, D., Greer P.J., Huang, Y., Gaultier, C., Mathis, C., 1999. PET imaging of serotanin $1 \mathrm{~A}$ receptar binding in depression. Biol. Psychiatry 46 (10), 1375-1387.

Favale, E., Rubino, V., Mainardi, R., Lunardi, G., Albano, C., 1995. Anticonvulsivant effect of fluoxetine in humans. Neurology 45 (10), 1926-1927.

Favale, E., Audenino, D., Cocito, L., Albano, C., 2003. The anti. convulsant effect of citalopram as an indirect evidence of serotoninergic impairment in human epileptogenesis. Seizure 12 (5), 316-318.

Gattaz, W.F., Valente, K.D., Raposo, N.R.B., Vicentris, S., Talib. L.L., 2011. Increased PLA $A_{2}$ activity in the hippocampus of patients with temporal labe epilepsy and psychasis. J. Psychiatr. Res. 45 (12), 16:17-1620.

Hasler, G., Bormretsch, R., Giovacchini, G., Toczek, M.T., Bagic, A., Lucknbaugh, D.A., Drevets, W.C., Theodore, W.H., 2007. $5 \mathrm{HT} 1 \mathrm{~A}$ Receptor binding in temporal lobe epilepsy patients with and without major depression. Biol. Psychiatry 62 (11). $1258-1264$.

Hung, C.F., Lung, F.W., Chen, C.H., O'Nions, E., Hung, T.H., Chong, M.Y. Wu, C.K., When, J.K., Lin, P.Y, 2011. Association between suicide attempt and a tri-allelic functional polymorphism in serotonin transporter gene promoter in Chinese patients with schizophrenia. Neurosci. Lett. 504 (3), 242-246.

Jobe, P.C., Dailey, J.W., 2000. Genetically epilepsy-prone rats (GEPRS) in drug research. CNS. Drug Rev 6 (3), 241-260.

Jobe, P.C., Dailey, J.W., Reigel, C.E., 1986. Noradrenergic and serotoninergic determinants of seizure susceptibility and severity in genetically epilepsy-prone rats. Life Sci. 39 (9), $775-782$

Jobe, P.C., Mishra, P.K., Adams-Curtis, L.E., Deoskar, V.U., Ko, K.H., Browning, R.A., Dailey, J.W., 1995. The genetically epilepsy-prone rat (GEPR). ItaL. J. Neunal. Sci. 16 (1-2). 91-99.

Kandratavicius, L., Rosa-Neto, P., Monteiro, M.R., Guiot, M.C., Assirti Jr. J.A., Calotti, C.G., Kobayashi, E., Leite, J.P., $2013 \mathrm{a}$ Distinct increased metabotropic glutamate receptor type 5 (mGluA5) in temporal. labe epilepsy with and without hippocampal sclerosis. Hippocampus 23 (12), 1212-1230.

Kandratavicius, L., Monteiro, M.R., Assirati Jr., J.A., Carlotti, C.G. Hallak, J.E., Leite, J.P., 2013b. Neurotrophins in mesial tempo ral lobe epilepsy with and without psychiatric comorbidities. J. Neuropathol. Exp Neurol. 72 (11), 1029-1042.

Kwan, P., Arzimanoglou, A., Berg. A. T., Brodie, M. J., Allen Hauser, W. Mathern, G. Moshé, S.L., Perucca, E., Wiebe, 5., French, J. 2010. Definition of drug resistant epilepsy: consensus proposal by the ad hoc task fonce of the ILAE Commission on Therapeutics Strategies. Epilepsia 51 (6), 1069-1077.

Li, B., Wang, L., Sun, $Z_{\text {., }}$ Zhou, $Y$, Shao, D., Zhao, J., Song, $Y$. Lv, J., Dong, X., Liu, C., Wang, P., Zhang, X., Cui, R., 2014 The anticonvulsant effects of SR 57227 on pentylenetetrazoleinduced seizure in mice. PLO5 ONE 9 (4), e93158.

Louw, D., Sutherland, G.R., Glavin, G.B., Girvin, J., 1989. A study of monoamines metabolism in human epilepsy. Can. J. Neurol. Sci. 16 (4), 394-397.

Merrill, M.A., Clough, R.W., Dailey, J.W., Jabe, R.C., Browning, R.A. 2007 . Localization of the serotaninergic terminal fields modulating seizures in the genetically epilepsy-prone rat. Epilepsy Res. $76(2-3), 93-102$.

Mori, A., Hiramatsu, M., Namba, S., Nishimoto, A., Ohmoto, T. Mayanagi, Y., Asakura, T., 1987. Decreased dopamine level in the epileptic focus. Res. Commun. Chem. Pathol. Pharmacol. 56 (2), $157-164$.

Naffah-Mazzacoratti, M.G., Amado, D., Culdert, A., Gronich, G., Marino, R., Calderazzo, L., Cavalheiro, E.A., 1996. Monoamines and their metabolites in cerebrospinal fluid and temporal cortes of epileptic patients. Epilepsy Res. 25 (2), 133-137. 
ANEXO 2. ARTIGO PUBLICADO: EPILEPSY RESEARCH(2015), 18 - 25

Pacia, S.V., Dovle, W.K., Broderick, P.A., 2001. Biogenic amines in the human neocortex in paients with neocortical and mesial temporal lobe epilepsy: identification with in situ microvoltammetry. Brain Res. 899 (1-2), 106-111.

Palomero-Gallagher, N., Schleicher, A., Bidmon, H.J., Pannek, H.W., Hans, V., Gorji, A., Speckmann, E.J., Zilles, K., 2012. Multireceptor analysis in human neocortex reveals complex alterations of receptor ligand binding in focal epilepsies. Epilepsia 3 (11), 1987-1997.

Picard, M., Cloix, J.F., Hevor, T.K., 2011. Serotonergic neurotransmission plays a major role in the action of the slycogenic convulsant methionine sulfoximine. Neurosci. Res. 70 (3), 313-320.

Pintor, M., Mefford, L.N., Hutter, I., Pocotte, S.L., Wyler, A.R., Nadi, N.S., 1990. Levels of biogenic amines, their metabolites, and tyrosine hydroxylase in the human epileptic temporal cortex. Synapse 5 (2), 152-156.

Rocha, L., Alonso-Venegas, M. Villeda-Hernández, J., Mújica, M. Cisneros-Franco, J.M., López-Gomez, M., Zavala-Tecuapetla, C. Frias-Soria, C.L., Segovia-Vila, J., Borsodi, A., 2012. Dopamine abnormalities in the neocortex of patients with temporal lobe epilepsy. Neurobiol. Dis. 45 (1), 499-507.

Ryu, J.R., Jobe, P.C., Milbrandt, J.C., Mishra, P.K., Clough, R.W., Browning, R.A., Dailey, J.W., Seo, D.O., Ko, K.H., 1999. Morphological deficits in noradrenergic neurons in GEPR-9s stem from abnormalities in both the locus coeruleus and its target tissues. Exp. Neurol. 156 (1), 84-91.

Sargent, P.A., Kjaer, K.H., Bench, C.J., Rabiner, E.A., Messa, C., Meyer, J., Gunn, R.N., Grasby, P.M., Cowen, P.J., 2000. Brain serotonin $1 \mathrm{~A}$ receptor binding measured by positron emission tomography with [11C]WAY-100635. Arch. Gen. Psychiatry 57 (2), 174-180.
Schenkel, L.C., Bragatti, J.A., Becker, J.A., Torres, C.M., Martin, K.C., Souza, A.C., Manfro, G.G., Leistner-Segal, S., Bianchin, M.M., 2011. Serotonin gene polymorphisms and psychiatry comomorbidities in temporal lobe epilepsy. Epilepsy Res. 12 (5), $1-7$.

Smolders, I., Clinckers, R., Meurs, A., De Bundel, D., Portelli, J., Ebinger, G., Michotte, Y., 2008. Direct enhancement of hippocampal dopamine or serotonin levels as a pharmacodynamic measure of combined antidepressant-anticonvulsant action. Neuropharmacology 54 (6), 1017-1028.

Specchio, L.M., ludice, A., Specchio, N., La Neve, A., Spinelli, A. Galli, R., Rocchi, R., Ulivelli, M., de Tommaso, M., Ptzzanelli, C., Murri, L., 2004. Citalopram as treatment of depres. sion in patients with epilepsy. Clin. Neuropharmacol. 27 (3), 133-136.

Trindade-Filho, E.M., Castro-Neto, E.F., Carvalho, R., Lima, E. Scorza, FA., Amado, D., Naffah-Mazzacorattti, M.G., Cavalheiro, E.A., 2008. Serotonin depletion effects on the pilocarpine model of epilepsy. Epilepsy Res. 82 (2-3), 194-199.

Veriano Jr., A., Capovilla, G., Fattore, C., Franco, V., Gambardella, A., Guerrini, R., La Briola, F., Ladogana, M., Rosati, E., Specchio, L.M., Striano, S., Perucca, E., 2010. Characteristics of a large population of patients with refractory epilepsy attending tertiary referral centers in Italy. Epilepsia 51 (5), 921-925.

Vermoesen, K., Messie, A., Smolders, I., Clinckers, R., 2012. The antidepressants citalopram and reboxetine reduce seizure fre quency in rats with chronic epilepsy, Epilepsia 53 (5), 870-878.

Yan, Q.S., Jobe, P.C., Dailey, J.W., 1994. Evidence that a serotonergic mechanism is involved in the anticonvulsant effect of fluoxetine in genetically epilepsy-prone rats. Eur. J. Pharmacol. $252(1), 105-112$ 


\section{ANEXO 3. ARTIGO PUBLICADO: EUROPEAN JOURNAL OF NEUROLOGY}

\section{OR I G I N A L A R T I CLE}

\section{5-hydroxytryptamine1A receptor density in the hippocampus of patients with temporal lobe epilepsy is associated with disease duration}

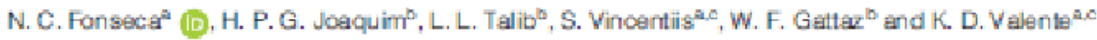

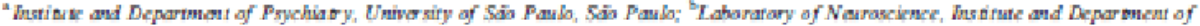

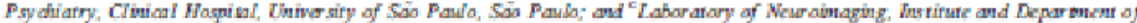

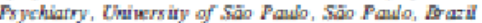

\section{Keywords:}

cpilcpy surgery,

hippocampal sckerosis,

hip pocampus, nefractory,

scrotonin, western

blotting

Received 29 July 2016

Accepted 4 January 2017

Europand Journal of

Netealogy 2017, 24: 602608

dci:10.1111, kne 13252

\section{Introduction}

There is evidence, from animal modek, suggesting that there is an association between scrotonin (5-HT) 5-HT receptors (5-HTRs) and epilepsy [1,2]. Serotonergie regulatory mechanisms have been described in genetically epilepsy-prone rats, an audiogenic seizure model [3-6]. In one madel, depletion of 5-HT density increases seizure severity and 5-HT replacement attenuates it [5]. It was also demonstrated that 5-hydroxytryptaminelA receptor (5-HTlAR) agonist blocked cpilcptiform activity in a model of cpilcpsy induood by picrotoxin, a GABA receptor antagonist, and this antiepileptic effect was blocked by 5-HTIAR antagonist, suggesting a significant role of 5-HTlAR in

Correppondeno: R. D. Valente and N.C. Fonseca, Rua Dr. Owtis

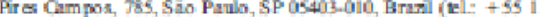

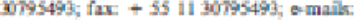

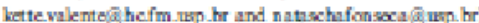

anticomvulsant propertics [7]. Additionally, in a study with kindled cats, a model of epilepsy produced by focal electrical stimulation, 5-HTIAR agonist led to an inerease in the threshold of generalizod scizures [8]. A study with amygdala-kindled rats has also demonstrated that 5-HTlAR agonist slightly suppressed the development of behavioral and eloctrographic seirures [9].

Neuroimaging studies using positron emission tomography (PET) with a seloctive 5-HTIAR tracer demonstrated a docrease in 5-HTLAR binding potential in the epileptogenie area of patients with temporal lobe cpilepsy (TLE), mainly in those with depression [10-13].

Temporal lobe epilepsy caused by hippocampal sclerosis (HS) is the most common caue of pharmacoresistant focal epilepsy refened to surgery [14] and it represents an excellent model for neurophysiologic studies. Howeyci, there are few studies in buman 


\section{ANEXO 3. ARTIGO PUBLICADO: EUROPEAN JOURNAL OF NEUROLOGY (2017), 24(4): $602-608$}

brain tissue that have evaluated the role of 5-HTRs in epileptogenesis [15-17]. Gracbenitz at al. [16] analyzed the amygdal of an etiologically heterogeneous sample of patients with TLE and found a lower density (downregulation) of 5-HTIAR. The same group [15] observed higher 5-HTIAR densty when analyzing the middle temporal gyrus of pharmigoresistant TLE in a similar samplc. A possible reason for these contradictory results is the region analynod

Our previous work demongtrated that 5-HT density is downregulated in the resected hippocampal tissue of patients with TLE-HS [18]. It is reasonable to assume that 5-HTRs are upregulatod, resulting in an increased density.

To date, no studies have evaluated these 5-HTRs in hippocampal tisale, especially in an etiologically homogencous sample of patients with TLE-HS. The lack of human experimental data led us to investigate 5-HTRs in the human hippocampus. In the present study, we measurod 5-HTIAR density in hippocampal tiscues from a series of paticnts with pharmacoresstant TLEHS and cvaluated the relationship between 5-HTlAR and epilepsy-related clinical variables. We ako studied the association betwoen the 5-HTIAR density and the presence of psychiatric comorbidities.

\section{Materials and methods}

\section{Patients}

The study sample comprised the hippocampal tissue of 34 patients [18 female $(52.9 \%)$, mean age $35.3 \pm 12.6$ ycars] with TLE-HS [19]. Samples of the hippocampi were collected during the surgeries and storod at $-70^{\circ} \mathrm{C}$ for subsequent analyses.

The mean age at the onset of epilepsy was 9.7 years (SD \pm 7.4 ) and the average duration of epilepsy was 25.5 years $(\mathrm{SD} \pm 11.6)$. Psychiatric comobidities oocurred in $55.9 \%(19 / 34)$ and inchuded mood disordicrs in $35.3 \%(12 / 34)$ and psychosis in $20.6 \%(7 / 34)$. Generalined tonie-elonic (GTC) seizures, status epilepticus and febrile seizures oceurred in $61.8 \%$ (21/34), $8.8 \%(3 / 34)$ and $17.6 \%(6 / 34)$ of these patients. All patients were taking anticpileptic drugs either as monotherapy or polytherapy at the time of surgery (Table 1). Fourteen $(41.2 \%)$ patients were using psychotropie modication [antipsychotics and selective serotonin reuptake inhibitors (SSRIs)].

\section{Methods}

The local ethics committec of the University of Sāo Paulo approved this study. A written informod consent was obtained from all participants or parents.
Hippocampal tissue prepuration

The hippocampal tisue was dissoctod and stored at $-70^{\circ} \mathrm{C}$ and then homogenixed in a lysis solution (radio immunoprecipitation assay buffer plus phosphatase and protease inhibitors) to a final tissue concentration of $200 \mathrm{mg} / \mathrm{mL}$. We stored homogenate aliquots at $-70^{\circ} \mathrm{C}$.

\section{Western bloting techilgie?}

Before electrophoresis, total protein kvels were determined by the detergent-compatible Protein Assay (Bio-Rad, Life Sciences Group, Hercules, CA, USA) using a modification of the Lowry method [20]. For each sample, $25 \mathrm{mg}$ of protein was separated by eloctrophoresis on $10 \%$ polyacrylamide gels (160 V) $90 \mathrm{~min}$ ) and transferred to nitrocelhulose membranes (250 $\mathrm{mA}, 60 \mathrm{~min}$ ). The protein molocular weight marker was from Bio-Rad. Unspecific hinding was blocked for $1 \mathrm{~h}$ at room temperature of $21^{\circ} \mathrm{C}$ with $5 \%$ non-fat milk in $0.02 \%$ Tris-Buffered Saline $0.1 \%$ - Tween $20 \%$ (TBS-T).

Mcmbrancs were incubatod overnight with a monoclonal, primary antibody against 5-HTIAR (anti-5-HTlAR antibody, ab64994, Abcam, Cambridge, MA, USA). The antibody was diluted $1: 1000$ in $0.02 \%$ TBS-T. Mcmbranes were then washod and incubated for 1 h with the scoondary antibody (anti-rabbit scoondary antibody, SigmaAldrich, St Louis, MO, USA) dilutod 1:20000 in $0.02 \%$ TBS-T and subsequently washed with $0.02 \%$ TBS-T. Enhanced chemiluminescence (ECL Select GE Life Sciences, Marlborough, M.A. USA) reagent was poured onto the membranes, and photography and densitometry of distinet bands were performod using Chemilmager 4000 sysem and v5.5 software (Alpha Innotech, San Leandro, CA, USA). We analyzod each sample in duplicate. The method was semiquantitative, so we compared the intensity of density between samples.

\section{Statistical analysis}

We analyzed age at epilepsy onset, epilepsy duration. presenoc and frequency of febrile scizures, presence and frequency of status epilepticus, presence and frequency of GTC seizures, frequency of dyseognitive seizures and antiepileptic drugs (monotherapy versus polytherapy). We ako evaluated the use of SSRIs, antipsychotic drugs and the presence and type of psychiatric disonder.

First, we assessod the relationships betwecn 5-HTlAR and the elinical variables with: (i) Wilcoxon-Mann-Whitncy tcst or Kruska-Wallis test for independent variables depending on the number of 


\section{ANEXO 3. ARTIGO PUBLICADO: EUROPEAN JOURNAL OF NEUROLOGY (2017), 24(4): $602-608$}

604 N.C. FON'SECM ET N.

Table 1 Patient chanceristion

\begin{tabular}{|c|c|c|c|c|c|c|c|c|c|c|}
\hline Gender & $\begin{array}{l}\text { Age at } \\
\text { aurgery } \\
\text { (years) }\end{array}$ & $\begin{array}{l}\text { Age of anset. } \\
\text { of epilepry } \\
\text { (years) }\end{array}$ & $\begin{array}{l}\text { Sairure } \\
\text { frequency }\end{array}$ & $\begin{array}{l}\text { GTC } \\
\text { frequency }\end{array}$ & SE & $\begin{array}{l}\text { Fehrile } \\
\text { seimure }\end{array}$ & $\begin{array}{l}\text { Paychistric } \\
\text { disonder }\end{array}$ & MED & Phychatropic & SHT1A \\
\hline M & io & 0.75 & $\mathrm{~W}$ & MO & $=$ & $=$ & $=$ & CB2 & RTSP & 37674 \\
\hline F & 13 & 5 & MO & $=$ & $=$ & - & $=$ & CEZ & - & 38493 \\
\hline M & 15 & 3 & W & - & $=$ & + & $\mathrm{De}$ & $\mathrm{CBZ}$ & SER & 39312 \\
\hline M & 17 & 1 & MO & - & - & $=$ & $\mathrm{De}$ & $\mathrm{CBZ} / \mathrm{TPM} / \mathrm{BZD}$ & SER/RISP/H.AL. & 58968 \\
\hline $\mathrm{M}$ & 18 & 1 & Mo & $=$ & $=$ & $=$ & $=$ & $\mathrm{CBZ}$ & $=$ & 1506 \\
\hline $\mathrm{M}$ & 20 & 100 & $\mathrm{~s}$ & - & - & $=$ & - & CBZ,PB & - & 6il 425 \\
\hline M & 22 & 1 & w & $\mathrm{s}$ & + & $=$ & $=$ & $\mathrm{CBZ} / \mathrm{PB} / \mathrm{BZD}$ & - & 315315 \\
\hline M & 24 & 0.4 & MO & MO & + & $=$ & $=$ & CBZ & - & 24402 \\
\hline $\mathrm{M}$ & 28 & 5 & MO & $\mathbf{s}$ & - & + & $\mathbf{P}$ & VPA PB & HAL & 42407 \\
\hline M & 29 & 16 & $\mathrm{~W}$ & $\mathrm{~s}$ & $=$ & + & De & CBZ/VPA,PB/EZD & SER/RTSP & 304 \\
\hline $\mathrm{M}$ & 29 & 5 & MO & $=$ & $=$ & $=$ & $=$ & CHZ/VPA,BZT & - & 171980 \\
\hline $\mathbf{F}$ & 33 & 21 & W & $\mathrm{s}$ & $=$ & $=$ & $=$ & $\mathrm{CEZ} / \mathrm{BZD}$ & $=$ & 68796 \\
\hline $\mathbf{F}$ & 34 & 11 & $\mathrm{w}$ & $=$ & - & - & $\mathrm{De}$ & CBZ/VPA & SER & 199 on \\
\hline M & 35 & 9 & $\mathbf{D}$ & $\mathrm{s}$ & - & - & $\mathbf{P}$ & CB?/BRT & - & 41769 \\
\hline $\mathbf{F}$ & 35 & 12 & MO & $\mathrm{s}$ & - & - & De & CBZ/LMT/BZD & - & 45864 \\
\hline M & 37 & 20 & MO & $\mathrm{s}$ & - & - & $\mathbf{P}$ & $\mathrm{CHZ}$ & - & 42563 \\
\hline $\mathbf{F}$ & 37 & 21 & MO & $=$ & $=$ & $=$ & De & $\mathrm{CBZ} / \mathrm{B} 2 \mathrm{D}$ & FLX & 121212 \\
\hline $\mathbf{F}$ & 38 & 0.75 & MO & MO & - & + & $=$ & $\mathrm{CEZ} / \mathrm{BZD}$ & - & 130221 \\
\hline $\mathbf{F}$ & 39 & 9 & MO & $s$ & - & - & De & CBz/PHT & - & 3211867 \\
\hline $\mathbf{F}$ & 40 & 5 & MO & $\$$ & - & $=$ & $\mathrm{De}$ & LMT/TPM/FB & - & iis 479 \\
\hline $\mathbf{F}$ & 41 & 14 & w & - & - & - & $\mathrm{De}$ & CEZ/LMT/BZD & FLX & 36555 \\
\hline $\mathbf{F}$ & 41 & 18 & D & MO & $=$ & $=$ & $\mathbf{P}$ & PHT/BZD & R.ISP & 36.855 \\
\hline $\mathbf{F}$ & 41 & 14 & W & $=$ & - & $=$ & De & PHT/TPM/PB & SER & 327600 \\
\hline M & 42 & 1 & MO & $\mathrm{s}$ & + & - & - & OXC/LMT/BZT & $=$ & 6il 425 \\
\hline $\mathbf{F}$ & 43 & 8 & MO & $\$$ & $=$ & $=$ & $\mathbf{P}$ & $\mathrm{CHZ} / \mathrm{PB}$ & HAL & 76167 \\
\hline $\mathbf{F}$ & 43 & 12 & MO & $=$ & - & + & $\mathrm{De}$ & CE2 & SER & 61425 \\
\hline M & 44 & 21 & W & $\mathrm{s}$ & $=$ & - & $\mathbf{F}$ & $\mathrm{CBZ} / \mathrm{BZD}$ & R.SPF & 46,683 \\
\hline $\mathbf{F}$ & 44 & 29 & MO & MO & $=$ & $=$ & $=$ & $\mathrm{CBZ}$ & $=$ & 82719 \\
\hline $\mathbf{F}$ & 45 & i & MO & $\mathrm{s}$ & $=$ & $=$ & $\mathrm{P}$ & PHT/LMT/BTD & R.TSP & 87633 \\
\hline $\mathbf{F}$ & 45 & 10 & $\mathrm{~W}$ & $\mathrm{~s}$ & $=$ & - & A & OXC/PB & - & 14498 \\
\hline M & 47 & 12 & MO & MO & $=$ & $=$ & $=$ & $\mathrm{CB} / \mathrm{PB}$ & $=$ & 36355 \\
\hline M & 50 & 16 & MO & $=$ & $=$ & $=$ & $=$ & CEZ/FHT/LMT/FB & $=$ & 11547 \\
\hline $\mathbf{F}$ & 51 & 8 & W & $\$$ & $=$ & + & $=$ & PHT/TPM/PB/BZD & $=$ & 72072 \\
\hline $\mathbf{F}$ & 69 & 9 & MO & $=$ & $=$ & $=$ & $=$ & CB2/PB & $=$ & 32928 \\
\hline
\end{tabular}

5HT1A, 5-hydroxytryptaminel/A; A, anviety; A.ED, an fepileptic drug, BZD, henaodiazegine, CBZ carhamaxpine, D, daily; De, depression; F, female FLX, fluovetine; GTC generalized tonic donic; HML, halopenidoli, LMT, lamotrigine; M, mak; MO, monthly; OXC

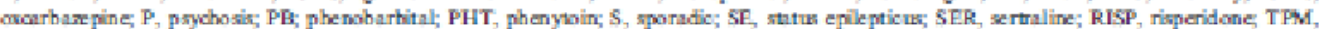
vopiramas; VPA, valproic acit; $\mathrm{W}$, wockly.

groups, and (ii) Spearman correlation coefficient for continuous and ondinal variables.

Second, the associations of 5-HT1AR density with independent variables were assessed with a gammadistributed generalizod linear model to accommodate confounding factors We verified the nomality of the distributions of the values via examination of quantile-quantile plots.

Significance was set at $5 \%$, and all tests were twotaikd. We used the Statistical Package for the Social Sciences, version 14.0 (SPSS Inc., Chicago, IL, USA).

\section{Results}

There was an association betwoen higher density of 5-HTlAR and longer duration of epilepsy (Spearman coefficient: $P=0.040$; gamma distributed generalized linear model (GLM): $P=0.026$ ) (Table 2, Fig. 1).

There was no significant difference in epilepsy duration related to the use of SSRIs (WikoxonMann-Whitney: $P=0.200$ ) or the use of antipsychoties (Wikoson-Mann-Whitney: $P=0.476$ ) and the type of psychiatric disease (Kruskal-Wallis: $P=0.586$ ). We used the GLM to evaluate the interference of confounding factors in ow results. By using this analysis, we found that 5-HTLAR density increasod by $21 \%$ with each year of cpilcpsy $(P=0.026$ ).

The 5-HT1AR was not associated with the presence of a psychiatrie disonder (Wilcoxon-Mann-Whitney: $P=0.267$ ) or other clinieal wariables including age at the onet of epilepsy (Spearman corrclation: $P=$ 0.265 ), age at surgery (Spearman correlation: $P=$ 


\section{ANEXO 3. ARTIGO PUBLICADO: EUROPEAN JOURNAL OF NEUROLOGY (2017), 24(4): $602-608$}

Table 2 Carrelation betaeen 5-hydraytryptaminel.A (5-HT1A) receptors and epilepry cli nical variable

\begin{tabular}{lcc}
\hline & SHTiA & \\
\cline { 2 - 3 } & Spearman correlation & Pvalue \\
\hline Age at murgery (yours) & $0.16 \delta$ & 0.347 \\
Age of onset of eplepry (years) & -0.197 & 0.265 \\
Duration of eqiegsy (years) & 0.354 & 0.640 \\
\hline
\end{tabular}

Bobd indicater significance

Batlent 4

\section{Fatient $\mathbf{B}$}

SHT1A

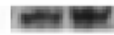

Figure I Representative westem biotting films revealed by chemil uninescence showing 5-hydroxytryptaminelA (5-HT 1A) exprexion at a band sive of $46 \mathrm{kDa}$. Samplas were ansly and in dupliats for each patient (oohumn 1 and 2 ) and the rexptor dasity was convertad to numeric numbers eledronieslly by Chemilmager $\$ 000$ system and $\mathbf{v} .5 \mathrm{soflware}$ Patient A, fqilequy duration of 60 years and 5-HTIA recopter derkity average of 329.238. Patient B, epilepsy durstion of 37 years and 5-HIT IA receptor denaity average of 130.221 .

0.347), frequency of seizures (Kruskal-Wallis: $P=0.268$ ), incidence of GTC scizures (Krukal-Wallis: $P=0.485$ ), presence of GTC scisures (WikcoxonMann-Whitney: $P=0.321$ ), history of status epilepticus (Wikoxon-Mann-Whitney: $P=0.153$ ) or history of febrile seizures (Wilcoxon-Mann-Whitney: $P=0.258$ ). Furthermore, there was no association with the type of psychiatric disorder (Kruskal-Wallis: $P=0.177$ ) or use of SSRIs (Wilcowon-MannWhitncy: $P=0.626$ ) (Table 3, Fig. 2).

There were no differences in 5-HTLAR densities between the patients on monotherapy and those on polytherapy (Wilcoxon-Mann-Whitney: $P=0.406$ ).

\section{Discussion}

In our study, we measured 5-HTLAR density using western blotting, a tochnique often used for protein detection [21]. Western blotting is used to evaluate the protein density of different types of roceptors in animal and human cortical tissue [22-24], including serotonergic receptors [25,26]. Few studies have evaluated serotonergic rexptors in human cortical tissue. Furthermore, the limited studies available differ in the methodology cmployed and the region used to determine 5-HTIAR, i.e. amygdala [16] and neocortical region $[15,17]$.

There is a wide distribution of 5-HTlARs throughout the brain. However, the highes density is found in the limbie system, particularly the hippocampus. Duc to the importanee of the hippocampus, we
Table 3 Correlation betwen 5hydrosytryptamine IA (5-HTIN) receptors and eqiilepsy clinionl wariable

\begin{tabular}{|c|c|c|c|c|}
\hline & \multirow[b]{2}{*}{$n$} & \multicolumn{3}{|l|}{ SHTIA } \\
\hline & & Mean & SD & Prvalue \\
\hline \multicolumn{5}{|c|}{ Prychintrio disord enss } \\
\hline None & 15 & $131.913,00$ & $96,990,13$ & \multirow[t]{3}{*}{0.177} \\
\hline Mood disarders & 12 & $120.709,33$ & $106.256,67$ & \\
\hline Paychoria & 7 & $53.566,00$ & $19.8 \times 6.36$ & \\
\hline \multicolumn{5}{|l|}{ Gender" } \\
\hline Female & 18 & $127.582,00$ & 100662,97 & \multirow[t]{2}{*}{0.152} \\
\hline Male & 16 & $94.115,13$ & 34.685 .06 & \\
\hline \multicolumn{5}{|l|}{ Febrile sei nure } \\
\hline Ahsent & 28 & 122060,25 & $94,315,35$ & \multirow[t]{2}{*}{0.258} \\
\hline $\begin{array}{l}\text { Present } \\
\text { GTC seirsures" }\end{array}$ & 6 & $64.105,17$ & $35,009, \pi 7$ & \\
\hline Ahsent & 13 & $131.670,00$ & $102.336,31$ & \multirow[t]{2}{*}{0.321} \\
\hline Present & 21 & $99.552,76$ & 85006,25 & \\
\hline \multicolumn{5}{|l|}{ SE } \\
\hline Absent & 31 & $102,629,55$ & 86604,89 & \multirow[t]{2}{*}{0.153} \\
\hline Fresent & 3 & $206.934,00$ & 130.95381 & \\
\hline \multicolumn{5}{|l|}{$\mathrm{PD}^{\mathrm{s}}$} \\
\hline Absent & 15 & $127.764,00$ & $97.720,71$ & \multirow[t]{2}{*}{0.267} \\
\hline Fresent & 19 & 99255,68 & 90849,43 & \\
\hline \multicolumn{5}{|l|}{ Seirure frequency } \\
\hline Daily & 2 & $39,312,00$ & $3,474,72$ & \multirow[t]{4}{*}{0.268} \\
\hline Wokly & ii & iza.se, is & $111.935,91$ & \\
\hline Monthly & 20 & $116.789,40$ & 58664,24 & \\
\hline Sporadie & i & $61.425,00$ & & \\
\hline \multicolumn{5}{|l|}{ GTC frequency" } \\
\hline Nane & 13 & $131.6 \times 500$ & $1023+6,31$ & \multirow[t]{3}{*}{0.455} \\
\hline Monthly & 6 & $94.731,00$ & i2.046,74 & \\
\hline Sporndie & 15 & $101.481,47$ & $93.006,67$ & \\
\hline \multicolumn{5}{|l|}{ Polytherapy" } \\
\hline Na & 7 & $90, \times 2,00$ & $79.242,12$ & \multirow[t]{2}{*}{0.406} \\
\hline Yea & 27 & $117.257,93$ & $97.564,58$ & \\
\hline \multicolumn{5}{|l|}{ SSRI } \\
\hline $\mathrm{No}$ & 26 & 112297,63 & $92.342,65$ & \multirow[t]{2}{*}{0.626} \\
\hline Yes & 8 & $110.42,58$ & $164.105,40$ & \\
\hline
\end{tabular}

"Krukal-Wallis ter, "Wikonon-Mamn-Whitney teat GTC, genera'

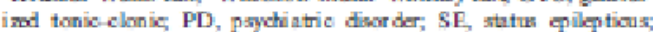
SSRI, seloctive serovnin reuptike inhihitor.

decided to analyze the density of 5-HTIAR in this region. Therefore, this is the first study measuring the density of 5-HTIAR in the hippocampus of patients neficred for epilepsy surgery.

A major strength of the current sudy is the fact that we considerod an etiologically homogeneous group of patiente with HS, all with pharmacoresistant epilepsy. Our most signifieant finding was the presence of a correlation between a higher density of 5-HTIAR and a longer duration of epilepsy in patients with TLE-HS. This phenomenon may reflect a regulatory enhancement of endogenous serotonergic neurotransmission in response to enduring epileptiform activity.

The increase of 5-HTIAR density could be a compensatory response to a roduced 5-HTIAR activity. 


\section{ANEXO 3. ARTIGO PUBLICADO: EUROPEAN JOURNAL OF NEUROLOGY (2017), 24(4): $602-608$}

606 N. C. FOMSECA ET M.
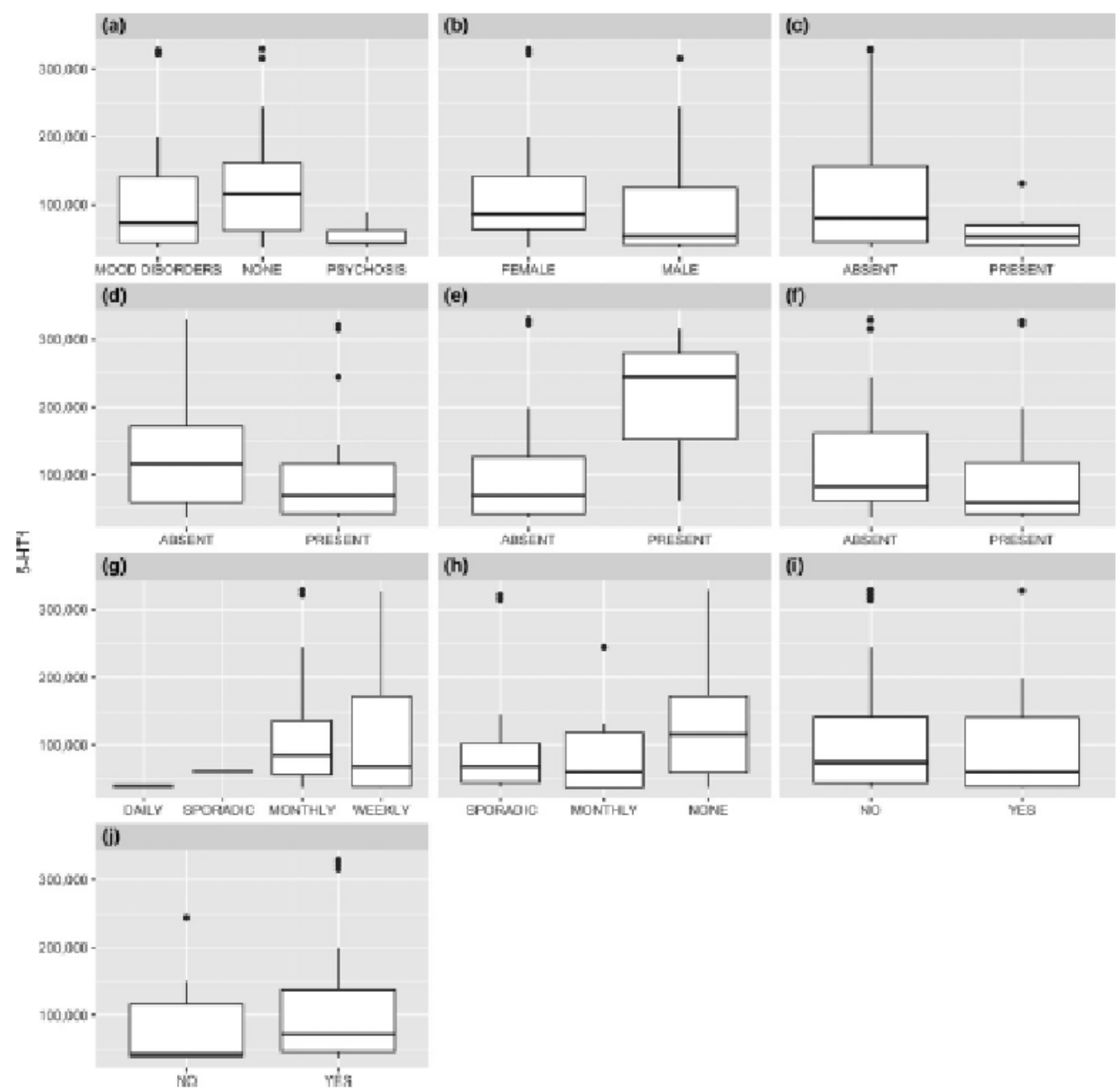

Figure 2 Boxplot gr aphic from the rexults dexcribed in Tahle 3. 5-HTl, 5hydronytryptaminel. (a) Psychiatric disonder (PD) descrip:

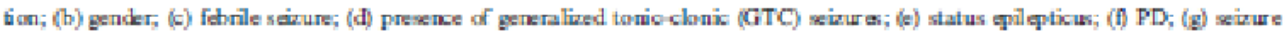
frequency; (h) GTC frequency; (i) selective serotonin reuplake in hibitar; (j) polyther apy.

Indeed, PET rexptor studies in patients with TLE demonstrated a reduction in 5-HTlAR binding $[1,13,27]$, whereas other studies suggested 5-HT byperinncryation and increasod synthesis in tissuc from patients with epilepsy [28,29].

In agroement with our results, Bogacrt et al. [30] found a late relative increase of 4-18F-fluoro- $N-2-(1-$ (2-methoxypheny])-1-piperazinyl)ethyl- $N$-2-pyridinylbenzamine hippocampal binding in the model of limbic epilepsy induoed by katnic acid. As 4-18F-fluoro-
N-2-(1-(2-methoxyphenyD)-1-piperazingl)ethyl-N-2-pyridinyl-benzamine is a 5-HT1AR tracer, these findings sug gest an increase of 5-HTIAR induced by epilepsy.

Although some authors $[31,32]$ postulate that 5HTLAR has a proconvulsant effoct, most studics have shown the opposite $[3,4,33-35]$. Studies in the hippocampus of rats have demonstrated a potential serotonergic antiepileptic effoct via 5-HTIAR 17,36$]$. Kim et al. [37] proposed that these contradictory results are due to different 5-HTl AR activation, observing 


\section{ANEXO 3. ARTIGO PUBLICADO: EUROPEAN JOURNAL OF NEUROLOGY (2017), 24(4): $602-608$}

antionnukive effects when the post-synaptic roceptor is activated and a proconvulsant effect when the presynaptic receptor is activated.

There are some notable findings relating to the density of 5-HTlAR and epileptogenicity in mice [38,39] and humans $[15,16]$. When considering studies involving human tissue, we must take into account that different regions may render other reaults This study differs from previous reports in several areas. It is the first study to addres the human hippocampus rather than the amygdala [16] or neocortical region [15]. Furthermore, we only included patients with HS. Ako, previous studies used multireceptor analysis with autoradiography as opposed to western blotting $[15,16]$. Therefore, eaution should be exercised when comparing our results with those from previous studies because of these significant methodological differences.

Concerning psychiatric comorbidities, our sample was very heterogeneous and included patients with TLE with and without psychiatric comorbidity. Some paticnts had mood disorders and others had psychosis, which led to the creation of smaller subgroups. For this reason, further conclusions about the possible relationship between psychiatric disorders and the density of 5-HTR were not posible. This represents a limitation of the current study bocause psychiatric disonders, especially mood disorders, represent a major concern in TLE-HS.

One must also consider that some of our patients received chronic treatment with SSRIs, which are known to affect serotoninergic transmission over a wide range of both pre- and post-synaptic roceptor subtypes that have a large spectrum of binding potential, which explains their proepileptic and antiepileptic effects [1,40-42]. Although the role of SSRIs is controversial, they seem to impact epileptogenesis $[1,41,43]$ Therefore, our results may reflect the potential impact of SSRIs.

In conclusion, we demonstrated that hippocampal 5-HTIAR density is associated with epilepsy duration in patients with TLE-HS. We hypothesize that this represents a potential regulatory enhanecment of endogenous serotonergic neurotransmiscion in response to prolonged and enduring epileptiform activity. This phenomenon, previously reported in animal studies, is now docunented in the hippocampal tissue of patients with pharmacoresistant TLE-HS.

\section{Acknowledgements}

We thank Bernando dos Santos for his statistical support. Prof. Kette D. Valente was supported by the National Council of Tochnological and Scientific
Development (CNPq) and Agency of the Sāo Paulo Rescarch Foundation (FAPESP).

\section{Disclosure of conflicts of interest}

The authors declare no financial or other confticts of interest.

\section{References}

1. Browning RA, Wood AV, Merrill MA, Dailey JW, Jobe PC. Finhanoment of the anticinivuleint effed of fluox. etine following blockad of S-HT1A receplors. Eur $J$ Phurnacel 1997; 336: 1-6.

2. Sistrick MA, Deiley JW, Jobe PC, Browning RA. Abnonnalities in 5-HT1A and 5-HT1B reopler binding in sevene-seisure genetically epplepsy-prone fats (GFPR. 9). Neuropharmerodogy 1996 ; $35: 111-118$

3. Deiley $\mathcal{W}$, Mishra PK, Ko KH, Penny JE, Jobe PC. Serolonergic abnonnalities in the central nerwous sysiem of seizure-naive genetically epilepsy-prone tatz. Life Sri $1992 ; 50$ 319-326.

4. Jobe PC, Dailey JW. Genetieally epilepsy-prone rals (GEPRs) in drug reserch. CNS Dng Rev 2000; ti: 241260.

5. Gough $\mathbb{R}$, Statnick M, Maning-Sinith $M$, ef of. Fetal raphe tranclatantes roduoe seisure severity in serolonindepleted GEPRs. NenraRepart 1966; 8: 341-346.

6. Filikovicky J, Gienter K, Bagdy G. A serotonin-1 A receptor agonist and $\mathrm{N}$-methyl-Daspariate reapior

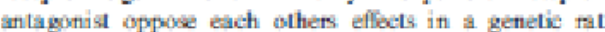
epalepry model. Neumasa Lefit 1999; 261 $89-92$.

7. Lu KT, Gean PW. Endogenous serotonin inhibits epaleptiform setivity in rall hippocampal CAl neurons via S-hydroxytryptaminie $1 \mathrm{~A}$ roceplor activation. Neurocience 1908 ; 860 729-737.

8. Wald $Y$, Nakimura $M$, Hackawa $H$, Yamaguchi $N$. Intra-hippocampal injection of s-hydroxy-2-(di-n-propybamino)tdralin (8-OH-DPAT) inhibils partial and generalined seivures induced by kindiling stimulation in cals. Newrasei Lert 1993; 159: 179-182.

9. Wada $Y$, Shiraishi I, Nakeamura M, Koshino $Y$. Role of serotonin reoplor subtypes in the developinent of amyg-

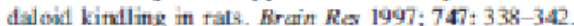

10. Martines $\mathrm{A}$, Finegeris $\mathrm{A}$, Gannon DM, ef af. The $\mathrm{S}=$ HT1A receplor and S-HT transporter in temporal bobe epilepay. Neursboy 2013; 80t: 1465-1471.

11. Aseem-Hilger E, Lanzenberger R, Savi M, ef af. Central servionin 1 A receptor binding in temporal lobe epilepsy: a [earbonyl-11 GWAY-1066 35 PET study. Epilepsy Behav 2010; 19: 467-473.

12. Didebi A, Rywlin P, Lothe A, er al. PET imaging of brain 5-HT1A receplors in the preoperative evaluation of temporal bite epilepsy. Binin 2008; 131: 2751-2764.

13. Gioyscehini G, Tocrek MT, Bonweisch R. et al. 5-HT 1A roeplors are reduoed in lemporal lobe epilepoy afler partisal-wol ume correction. I Nuel Med 2005; th: 1128 1135 .

14. 睡 umcke I, Coras $\mathrm{R}$, Myata H, Oukara C. Defining chinico-neuropaihologeal subiypes of mextal lanporal lobe epilepoy with hippocampal scicterosis. Brain Paihol 2012; 22: $902-411$. 


\section{ANEXO 3. ARTIGO PUBLICADO: EUROPEAN JOURNAL OF NEUROLOGY (2017), 24(4): 602 - 608}

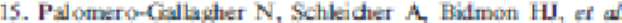

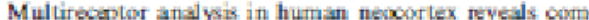
plex slterations of raxeptor ligand binding in foeal epilepsies. Finilepsia 2012; 53: 1987-1997

16. Graebenils $\mathrm{S}$, Kalo O, Speckmann EJ, et al. Interictil like network activily and reoeptor expression in the

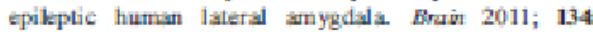
$2929-2947$

17. Yang $Z$, Liu $X$, Yin $Y$, Sun $S$, Deng $X$. Involvement of 5- $\mathrm{HT}_{7}$ raecpiors in the paihogenests of temporal lobe

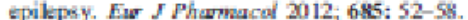

18. da Finseca NC, Jaxquiri HP, Tahib LL, ef al. Hip pocampal serotonin depletion is ralated to the presence of generalined tonic-elonic seizures, buil not to paychratrie disonders in patients with temporal bobe epilepsy.

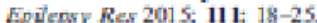

19. Kwan $\mathbf{P}$, Arzirianoglou A, Elerg AT, et af. Definition of drug resistant epilepsy: eonsensus proposal by the ad hose lask force of the ILAE commission on therapeuti. strateges. Errilasin 2010;51: 1069-1077.

20. Lowry OH, Rosbraigh NJ, Farr L, Randall RJ. Prolein measurement with the folin phenol reagent. I Bio Chem 1951; 193: 265-275.

21. Mahmood T, Yang PC. Western blot: technique, theory, and trouble shosting. $N$ Am $J$ Mad Sci $2012 ; 4: 429-434$

2. Mannova $Z$, Monoranu CM, Fetr $s$, Walitas $s$, Ginüblatl E. Region-specific regutation of the serolonin 2A receptor expreasion in development and againg in posi mortem human brain. Nenegathal Apgl Nenrabial $2015.41 \cdot 520-532$

23. Rocha L, Lorigadoe-Pedre L, Oroco-Sustex S, et at. Autoradiography revalk selketive changes in seroloni binding in neocortex of patiants with temponal bobe epolepsy. Prog Newapsychopharmacal Biol Psychiatry 2007 31: $1208-1218$.

24. Wang L, Ly Y, Deng W, et al. S-HT6 receptor recruit ment of mTOR moduleta serare tetivily in epilepry. Mal Neurebial 2015; 51: 1292-1299.

25. Jiang $X$, Xing $G$, Yang $C$, a al Sires impairs S-HT2A reoptor-matiated serotonerge facibiation of GABA release in juvenile rat basoliteral anygdal. Neurupoy chaphermacology 2009, 34: 410-423.

26. Speranre L, Chimbery A, Di Domenics M, af at The serolonin receplor 7 promotes neunie outgrowith vil ERK and Cdis signahing pathways. Neuropharnaelogy $2013 ; 67: 155-167$.

27. Liew CJ, Lim YM, Bonwelich R, at al. 18F-FCWAY and $1 \mathrm{gF}$ FDG PET in MRI-negative temporal bobe epilepsy. Epilensia 2009; 혜: 234-239.

25. Chugani DC, Chugani HT, Murik O, et al. Inaghing epileptogerac tubers in children with tuberous sclerosi complex using alpha-[1]C]methyl-L-tryptophan poxtront emisaion tomography An Nerod 1908; 44: $858-866$.

29. Trotier S, Evrard B, Vignal JP, Seanain JM, Chauvd P. The serotonergic innervation of the cerebral cortex in man and ils changes in focal cortical dysplaxis. Epilep.ny Res 1996; 25: 79-106.
30. Hoggert PV, Tiege XD, Vanderwinden JM, et al. Com paralive study of hippocampal neuronal low and in yiwi binding of 5-HTla recepiors in the $\mathrm{KA}$ moxlel of timbic epilepry in the rat. Fpilepsy Res 2001; 47: 127-139.

31. Gerber K, Fibkowsky J, Halasz P, Bagdy C. The 5HT1A ayonid S-OH-DPAT incresses the number of spike-wave discharges in a genetic rat model of absena. epilepry. Bruin Res 1998; 810 : 243-245

32. Jakus $R$, Giraf $M$, Juhas $G$, et al. 5-HT2C recoptor inhibit and S-HT1A roceptors activate the genaration of spike-wave discharger in à genetic rat model of absenge epilepsy. Exp Neurol 2003 184: $964-972$

33. Dailey JW, Reigel CE, Mishra PK, Jobe PC. Newsbiol oggy of seirure predtsposition in the genetically epilepsy. prone ral. Enilepsy Res 1989; 3: 3-17.

44. Perizic D, Laxe J, Jazvinical Jembred M, Swob Sto D. Stimulation of $5-\mathrm{HT}$ iA receptors incresses the sizure thresholl for picrotowin in mice. Fur I Phamara $2005 ; 527: 105-110$

35. Waianabe $\mathrm{K}$ A shby $\mathrm{CR}$ Jo Kataumon $\mathrm{H}$, Minabe $\gamma$. The efloct of the acule administration of various selas tive S-HT reoptor antagoniats on focal hippocampal seizures in freely-moving rais. Fue II Phanned 2000 ; 398 $239-246$.

36. Salgade-Comirariat D, Alkadhi KA. Senotonin in hihits epileptiform discharge by activation on S-HT1A reasp. tors in CA1 pyramidal neuronk. Neuropharnacolog. 1997; 36: $1705-1712$

37. Kim DS, Kim JE, Kwak SE, et al. Seirure activily selectively reduces 3-HT1A receptor immunereactivity in CAl interneurons in the hippocampus of seizure-prome gerbilx. Bruin Res 2007; 1154: 181-193.

35. Ciaribolli M, Tulka P, Samanin R, Verrami A. Stimula tion of 5-HT $1 \mathrm{~A}$ rocepiors in the dorsal hippocampus and inhibition of seizures induced by kainie scid in rals. Er I Phennacol 1996; 119: 813-818.

39. Lojex-Meraz ML, Gonzalez-Trujano ME, Neri-Bgzán L, Hong E, Rocha LL. 5-HT1A receptor asonists modify eqileptic setrures in three experimental models in

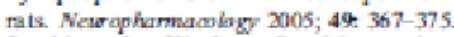

40. Sinolders L, Ginckers $\mathbb{R}$, Meurs A, ef af. Dinect entianoement of hippocampal dopanine or serolonin level as a phamacodynamie measure of combined antidepressant-antioonvuksant setion. Nenaphamaan? ogy 2008; 54: $1017-1028$.

41. Vermoesan K, Massie A, Smoklers I, Cinckers $\mathbb{R}$. The antidepresants citalopram and reboxeline reduoe seirure frequency in rats with ehronic epilepsy. Epilepsia 2012 53: $870-878$

42. Clinckers R, Sroblders L, Meurs A, Ebinger G, Midhothe Y. Antionvulsant action of hippocanjol dopemine and serotonin is independently modiated by $\mathrm{D}$ and $5-\mathrm{HI}$ receptors. I Neirachem 2004; 89. 834-843.

43. Yan QS, Jobe PC, Dailey JW. Evidence that a seroton-

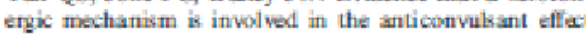
of flloosetine in ganetically eppilepsy-prone tals. Eir $J$ Phannercol 1994; 252: 105-112. 
ANEXO 4 -TABELA CARACTERIZAÇÃO PACIENTES - 5-HT1A

\begin{tabular}{|c|c|c|c|c|c|c|c|c|c|c|c|c|}
\hline Paciente & Sexo & $\begin{array}{l}\text { Idade na } \\
\text { cirurgia } \\
\text { (anos) }\end{array}$ & $\begin{array}{l}\text { Idade início } \\
\text { epilepsia } \\
\text { (anos) }\end{array}$ & $\begin{array}{l}\text { Duração da } \\
\text { epilepsia } \\
\text { (anos) }\end{array}$ & $\begin{array}{l}\text { Frequência } \\
\text { das crises }\end{array}$ & $\begin{array}{l}\text { História de } \\
\text { crises } \\
\text { febris }\end{array}$ & $\begin{array}{l}\text { História } \\
\text { de CTCG }\end{array}$ & $\begin{array}{l}\text { Frequência } \\
\text { CTOG }\end{array}$ & $\begin{array}{l}\text { História } \\
\text { de EME }\end{array}$ & FAES & $\begin{array}{c}\text { ISRS/ } \\
\text { Antipsicóticos }\end{array}$ & TP \\
\hline 4 & $\mathrm{Fe}$ & 40 & 5 & 35 & Me & $\cdot$ & + & E & - & LMT/TPM/PB & - & De \\
\hline 5 & $\mathrm{Fe}$ & 35 & 12 & 23 & Me & - & + & E & - & $\mathrm{CBZ} / \mathrm{LMT} / \mathrm{PB}$ & - & De \\
\hline 6 & $\mathrm{Fe}$ & 39 & 9 & 30 & $\mathrm{Me}$ & - & + & E & - & $\mathrm{CBZ/PHT}$ & - & De \\
\hline 7 & $M$ & 29 & 16 & 13 & $s$ & + & + & $E$ & - & CBZ/NPA/PB/BZD & SER/RISP & De \\
\hline 9 & $\mathrm{Fe}$ & 45 & 10 & 35 & $s$ & - & + & E & - & $\mathrm{OXC/PB}$ & - & A \\
\hline 10 & $M$ & 37 & 20 & 17 & $\mathrm{Me}$ & - & + & E & - & $\mathrm{CBZ}$ & - & P \\
\hline 11 & M & 27 & 5 & 22 & $\mathrm{Me}$ & + & + & E & - & $V P A / P B$ & - & P \\
\hline 12 & $\mathrm{Fe}$ & 43 & 8 & 36 & Me & - & + & $\mathrm{E}$ & - & $\mathrm{CBZ} / \mathrm{PB}$ & HAL & $\mathrm{P}$ \\
\hline 13 & $\mathrm{Fe}$ & 41 & 18 & 23 & D & - & + & Me & - & PHT/BZD & - & $\mathrm{P}$ \\
\hline 14 & $\mathrm{Fe}$ & 45 & 1 & 44 & $\mathrm{Me}$ & - & + & $E$ & - & PHT/LMT/BZD & RISP & $\mathrm{P}$ \\
\hline 15 & M & 44 & 21 & 23 & $s$ & - & + & E & - & CBZ/BZD & RISP & P \\
\hline 17 & $M$ & 35 & 9 & 26 & D & . & + & E & - & CBZ/BZD & . & $P$ \\
\hline 18 & M & 22 & 1 & 21 & $s$ & - & + & $E$ & + & $\mathrm{CBZ} / \mathrm{PB} / \mathrm{BZD}$ & - & N \\
\hline 20 & $M$ & 10 & 0.75 & 10 & $s$ & - & + & $\mathrm{Me}$ & - & $\mathrm{CBZ}$ & RISP & $\mathrm{N}$ \\
\hline 21 & $\mathrm{Fe}$ & 44 & 29 & 15 & Me & - & + & $\mathrm{Me}$ & - & CBZ & - & $\mathrm{N}$ \\
\hline 22 & $\mathrm{M}$ & 24 & 0.4 & 24 & $\mathrm{Me}$ & - & + & Me & + & $\mathrm{CBZ}$ & - & $\mathrm{N}$ \\
\hline 24 & $\mathrm{Fe}$ & 51 & 8 & 43 & $s$ & + & + & $E$ & - & $\mathrm{PHT} / \mathrm{TPM} / \mathrm{PB} / \mathrm{BZD}$ & - & $\mathrm{N}$ \\
\hline 25 & $\mathrm{Fe}$ & 38 & 0.75 & 37 & $\mathrm{Me}$ & + & + & Me & - & CBZ/BZD & - & $\mathrm{N}$ \\
\hline 27 & M & 42 & 1 & 41 & Me & - & + & $E$ & + & OXC/LMT/BZD & - & $\mathrm{N}$ \\
\hline 28 & $M$ & 47 & 12 & 35 & Me & - & + & Me & - & $\mathrm{CBZ} / \mathrm{PB}$ & - & $\mathrm{N}$ \\
\hline 29 & $\mathrm{Fe}$ & 33 & 21 & 12 & $s$ & - & + & $E$ & - & CBZ/BZD & - & N \\
\hline 30 & $\mathrm{Fe}$ & 41 & 14 & 27 & s & - & - & - & - & $\mathrm{PHT} / \mathrm{TPM} / \mathrm{PB}$ & SER & De \\
\hline 31 & M & 15 & 3 & 12 & s & + & - & - & - & $\mathrm{CBZ}$ & SER & De \\
\hline 32 & $\mathrm{Fe}$ & 34 & 11 & 23 & s & - & - & - & - & $\mathrm{CBZ} / \mathrm{NPA}$ & SER & De \\
\hline 33 & $\mathrm{Fe}$ & 43 & 12 & 29 & Me & + & - & - & - & $\mathrm{CBZ} / \mathrm{PB} / \mathrm{BZD}$ & SER & De \\
\hline 34 & $\mathrm{Fe}$ & 37 & 21 & 16 & Me & - & - & - & - & CBZ/BZD & FLX & De \\
\hline 35 & $\mathrm{Fe}$ & 41 & 14 & 27 & s & - & - & - & - & $C B Z / L M T / B Z D$ & $F L X$ & De \\
\hline 36 & $\mathrm{M}$ & 17 & 1 & 16 & Me & - & - & - & - & $\mathrm{CBZ} / \mathrm{TPM} / \mathrm{BZD}$ & SER/RISP/HAL & De \\
\hline 37 & $\mathrm{Fe}$ & 69 & 9 & 60 & $\mathrm{Me}$ & - & - & - & - & $\mathrm{CBZ} / \mathrm{PB}$ & - & $\mathrm{N}$ \\
\hline 39 & $\mathrm{Fe}$ & 13 & 5 & 8 & Me & - & - & - & - & $\mathrm{CBZ}$ & - & $\mathrm{N}$ \\
\hline 41 & M & 20 & 10 & 10 & $s$ & - & - & - & - & $\mathrm{CBZ} / \mathrm{PB}$ & - & N \\
\hline 42 & $M$ & 29 & 5 & 24 & Me & - & - & - & - & $\mathrm{CBZ} / \mathrm{NPA} / \mathrm{BZD}$ & - & $\mathrm{N}$ \\
\hline 43 & M & 50 & 16 & 34 & $\mathrm{Me}$ & - & - & - & - & $\mathrm{CBZ/LMT/PB/PHT}$ & - & N \\
\hline 44 & M & 18 & 1 & 17 & Me & - & - & - & . & CBZ & - & $\mathrm{N}$ \\
\hline
\end{tabular}


ANEXO 5. TABELA CARACTERIZAÇÃO PACIENTES - 5-HT2A

\begin{tabular}{|c|c|c|c|c|c|c|c|c|c|c|c|c|}
\hline Paciente & Sexo & $\begin{array}{c}\text { Idade na } \\
\text { cirurgia } \\
\text { (anos) }\end{array}$ & $\begin{array}{l}\text { Idade início } \\
\text { epilepsia } \\
\text { (anos) }\end{array}$ & $\begin{array}{c}\text { Duração da } \\
\text { epilepsia } \\
\text { (anos) }\end{array}$ & $\begin{array}{c}\text { Frequência } \\
\text { das crises }\end{array}$ & $\begin{array}{c}\text { História de } \\
\text { crises } \\
\text { febris }\end{array}$ & $\begin{array}{l}\text { História } \\
\text { de CTCG }\end{array}$ & $\begin{array}{l}\text { Frequência } \\
\text { CTCG }\end{array}$ & $\begin{array}{l}\text { História de } \\
\text { EME }\end{array}$ & FAEs & $\begin{array}{c}\text { ISRS/ } \\
\text { Antipsicóticos }\end{array}$ & TP \\
\hline 1 & $\mathrm{Fe}$ & 13 & 5 & 7 & $\mathrm{~s}$ & + & + & $E$ & . & $O X C / B Z D$ & . & De \\
\hline 4 & $\mathrm{Fe}$ & 40 & 5 & 35 & Me & - & + & $E$ & . & $\mathrm{LMT} / \mathrm{TPM} / \mathrm{PB}$ & . & $\mathrm{De}$ \\
\hline 5 & $\mathrm{Fe}$ & 35 & 12 & 23 & Me & . & + & $E$ & . & $\mathrm{CBZ} / \mathrm{LMT} / \mathrm{PB}$ & - & De \\
\hline 9 & $\mathrm{Fe}$ & 45 & 10 & 35 & $\mathrm{~s}$ & - & + & $\mathrm{E}$ & . & $\mathrm{OXC} / \mathrm{PB}$ & . & A \\
\hline 10 & M & 37 & 20 & 17 & Me & - & + & $\mathrm{E}$ & . & $\mathrm{CBZ}$ & - & $\mathrm{P}$ \\
\hline 11 & M & 27 & 5 & 22 & Me & + & + & $\mathrm{E}$ & . & $\mathrm{VPA} / \mathrm{PB}$ & - & $\mathrm{P}$ \\
\hline 12 & $\mathrm{Fe}$ & 43 & 8 & 35 & Me & . & + & $E$ & . & $\mathrm{CBZ} / \mathrm{PB}$ & HAL & $P$ \\
\hline 13 & $\mathrm{Fe}$ & 41 & 18 & 23 & $D$ & . & + & Me & . & PHT/BZD & - & $\mathrm{P}$ \\
\hline 14 & $\mathrm{Fe}$ & 45 & 1 & 44 & Me & - & + & $E$ & . & PHT/LMT/BZD & RISP & $P$ \\
\hline 17 & $\mathrm{M}$ & 35 & 9 & 26 & D & - & + & $\mathrm{E}$ & - & CBZ/BZD & - & $P$ \\
\hline 18 & M & 22 & 1 & 21 & s & - & + & $E$ & + & $\mathrm{CBZ} / \mathrm{PB} / \mathrm{BZD}$ & - & N \\
\hline 20 & M & 10 & 0.75 & 10 & s & - & + & Me & - & $\mathrm{CBZ}$ & RISP & N \\
\hline 22 & M & 24 & 0.4 & 24 & Me & - & + & Me & + & $\mathrm{CBZ}$ & - & N \\
\hline 24 & $\mathrm{Fe}$ & 51 & 8 & 43 & $\mathrm{~s}$ & + & + & $\mathrm{E}$ & . & $\mathrm{PHT} / \mathrm{TPM} / \mathrm{PB} / \mathrm{BZD}$ & - & $\mathrm{N}$ \\
\hline 25 & $\mathrm{Fe}$ & 38 & 0.75 & 37 & Me & + & + & Me & . & $\mathrm{CBZ} / \mathrm{BZD}$ & . & N \\
\hline 27 & $\mathrm{M}$ & 42 & 1 & 41 & Me & . & + & $E$ & + & OXC/LMT/BZD & - & N \\
\hline 28 & M & 47 & 12 & 35 & Me & - & + & Me & . & $\mathrm{CBZ} / \mathrm{PB}$ & - & $\mathrm{N}$ \\
\hline 29 & $\mathrm{Fe}$ & 33 & 21 & 12 & s & - & + & $E$ & - & $\mathrm{CBZ} / \mathrm{BZD}$ & - & $\mathrm{N}$ \\
\hline 30 & $\mathrm{Fe}$ & 41 & 14 & 27 & s & - & - & - & . & $\mathrm{PHT} / \mathrm{TPM} / \mathrm{PB}$ & SER & De \\
\hline 31 & M & 15 & 3 & 12 & s & + & . & . & . & $\mathrm{CBZ}$ & SER & De \\
\hline 32 & $\mathrm{Fe}$ & 34 & 11 & 23 & s & . & . & . & . & CBZNPA & SER & De \\
\hline 33 & $\mathrm{Fe}$ & 43 & 12 & 29 & Me & + & . & . & . & $\mathrm{CBZ} / \mathrm{PB} / \mathrm{BZD}$ & SER & De \\
\hline 34 & $\mathrm{Fe}$ & 37 & 21 & 16 & Me & . & . & . & . & $\mathrm{CBZ} / \mathrm{BZD}$ & FLX & De \\
\hline 35 & $\mathrm{Fe}$ & 41 & 14 & 27 & $\mathrm{~s}$ & - & . & . & - & CBZ/LMT/BD & $F D X$ & De \\
\hline 36 & M & 17 & 1 & 16 & Me & - & . & . & . & $\mathrm{CBZ} / \mathrm{TPM} / \mathrm{BZD}$ & SER/RISP/HAL & De \\
\hline 39 & $\mathrm{Fe}$ & 13 & 5 & 8 & Me & - & . & . & . & $\mathrm{CBZ}$ & - & N \\
\hline 41 & M & 20 & 10 & 10 & $\mathrm{~s}$ & - & - & - & . & $\mathrm{CBZ} / \mathrm{PB}$ & - & N \\
\hline 42 & $\mathrm{M}$ & 29 & 5 & 24 & Me & - & - & - & - & CBZNPA/BZD & . & $\mathrm{N}$ \\
\hline 43 & $\mathrm{M}$ & 50 & 16 & 34 & Me & - & - & . & . & CBZ/LMT/PB/PHT & . & $\mathrm{N}$ \\
\hline 44 & $\mathrm{M}$ & 18 & 1 & 17 & Me & - & - & - & - & $\mathrm{CBZ}$ & - & N \\
\hline
\end{tabular}


ANEXO 6. TABELA CARACTERIZAÇÃO PACIENTES - 5-HT6

\begin{tabular}{|c|c|c|c|c|c|c|c|c|c|}
\hline Paciente & Sexo & $\begin{array}{c}\text { Idade na } \\
\text { cirurgia } \\
\text { (anos) }\end{array}$ & $\begin{array}{l}\text { Idade início } \\
\text { epilepsia } \\
\text { (anos) }\end{array}$ & $\begin{array}{c}\text { Duração da } \\
\text { epilepsia } \\
\text { (anos) }\end{array}$ & $\begin{array}{l}\text { Frequência } \\
\text { das crises }\end{array}$ & $\begin{array}{c}\text { História de } \\
\text { crises } \\
\text { febris }\end{array}$ & $\begin{array}{l}\text { História } \\
\text { de CTCG }\end{array}$ & $\begin{array}{c}\text { Frequência } \\
\text { CTCG }\end{array}$ & $\begin{array}{l}\text { História } \\
\text { de EME }\end{array}$ \\
\hline 4 & $\mathrm{Fe}$ & 40 & 5 & 35 & Me & - & + & $E$ & - \\
\hline 5 & $\mathrm{Fe}$ & 35 & 12 & 23 & Me & - & + & $E$ & - \\
\hline 9 & $\mathrm{Fe}$ & 45 & 10 & 35 & $S$ & - & + & $E$ & - \\
\hline 13 & $\mathrm{Fe}$ & 41 & 18 & 23 & $D$ & - & + & Me & - \\
\hline 14 & $\mathrm{Fe}$ & 45 & 1 & 44 & $\mathrm{Me}$ & - & + & $E$ & - \\
\hline 18 & $M$ & 22 & 1 & 21 & $\mathrm{~S}$ & - & + & $E$ & + \\
\hline 20 & $M$ & 10 & 0.75 & 10 & $\mathrm{~S}$ & - & + & $\mathrm{Me}$ & - \\
\hline 24 & $\mathrm{Fe}$ & 51 & 8 & 43 & $S$ & + & + & $E$ & - \\
\hline 25 & $\mathrm{Fe}$ & 38 & 0.75 & 37 & Me & + & + & Me & - \\
\hline 27 & $M$ & 42 & 1 & 41 & Me & - & + & $E$ & + \\
\hline 31 & $M$ & 15 & 3 & 12 & $S$ & + & - & - & - \\
\hline 32 & $\mathrm{Fe}$ & 34 & 11 & 23 & $S$ & - & - & - & - \\
\hline 34 & $\mathrm{Fe}$ & 37 & 21 & 16 & Me & - & - & - & - \\
\hline 39 & $\mathrm{Fe}$ & 13 & 5 & 8 & $\mathrm{Me}$ & - & - & - & - \\
\hline 43 & $M$ & 50 & 16 & 34 & Me & - & - & - & - \\
\hline
\end{tabular}


ANEXO 7 - TABELA CARACTERIZAÇÃO PACIENTES - 5-HT7

\begin{tabular}{|c|c|c|c|c|c|c|c|c|c|c|c|c|}
\hline Paciente & Sexo & $\begin{array}{l}\text { Idade na } \\
\text { cirurgia } \\
\text { (anos) }\end{array}$ & $\begin{array}{l}\text { Idade início } \\
\text { epilepsia } \\
\text { (anos) }\end{array}$ & $\begin{array}{l}\text { Duração da } \\
\text { epilepsia } \\
\text { (anos) }\end{array}$ & $\begin{array}{l}\text { Frequência } \\
\text { das crises }\end{array}$ & $\begin{array}{c}\text { História de } \\
\text { crises } \\
\text { febris }\end{array}$ & $\begin{array}{l}\text { História } \\
\text { de CTCG }\end{array}$ & $\begin{array}{l}\text { Frequência } \\
\text { CTCG }\end{array}$ & $\begin{array}{l}\text { História de } \\
\text { EME }\end{array}$ & FAEs & $\begin{array}{c}\text { ISRS/ } \\
\text { Antipsicóticos }\end{array}$ & TP \\
\hline 4 & $\mathrm{Fe}$ & 40 & 5 & 35 & Me & . & + & E & - & LMT/TPM/PB & - & De \\
\hline 5 & $\mathrm{Fe}$ & 35 & 12 & 23 & Me & - & + & $E$ & - & $\mathrm{CBZ} / \mathrm{LMT} / \mathrm{PB}$ & - & De \\
\hline 6 & $\mathrm{Fe}$ & 39 & 9 & 30 & $\mathrm{Me}$ & - & + & E & - & $\mathrm{CBZ} / \mathrm{PHT}$ & - & De \\
\hline 9 & $\mathrm{Fe}$ & 45 & 10 & 35 & $s$ & - & + & E & - & $\mathrm{OXC/PB}$ & - & A \\
\hline 10 & M & 37 & 20 & 17 & $\mathrm{Me}$ & - & + & E & - & $\mathrm{CBZ}$ & - & $\mathrm{P}$ \\
\hline 11 & M & 27 & 5 & 22 & $\mathrm{Me}$ & + & + & E & - & VPA/PB & - & P \\
\hline 12 & $\mathrm{Fe}$ & 43 & 8 & 35 & Me & - & + & E & - & $\mathrm{CBZ} / \mathrm{PB}$ & HAL & $\mathrm{P}$ \\
\hline 13 & $\mathrm{Fe}$ & 41 & 18 & 23 & $D$ & - & + & $\mathrm{Me}$ & - & PHT/BZD & - & $\mathrm{P}$ \\
\hline 14 & $\mathrm{Fe}$ & 45 & 1 & 44 & $\mathrm{Me}$ & - & + & $E$ & - & PHT/LMT/BZD & RISP & P \\
\hline 15 & $M$ & 44 & 21 & 23 & $s$ & - & + & E & - & CBZ/BZD & RISP & $\mathrm{P}$ \\
\hline 17 & M & 35 & 9 & 26 & D & - & + & $E$ & - & $\mathrm{CBZ} / \mathrm{BZD}$ & - & $\mathrm{P}$ \\
\hline 20 & M & 10 & 0.75 & 10 & s & - & + & Me & - & CBZ & RISP & N \\
\hline 21 & $\mathrm{Fe}$ & 44 & 29 & 15 & Me & - & + & Me & - & $\mathrm{CBZ}$ & - & N \\
\hline 22 & $\mathrm{M}$ & 24 & 0.4 & 24 & Me & - & + & Me & + & $\mathrm{CBZ}$ & - & N \\
\hline 24 & $\mathrm{Fe}$ & 51 & 8 & 43 & $s$ & + & + & $E$ & - & PHT/TPM/PB/BZD & - & $\mathrm{N}$ \\
\hline 25 & $\mathrm{Fe}$ & 38 & 0.75 & 37 & $\mathrm{Me}$ & + & + & Me & - & CBZ/BZD & - & $\mathrm{N}$ \\
\hline 27 & M & 42 & 1 & 41 & Me & - & + & $E$ & + & OXC/LMT/BZD & - & N \\
\hline 28 & $M$ & 47 & 12 & 35 & Me & - & + & Me & - & $\mathrm{CBZ} / \mathrm{PB}$ & - & $\mathrm{N}$ \\
\hline 29 & $\mathrm{Fe}$ & 33 & 21 & 12 & $s$ & - & + & $E$ & - & $\mathrm{CBZ} / \mathrm{BZD}$ & - & N \\
\hline 30 & $\mathrm{Fe}$ & 41 & 14 & 27 & $s$ & - & - & . & - & PHT/TPM/PB & SER & De \\
\hline 31 & M & 15 & 3 & 12 & $s$ & + & - & - & - & CBZ & SER & De \\
\hline 32 & $\mathrm{Fe}$ & 34 & 11 & 23 & $s$ & - & - & - & - & $\mathrm{CBZ} / \mathrm{VPA}$ & SER & De \\
\hline 33 & $\mathrm{Fe}$ & 43 & 12 & 29 & Me & + & - & - & - & $\mathrm{CBZ} / \mathrm{PB} / \mathrm{BZD}$ & SER & De \\
\hline 34 & $\mathrm{Fe}$ & 37 & 21 & 16 & $\mathrm{Me}$ & - & - & - & - & CBZ/BZD & $\mathrm{FLX}$ & De \\
\hline 35 & $\mathrm{Fe}$ & 41 & 14 & 27 & $s$ & - & - & - & - & CBZ/LMT/BZD & $F L X$ & De \\
\hline 36 & $M$ & 17 & 1 & 16 & $\mathrm{Me}$ & - & - & - & - & $\mathrm{CBZ} / \mathrm{TPM} / \mathrm{BZD}$ & SER/RISP/HAL & De \\
\hline 37 & $\mathrm{Fe}$ & 69 & 9 & 60 & $\mathrm{Me}$ & - & - & - & - & CBZ/PB & $\cdot$ & N \\
\hline 39 & $\mathrm{Fe}$ & 13 & 5 & 8 & $\mathrm{Me}$ & - & - & . & - & $\mathrm{CBZ}$ & - & N \\
\hline 41 & M & 20 & 10 & 10 & $s$ & - & - & . & - & $\mathrm{CBZ} / \mathrm{PB}$ & - & $\mathrm{N}$ \\
\hline 42 & M & 29 & 5 & 24 & Me & - & - & - & - & CBZ/VPA/BZD & - & $\mathrm{N}$ \\
\hline 43 & M & 50 & 16 & 34 & Me & - & - & - & - & $\mathrm{CBZ} / \mathrm{LMT} / \mathrm{PB} / \mathrm{PHT}$ & - & $\mathrm{N}$ \\
\hline
\end{tabular}




\section{ANEXO 8- TABELA CARACTERIZAÇÃO PACIENTES - 5-HTT}

\begin{tabular}{|c|c|c|c|c|c|c|c|c|c|}
\hline Paciente & Sexo & $\begin{array}{c}\text { Idade na } \\
\text { cirurgia } \\
\text { (anos) }\end{array}$ & $\begin{array}{l}\text { Idade início } \\
\text { epilepsia } \\
\text { (anos) }\end{array}$ & $\begin{array}{c}\text { Duração da } \\
\text { epilepsia } \\
\text { (anos) }\end{array}$ & $\begin{array}{l}\text { Frequência } \\
\text { das crises }\end{array}$ & $\begin{array}{c}\text { História de } \\
\text { crises } \\
\text { febris }\end{array}$ & $\begin{array}{l}\text { História } \\
\text { de CTCG }\end{array}$ & $\begin{array}{l}\text { Frequência } \\
\text { CTCG }\end{array}$ & $\begin{array}{l}\text { História } \\
\text { de EME }\end{array}$ \\
\hline 4 & $\mathrm{Fe}$ & 40 & 5 & 35 & Me & - & + & $\mathrm{E}$ & - \\
\hline 5 & $\mathrm{Fe}$ & 35 & 12 & 23 & $\mathrm{Me}$ & - & + & $\mathrm{E}$ & - \\
\hline 6 & $\mathrm{Fe}$ & 39 & 9 & 30 & $\mathrm{Me}$ & - & + & $E$ & - \\
\hline 7 & $\mathrm{M}$ & 29 & 16 & 13 & $S$ & + & + & $\mathrm{E}$ & - \\
\hline 9 & $\mathrm{Fe}$ & 45 & 10 & 35 & $S$ & - & + & $\mathrm{E}$ & - \\
\hline 10 & $\mathrm{M}$ & 37 & 20 & 17 & Me & - & + & $\mathrm{E}$ & - \\
\hline 12 & $\mathrm{Fe}$ & 43 & 8 & 35 & Me & - & + & $\mathrm{E}$ & - \\
\hline 13 & $\mathrm{Fe}$ & 41 & 18 & 23 & $\mathrm{D}$ & - & + & Me & - \\
\hline 14 & $\mathrm{Fe}$ & 45 & 1 & 44 & Me & - & + & $\mathrm{E}$ & - \\
\hline 18 & $\mathrm{M}$ & 22 & 1 & 21 & $S$ & - & + & $E$ & + \\
\hline 20 & $\mathrm{M}$ & 10 & 0.75 & 10 & $S$ & - & + & Me & - \\
\hline 21 & $\mathrm{Fe}$ & 44 & 29 & 15 & $\mathrm{Me}$ & - & + & Me & - \\
\hline 24 & $\mathrm{Fe}$ & 51 & 8 & 43 & $S$ & + & + & $\mathrm{E}$ & - \\
\hline 25 & $\mathrm{Fe}$ & 38 & 0.75 & 37 & Me & + & + & $\mathrm{Me}$ & - \\
\hline 27 & $\mathrm{M}$ & 42 & 1 & 41 & $\mathrm{Me}$ & - & + & $\mathrm{E}$ & + \\
\hline 30 & $\mathrm{Fe}$ & 41 & 14 & 27 & $S$ & - & - & - & - \\
\hline 31 & $\mathrm{M}$ & 15 & 3 & 12 & $S$ & + & - & - & - \\
\hline 32 & $\mathrm{Fe}$ & 34 & 11 & 23 & $S$ & - & - & - & - \\
\hline 34 & $\mathrm{Fe}$ & 37 & 21 & 16 & $\mathrm{Me}$ & - & - & - & - \\
\hline 37 & $\mathrm{Fe}$ & 69 & 9 & 60 & $\mathrm{Me}$ & - & - & - & - \\
\hline 39 & $\mathrm{Fe}$ & 13 & 5 & 8 & $\mathrm{Me}$ & - & - & - & - \\
\hline 42 & $\mathrm{M}$ & 29 & 5 & 24 & $\mathrm{Me}$ & - & - & - & - \\
\hline 43 & $\mathrm{M}$ & 50 & 16 & 34 & $\mathrm{Me}$ & - & - & - & - \\
\hline 44 & $M$ & 18 & 1 & 17 & $\mathrm{Me}$ & - & - & - & - \\
\hline
\end{tabular}




\section{ANEXO 9 - ANÁLISES ESTATÍSTICAS}

- ANÁLISE ESTATÍSTICA 5-HT

$5 \mathrm{HT}{ }^{*} \mathrm{PD}$

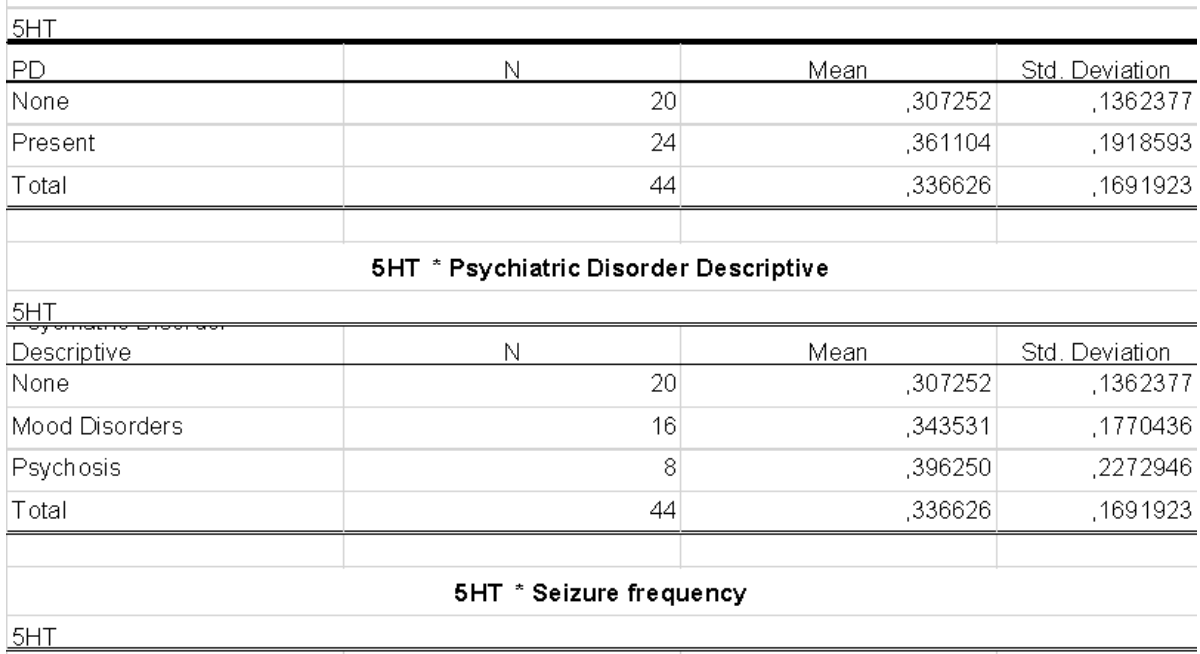

\begin{tabular}{|c|c|c|c|}
\hline Seizure frequency & $N$ & Mean & Std. Deviation \\
\hline Daily & 5 & .392758 & .1900508 \\
\hline Weekly & 16 & .290930 & .1886230 \\
\hline Monthly & 22 & .361421 & .1513500 \\
\hline Esporadic & 1 & .241600 & \\
\hline Total & 44 & .336626 &, 1691923 \\
\hline \multicolumn{4}{|c|}{$5 H T{ }^{*} \mathrm{GTC}$ frequency } \\
\hline $5 \mathrm{HT}$ & & & \\
\hline
\end{tabular}

\begin{tabular}{|l|r|r|r}
\hline GTC frequency & $N$ & Mean & Std. Deviation \\
\hline None & 15 & .408432 & .1612798 \\
\hline Monthly & 10 & .275160 & .0888362 \\
\hline Esporadic & 19 & .312287 & .1928383 \\
\hline Total & 44 & .336626 & .1691923 \\
\hline
\end{tabular}

$5 \mathrm{HT}{ }^{*} \mathrm{SE}$

\begin{tabular}{|c|c|c|c|}
\hline \multicolumn{4}{|l|}{$5 \mathrm{HT}$} \\
\hline SE & $N$ & Mean & Std. Deviation \\
\hline None & 38 & .339978 & .1717266 \\
\hline Present & 6 & .315392 &, 1653218 \\
\hline Total & 44 & .336626 & .1691923 \\
\hline \multicolumn{4}{|c|}{$5 \mathrm{HT}{ }^{*}$ Febrile Seizure } \\
\hline \multicolumn{4}{|l|}{$5 \mathrm{HT}$} \\
\hline Febrile Seizure & $N$ & Mean & Std. Deviation \\
\hline None & 35 & .355014 & .1747565 \\
\hline Present & 9 & .265117 & .1297636 \\
\hline Total & 44 & .336626 & .1691923 \\
\hline
\end{tabular}




\begin{tabular}{|c|c|c|c|c|}
\hline & \multicolumn{3}{|c|}{$5 \mathrm{HT}$} & \multirow[b]{2}{*}{ p-value } \\
\hline & $\mathrm{N}$ & Mean & SD & \\
\hline $\mathrm{PD}^{1}$ & & & & 0,334 \\
\hline None & 20 & 0,31 & 0,14 & \\
\hline Present & 24 & 0,36 & 0,19 & \\
\hline Psychiatric Disorder Descriptive ${ }^{2}$ & & & & 0,549 \\
\hline None & 20 & 0,31 & 0,14 & \\
\hline Mood Disorders & 16 & 0,34 & 0,18 & \\
\hline Psychosis & 8 & 0,40 & 0,23 & \\
\hline Seizure frequency ${ }^{2}$ & & & & 0,211 \\
\hline Daily & 5 & 0,39 & 0,19 & \\
\hline Weekly & 16 & 0,29 & 0,19 & \\
\hline Monthly & 22 & 0,36 & 0,15 & \\
\hline Esporadic & 1 & 0,24 & & \\
\hline$S^{1}$ & & & & 0,657 \\
\hline None & 38 & 0,34 & 0,17 & \\
\hline Present & 6 & 0,32 & 0,17 & \\
\hline GTC seizures ${ }^{1}$ & & & & 0,019 \\
\hline None & 15 & 0,41 & 0,16 & \\
\hline Present & 29 & 0,30 & 0,16 & \\
\hline GTC frequency ${ }^{2}$ & & & & 0,065 \\
\hline None & 15 & 0,41 & 0,16 & \\
\hline Monthly & 10 & 0,28 & 0,09 & \\
\hline Esporadic & 19 & 0,31 & 0,19 & \\
\hline Febrile Seizure ${ }^{1}$ & & & & 0,250 \\
\hline None & 35 & 0,36 & 0,17 & \\
\hline Present & 9 & 0,27 & 0,13 & \\
\hline Monotherapy ${ }^{1}$ & & & & 0,179 \\
\hline No & 34 & 0,32 & 0,17 & \\
\hline Yes & 10 & 0,38 & 0,16 & \\
\hline Polytherapy ${ }^{1}$ & & & & 0,302 \\
\hline No & 9 & 0,38 & 0,17 & \\
\hline Yes & 35 & 0,33 & 0,17 & \\
\hline
\end{tabular}

1Wilcoxon-Mann-Whitney test; ${ }^{2}$ Kruskal-Wallis test

Nonparametric Correlations

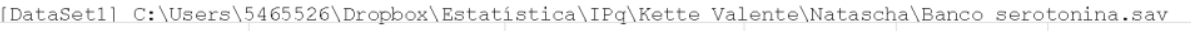

\begin{tabular}{|c|c|c|c|c|c|}
\hline \multicolumn{6}{|c|}{ Correlations } \\
\hline & & & $5 \mathrm{HT}$ & $\begin{array}{l}\text { Age of onset of } \\
\text { epilepsy (Vrs) }\end{array}$ & $\begin{array}{l}\text { Duration of } \\
\text { epilepsy (yrs) }\end{array}$ \\
\hline \multirow[t]{9}{*}{ Spearman's tho } & \multirow[t]{3}{*}{$5 \mathrm{HT}$} & Correlation Coefficient & 1,000 &,- 012 &,- 051 \\
\hline & & Sig. (2-tailed) & & 938 &, 745 \\
\hline & & $\mathrm{N}$ & 44 & 44 & 44 \\
\hline & \multirow[t]{3}{*}{ Age of onset of epilepsy (yrs) } & Correlation Coefficient &,- 012 & 1,000 &,- 091 \\
\hline & & Sig. (2-tailed) & ,938 & & .558 \\
\hline & & $\mathrm{N}$ & 44 & 44 & 44 \\
\hline & \multirow[t]{3}{*}{ Duration of epilepsy (yrs) } & Correlation Coefficient &,- 051 & $\begin{array}{ll}-, 091 \\
\end{array}$ & 1,000 \\
\hline & & Sig. (2-tailed) &, 745 &, 558 & \\
\hline & & $\mathrm{N}$ & 44 & 44 & 44 \\
\hline
\end{tabular}

\begin{tabular}{lrr}
\hline & \multicolumn{2}{c}{$5 \mathrm{HT}$} \\
& Corr. & p-value \\
\hline Age of onset of epilepsy (yrs) & $-0,012$ & 0,938 \\
Duration of epilepsy (yrs) & $-0,051$ & 0,745 \\
\hline
\end{tabular}

Spearman coefficient 
- GENERALIZED LINEAR MODELS 5-HT X FATORES CONFUSIONAIS

Model Information

\begin{tabular}{ll}
\hline Dependent Variable & 5HT \\
Probability Distribution & Gamma \\
Link Function & Log \\
\hline
\end{tabular}

Omnibus Test ${ }^{a}$

\begin{tabular}{rrrr} 
Likelihood Ratio Chi-Square & df & \multicolumn{2}{c}{ Sig. } \\
\hline 10,541 & 3 &, 014
\end{tabular}

Dependent Variable: $5 \mathrm{HT}$

Model: (Intercept), GTCseizures, ISRS, GTCseizures * ISRS

Compares the fitted model against the intercept-only model.

Tests of Model Effects

Type III

\begin{tabular}{lrrr} 
Source & Wald Chi-Square & df & \multicolumn{2}{c}{ Sig. } \\
\hline (Intercept) & 150,018 & 1 &, 000 \\
GTCseizures & 9,019 & 1 &, 003 \\
ISRS &, 321 & 1 &, 571 \\
GTCseizures * ISRS & 7,159 & 1 &, 007 \\
\hline
\end{tabular}

Dependent Variable: $5 \mathrm{HT}$

Model: (Intercept), GTCseizures, ISRS, GTCseizures * ISRS

\begin{tabular}{|c|c|c|c|c|c|c|c|}
\hline \multicolumn{8}{|c|}{ Estimated Marginal Means: GTC seizures* ISRS } \\
\hline \multicolumn{8}{|c|}{ Pairwise Comparisons } \\
\hline \multirow[b]{2}{*}{ (1) GTCseizures"ISRS } & \multirow[b]{2}{*}{ (J) GTCseizures ${ }^{\star} \mid S R S$} & \multirow[b]{2}{*}{ Mean Difference } & \multirow[b]{2}{*}{ Std Error } & \multirow[b]{2}{*}{$\mathrm{df}$} & \multirow[b]{2}{*}{$\mathrm{sig}$} & \multicolumn{2}{|c|}{$\begin{array}{l}\text { 95\% Wald Confidence Interval for } \\
\text { Difference }\end{array}$} \\
\hline & & & & & & Lower & Upper \\
\hline \multirow[t]{3}{*}[\text{[GTCseizures}=0]{$^{*}[$ ISR $S=0]$} & {$[\text { GTCseizures }=0]^{*}[$ [SRS $=1]$} & -.168184 & .0964379 & 1 & .081 & -.357199 & .020831 \\
\hline & [GTCseizures $=1$ ] $*$ [SRS $=0$ ] & .020448 & .0570307 & 1 & .720 & $-0,01330$ & .132226 \\
\hline & [GTCseizures $=1]^{*}[\mid \mathrm{SRS}=1]$ & $.165646^{\mathrm{a}}$ & .0716853 & 1 & .021 & .025146 & .306147 \\
\hline \multirow[t]{3}{*}{ [GTCseizures $=0]^{*}[$ [SR $S=1]$} & [GTCseizures $=0$ ] $[$ [ISRS $=0$ ] & .168184 & .0964379 & 1 & .081 & -.020831 & .357199 \\
\hline & [GTCseizures $=1]^{*}[\mid S R S=0$ ] & $.188632^{\mathrm{a}}$ & .0859824 & 1 & .028 & .020109 & .357154 \\
\hline & [GTCseizures $=1] *[\mid S R S=1]$ & $.333830^{\mathrm{a}}$ & .0963289 & 1 & .001 & .145029 & .522631 \\
\hline \multirow[t]{3}{*}{ [GTCseizures $=1]^{*}[$ ISR $S=0$ ] } & [GTCseizures $=0$ ] [ISRS $=0$ ] & -.020448 & .0570307 & 1 & .720 & -.132226 & .091330 \\
\hline & [GTCseizures=0]*[ISRS=1] & $-.188632^{\mathrm{a}}$ & .0859824 & 1 & .028 & -.357154 & -.020109 \\
\hline & [GTCseizures $=1] *[$ [SRS $=1]$ & $.145198^{\mathrm{a}}$ & .0568462 & 1 & .011 & .033782 & .256615 \\
\hline \multirow[t]{3}{*}{ [GTCseizures $=1]^{*}[$ ISR $S=1]$} & {$[$ GTCseizures $=0] *[$ [SRS $=0]$} & $-.165646^{\mathrm{a}}$ & .0716853 & 1 & .021 & -306147 & -.025146 \\
\hline & [GTCseizures $=0] *[$ [SRS $=1]$ & $-.333830^{\mathrm{a}}$ & .0963289 & 1 & .001 & -.522631 & -.145029 \\
\hline & [GTCseizures $=1$ ] $*$ [SRS $=0$ ] & $-.145198^{\mathrm{a}}$ & .0568462 & 1 & .011 & -256615 &,- 033782 \\
\hline
\end{tabular}

MEANS 


\begin{tabular}{ll|r|r|r}
\hline \multicolumn{1}{l}{ Report } \\
\hline 5HT & \multicolumn{1}{l}{} \\
\hline \hline GTC seizures & SSRS & N & Mean & Std. Deviation \\
\hline None & 0 & 8 &, 329946 &, 1430713 \\
& 1 & 7 &, 498130 &, 1386063 \\
& Total & 15 &, 408432 &, 1612798 \\
\hline Present & 0 & 27 &, 309498 &, 1649709 \\
& 1 & 2 &, 164300 &, 0505864 \\
& Total & 29 &, 299484 &, 1635998 \\
\hline Total & 0 & 35 &, 314172 &, 1584360 \\
& 1 & 9 &, 423946 &, 1907827 \\
& Total & 44 &, 336626 &, 1691923 \\
\hline \hline
\end{tabular}

\section{MEANS}

\begin{tabular}{l|r|r|r}
\hline $5 \mathrm{HT}$ & $\mathrm{N}$ & \multicolumn{1}{c}{ Mean } & \multicolumn{1}{c}{ Std. Deviation } \\
\hline \hline GTC frequency & 15 &, 408432 &, 1612798 \\
\hline None & 10 &, 275160 &, 0888362 \\
\hline Monthly & 19 &, 312287 &, 1928383 \\
\hline Esporadic & 44 &, 336626 &, 1691923 \\
\hline Total & & &
\end{tabular}

- ANÁLISE 5-HT1A E 5-HT2A

\begin{tabular}{|c|c|c|c|c|c|c|}
\hline \multirow[b]{2}{*}{0} & & \multicolumn{3}{|c|}{ 5HT1 } & \multicolumn{2}{|c|}{ SHT2A } \\
\hline & & Valid $\mathrm{N}$ & Mean & $\begin{array}{l}\text { Standard } \\
\text { Deviation }\end{array}$ & Mean & $\begin{array}{l}\text { Standard } \\
\text { Deviation }\end{array}$ \\
\hline \multirow[t]{3}{*}{ PD Descriptive } & None & 15 & $131.913,60$ & $96.990,13$ & $134.228,57$ & $100.340,55$ \\
\hline & Mood disorders & 12 & $120.709,33$ & 106286,67 & $174.512,89$ & $116.919,12$ \\
\hline & Psychosis & 7 & $53.586,00$ & $19.836,36$ & $116.496,00$ & $106.021,52$ \\
\hline \multirow[t]{2}{*}{ Gender } & Female & 18 & $127.582,00$ & $100.662,97$ & 142954,13 & $106.858,6$ \\
\hline & Male & 16 & $94.115,13$ & $84.585,08$ & $143.177,14$ & $107.709,27$ \\
\hline \multirow[t]{2}{*}{ Febrile Seizure } & Absent & 28 & $122.060,25$ & $99.315,35$ & $147.414,33$ & $107.400,20$ \\
\hline & Present & 6 & $64.105,17$ & $35.089,77$ & 122169,60 & $103.371,02$ \\
\hline \multirow[t]{2}{*}{ GTC seizures presence } & Absent & 13 & $131.670,00$ & $102.336,31$ & $150.972,67$ & $111.915,16$ \\
\hline & Present & 21 & $99.552,76$ & $88.066,25$ & $137.477,65$ & $103.568,7$ \\
\hline \multirow[t]{2}{*}{ SE } & Absent & 31 & $102.629,55$ & $86.604,89$ & $133.914,77$ & $98.200,86$ \\
\hline & Present & 3 & $206.934,00$ & $130.953,81$ & 222336,00 & $155.830,05$ \\
\hline \multirow[t]{2}{*}{ PD } & Absent & 15 & $127.764,00$ & $97.720,71$ & $129.533,54$ & $102.824,75$ \\
\hline & Present & 19 & $99.255,68$ & $90.849,43$ & $154.053,50$ & $109.329,96$ \\
\hline \multirow[t]{4}{*}{ Seizure fequency } & Daily & 2 & $39.312,00$ & $3.474,72$ & $165.024,00$ & $182.060,20$ \\
\hline & Weekly & 11 & $120.589,18$ & $111.935,91$ & $181.424,89$ & $129.489,4 \mathrm{~S}$ \\
\hline & Monthly & 20 & $116.789,40$ & $88.664,24$ & $124.568,47$ & $85.796,37$ \\
\hline & Esporadic & 1 & $61.425,00$ & & $68.256,00$ & \\
\hline \multirow[t]{6}{*}{ GTC frequency } & None & 13 & $131.670,00$ & $102.336,31$ & $150.972,67$ & $111.915,16$ \\
\hline & Daily & 0 & & & & \\
\hline & Weekly & 0 & & & & \\
\hline & Monthly & 6 & $94.731,00$ & 82046,74 & $186.624,00$ & $110.077,80$ \\
\hline & Esporadic & 15 & $101.481,47$ & $93.066,67$ & $117.000,00$ & $98.186,47$ \\
\hline & No GTC seizure & 0 & & & & \\
\hline \multirow[t]{2}{*}{ SSRI } & No & 26 & $112.297,50$ & 92342,63 & 132113,45 & $96.006,03$ \\
\hline & Yes & 8 & $110.322,88$ & $104.105,40$ & $177.470,86$ & $133.037,96$ \\
\hline \multirow[t]{2}{*}{ Antipsychotic } & No & 26 & $129.874,50$ & $100.096,46$ & $140.488,00$ & $109.173,02$ \\
\hline & Yes & 8 & $53.197,63$ & $19.339,65$ & 152928,00 & $97.704,61$ \\
\hline \multirow[t]{2}{*}{ Polytherapy } & No & 7 & $90.792,00$ & $79.242,12$ & $169.344,00$ & $116.055,50$ \\
\hline & Yes & 27 & $117.287,93$ & $97.564,58$ & $136.205,57$ & $104.034,47$ \\
\hline \multirow[t]{2}{*}{ Psychotropic } & No & 20 & $127.968,75$ & $99.958,23$ & $136.613,65$ & $100.947,5$ \\
\hline & Yes & 14 & $88.781,64$ & $81.609,18$ & 152196,67 & $115.177,7 \mathrm{~s}$ \\
\hline
\end{tabular}




\begin{tabular}{|c|c|c|c|c|c|c|c|}
\hline \multirow{3}{*}{ PDDescriptive } & \multirow[b]{2}{*}{$\mathbf{N}$} & \multicolumn{3}{|c|}{ 5भ1 } & \multicolumn{3}{|c|}{$5 H \pi 2 A$} \\
\hline & & Mean & SD & p-value & Mean & SD & p-value \\
\hline & & & & 0,177 & & & 0,440 \\
\hline None & 15 & $131.913,60$ & $96.990,13$ & & $134.228,57$ & $100.340,59$ & \\
\hline Mbod disorders & 12 & $120.709,33$ & $106.286,67$ & & $174.512,89$ & $116.919,12$ & \\
\hline Psydhosis & 7 & $53.586,00$ & $19.836,36$ & & $116.496,00$ & $106.021,52$ & \\
\hline Gender & & & & 0,152 & & & 0,861 \\
\hline Female & 18 & $127.582,00$ & $100.662,97$ & & 142954,13 & $106.858,64$ & \\
\hline Male & 16 & $94.115,13$ & $84.585,08$ & & $143.17 /, 14$ & $107.709,27$ & \\
\hline Febrile Seizure & & & & 0,258 & & & 0,908 \\
\hline Absent & & 122060,25 & $99.315,35$ & & $147.414,33$ & $107.400,20$ & \\
\hline Present & 6 & $64.105,17$ & $35.089,77$ & & 122169,60 & $103.371,02$ & \\
\hline GTC seizures presenœe & & & & 0,32 & & & 0,723 \\
\hline Absent & 13 & $131.6 \pi 0,00$ & 102336,31 & & $150.972,67$ & $111,915,16$ & \\
\hline Present & 2 & $99.552,76$ & $88.066,25$ & & $137.477,65$ & $103.568,74$ & \\
\hline SE & & & & 0,153 & & & 0,252 \\
\hline Absent & 31 & 102629,55 & $86.604,89$ & & $133.914,77$ & $98.200,86$ & \\
\hline Present & 3 & $206.934,00$ & $130.953,81$ & & 222336,00 & $155.830,09$ & \\
\hline PD & & & & 0,267 & & & 0,614 \\
\hline Absent & 15 & $127.764,00$ & $97.720,71$ & & $129.533,54$ & 102824,75 & \\
\hline Present & 19 & $99.255,68$ & $90.849,43$ & & $154.053,50$ & $109.389,96$ & \\
\hline Seizre frequency & & & & 0,268 & & & 0,761 \\
\hline Daily & & $39.312,00$ & $3.474,72$ & & $165.024,00$ & 182060,20 & \\
\hline weelly & & $120.589,18$ & $111.935,91$ & & $181.424,89$ & $129.489,49$ & \\
\hline Monthly & 20 & $116.789,40$ & $88.664,24$ & & $124.568,47$ & $85.795,37$ & \\
\hline Esporadic & & $61,425,00$ & & & $68.256,00$ & & \\
\hline GIC frequency & & & & 0,485 & & & 0,452 \\
\hline None & 13 & $131,6 \pi, 00$ & 102336,31 & & $150.972,67$ & $111.915,16$ & \\
\hline Monthly & & $94.731,00$ & 82046,74 & & $186.624,00$ & $110.077,80$ & \\
\hline Esporadic & 15 & 101. 481,47 & $93.066,67$ & & $117.000,00$ & $98.186,47$ & \\
\hline SSPI & & & & 0,626 & & & 0,400 \\
\hline No & 26 & 112297,50 & 92342,63 & & 132113,45 & $96.006,03$ & \\
\hline Yes & 8 & $110.322,88$ & $104.105,40$ & & $177.470,86$ & $133.037,96$ & \\
\hline Antipsychotic & & & & 0,028 & & & 0,590 \\
\hline No & & $129.874,50$ & $100.096,46$ & & $140.488,00$ & $109.173,02$ & \\
\hline Yes & 8 & $53.197,63$ & $19.339,65$ & & 152928,00 & $97.704,61$ & \\
\hline Polytherapy & & & & 0,406 & & & 0,686 \\
\hline No & & $90.792,00$ & $79.242,12$ & & $169.344,00$ & $116.055,50$ & \\
\hline Yes & 27 & $117.287,93$ & $97.564,58$ & & $136.205,57$ & $104.034,47$ & \\
\hline Psychotropic & & & & 0,234 & & & 0,707 \\
\hline No & 20 & $127.968,75$ & $99.958,23$ & & $136.613,65$ & $100.947,54$ & \\
\hline Yes & 14 & $88.781,64$ & $81.609,18$ & & 152196,67 & $115.17 / 79$ & \\
\hline
\end{tabular}

\begin{tabular}{|c|c|c|c|c|c|c|c|c|c|}
\hline \multicolumn{10}{|c|}{ Nonparametric Correlations } \\
\hline \multicolumn{10}{|c|}{ Correlations } \\
\hline \multirow[t]{3}{*}{ Spearman's rho } & & & & & & & & & \\
\hline & \multicolumn{3}{|c|}{$5 \mathrm{HT} 1$} & \multicolumn{3}{|c|}{$5 \mathrm{HT} 2 \mathrm{~A}$} & \multicolumn{3}{|c|}{$5 \mathrm{HT}$} \\
\hline & $\mathrm{N}$ & $\begin{array}{l}\text { Correlation } \\
\text { Coefficient }\end{array}$ & Sig. (2-tailed) & $\mathrm{N}$ & $\begin{array}{l}\text { Correlation } \\
\text { Coefficient }\end{array}$ & Sig. (2-tailed) & $\mathrm{N}$ & $\begin{array}{l}\text { Correlation } \\
\text { Coefficient }\end{array}$ & $\begin{array}{l}\text { Sig. (2- } \\
\text { tailed) }\end{array}$ \\
\hline $5 \mathrm{HT} 1$ & 34 & 1,000 & & 29 & 0,484 & 0,008 & 34 & $-0,080$ & 0,655 \\
\hline $5 \mathrm{HT} 2 \mathrm{~A}$ & 29 & 0,484 & 0,008 & 29 & 1,000 & & 29 & $-0,319$ & 0,092 \\
\hline $5 \mathrm{HT}$ & 34 & $-0,080$ & 0.655 & 29 & $-0,319$ & 0,092 & 34 & 1,000 & \\
\hline Age at surgery (yrs) & 34 & 0,166 & 0,347 & 29 & $-0,109$ & 0,574 & 34 & $-0,206$ & 0,241 \\
\hline Age of onset of epilepsy (yrs) & 34 & $-0,197$ & 0,265 & 29 & $-0,175$ & 0,363 & 34 & $-0,081$ & 0,648 \\
\hline Duration of epilepsy (yrs) & 34 & 0,354 & 0,040 & 29 & $-0,069$ & 0,724 & 34 & $-0,027$ & 0,879 \\
\hline
\end{tabular}

\begin{tabular}{lrrrr}
\hline & \multicolumn{2}{c}{ 5HT1 } & \multicolumn{2}{c}{ 5HT2A } \\
& Corelation & p-value & Corelation & p-value \\
\hline 5HT2A & 0,484 & 0,008 & & \\
5HT & $-0,080$ & 0,655 & $-0,319$ & 0,092 \\
Age at surgery (yrs) & 0,166 & 0,347 & $-0,109$ & 0,574 \\
Age of onset of epilepsy (yrs) & $-0,197$ & 0,265 & $-0,175$ & 0,363 \\
Duration of epilepsy (yrs) & 0,354 & 0,040 & $-0,069$ & 0,724 \\
\hline
\end{tabular}

Spearman coefficient 
- GENERALIZED LINEAR MODELS 5-HT1A X FATORES CONFUSIONAIS

\begin{tabular}{|c|c|c|c|}
\hline \multicolumn{2}{|c|}{ Model Information } & & \\
\hline Dependent Variable & $5 \mathrm{HT} 1$ & & \\
\hline Probability Distribution & Gamma & & \\
\hline Link Function & $\log$ & & \\
\hline \multicolumn{4}{|c|}{ Goodness of Fit ${ }^{\mathrm{a}}$} \\
\hline & Value & df & Value/df \\
\hline Deviance & 13,277 & 31 & 0,428 \\
\hline Scaled Deviance & 36,060 & 31 & \\
\hline Pearson Chi-Square & 13,961 & 31 & 0,450 \\
\hline Scaled Pearson Chi-Square & 37,917 & 31 & \\
\hline Log Likelihood $^{\mathrm{b}}$ & $-418,901$ & & \\
\hline Akaike's In formation Criterion (AIC) & 845,802 & & \\
\hline $\begin{array}{l}\text { Finite Sample Corrected AIC } \\
\text { (AICC) }\end{array}$ & 847,182 & & \\
\hline $\begin{array}{l}\text { Bayesian Information Criterion } \\
\text { (BIC) }\end{array}$ & 851,908 & & \\
\hline Consistent AIC (CAIC) & 855,908 & & \\
\hline
\end{tabular}

Dependent Variable: $5 \mathrm{HT} 1$

a. Information criteria are in smaller-is-better form.

b. The full log likelihood function is displayed and used in computing information criteria.

\section{Omnibus Test ${ }^{\mathrm{a}}$}

\begin{tabular}{|c|c|c|c|}
\hline Likelihood Ratio Chi-Square & df & Sig. & \\
\hline 13,705 & 2 & 0,001 & \\
\hline \multicolumn{3}{|c|}{$\begin{array}{l}\text { Dependent Variable: } 5 \mathrm{HT} 1 \\
\text { Model: (Intercept), Antipsychotic, Duration }\end{array}$} & \\
\hline \multicolumn{4}{|c|}{ a. Compares the fitted model against the intercept-only model. } \\
\hline \multicolumn{4}{|c|}{ Tests of Model Effe cts } \\
\hline & \multicolumn{3}{|c|}{ Type III } \\
\hline Source & $\begin{array}{c}\text { Likelihood Ratio } \\
\text { Chi-Square }\end{array}$ & df & Sig. \\
\hline (Intercept) & 182,180 & 1 & 0,000 \\
\hline Antipsychotic & 8,874 & 1 & 0,003 \\
\hline Duration & 4,956 & 1 & 0,026 \\
\hline
\end{tabular}

\begin{tabular}{|c|c|c|c|c|c|c|c|c|c|c|}
\hline \multicolumn{11}{|c|}{ Parameter Estimates } \\
\hline \multirow[b]{2}{*}{ Parameter } & \multirow[b]{2}{*}{ B } & \multirow[b]{2}{*}{ Std. Error } & \multicolumn{2}{|c|}{ Interval } & \multicolumn{3}{|c|}{ Hypothesis Test } & \multirow[b]{2}{*}{$\operatorname{Exp}(B)$} & \multicolumn{2}{|c|}{ Confidence Interval for } \\
\hline & & & Lower & Upper & $\begin{array}{l}\text { Wald Chi- } \\
\text { Square }\end{array}$ & df & Sig. & & Lower & Upper \\
\hline (Intercept) & 11,196 & 0,2767 & 10,642 & 11,756 & 1636,789 & 1 & 0,000 & 72839,959 & 41872,489 & \#\#\#\#曲) \\
\hline Antipsychotic & $-0,842$ & 0,2464 & $-1,319$ & $-0,323$ & 11,692 & 1 & 0,001 & 0,431 & 0,267 & 0,724 \\
\hline Duration & 0,021 & 0,0096 & 0,003 & 0,041 & 4,837 & 1 & 0,028 & 1,021 & 1,003 & 1,042 \\
\hline (Scale) & $.368^{a}$ & 0,0844 & 0,242 & 0,595 & & & & & & \\
\hline
\end{tabular}


- ANÁLISE ESTATÍSTICA 5-HT7

\begin{tabular}{|c|c|c|c|c|}
\hline & & & $5 \mathrm{HT} 7$ & \\
\hline & & Valid N & Mean & $\begin{array}{l}\text { Standard } \\
\text { Deviation }\end{array}$ \\
\hline Gender & Female & 18 & 120874 & 83590 \\
\hline & Male & 13 & 117098 & 95466 \\
\hline Seizure frequency & 0 & 1 & 109475 & \\
\hline & Daily & 1 & 200100 & \\
\hline & Weekly & 9 & 148867 & 92179 \\
\hline & Monthly & 19 & 105877 & 86791 \\
\hline & Sporadic & 1 & 36975 & \\
\hline GTC presence & None & 12 & 94594 & 83473 \\
\hline & Present & 19 & 134888 & 88088 \\
\hline GTC frequency & None & 12 & 94594 & 83473 \\
\hline & Daily & 0 & & \\
\hline & Weekly & 0 & & \\
\hline & Monthly & 6 & 100050 & 81528 \\
\hline & Sporadic & 13 & 150967 & 89347 \\
\hline SE & None & 29 & 121242 & 88552 \\
\hline & Present & 2 & 90988 & 83562 \\
\hline Febrile Seizure & None & 26 & 127006 & 87894 \\
\hline & Present & 5 & 79170 & 79887 \\
\hline Presence Psychiatric Disorder & None & 13 & 120015 & 81531 \\
\hline & Present & 18 & 118767 & 93456 \\
\hline PSYCHOTROPIC & None & 18 & 124700 & 86569 \\
\hline & Present & 13 & 111800 & 91104 \\
\hline SSRI & None & 24 & 129080 & 86749 \\
\hline & Present & 7 & 85726 & 86590 \\
\hline Antypsychotic & None & 24 & 118326 & 85385 \\
\hline & Present & 7 & 122597 & 100395 \\
\hline Type of Psychiatric Disorder & None & 13 & 120015 & 81531 \\
\hline & Mood disorders & 11 & 89946 & 84903 \\
\hline & Psychosis & 7 & 164057 & 93895 \\
\hline Polytherapy & None & 7 & 111132 & 95226 \\
\hline & Present & 24 & 121670 & 86790 \\
\hline
\end{tabular}

\begin{tabular}{|c|c|c|c|}
\hline \multicolumn{4}{|c|}{$5 \mathrm{HT7}{ }^{*}$ Seizure frequency } \\
\hline $5 \mathrm{HT} 7$ & & & \\
\hline Seizure frequency & $\mathrm{N}$ & Mean & Std. Deviation \\
\hline $\begin{array}{ll}\text { Daily } \\
\end{array}$ & 2 & 154787,50 & 64081,552 \\
\hline Weekly & 9 & 148866,67 & 92179,124 \\
\hline Monthly & 19 & 105876,58 & 86790,879 \\
\hline Sporadic & 1 & 36975,00 & \\
\hline Total & 31 & 119290,48 & 87227,211 \\
\hline
\end{tabular}

\begin{tabular}{lrrrr}
\hline & \multicolumn{2}{c}{$5 \mathrm{HT7}$} \\
& N & Mean & SD & p-value \\
\hline Seizure frequency & & & & $0,066^{2}$ \\
Daily & 2 & 154788 & 64082 & \\
Weekly & 9 & 148867 & 92179 & \\
Monthly & 19 & 105877 & 86791 & \\
Sporadic & 1 & 36975 & &
\end{tabular}

${ }^{2}$ Kruskal-Wallis Test 


\begin{tabular}{|c|c|c|c|c|}
\hline \multirow{3}{*}{ Gender } & \multicolumn{2}{|r|}{$5 \mathrm{HT7}$} & \multirow[b]{2}{*}{ SD } & \multirow[b]{2}{*}{ P-value } \\
\hline & $\mathrm{N}$ & Mean & & \\
\hline & & & & $0,562^{1}$ \\
\hline Female & 18 & 120874 & 83590 & \\
\hline Male & 13 & 117098 & 95466 & \\
\hline Seizure frequency & & & & $0,057^{3}$ \\
\hline Daily & 1 & 200100 & & \\
\hline Weekly & 9 & 148867 & 92179 & \\
\hline Monthly & 19 & 105877 & 86791 & \\
\hline Sporadic & 1 & 36975 & & \\
\hline GTC presence & & & & $0,320^{1}$ \\
\hline None & 12 & 94594 & 83473 & \\
\hline Present & 19 & 134888 & 88088 & \\
\hline GTC frequency & & & & $0,136^{3}$ \\
\hline None & 12 & 94594 & 83473 & \\
\hline Monthly & 6 & 100050 & 81528 & \\
\hline Sporadic & 13 & 150967 & 89347 & \\
\hline SE & & & & $0,469^{1}$ \\
\hline None & 29 & 121242 & 88552 & \\
\hline Present & 2 & 90988 & 83562 & \\
\hline Febrile Seizure & & & & $0,133^{1}$ \\
\hline None & 26 & 127006 & 87894 & \\
\hline Present & 5 & 79170 & 79887 & \\
\hline Presence Psychiatric Disorder & & & & $0,857^{1}$ \\
\hline None & 13 & 120015 & 81531 & \\
\hline Present & 18 & 118767 & 93456 & \\
\hline PSYCHOTROPIC & & & & $0,873^{1}$ \\
\hline None & 18 & 124700 & 86569 & \\
\hline Present & 13 & 111800 & 91104 & \\
\hline SSRI & & & & $0,333^{1}$ \\
\hline None & 24 & 129080 & 86749 & \\
\hline Present & 7 & 85726 & 86590 & \\
\hline Antypsychotic & & & & $0,943^{1}$ \\
\hline None & 24 & 118326 & 85385 & \\
\hline Present & 7 & 122597 & 100395 & \\
\hline Type of Psychiatric Disorder & & & & $0,306^{2}$ \\
\hline None & 13 & 120015 & 81531 & \\
\hline Mood disorders & 11 & 89946 & 84903 & \\
\hline Psychosis & 7 & 164057 & 93895 & \\
\hline Polytherapy & & & & $0,464^{1}$ \\
\hline None & 7 & 111132 & 95226 & \\
\hline Present & 24 & 121670 & 86790 & \\
\hline
\end{tabular}

\begin{tabular}{|c|c|c|c|}
\hline \multicolumn{2}{|c|}{ Nonparametric Correlations } & & \\
\hline \multicolumn{4}{|c|}{ Correlations } \\
\hline \multirow{3}{*}{$\begin{array}{l}\text { Spearman's rho } \\
5 \mathrm{HT} 7\end{array}$} & & & \\
\hline & & & \\
\hline & $\begin{array}{l}\text { Correlation } \\
\text { Coefficient }\end{array}$ & Sig. (2-tailed) & $\mathrm{N}$ \\
\hline Age at surgery (yrs) & 0,325 & 0,074 & 31 \\
\hline Age of onset of epilepsy (yrs) & 0,334 & 0,067 & 31 \\
\hline Epilepsy Duration & 0,144 & 0,439 & 31 \\
\hline $5 \mathrm{HT}$ & 0,005 & 0,979 & 31 \\
\hline
\end{tabular}




\begin{tabular}{lrrr}
\hline & & \multicolumn{2}{c}{$5 \mathrm{HT7}$} \\
& $\mathrm{N}$ & Correlation & P-value \\
\hline Age at surgery (yrs) & 31 & 0,325 & 0,074 \\
Age of onset of epilepsy (yrs) & 31 & 0,334 & 0,067 \\
Epilepsy Duration & 31 & 0,144 & 0,439 \\
5HT & 31 & 0,005 & 0,979 \\
\hline
\end{tabular}

Spearman correlation

\section{ANÁLISE ESTATÍSTICA 5-HT6 E SERT}

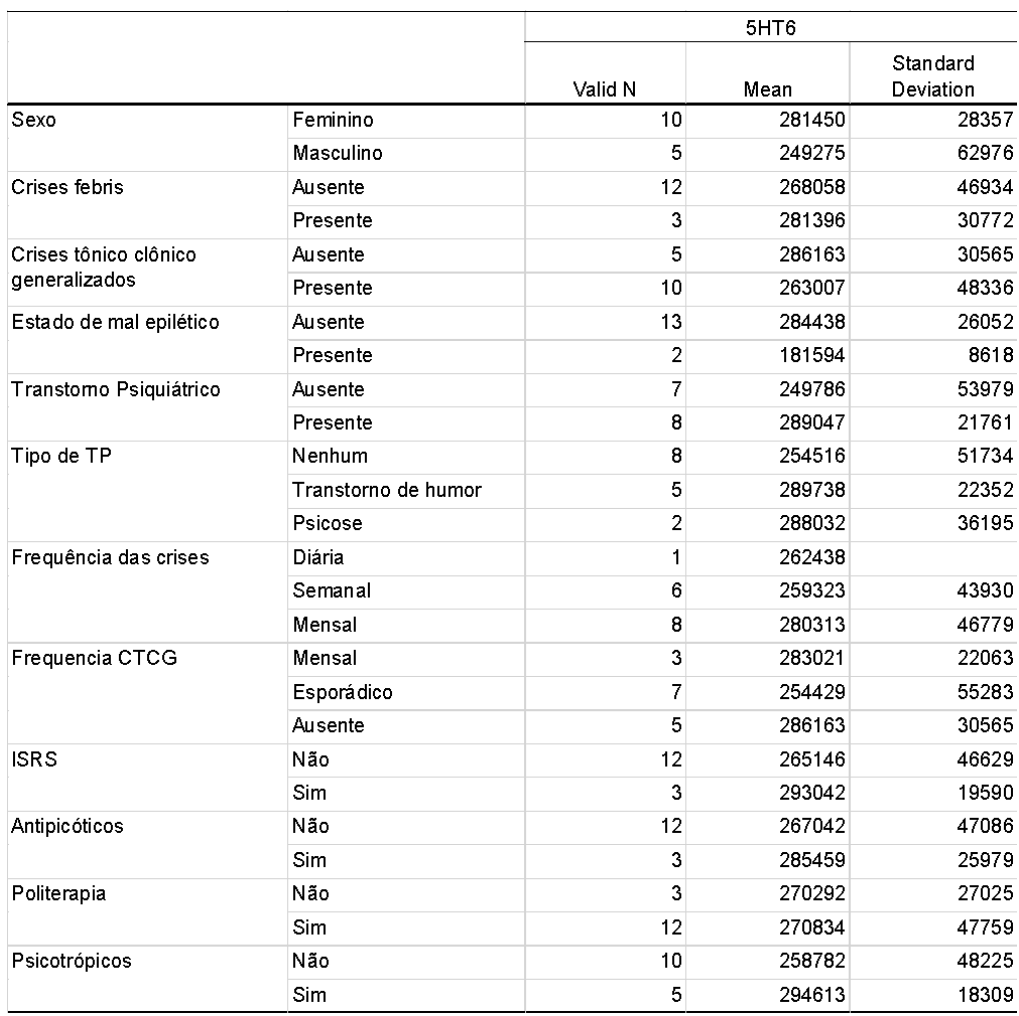




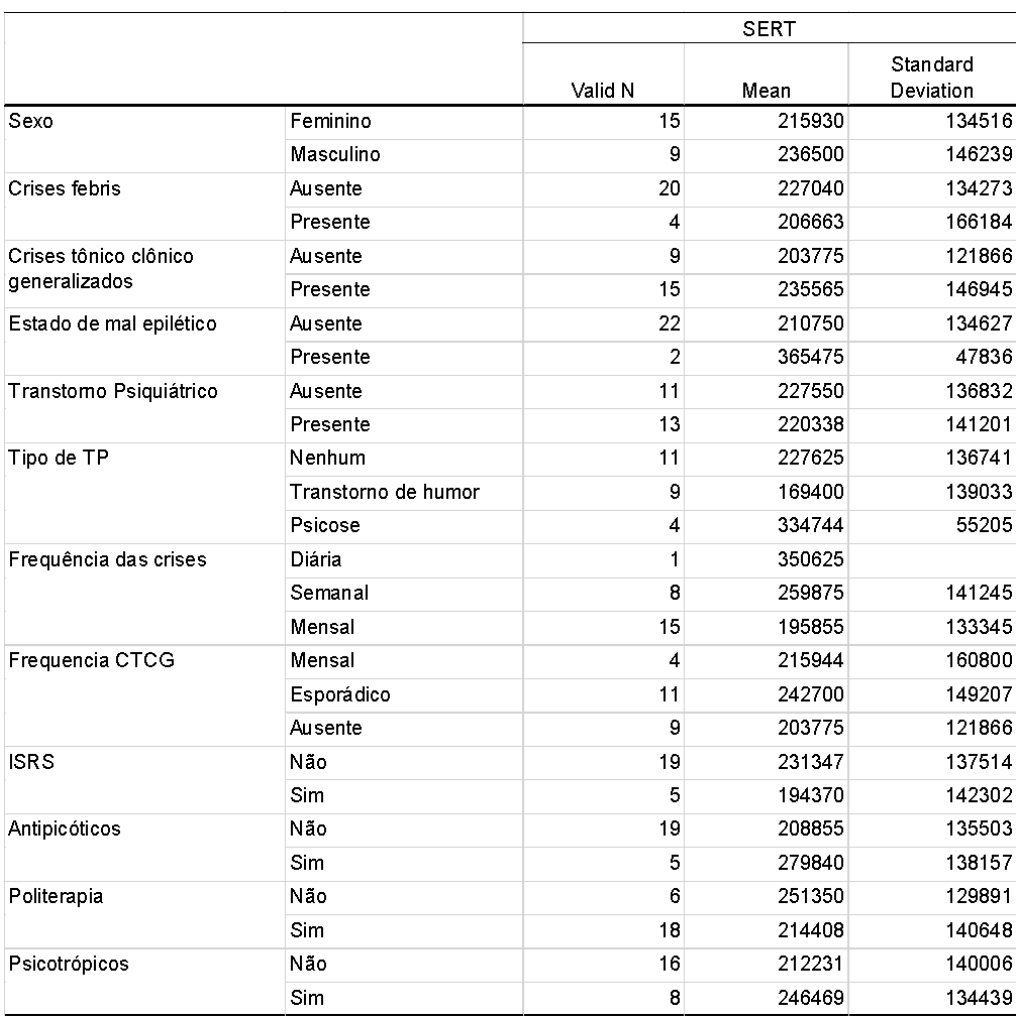




\begin{tabular}{|c|c|c|c|c|c|c|c|c|}
\hline & \multicolumn{3}{|c|}{ SERT } & \multirow[b]{2}{*}{$p$-value } & \multicolumn{3}{|c|}{$5 \mathrm{HT} 6$} & \multirow[b]{2}{*}{$\mathrm{p}$-value } \\
\hline & $\mathrm{N}$ & Mean & SD & & $\mathbf{N}$ & Mean & SD & \\
\hline Sexo & & & & $0,551^{1}$ & & & & $0,462^{1}$ \\
\hline Feminino & 15 & 215930 & 134516 & & 10 & 281450 & 28357 & \\
\hline Masculino & 9 & 236500 & 146239 & & 5 & 249275 & 62976 & \\
\hline Crises febris & & & & $0,614^{1}$ & & & & $0,885^{1}$ \\
\hline Ausente & 20 & 227040 & 134273 & & 12 & 268058 & 46934 & \\
\hline Presente & 4 & 206663 & 166184 & & 3 & 281396 & 30772 & \\
\hline Crises tônico clônico generalizados & & & & $0,905^{1}$ & & & & $0,358^{1}$ \\
\hline Ausente & 9 & 203775 & 121866 & & 5 & 286163 & 30565 & \\
\hline Presente & 15 & 235565 & 146945 & & 10 & 263007 & 48336 & \\
\hline Estado de mal epilético & & & & $0,174^{1}$ & & & & $0,027^{1}$ \\
\hline Ausente & 22 & 210750 & 134627 & & 13 & 284438 & 26052 & \\
\hline Presente & 2 & 365475 & 47836 & & 2 & 181594 & 8618 & \\
\hline Transtorno Psiquiátrico & & & & $0,602^{1}$ & & & & $0,105^{1}$ \\
\hline Ausente & 11 & 227550 & 136832 & & 7 & 249786 & 53979 & \\
\hline Presente & 13 & 220338 & 141201 & & 8 & 289047 & 21761 & \\
\hline Tipo de TP & & & & $0,128^{2}$ & & & & $0,318^{2}$ \\
\hline Nenhum & 11 & 227625 & 136741 & & 8 & 254516 & 51734 & \\
\hline Transtorno de humor & 9 & 169400 & 139033 & & 5 & 289738 & 22352 & \\
\hline Psicose & 4 & 334744 & 55205 & & 2 & 288032 & 36195 & \\
\hline Frequência das crises & & & & $0,250^{3}$ & & & & $0,176^{3}$ \\
\hline Diária & 1 & 350625 & & & 1 & 262438 & & \\
\hline Semanal & 8 & 259875 & 141245 & & 6 & 259323 & 43930 & \\
\hline Mensal & 15 & 195855 & 133345 & & 8 & 280313 & 46779 & \\
\hline Frequencia CTCG & & & & $0,871^{3}$ & & & & $0,589^{3}$ \\
\hline Mensal & 4 & 215944 & 160800 & & 3 & 283021 & 22063 & \\
\hline Esporádico & 11 & 242700 & 149207 & & 7 & 254429 & 55283 & \\
\hline Ausente & 9 & 203775 & 121866 & & 5 & 286163 & 30565 & \\
\hline ISRS & & & & $0,434^{1}$ & & & & $0,279^{1}$ \\
\hline Não & 19 & 231347 & 137514 & & 12 & 265146 & 46629 & \\
\hline Sim & 5 & 194370 & 142302 & & 3 & 293042 & 19590 & \\
\hline Antipicóticos & & & & $0,374^{1}$ & & & & $0,516^{1}$ \\
\hline Não & 19 & 208855 & 135503 & & 12 & 267042 & 47086 & \\
\hline Sim & 5 & 279840 & 138157 & & 3 & 285459 & 25979 & \\
\hline Politerapia & & & & $0,571^{1}$ & & & & $0,665^{1}$ \\
\hline Não & 6 & 251350 & 129891 & & 3 & 270292 & 27025 & \\
\hline Sim & 18 & 214408 & 140648 & & 12 & 270834 & 47759 & \\
\hline Psicotrópicos & & & & $0,646^{1}$ & & & & $0,086^{1}$ \\
\hline Não & 16 & 212231 & 140006 & & 10 & 258782 & 48225 & \\
\hline Sim & 8 & 246469 & 134439 & & 5 & 294613 & 18309 & \\
\hline
\end{tabular}

'Wilcoxon-Mann-Whitney Test; ${ }^{2}$ Kruskal-Wallis Test; ${ }^{3}$ Jonckheere-Terpstra Test

Nonparametric Correlations

\begin{tabular}{|l|r|r|r|}
\hline \multicolumn{2}{|c|}{ Correlations } \\
\hline $\begin{array}{l}\text { Spearman's rho } \\
\text { 5HT6 }\end{array}$ & \multicolumn{2}{c|}{} \\
\hline \hline & Correlation Coefficient & Sig. (2-tailed) & $\mathrm{N}$ \\
\hline 5HT & $-0,066$ & 0,815 & 15 \\
\hline Idade na cirurgia & 0,169 & 0,547 & 15 \\
\hline Idade de início & 0,273 & 0,325 & 15 \\
\hline Duração epilepsia (anos) & 0,081 & 0,775 & 15 \\
\hline
\end{tabular}




\begin{tabular}{|c|c|c|c|}
\hline \multicolumn{4}{|c|}{ Nonparametric Correlations } \\
\hline \multicolumn{4}{|c|}{ Correlations } \\
\hline \multicolumn{4}{|l|}{$\begin{array}{l}\text { Spearman's rho } \\
\text { SERT }\end{array}$} \\
\hline & Correlation Coefficient & Sig. (2-tailed) & $\mathrm{N}$ \\
\hline$\overline{5 \mathrm{HT}}$ & $-0,087$ & 0,688 & 24 \\
\hline Idade na cirurgia & $-0,020$ & 0,927 & 24 \\
\hline Idade de início & $-0,303$ & 0,150 & 24 \\
\hline Duração epilepsia (anos) & 0,072 & 0,738 & 24 \\
\hline
\end{tabular}

\begin{tabular}{lrrrr}
\hline & \multicolumn{2}{c}{ SERT } & \multicolumn{2}{c}{ 5HT6 } \\
& Corr. & p-value & Corr. & p-value \\
\hline 5HT & $-0,087$ & 0,688 & $-0,066$ & 0,815 \\
Idade na cirurgia & $-0,020$ & 0,927 & 0,169 & 0,547 \\
Idade de início & $-0,303$ & 0,150 & 0,273 & 0,325 \\
Duração epilepsia (anos) & 0,072 & 0,738 & 0,081 & 0,775 \\
\hline
\end{tabular}

Spearman coefficient 


\section{REFERÊNCIAS}


Ablah E, Hesdorffer DC, Liu Y, Paschal AM, Hawley S, Thurman D. et al. Prevalence of epilepsy in rural Kansas. Epilepsy Res. 2014; 108(4):792-801. ISSN 1872-6844. Disponível em: < https://www.ncbi.nlm.nih.gov/pubmed/24613507 >.

Alenina N, Klempin F. The role of serotonin in adult hippocampal neurogenesis. Behav Brain Res. 2015; 277:49-57. ISSN 1872-7549. Disponível em: < https://www.ncbi.nlm.nih.gov/pubmed/25125239 >.

Alvarez JC, Bothua D, Collignon I, Advenier C, Spreux-Varoquaux O. Simultaneous measurement of dopamine, serotonin, their metabolites and tryptophan in mouse brain homogenates by high-performance liquid chromatography with dual coulometric detection. Biomed Chromatogr. 1999;13(4):293-8.. ISSN 0269-3879. Disponível em: < https://www.ncbi.nlm.nih.gov/pubmed/10416063 >.

Andrade-Valença, L. P. A, Valenca, MM; Velasco, TR. Epilepsia do lobo temporal mesial associada à esclerose hipocampal. Journal of Epilepsy and Clinical Neurophysiology. 2006; 12: 31-36. ISSN 1676-2649. Disponível em: < http://www.scielo.br/scielo.php?script=sci_arttext\&pid=S1676-

$26492006000100007 \&$ nrm=iso $>$.

Anhoury S, Brown RJ, Krishnamoorthy ES, Trimble MR. Psychiatric outcome after temporal lobectomy: a predictive study. Epilepsia. 2000;41(12):1608-15. ISSN 00139580. Disponível em: < https://www.ncbi.nlm.nih.gov/pubmed/11114220 >.

Assem-Hilger E, Lanzenberger R, Savli M, Wadsak W, Mitterhauser M, Mien LK. et al. Central serotonin $1 \mathrm{~A}$ receptor binding in temporal lobe epilepsy: a [carbonyl(11)C]WAY-100635 PET study. Epilepsy Behav. 2010;19(3):467-73. ISSN 1525-5069. Disponível em: < https://www.ncbi.nlm.nih.gov/pubmed/20850389 >.

Assié MB, Ravailhe V, Faucillon V, Newman-Tancredi A.. Contrasting contribution of 5hydroxytryptamine $1 \mathrm{~A}$ receptor activation to neurochemical profile of novel antipsychotics: frontocortical dopamine and hippocampal serotonin release in rat brain. J Pharmacol Exp Ther. 2005;315(1):265-72. ISSN 0022-3565. Disponível em: < https://www.ncbi.nlm.nih.gov/pubmed/15987834 >.

Avanzini, G. Animal models relevant to human epilepsies. Ital J Neurol Sci. 1995:16(1-2):5-8. ISSN 0392-0461. https://www.ncbi.nlm.nih.gov/pubmed/7642352 >.

Disponível

em:

Aydemir N, Ozkara C, Canbeyli R, Tekcan A. Changes in quality of life and selfperspective related to surgery in patients with temporal lobe epilepsy. Epilepsy Behav. 2004;5(5):735-42. ISSN 1525-5050. https://www.ncbi.nlm.nih.gov/pubmed/15380127 >.

Disponível em: 
Baumann $\mathrm{MH}$, Ayestas MA, Rothman RB.. Functional consequences of central serotonin depletion produced by repeated fenfluramine administration in rats. $\mathbf{J}$ Neurosci. 1998;18(21):9069-77. ISSN 0270-6474. Disponível em: < https://www.ncbi.nlm.nih.gov/pubmed/9787010 >.

Beleza P. Refractory epilepsy: a clinically oriented review. Eur Neurol. 2009;62(2):6571. ISSN 1421-9913. Disponível em: < https://www.ncbi.nlm.nih.gov/pubmed/19521080 >.

Berger M, Gray JA, Roth BL. The expanded biology of serotonin. Annu Rev Med. 2009;60:355-66. ISSN 1545-326X. Disponível em: < https://www.ncbi.nlm.nih.gov/pubmed/19630576 >.

Berumen LC, Rodríguez A, Miledi R, García-Alcocer G. Serotonin receptors in hippocampus. ScientificWorldJournal. 2012;2012:823493. ISSN 1537-744X. Disponível em: < https://www.ncbi.nlm.nih.gov/pubmed/22629209 >.

Blümcke I. Neuropathology of focal epilepsies: a critical review. Epilepsy Behav. 2009;15(1): 34-9. ISSN 1525-5069. Disponível em: < https://www.ncbi.nlm.nih.gov/pubmed/19248840 >.

Blümcke I, Coras R, Miyata H, Ozkara C.. Defining clinico-neuropathological subtypes of mesial temporal lobe epilepsy with hippocampal sclerosis. Brain Pathol. 2012;22(3):402-11. ISSN 1750-3639. Disponível em: < https://www.ncbi.nlm.nih.gov/pubmed/22497612 >.

Blümcke I, Thom M, Aronica E, Armstrong DD, Bartolomei F, Bernasconi A, et al. International consensus classification of hippocampal sclerosis in temporal lobe epilepsy: a Task Force report from the ILAE Commission on Diagnostic Methods. Epilepsia. 2013;54(7):1315-29. ISSN 1528-1167. Disponível em: < https://www.ncbi.nlm.nih.gov/pubmed/23692496 >.

Bortolozzi A, Díaz-Mataix L, Scorza MC, Celada P, Artigas F. The activation of 5-HT receptors in prefrontal cortex enhances dopaminergic activity. $\mathbf{J}$ Neurochem. 2005;95(6):1597-607. ISSN 0022-3042. Disponível em: < https://www.ncbi.nlm.nih.gov/pubmed/16277612 >.

Briellmann RS, Hopwood MJ, Jackson GD. Major depression in temporal lobe epilepsy with hippocampal sclerosis: clinical and imaging correlates. J Neurol Neurosurg Psychiatry. 2007; 78(11):1226-30. ISSN 1468-330X. Disponível em: < https://www.ncbi.nlm.nih.gov/pubmed/17259350 >.

Broderick PA, Pacia SV, Doyle WK, Devinsky O.. Monoamine neurotransmitters in resected hippocampal subparcellations from neocortical and mesial temporal lobe epilepsy patients: in situ microvoltammetric studies. Brain Res. 2000;878(1-2):48-63. ISSN 0006-8993. Disponível em: < https://www.ncbi.nlm.nih.gov/pubmed/10996135 >. 
Browning RA, Wood AV, Merrill MA, Dailey JW, Jobe PC. Enhancement of the anticonvulsant effect of fluoxetine following blockade of $5-\mathrm{HT} 1 \mathrm{~A}$ receptors. Eur $\mathbf{J}$ Pharmacol. 1997;336(1):1-6. ISSN 0014-2999. Disponível em: < https://www.ncbi.nlm.nih.gov/pubmed/9384247 >.

Buchanan GF, Murray NM, Hajek MA, Richerson GB. Serotonin neurones have anticonvulsant effects and reduce seizure-induced mortality. J Physiol. 2014;592(19):4395-410. ISSN 1469-7793. Disponível em: < https://www.ncbi.nlm.nih.gov/pubmed/25107926 >.

Camacho DL, Castillo M.. MR imaging of temporal lobe epilepsy. Semin Ultrasound CT MR. 2007; 28(6):424-36. ISSN 0887-2171. Disponível em: < https://www.ncbi.nlm.nih.gov/pubmed/18074999 >.

Carr GV, Lucki I.. The role of serotonin receptor subtypes in treating depression: a review of animal studies. Psychopharmacology (Berl). 2011;213(2-3):265-87.ISSN 1432-2072. Disponível em: < https://www.ncbi.nlm.nih.gov/pubmed/21107537 >.

Cavalheiro EA. The pilocarpine model of epilepsy. Ital J Neurol Sci. 1995;16(1-2):337. ISSN 0392-0461. Disponível em: < https://www.ncbi.nlm.nih.gov/pubmed/7642349 $>$.

Cavalheiro EA, Fernandes MJ, Turski L, Naffah-Mazzacoratti MG. Spontaneous recurrent seizures in rats: amino acid and monoamine determination in the hippocampus. Epilepsia. 1994;35(1): 1-11. ISSN 0013-9580. Disponível em: < https://www.ncbi.nlm.nih.gov/pubmed/8112229 >.

Charnay Y, Léger L. Brain serotonergic circuitries. Dialogues Clin Neurosci. 2010;12(4):471-87. ISSN 1294-8322. Disponível em: < https://www.ncbi.nlm.nih.gov/pubmed/21319493 >.

Cheetham SC, Crompton MR, Katona CL, Horton RW. Brain 5-HT1 binding sites in depressed suicides. Psychopharmacology (Berl). 1990;102(4):544-8. ISSN 00333158. Disponível em: < https://www.ncbi.nlm.nih.gov/pubmed/2096412 >.

Cloix JF, Tahi Z, Boissonnet A, Hévor T.. Brain glycogen and neurotransmitter levels in fast and slow methionine sulfoximine-selected mice. Exp Neurol. 2010;225(2):274-83. ISSN 1090-2430. Disponível em: < https://www.ncbi.nlm.nih.gov/pubmed/20547153 >.

Cloix JF, Tahi Z, Martin B, Hévor T.. Selection of two lines of mice based on latency to onset of methionine sulfoximine seizures. Epilepsia. 2010;51(1):118-28. ISSN 15281167. Disponível em: < https://www.ncbi.nlm.nih.gov/pubmed/20015245 >. 
Cuellar-Herrera M, Velasco AL, Velasco F, Trejo D, Alonso-Vanegas M, Nuche-Bricaire $A$, et al. Alterations of 5-HT1A receptor-induced G-protein functional activation and relationship to memory deficits in patients with pharmacoresistant temporal lobe epilepsy. Epilepsy Res. 2014;108(10):1853-63. ISSN 1872-6844. Disponível em: < https://www.ncbi.nlm.nih.gov/pubmed/25304920 >.

D'Alessio L, Giagante B, Papayannis C, Oddo S, Silva W, Solís P, et al. Psychotic disorders in Argentine patients with refractory temporal lobe epilepsy: a case-control study. Epilepsy Behav. 2009;14(4):604-9. ISSN 1525-5069. Disponível em: < https://www.ncbi.nlm.nih.gov/pubmed/19236954 >.

Dailey JW, Mishra PK, Ko KH, Penny JE, Jobe PC. Serotonergic abnormalities in the central nervous system of seizure-naive genetically epilepsy-prone rats. Life Sci.

$\begin{array}{lll}\text { 1992;50(4):319-26. ISSN } & \text { 0024-3205. } \\ \text { https://www.ncbi.nlm.nih.gov/pubmed/1732702 >. }\end{array}$

Dailey JW, Reigel CE, Mishra PK, Jobe PC. Neurobiology of seizure predisposition in the genetically epilepsy-prone rat. Epilepsy Res. 1989;3(1):3-17. ISSN 0920-1211. Disponível em: < https://www.ncbi.nlm.nih.gov/pubmed/2563686 >.

Dailey JW, Reith ME, Yan QS, Li MY, Jobe PC. Anticonvulsant doses of carbamazepine increase hippocampal extracellular serotonin in genetically epilepsyprone rats: dose response relationships. Neurosci Lett. 1997;227(1):13-6. ISSN 03043940. Disponível em: < https://www.ncbi.nlm.nih.gov/pubmed/9178847 >.

Dailey JW, Yan QS, Mishra PK, Burger RL, Jobe PC. Effects of fluoxetine on convulsions and on brain serotonin as detected by microdialysis in genetically epilepsyprone rats. J Pharmacol Exp Ther. 1992;260(2):533-40. ISSN 0022-3565. Disponível em: < https://www.ncbi.nlm.nih.gov/pubmed/1738103 >.

Daws LC, Gould GG. Ontogeny and regulation of the serotonin transporter: providing insights into human disorders. Pharmacol Ther. 2011;131(1):61-79. ISSN 1879-016X. Disponível em: < https://www.ncbi.nlm.nih.gov/pubmed/21447358 >.

Dayer A. Serotonin-related pathways and developmental plasticity: relevance for psychiatric disorders. Dialogues Clin Neurosci. 2014;16(1):29-41. ISSN 1958-5969. Disponível em: < https://www.ncbi.nlm.nih.gov/pubmed/24733969 >.

De Deurwaerdère $P, \mathrm{Di}$ Giovanni G. Serotonergic modulation of the activity of mesencephalic dopaminergic systems: Therapeutic implications. Prog Neurobiol. $\begin{array}{ll}2017 ; 151: 175-236 . \quad I S S N & 1873-5118 . \\ \text { https://www.ncbi.nlm.nih.gov/pubmed/27013075 >. }\end{array}$

Dekker AD, Vermeiren Y, Carmona-Iragui M, Benejam B, Videla L, Gelpi E. et al. Monoaminergic impairment in Down syndrome with Alzheimer's disease compared to early-onset Alzheimer's disease. Alzheimers Dement (Amst). 2018;10:99-111. ISSN 2352-8729. Disponível em: < https://www.ncbi.nlm.nih.gov/pubmed/29780859 >. 
Didelot $A$, Ryvlin $P$, Lothe A, Merlet I, Hammers A, Mauguière F. PET imaging of brain $5-\mathrm{HT} 1 \mathrm{~A}$ receptors in the preoperative evaluation of temporal lobe epilepsy. Brain. 2008;131(Pt 10): 2751-64. ISSN 1460-2156. Disponível em: < https://www.ncbi.nlm.nih.gov/pubmed/18790822 >.

Donaldson ZR, Hen R.. From psychiatric disorders to animal models: a bidirectional and dimensional approach. Biol Psychiatry. 2015;77(1):15-21. ISSN 1873-2402. Disponível em: < https://www.ncbi.nlm.nih.gov/pubmed/24650688

Dorfer C, Czech T, Aull-Watschinger S, Baumgartner C, Jung R, Kasprian G. et al. Mesial temporal lobe epilepsy: long-term seizure outcome of patients primarily treated with transsylvian selective amygdalohippocampectomy. $\mathbf{J}$ Neurosurg. 2018;129(1):174-181. ISSN 1933-0693. Disponível em: < https://www.ncbi.nlm.nih.gov/pubmed/29027855 >.

Drevets WC, Frank E, Price JC, Kupfer DJ, Holt D, Greer PJ, et al. PET imaging of serotonin 1A receptor binding in depression. Biol Psychiatry. 1999;46(10):1375-87. ISSN 0006-3223. Disponível em: < https://www.ncbi.nlm.nih.gov/pubmed/10578452 >.

Eid T, Ghosh A, Wang Y, Beckström H, Zaveri HP, Lee TS, et al. Recurrent seizures and brain pathology after inhibition of glutamine synthetase in the hippocampus in rats. Brain. 2008; 131(Pt 8):2061-70. ISSN 1460-2156. Disponível em: < https://www.ncbi.nlm.nih.gov/pubmed/18669513 >.

Engel J Jr, Pitkänen A, Loeb JA, Dudek FE, Bertram EH 3rd, Cole AJ, et al. Epilepsy biomarkers. Epilepsia. 2013;54(Suppl 4): 61-9. ISSN 1528-1167. Disponível em: < https://www.ncbi.nlm.nih.gov/pubmed/23909854 >.

Englot DJ, Rolston JD, Wang DD, Sun PP, Chang EF, Auguste KI. Seizure outcomes after temporal lobectomy in pediatric patients. J Neurosurg Pediatr. 2013;12(2):13441. ISSN 1933-0715. Disponível em: < https://www.ncbi.nlm.nih.gov/pubmed/23768202 >.

Faingold CL. The genetically epilepsy-prone rat. Gen Pharmacol. 1988;19(3):331-8. ISSN 0306-3623. Disponível em: < https://www.ncbi.nlm.nih.gov/pubmed/2901380 >.

Faingold CL, Randall M, Mhaskar Y, Uteshev VV. Differences in serotonin receptor expression in the brainstem may explain the differential ability of a serotonin agonist to block seizure-induced sudden death in DBA/2 vs. DBA/1 mice. Brain Res. 2011;1418:104-10. ISSN 1872-6240. Disponível em: <

https://www.ncbi.nlm.nih.gov/pubmed/21920504 >.

Faingold CL, Randall M, Zeng C, Peng S, Long X, Feng HJ. Serotonergic agents act on 5-HT. Epilepsy Behav. 2016;64(Pt A):166-170. ISSN 1525-5069. Disponível em: < https://www.ncbi.nlm.nih.gov/pubmed/27743549 >. 
Faingold CL, Tupal S, Randall M. Prevention of seizure-induced sudden death in a chronic SUDEP model by semichronic administration of a selective serotonin reuptake inhibitor. Epilepsy Behav. 2011;22(2):186-9. ISSN 1525-5069. Disponível em: < https://www.ncbi.nlm.nih.gov/pubmed/21783426 >.

Favale E, Audenino D, Cocito L, Albano C. The anticonvulsant effect of citalopram as an indirect evidence of serotonergic impairment in human epileptogenesis. Seizure. 2003;12(5):316-8. ISSN 1059-1311. Disponível em: <

https://www.ncbi.nlm.nih.gov/pubmed/12810346 >.

Favale E, V. Rubino, P. Mainardi, G. Lunardi, C. AlbanoAnticonvulsant effect of fluoxetine in humans. Neurology. 1995;45(10):1926-7. ISSN 0028-3878. Disponível em: < https://www.ncbi.nlm.nih.gov/pubmed/7477995 >.

Fazel S, Wolf A, Långström N, Newton CR, Lichtenstein P. Premature mortality in epilepsy and the role of psychiatric comorbidity: a total population study. Lancet. 2013;382(9905):1646-54. ISSN 1474-547X. Disponível em: < https://www.ncbi.nlm.nih.gov/pmc/articles/PMC3899026/>.

Feng HJ, Faingold CL. Abnormalities of serotonergic neurotransmission in animal models of SUDEP. Epilepsy Behav. 2017;71(Pt B):174-180. ISSN 1525-5069. Disponível em: < https://www.ncbi.nlm.nih.gov/pubmed/26272185 >.

Feng J, Cai X, Zhao J, Yan Z. Serotonin receptors modulate GABA(A) receptor channels through activation of anchored protein kinase $\mathrm{C}$ in prefrontal cortical neurons. J Neurosci. 20011;21(17):6502-11. ISSN 1529-2401. Disponível em: < https://www.ncbi.nlm.nih.gov/pubmed/11517239 >.

Ferrari F, Villa RF. The Neurobiology of Depression: an Integrated Overview from Biological Theories to Clinical Evidence. Mol Neurobiol. 2017;54(7):4847-4865. ISSN 1559-1182. Disponível em: < https://www.ncbi.nlm.nih.gov/pubmed/27510505 >.

Fisher PD, Sperber EF, Moshé SL. Hippocampal sclerosis revisited. Brain Dev, $\begin{array}{lr}\text { 1998;20(8):563-73. ISSN } & \text { 0387-7604. } \\ \text { https://www.ncbi.nlm.nih.gov/pubmed/9865538 >. }\end{array}$

Fisher RS, Acevedo C, Arzimanoglou A, Bogacz A, Cross JH, Elger CE. et al. ILAE official report: a practical clinical definition of epilepsy. Epilepsia. 2014;55(4):475-82. ISSN 1528-1167. Disponível em: < https://www.ncbi.nlm.nih.gov/pubmed/24730690 >.

Forsgren L, Nyström L. An incident case-referent study of epileptic seizures in adults. Epilepsy Res. 1990;6(1):66-81.. ISSN 0920-1211. Disponível em: < https://www.ncbi.nlm.nih.gov/pubmed/2357957 >. 
Gaitatzis A, Trimble MR, Sander JW. The psychiatric comorbidity of epilepsy. Acta Neurol Scand. 2004;110(4):207-20.. ISSN 0001-6314. Disponível em: < https://www.ncbi.nlm.nih.gov/pubmed/15355484 >.

Gattaz WF, Valente KD, Raposo NR, Vincentiis S, Talib LL. Increased PLA2 activity in the hippocampus of patients with temporal lobe epilepsy and psychosis. J Psychiatr Res. $2011 \quad ; 45(12): 1617-20 . . \quad$ ISSN 1879-1379. Disponível em: < https://www.ncbi.nlm.nih.gov/pubmed/21813137 >.

García-Morales I, de la Peña Mayor P, Kanner AM. Psychiatric comorbidities in epilepsy: identification and treatment. Neurologist. 2008;14(6 Suppl 1):S15-25. . ISSN 1074-7931. Disponível em: < https://www.ncbi.nlm.nih.gov/pubmed/19225366 >.

Giovacchini G, Toczek MT, Bonwetsch R, Bagic A, Lang L, Fraser C, et al. 5-HT 1A receptors are reduced in temporal lobe epilepsy after partial-volume correction. J Nucl Med. 2005;46(7):1128-35. ISSN 0161-5505. Disponível em: < https://www.ncbi.nlm.nih.gov/pubmed/16000281 >.

Giussani G, Franchi C, Messina P, Nobili A, Beghi E; EPIRES Group. Prevalence and incidence of epilepsy in a well-defined population of Northern Italy. Epilepsia. 2014 Oct;55(10):1526-33. ISSN 1528-1167. Disponível em: < https://www.ncbi.nlm.nih.gov/pubmed/25090941 >.

Goldberg EM, Coulter DA. Mechanisms of epileptogenesis: a convergence on neural circuit dysfunction. Nat Rev Neurosci. 2013;14(5):337-49. ISSN 1471-0048. Disponível em: < https://www.ncbi.nlm.nih.gov/pubmed/23595016 >.

Gonçalves EB, Cendes F. Depression in patients with refractory temporal lobe epilepsy. Arq Neuropsiquiatr. 2011;69(5):775-7. ISSN 1678-4227. Disponível em: < https://www.ncbi.nlm.nih.gov/pubmed/22042180 >.

Gonçalves-Ferreira A, Campos AR, Herculano-Carvalho M, Pimentel J, Bentes C, Peralta AR, et al. Amygdalohippocampotomy: surgical technique and clinical results. J Neurosurg. 2013 ;118(5):1107-13. ISSN 1933-0693. Disponível em: < https://www.ncbi.nlm.nih.gov/pubmed/23432145 >.

Graebenitz S, Kedo O, Speckmann EJ, Gorji A, Panneck H, Hans V, et al. Interictallike network activity and receptor expression in the epileptic human lateral amygdala. Brain. 2011;134(Pt 10):2929-47. ISSN 1460-2156. Disponível em: < https://www.ncbi.nlm.nih.gov/pubmed/21893592 >.

Hamon M, Blier P. Monoamine neurocircuitry in depression and strategies for new treatments. Prog Neuropsychopharmacol Biol Psychiatry. 2013;45:54-63. ISSN 1878-4216. Disponível em: < https://www.ncbi.nlm.nih.gov/pubmed/23602950 >. 
Hasler G, Bonwetsch R, Giovacchini G, Toczek MT, Bagic A, Luckenbaugh DA, et al. 5-HT1A receptor binding in temporal lobe epilepsy patients with and without major depression. Biol Psychiatry. 2007;62(11):1258-64. ISSN 0006-3223. Disponível em: < https://www.ncbi.nlm.nih.gov/pubmed/17588547 >.

Hecimovic $\mathrm{H}$, et al. Neuroanatomical and Neurobiological Bases of Psychiatric Disorders. In: ETTINGER, A. B. e KANNER, A. M. (Ed.). Psychiatric Issues in Epilepsy: A Practical Guide to Diagnosis and Treatment. First. Philadelphia, PA: Lippincott Williams \& Wilkins, v.1, 2001. cap. 7, p.400. ISBN 97807817217690781721768.

Hensler JG, Artigas F, Bortolozzi A, Daws LC, De Deurwaerdère P, Milan L, et al. Catecholamine/Serotonin interactions: systems thinking for brain function and disease. Adv Pharmacol. 2013;68:167-97. ISSN 1557-8925. Disponível em: < https://www.ncbi.nlm.nih.gov/pubmed/24054145 >.

Hesdorffer DC, Hauser WA, Annegers JF, Cascino G. Major depression is a risk factor for seizures in older adults. Ann Neurol. 2000;47(2):246-9. ISSN 0364-5134. Disponível em: < https://www.ncbi.nlm.nih.gov/pubmed/10665498 >.

Hesdorffer DC, Hauser WA, Olafsson E, Ludvigsson P, Kjartansson O. Depression and suicide attempt as risk factors for incident unprovoked seizures. Ann Neurol. 2006;59(1):35-41. ISSN 0364-5134. Disponível em: < https://www.ncbi.nlm.nih.gov/pubmed/16217743 >.

Hitiris N, Mohanraj R, Norrie J, Sills GJ, Brodie MJ.. Predictors of pharmacoresistant epilepsy. Epilepsy Res. 2007;75(2-3):192-6. ISSN 0920-1211. Disponível em: < https://www.ncbi.nlm.nih.gov/pubmed/17628429 >.

Holm E, Foged MT, Beniczky S, Jespersen B, Brennum J, Pinborg LH' Efficacy of the Danish epilepsy surgery programme. Acta Neurol Scand. 2018;137(2):245-251. ISSN 1600-0404. Disponível em: < https://www.ncbi.nlm.nih.gov/pubmed/28994451 >.

Ito S, Suhara T, Ito H, Yasuno F, Ichimiya T, Takano A, et al. Changes in central 5$\mathrm{HT}(1 \mathrm{~A})$ receptor binding in mesial temporal epilepsy measured by positron emission tomography with [(11)C]WAY100635. Epilepsy Res. 2007;73(1):111-8. ISSN 09201211. Disponível em: < https://www.ncbi.nlm.nih.gov/pubmed/17097271 >.

Jobe PC, Brown RD, Dailey JW. Effect of Ro 4-1284 on audiogenic seizure susceptibility and intensity in epilepsy-prone rats. Life Sci. 1981;28(18):2031-8. ISSN 0024-3205. Disponível em: < https://www.ncbi.nlm.nih.gov/pubmed/6909499 >.

Jobe PC, Dailey JW. Genetically Epilepsy-Prone Rats (GEPRs) in Drug Research. CNS Drug Reviews. 2000;6(3):241-260. Disponível em: < https://onlinelibrary.wiley.com/doi/abs/10.1111/j.1527-3458.2000.tb00150.x >. 
Jobe PC, Dailey JW, Reigel CE. Noradrenergic and serotonergic determinants of seizure susceptibility and severity in genetically epilepsy-prone rats. Life Sci. 1986;39(9):775-82. ISSN 0024-3205. https://www.ncbi.nlm.nih.gov/pubmed/3747729 >.

Disponível

em:

Jobe PC, Dailey JW, Wernicke JF. A noradrenergic and serotonergic hypothesis of the linkage between epilepsy and affective disorders. Crit Rev Neurobiol. 1999:13(4):317-56

ISSN 0892-0915. Disponíve

em: $<$ https://www.ncbi.nlm.nih.gov/pubmed/11028680 >.

Jobe PC, Laird HE 2nd, Ko KH, Ray T, Dailey JW. Abnormalities in monoamine levels in the central nervous system of the genetically epilepsy-prone rat. Epilepsia. 1982;23(4):359-66. ISSN 0013-9580. Disponível em: < https://www.ncbi.nlm.nih.gov/pubmed/6284498 >.

Jobe PC, Mishra PK, Adams-Curtis LE, Deoskar VU, Ko KH, Browning RA, et al. The genetically epilepsy-prone rat (GEPR). Ital J Neurol Sci. 1995;16(1-2):91-9. ISSN 0392-0461. Disponível em: < https://www.ncbi.nlm.nih.gov/pubmed/7642359 >.

Josephson CB, Dykeman J, Fiest KM, Liu X, Sadler RM, Jette N, et al. Systematic review and meta-analysis of standard vs selective temporal lobe epilepsy surgery. Neurology. 2013;80(18):1669-76. ISSN 1526-632X. Disponível em: < https://www.ncbi.nlm.nih.gov/pubmed/23553475 >.

Kandratavicius L, Rosa-Neto P, Monteiro MR, Guiot MC, Assirati JA Jr, Carlotti CG Jr. Distinct increased metabotropic glutamate receptor type 5 (mGluR5) in temporal lobe epilepsy with and without hippocampal sclerosis. Hippocampus. 2013;23(12):1212-30. ISSN 1098-1063. Disponível em: < https://www.ncbi.nlm.nih.gov/pubmed/23804486 >.

Kandratavicius L, Monteiro MR, Hallak JE, Carlotti CG Jr, Assirati JA Jr, Leite JP. Microtubule-associated proteins in mesial temporal lobe epilepsy with and without psychiatric comorbidities and their relation with granular cell layer dispersion. Biomed Res Int, v. 2013, p. 960126, 2013. ISSN 2314-6141. Disponível em: < https://www.ncbi.nlm.nih.gov/pubmed/24069608 >.

Kandratavicius L, Monteiro MR, Assirati JA Jr, Carlotti CG Jr, Hallak JE, Leite JP, et al. Neurotrophins in mesial temporal lobe epilepsy with and without psychiatric comorbidities. J Neuropathol Exp Neurol. 2013;72(11):1029-42. ISSN 1554-6578. Disponível em: < https://www.ncbi.nlm.nih.gov/pubmed/24128677 >.

Kanner AM. Depression in epilepsy: a neurobiologic perspective. Epilepsy Curr. $\begin{array}{ll}2005 ; 5(1): 21-7 . . \quad \text { ISSN } & 1535-7597 . \\ \text { https://www.ncbi.nlm.nih.gov/pubmed/16059450 > }\end{array}$ 
Kanner AM. Mood disorder and epilepsy: a neurobiologic perspective of their relationship. Dialogues Clin Neurosci. 2008;10(1):39-45. ISSN 1294-8322. Disponível em: < https://www.ncbi.nlm.nih.gov/pubmed/18472483 >.

Kanner AM. Depression and epilepsy: a review of multiple facets of their close relation. Neurol Clin. 2009;27(4):865-80. ISSN 1557-9875. Disponível em: < https://www.ncbi.nlm.nih.gov/pubmed/19853213 >.

Kanner AM. Hippocampal atrophy: another common pathogenic mechanism of depressive disorders and epilepsy? Epilepsy Curr. 2011;11(5):149-50. ISSN 15357511. Disponível em: < https://www.ncbi.nlm.nih.gov/pubmed/22020737 >.

Kanner AM. Epilepsy: Psychiatric comorbidities and premature death in epilepsy. Nat Rev Neurol. 2013;9(11):606-8. ISSN 1759-4766. Disponível em: < https://www.ncbi.nlm.nih.gov/pubmed/24166201 >.

Kanner AM, Byrne R, Chicharro A, Wuu J, Frey M. A lifetime psychiatric history predicts a worse seizure outcome following temporal lobectomy. Neurology. 2009;72(9):793-9. ISSN 1526-632X. Disponível em: < https://www.ncbi.nlm.nih.gov/pubmed/19255406 >.

Kim SW, Shin IS, Kim JM, Youn T, Yang SJ, et al. The 5-HT2 receptor profiles of antipsychotics in the pathogenesis of obsessive-compulsive symptoms in schizophrenia. Clin Neuropharmacol. 2009;32(4):224-6. ISSN 1537-162X. Disponível em: < https://www.ncbi.nlm.nih.gov/pubmed/19644229 >.

Klemenhagen KC, Gordon JA, David DJ, Hen R, Gross CT. Increased fear response to contextual cues in mice lacking the 5-HT1A receptor. Neuropsychopharmacology. 2006;31(1):101-11.. ISSN 0893-133X. https://www.ncbi.nlm.nih.gov/pubmed/15920501 >.

Disponível em:

Koch-Stoecker SC, Bien CG, Schulz R, May TW. Psychiatric lifetime diagnoses are associated with a reduced chance of seizure freedom after temporal lobe surgery. Epilepsia. 2017;58(6):983-993. ISSN 1528-1167. Disponível em: < https://www.ncbi.nlm.nih.gov/pubmed/28378900 >.

Krucoff MO, Chan AY, Harward SC, Rahimpour S, Rolston JD, Muh C, et al. Rates and predictors of success and failure in repeat epilepsy surgery: A meta-analysis and systematic review. Epilepsia. 2017;58(12):2133-2142. ISSN 1528-1167. Disponível em: < https://www.ncbi.nlm.nih.gov/pubmed/28994113 >.

Kumar U, Medel-Matus JS, Redwine HM, Shin D, Hensler JG, Sankar R, et al. Effects of selective serotonin and norepinephrine reuptake inhibitors on depressive- and impulsive-like behaviors and on monoamine transmission in experimental temporal lobe epilepsy. Epilepsia. $2016 ; 57(3): 506-15$. ISSN 1528-1167. Disponível em: < https://www.ncbi.nlm.nih.gov/pubmed/26813337 >. 
Kwan P, Arzimanoglou A, Berg AT, Brodie MJ, Allen Hauser W, Mathern G, et al. Definition of drug resistant epilepsy: consensus proposal by the ad hoc Task Force of the ILAE Commission on Therapeutic Strategies. Epilepsia. 2010;51(6):1069-77. ISSN 1528-1167. Disponível em: < https://www.ncbi.nlm.nih.gov/pubmed/19889013 >.

Kwan P, Sperling MR. Refractory seizures: try additional antiepileptic drugs (after two have failed) or go directly to early surgery evaluation? Epilepsia. 2009;50 Suppl 8:5762. ISSN 1528-1167. Disponível em: < https://www.ncbi.nlm.nih.gov/pubmed/19702735 >.

Köhler S, Cierpinsky K, Kronenberg G, Adli M. The serotonergic system in the neurobiology of depression: Relevance for novel antidepressants. J Psychopharmacol. 2016;30(1):13-22. ISSN 1461-7285. Disponível em: < https://www.ncbi.nlm.nih.gov/pubmed/26464458 >.

Leopoldo M, Lacivita E, Berardi F, Perrone R, Hedlund PB. Serotonin 5-HT7 receptor agents: Structure-activity relationships and potential therapeutic applications in central nervous system disorders. Pharmacol Ther. 2011;129(2):120-48. ISSN 1879-016X. Disponível em: < https://www.ncbi.nlm.nih.gov/pubmed/20923682 >.

Liew CJ, Lim YM, Bonwetsch R, Shamim S, Sato S, Reeves-Tyer P, et al. 18F-FCWAY and 18F-FDG PET in MRI-negative temporal lobe epilepsy. Epilepsia. 2009;50(2):2349. ISSN 1528-1167. Disponível em: < https://www.ncbi.nlm.nih.gov/pubmed/18801033 $>$.

Lin W, Huang W, Chen S, Lin M, Huang Q, Huang H. The Role of 5-HTR6 in Mossy Fiber Sprouting: Activating Fyn and p-ERK1/2 in Pilocarpine-Induced Chronic Epileptic Rats. Cell Physiol Biochem. 2017;42(1):231-241. ISSN 1421-9778. Disponível em: < https://www.ncbi.nlm.nih.gov/pubmed/28535499 >.

Lin WH, Huang HP, Lin MX, Chen SG, Lv XC, Che CH, et al. Seizure-induced 5-HT release and chronic impairment of serotonergic function in rats. Neurosci Lett. 2013;534:1-6. ISSN $1872-7972$.

Lothe A, Didelot A, Hammers A, Costes N, Saoud M, Gilliam F, et al. Comorbidity between temporal lobe epilepsy and depression: a [18F]MPPF PET study. Brain. 2008;131(Pt 10):2765-82. ISSN 1460-2156. Disponível em: < https://www.ncbi.nlm.nih.gov/pubmed/18765418 >.

Lowry $\mathrm{OH}$, Rosebrough NJ, Farr AL, Randall RJ.. Protein measurement with the Folin phenol reagent. J Biol Chem. 1951 Nov;193(1):265-75. ISSN 0021-9258. Disponível em: < https://www.ncbi.nlm.nih.gov/pubmed/14907713 >. 
Lundberg J, Tiger M, Landén M, Halldin C, Farde L. Serotonin transporter occupancy with TCAs and SSRIs: a PET study in patients with major depressive disorder. Int $\mathbf{J}$ Neuropsychopharmacol. 2012;15(8):1167-72. ISSN 1469-5111. Disponível em: < https://www.ncbi.nlm.nih.gov/pubmed/22243688 >.

Lv J, Liu F. The Role of Serotonin beyond the Central Nervous System during Embryogenesis. Front Cell Neurosci. 2017;11:74. ISSN 1662-5102. Disponível em: < https://www.ncbi.nlm.nih.gov/pubmed/28348520 >.

Magiorkinis E, Diamantis A, Sidiropoulou K, Panteliadis C. Highights in the history of epilepsy: the last 200 years. Epilepsy Res Treat. 2014;2014:582039. ISSN 20901348. Disponível em: < https://www.ncbi.nlm.nih.gov/pubmed/25210626 >.

Magiorkinis E, Sidiropoulou K, Diamantis A. Hallmarks in the history of epilepsy: epilepsy in antiquity. Epilepsy Behav. 2010;17(1):103-8. ISSN 1525-5069. Disponível em: < https://www.ncbi.nlm.nih.gov/pubmed/19963440 >.

Malmgren K, Thom M. Hippocampal sclerosis--origins and imaging. Epilepsia. 2012;53 Suppl 4:19-33. ISSN 1528-1167. Disponível em: < https://www.ncbi.nlm.nih.gov/pubmed/22946718 >.

Mann JJ. Role of the serotonergic system in the pathogenesis of major depression and suicidal behavior. Neuropsychopharmacology. 1999;21(2 Suppl):99S-105S.. ISSN 0893-133X. Disponível em: < https://www.ncbi.nlm.nih.gov/pubmed/10432495 >.

Manna I, Labate A, Gambardella A, Forabosco P, La Russa A, Le Piane E, et al. Serotonin transporter gene (5- $\mathrm{Htt})$ : association analysis with temporal lobe epilepsy. Neurosci Lett. 2007;421(1):52-6. ISSN 0304-3940. Disponível em: < https://www.ncbi.nlm.nih.gov/pubmed/17548158 >.

Martinez A, Finegersh A, Cannon DM, Dustin I, Nugent A, Herscovitch P, et al. The 5HT1A receptor and 5-HT transporter in temporal lobe epilepsy. Neurology. 2013;80(16):1465-71. ISSN 1526-632X. Disponível em: < https://www.ncbi.nlm.nih.gov/pubmed/23516322 >.

Matsuura M, Oana Y, Kato M, Kawana A, Kan R, Kubota H, et al. A multicenter study on the prevalence of psychiatric disorders among new referrals for epilepsy in Japan. Epilepsia. $2003 ; 44(1): 107-14 . . \quad$ ISSN 0013-9580. Disponível em: < https://www.ncbi.nlm.nih.gov/pubmed/12581237 >.

Mazarati A, Siddarth P, Baldwin RA, Shin D, Caplan R, Sankar R. Depression after status epilepticus: behavioural and biochemical deficits and effects of fluoxetine. Brain. 2008;131(Pt 8):2071-83. ISSN 1460-2156. Disponível em: < https://www.ncbi.nlm.nih.gov/pubmed/18559371 >. 
Meltzer HY, Massey BW. The role of serotonin receptors in the action of atypical antipsychotic drugs. Curr Opin Pharmacol. 2011;11(1):59-67. ISSN 1471-4973. Disponível em: < https://www.ncbi.nlm.nih.gov/pubmed/21420906 >.

Menzler K, Iwinska-Zelder J, Shiratori K, Jaeger RK, Oertel WH, Hamer HM. et al. Evaluation of MRI criteria (1.5 T) for the diagnosis of hippocampal sclerosis in healthy subjects. Epilepsy Res. 2010 ;89(2-3):349-54. ISSN 1872-6844. Disponível em: < https://www.ncbi.nlm.nih.gov/pubmed/20307956 >.

Merlet I, Ostrowsky K, Costes N, Ryvlin P, Isnard J, Faillenot I, et al. 5-HT1A receptor binding and intracerebral activity in temporal lobe epilepsy: an [18F]MPPF-PET study. Brain. 2004;127(Pt 4):900-13. ISSN 0006-8950. Disponível em: < https://www.ncbi.nlm.nih.gov/pubmed/14985263 >.

Merrill MA, Clough RW, Dailey JW, Jobe PC, Browning RA. Localization of the serotonergic terminal fields modulating seizures in the genetically epilepsy-prone rat. Epilepsy Res. 2007;76(2-3):93-102. ISSN 0920-1211. Disponível em: < https://www.ncbi.nlm.nih.gov/pubmed/17689928 >.

Mishra PK, Dailey JW, Reigel CE, Jobe PC. Brain norepinephrine and convulsions in the genetically epilepsy-prone rat: sex-dependent responses to Ro 4-1284 treatment. Life Sci. 1988;42(11):1131-7. ISSN 0024-3205. Disponível em: < https://www.ncbi.nlm.nih.gov/pubmed/3347143 >.

Mnie-Filali O, Lambás-Señas L, Zimmer L, Haddjeri N. 5-HT7 receptor antagonists as a new class of antidepressants. Drug News Perspect. 2007;20(10):613-8. ISSN 02140934. Disponível em: < https://www.ncbi.nlm.nih.gov/pubmed/18301795 >.

Mori A, Hiramatsu M, Namba S, Nishimoto A, Ohmoto T, Mayanagi $Y$, et al. Decreased dopamine level in the epileptic focus. Res Commun Chem Pathol Pharmacol. 1987;56(2):157-64. ISSN 0034-5164. Disponível em: < https://www.ncbi.nlm.nih.gov/pubmed/3602584 >.

Moshé SL, Perucca E, Ryvlin P, Tomson T. Epilepsy: new advances. Lancet. 2015;385(9971):884-98. ISSN 1474-547X. Disponível em: < https://www.ncbi.nlm.nih.gov/pubmed/25260236 >.

Mulinari S. Monoamine theories of depression: historical impact on biomedical research. J Hist Neurosci. 2012;21(4):366-92. ISSN 1744-5213. Disponível em: < https://www.ncbi.nlm.nih.gov/pubmed/22947380 >.

Naffah-Mazzacoratti MG, Amado D, Cukiert A, Gronich G, Marino R, Calderazzo L, et al. Monoamines and their metabolites in cerebrospinal fluid and temporal cortex of epileptic patients. Epilepsy Res. 1996 Oct;25(2):133-7. ISSN 0920-1211. Disponível em: < https://www.ncbi.nlm.nih.gov/pubmed/8884171 >. 
Noguchi K, Watanabe T, Higuchi S, Chiba K. Determination of YM992, a novel selective serotonin reuptake inhibitor, in rat and dog plasma by high-performance liquid chromatography with fluorescence detection. Biomed Chromatogr. 2000;14(4):269$\begin{array}{lll}73 . & \text { ISSN } & \text { 0269-3879. } \\ \text { https://www.ncbi.nlm.nih.gov/pubmed/10861739 >. }\end{array}$

Pacia SV, Doyle WK, Broderick PA. Biogenic amines in the human neocortex in patients with neocortical and mesial temporal lobe epilepsy: identification with in situ microvoltammetry. Brain Res. 2001;899(1-2):106-11. ISSN 0006-8993. Disponível em: $<$ https://www.ncbi.nlm.nih.gov/pubmed/11311871 >.

Palomero-Gallagher N, Schleicher A, Bidmon HJ, Pannek HW, Hans V, Gorji A, et al. Multireceptor analysis in human neocortex reveals complex alterations of receptor ligand binding in focal epilepsies. Epilepsia. 2012;53(11):1987-97. ISSN 1528-1167. Disponível em: < https://www.ncbi.nlm.nih.gov/pubmed/22957946 >.

Parsey RV, Ogden RT, Miller JM, Tin A, Hesselgrave N, Goldstein E, et al. Higher serotonin $1 \mathrm{~A}$ binding in a second major depression cohort: modeling and reference region considerations. Biol Psychiatry. 2010;68(2):170-8. ISSN 1873-2402. Disponível em: < https://www.ncbi.nlm.nih.gov/pubmed/20497898 >.

Peixoto-Santos JE, Galvis-Alonso OY, Velasco TR, Kandratavicius L, Assirati JA, Carlotti CG, et al. Increased metallothionein I/II expression in patients with temporal lobe epilepsy. PLoS One. 2012;7(9):e44709. ISSN 1932-6203. Disponível em: < https://www.ncbi.nlm.nih.gov/pubmed/23028585 >.

Perini GI, Tosin C, Carraro C, Bernasconi G, Canevini MP, Canger R, et al. Interictal mood and personality disorders in temporal lobe epilepsy and juvenile myoclonic epilepsy. J Neurol Neurosurg Psychiatry. 1996;61(6):601-5.. ISSN 0022-3050. Disponível em: < https://www.ncbi.nlm.nih.gov/pubmed/8971108 >.

Peterson GL. A simplification of the protein assay method of Lowry et al. which is more generally applicable. Anal Biochem. 1977;83(2):346-56. ISSN 0003-2697. Disponível em: < https://www.ncbi.nlm.nih.gov/pubmed/603028 >.

Picard M, Cloix JF, Hevor TK. Serotonergic neurotransmission plays a major role in the action of the glycogenic convulsant methionine sulfoximine. Neurosci Res. 2011;70(3):313-20. ISSN 1872-8111. Disponível em: < https://www.ncbi.nlm.nih.gov/pubmed/21396968 >.

Pineda E, Shin D, Sankar R, Mazarati AM. Comorbidity between epilepsy and depression: experimental evidence for the involvement of serotonergic, glucocorticoid, and neuroinflammatory mechanisms. Epilepsia. 2010;51 Suppl 3:110-4. ISSN 15281167. Disponível em: < https://www.ncbi.nlm.nih.gov/pubmed/20618414 >. 
Pineda EA, Hensler JG, Sankar R, Shin D, Burke TF, Mazarati AM. Interleukin-1 $\beta$ causes fluoxetine resistance in an animal model of epilepsy-associated depression. Neurotherapeutics. 2012;9(2):477-85. ISSN 1878-7479. Disponível em: < https://www.ncbi.nlm.nih.gov/pubmed/22427156 >.

Pineda EA, Hensler JG, Sankar R, Shin D, Burke TF, Mazarati AM. Plasticity of presynaptic and postsynaptic serotonin $1 \mathrm{~A}$ receptors in an animal model of epilepsyassociated depression. Neuropsychopharmacology. 2011;36(6):1305-16. ISSN 1740-634X. Disponível em: < https://www.ncbi.nlm.nih.gov/pubmed/21346733 >.

Pintor M, Mefford IN, Hutter I, Pocotte SL, Wyler AR, Nadi NS. Levels of biogenic amines, their metabolites, and tyrosine hydroxylase activity in the human epileptic temporal cortex. Synapse. 1990;5(2):152-6. ISSN 0887-4476. Disponível em: < https://www.ncbi.nlm.nih.gov/pubmed/1968684 >.

Pugh MJ, Copeland LA, Zeber JE, Cramer JA, Amuan ME, Cavazos JE, et al. The impact of epilepsy on health status among younger and older adults. Epilepsia. 2005;46(11):1820-7. ISSN 0013-9580. Disponível em: < https://www.ncbi.nlm.nih.gov/pubmed/16302863 >.

Pytliak M, Vargová V, Mechírová V, Felšöci M. Serotonin receptors - from molecular biology to clinical applications. Physiol Res, 2011;60(1):15-25. ISSN 1802-9973. Disponível em: < https://www.ncbi.nlm.nih.gov/pubmed/20945968 >.

Rakitin A, Liik M, Oun A, Haldre S. Mortality risk in adults with newly diagnosed and chronic epilepsy: a population-based study. Eur J Neurol. 2011;18(3):465-70. ISSN 1468-1331. Disponível em: < https://www.ncbi.nlm.nih.gov/pubmed/20727008 >.

Ribot R, Ouyang B, Kanner AM. The impact of antidepressants on seizure frequency and depressive and anxiety disorders of patients with epilepsy: Is it worth investigating? Epilepsy Behav. 2017;70(Pt A):5-9. ISSN 1525-5069. Disponível em: < https://www.ncbi.nlm.nih.gov/pubmed/28407526 >.

Rocha L, Lorigados-Pedre L, Orozco-Suárez S, Morales-Chacón L, Alonso-Vanegas M, García-Maeso I, et al. Autoradiography reveals selective changes in serotonin binding in neocortex of patients with temporal lobe epilepsy. Prog Neuropsychopharmacol Biol Psychiatry. 2007;31(6):1208-18. ISSN 0278-5846. Disponível em: < https://www.ncbi.nlm.nih.gov/pubmed/17513030 >.

Rocha L, Alonso-Vanegas M, Villeda-Hernández J, Mújica M, Cisneros-Franco JM, López-Gómez M, et al. Dopamine abnormalities in the neocortex of patients with temporal lobe epilepsy. Neurobiol Dis. 2012;45(1):499-507. ISSN 1095-953X. Disponível em: < https://www.ncbi.nlm.nih.gov/pubmed/21964255 >. 
Sagher O, Thawani JP, Etame AB, Gomez-Hassan DM. Seizure outcomes and mesial resection volumes following selective amygdalohippocampectomy and temporal lobectomy. Neurosurg Focus. 2012;32(3):E8. ISSN 1092-0684. Disponível em: < https://www.ncbi.nlm.nih.gov/pubmed/22380862 >.

Sargent PA, Kjaer KH, Bench CJ, Rabiner EA, Messa C, Meyer J, et al. Brain serotonin $1 \mathrm{~A}$ receptor binding measured by positron emission tomography with [11C]WAY-100635: effects of depression and antidepressant treatment. Arch Gen Psychiatry. 2000;57(2):174-80. ISSN 0003-990X. Disponível em: < https://www.ncbi.nlm.nih.gov/pubmed/10665620 >.

Savic I, Lindström P, Gulyás B, Halldin C, Andrée B, Farde L. Limbic reductions of 5HT1A receptor binding in human temporal lobe epilepsy. Neurology. 2004;62(8):134351. ISSN 1526-632X. Disponível em: https://www.ncbi.nlm.nih.gov/pubmed/15111672 >.

Scharfman HE. The neurobiology of epilepsy. Curr Neurol Neurosci Rep. 2007;7(4):348-54.. ISSN 1528-4042. Disponível em: < https://www.ncbi.nlm.nih.gov/pubmed/17618543 >.

Schmidt D. Drug treatment of epilepsy: options and limitations. Epilepsy Behav. 2009;15(1):56-65. ISSN 1525-5069. Disponível em: < https://www.ncbi.nlm.nih.gov/pubmed/19236951 >.

Scorza F, Tucci PJ. Sudden death in Brazil: epilepsy should be in horizon. Arq Bras Cardiol. 2015;105(2):197-8. ISSN 1678-4170. Disponível em: < https://www.ncbi.nlm.nih.gov/pubmed/26352179 >.

Scorza FA, Arida RM, Naffah-Mazzacoratti Mda G, Scerni DA, Calderazzo L, Cavalheiro EA. The pilocarpine model of epilepsy: what have we learned? An Acad Bras Cienc. 2009;81(3):345-65.. ISSN 1678-2690. Disponível em: < https://www.ncbi.nlm.nih.gov/pubmed/19722008 >.

Sendrowski K, Sobaniec W. Hippocampus, hippocampal sclerosis and epilepsy. Pharmacol Rep. 2013;65(3):555-65. Disponível em: < https://www.ncbi.nlm.nih.gov/pubmed/23950578 >.

Seymour N, Granbichler CA, Polkey CE, Nashef L. Mortality after temporal lobe epilepsy surgery. Epilepsia. 2012;53(2):267-71. ISSN 1528-1167. Disponível em: < https://www.ncbi.nlm.nih.gov/pubmed/22126418 >.

Smolders I, Clinckers R, Meurs A, De Bundel D, Portelli J, Ebinger G. et al. Direct enhancement of hippocampal dopamine or serotonin levels as a pharmacodynamic measure of combined antidepressant-anticonvulsant action. Neuropharmacology. 2008;54(6):1017-28. ISSN 0028-3908.

Disponível em: https://www.ncbi.nlm.nih.gov/pubmed/18378264 >. 
Statnick MA, Dailey JW, Jobe PC, Browning RA. Abnormalities in brain serotonin concentration, high-affinity uptake, and tryptophan hydroxylase activity in severeseizure genetically epilepsy-prone rats. Epilepsia. 1996;37(4):311-21. ISSN 00139580. Disponível em: < https://www.ncbi.nlm.nih.gov/pubmed/8603634 >.

Steer S, Pickrell WO, Kerr MP, Thomas RH. Epilepsy prevalence and socioeconomic deprivation in England. Epilepsia. 2014;55(10):1634-41. ISSN 1528-1167. Disponível em: < https://www.ncbi.nlm.nih.gov/pubmed/25182657 >.

Stockmeier CA, Shapiro LA, Dilley GE, Kolli TN, Friedman L, Rajkowska G. Increase in serotonin-1A autoreceptors in the midbrain of suicide victims with major depressionpostmortem evidence for decreased serotonin activity. J Neurosci. 1998;18(18):7394401. ISSN 0270-6474. Disponível em: < https://www.ncbi.nlm.nih.gov/pubmed/9736659 >.

Talib L L, Joaquim HP, De Paula VJ. Metodologia em Neuroquímica. In: (Ed.). Clínica Psiquiátrica: a visão do Departamento e do Instituto de Psiquiatria do HCFMUSP. Primeira. São Paulo, SP: Manole. 2011;2:2048-2058. ISBN 9788520431382.

Tatum WO . Mesial temporal lobe epilepsy. J Clin Neurophysiol. 2012;29(5):356-65. ISSN 1537-1603. Disponível em: < https://www.ncbi.nlm.nih.gov/pubmed/23027091 >.

Tellez-Zenteno JF, Patten SB, Jetté N, Williams J, Wiebe S. Psychiatric comorbidity in epilepsy: a population-based analysis. Epilepsia. 2007;48(12):2336-44. ISSN 00139580. Disponível em: < https://www.ncbi.nlm.nih.gov/pubmed/17662062 >.

Thom M. Review: Hippocampal sclerosis in epilepsy: a neuropathology review. Neuropathol Appl Neurobiol. 2014 ;40(5):520-43. ISSN 1365-2990. Disponível em: < https://www.ncbi.nlm.nih.gov/pubmed/24762203 >.

Toczek MT, Carson RE, Lang L, Ma Y, Spanaki MV, Der MG, et al. PET imaging of 5HT1A receptor binding in patients with temporal lobe epilepsy. Neurology. 2003;60(5):749-56. ISSN 1526-632X. Disponível em: < https://www.ncbi.nlm.nih.gov/pubmed/12629228 >.

Trindade-Filho EM, de Castro-Neto EF, de A Carvalho R, Lima E, Scorza FA, Amado $D$, et al. Serotonin depletion effects on the pilocarpine model of epilepsy. Epilepsy Res. 2008;82(2-3):194-9. ISSN 1872-6844. Disponível em: < https://www.ncbi.nlm.nih.gov/pubmed/18845420 >.

Trottier S, Evrard B, Vignal JP, Scarabin JM, Chauvel P. The serotonergic innervation of the cerebral cortex in man and its changes in focal cortical dysplasia. Epilepsy Res. $\begin{array}{ll}\text { 1996;25(2):79-106. ISSN } & \text { 0920-1211. } \\ \text { https://www.ncbi.nlm.nih.gov/pubmed/8884167 >. }\end{array}$

Disponível

em: 
Törk I. Anatomy of the serotonergic system. Ann N Y Acad Sci. 1990;600:9-34; $\begin{array}{lccc}\text { discussion } & 34-5 . . & \text { ISSN } & 0077-8923 \\ \text { https://www.ncbi.nlm.nih.gov/pubmed/2252340 >. }\end{array}$

Umeda S, Stagliano GW, Borenstein MR, Raffa RB. A reverse-phase HPLC and fluorescence detection method for measurement of 5-hydroxytryptamine (serotonin) in Planaria. J Pharmacol Toxicol Methods. 2005;51(1):73-6.. ISSN 1056-8719. Disponível em: < https://www.ncbi.nlm.nih.gov/pubmed/15596117 >.

Uteshev VV, Tupal S, Mhaskar Y, Faingold CL. Abnormal serotonin receptor expression in DBA/2 mice associated with susceptibility to sudden death due to respiratory arrest. Epilepsy Res. 2010;88(2-3):183-8. ISSN 1872-6844. Disponível em: < https://www.ncbi.nlm.nih.gov/pubmed/20018491 >.

Vannemreddy PS, Kanner AM, Smith MC, Rossi M, Wallace D, Vannemreddy SN, et al. Chronic epilepsy due to low grade temporal lobe tumors and due to hippocampal sclerosis: do they differ in post-surgical outcome? J Neurooncol. 2013;115(2):225-31. ISSN 1573-7373. Disponível em: < https://www.ncbi.nlm.nih.gov/pubmed/23955571 >.

Veenstra-VanderWeele J, Anderson GM, Cook EH Jr. Pharmacogenetics and the serotonin system: initial studies and future directions. Eur J Pharmacol. 2000;410(23):165-181. ISSN 0014-2999. Disponível em: < https://www.ncbi.nlm.nih.gov/pubmed/11134668 >.

Vermoesen K, Massie A, Smolders I, Clinckers R. The antidepressants citalopram and reboxetine reduce seizure frequency in rats with chronic epilepsy. Epilepsia. 2012;53(5):870-8. ISSN 1528-1167. Disponível em: < https://www.ncbi.nlm.nih.gov/pubmed/22429158 >.

Wang HT, Han F, Shi YX. Activity of the 5-HT1A receptor is involved in the alteration of glucocorticoid receptor in hippocampus and corticotropin-releasing factor in hypothalamus in SPS rats. Int J Mol Med. 2009;24(2):227-31. ISSN 1107-3756. Disponível em: < https://www.ncbi.nlm.nih.gov/pubmed/19578795 >.

Wang L, Lv Y, Deng W, Peng X, Xiao Z, Xi Z, et al. 5-HT6 Receptor Recruitment of mTOR Modulates Seizure Activity in Epilepsy. Mol Neurobiol. 2015;51(3):1292-9. ISSN 1559-1182. Disponível em: < https://www.ncbi.nlm.nih.gov/pubmed/25034463 >.

Witkin JM, Baez M, Yu J, Barton ME, Shannon HE. Constitutive deletion of the serotonin-7 (5-HT(7)) receptor decreases electrical and chemical seizure thresholds. Epilepsy Res. 2007 ;75(1):39-45. ISSN 0920-1211. Disponível em: < https://www.ncbi.nlm.nih.gov/pubmed/17485199 >.

Yan QS, Jobe PC, Cheong JH, Ko KH, Dailey JW. Role of serotonin in the anticonvulsant effect of fluoxetine in genetically epilepsy-prone rats. Naunyn Schmiedebergs Arch Pharmacol. $1994 ; 350(2): 149-52$. ISSN 0028-1298. Disponível em: < https://www.ncbi.nlm.nih.gov/pubmed/7527501 >. 
Yan QS, Mishra PK, Burger RL, Bettendorf AF, Jobe PC, Dailey JW. Evidence that carbamazepine and antiepilepsirine may produce a component of their anticonvulsant effects by activating serotonergic neurons in genetically epilepsy-prone rats. $\mathbf{J}$ Pharmacol Exp Ther. 1992;261(2):652-9.. ISSN 0022-3565. Disponível em: < https://www.ncbi.nlm.nih.gov/pubmed/1374472 >.

Yang Y, Guo Y, Kuang Y, Wang S, Jiang Y, Ding Y, et al. Serotonin 1A receptor inhibits the status epilepticus induced by lithium-pilocarpine in rats. Neurosci Bull.

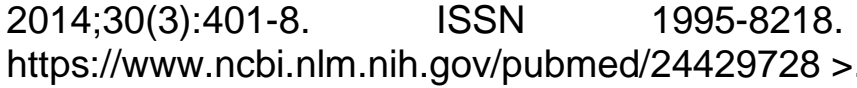

Yang Z, Liu X, Yin Y, Sun S, Deng X. Involvement of $5-\mathrm{HT}_{7}$ receptors in the pathogenesis of temporal lobe epilepsy. Eur J Pharmacol. 2012;685(1-3):52-8. ISSN 1879-0712. Disponível em: < https://www.ncbi.nlm.nih.gov/pubmed/22543085 >.

Zeng C, Long X, Cotten JF, Forman SA, Solt K, Faingold CL, et al. Fluoxetine prevents respiratory arrest without enhancing ventilation in DBA/1 mice. Epilepsy Behav. 2015;45:1-7. ISSN 1525-5069. Disponível em: https://www.ncbi.nlm.nih.gov/pubmed/25771493 >. 
10. APÊNDICE 


\section{APÊNDICE 1. INFORMAÇÕES BÁSICAS DE SUBMISSÃO NA PLATAFORMA BRASIL}

Plotoforma MINISTÉRIO DA SAÚDE - Conselho Nacional de Saúde - Comissão Nacional de Ética em Pesquisa - CONEP PROJETO DE PESQUISA ENVOLVENDO SERES HUMANOS

Projeto de Pesquisa: Atvidade serotoninérgica no hipocampo de pacientes com epilepsia de lobo temporal

Informaçöes Preliminares

\begin{tabular}{|c|c|}
\hline CPF/Documento: $\quad 169.920 .358-00$ & Nome: Kette Dualibi Ramos Valente \\
\hline Telefone: (11) $3079-5483$ & E-mail: kettevalentegmsn.com \\
\hline \multicolumn{2}{|l|}{ Instituiçäo Proponente } \\
\hline CNPJ: $60.448 .040 / 0001-22$ & Nome da Instituição: HOSPITAL DAS CLINICAS DA FACULDADE DE MEDICINA DA U S P \\
\hline
\end{tabular}

Essa submissäo de emenda é exclusiva do seu Centro Coordenador?

A emenda năo é exclusiva de șeu Centro Coordenador, então quando a emenda for aprovada, esta SERÁ replicada nos Centros Participantes vinculados e nos Comités de Ética das Instituiçóes Coparticipantes.

É um estudo internacional? Nằ

- Equipe de Pesquisa

\begin{tabular}{|l|l|}
\hline CPF/Documento & \\
\hline $792.863 .785-91$ & Natascha Cardoso da Fonseca \\
\hline
\end{tabular}

Área de Estudo

Grandes Areas do Conhecimento (CNPq)

- Grande Área 4. Ciências da Saúde

Propósito Principal do Estudo (OMS)

- Cièncias Básicas

Título Público da Pesquisa: Atividade serotoninérgica no hipocampo de pacientes com epilepsia de lobo temporal

Contato Público

\begin{tabular}{|c|l|l|l|}
\hline CPF/Documento & \multicolumn{1}{|c|}{ Nome } & \multicolumn{1}{c|}{ Telefone } & E-mail \\
\hline $169.920 .358-00$ & Kette Dualbi Ramos Valente & (11) $3079-5493$ & kettevalente@msn.com \\
\hline
\end{tabular}

Contato Kette Dualibi Ramos Valente 


\section{APÊNDICE 1. INFORMAÇÕES BÁSICAS DE SUBMISSÃO NA PLATAFORMA BRASIL}

Desenho de Estudo / Apoio Financeiro

Desenho:

Entre os individuos com epilepsia do lobo temporal (ELT) causada por esclenose mesial temporal (EMT), a incidẻncia de depressắo é maior do que entre aqueles com epilepsia do lobo temporal por outras causas. Estudos usando modelos animais e imagem funcional em humanos sugerem a existéncia de um mecanismo serotoninérgico comum. Neste estudo, nós avaliaremos a concentraçäa de serotonina (5HT) no hipocampo dos pacientes com ELT-EMT, que forem submetidos da cirurgia devido à presença de epilepsia refratária. Propomos avaliar a afinidade de ligaçắ dos receptores e transmissor serotoninérgicos no hipocampo destes mesmos pacientes e correl acionar estes dados com a presença de comorbid ades psiquiátricas e outras variáveis elínicas da epilepsia indicadores de gravidade. Para estes objetivos, nós avaliaremos as amostras de hipocampos de pacientes cirurgicamente tratados para ELT por EMT após a assinatura do Termo de Consentimento Livre e Esclanecido. A conoentraçáo de 5HT será medida através de high-performance liquid chromatography (HPLC) com detecção por fluorescéncia. Os receptores e transmissor de serotonina seráo avaliados por Westem Blot. Nossos achados podem contribuir pará delinear quais mecanismos serotoninérgicos podem estar relacionados com a presença de transtomos psiquiátricos e com a gravidade da epilepsia.

Apoio Financeiro

\begin{tabular}{|c|c|c|c|c|}
\hline CNPJ & Nome & E-mail & Telefone & Tipo \\
\hline & & & & $\begin{array}{l}\text { Financiamento } \\
\text { Próprio }\end{array}$ \\
\hline \multicolumn{5}{|c|}{ Palavra Chave } \\
\hline \multicolumn{5}{|c|}{ Palavra-chave } \\
\hline \multicolumn{5}{|l|}{ epilepsia } \\
\hline \multicolumn{5}{|l|}{ serotonina } \\
\hline hipocampo & & & & \\
\hline
\end{tabular}

Detalhamento do Estudo

Resumo:

Entre os individuos com epilepsia do lobo temporal (ELT) causada por esclerose mesial temporal (EMT). a incidéncia de depressä́o é maior do que entre aqueles com epilepsia do labo temporal por outras causas. Estudos usando modelos animais e imagem funcional em humanos sugerem a existência de um mecanisme serotoninérgice comum. Neste estudo, nós avaliaremos a concentragáo de serotonina (5HT) no hipocampo dos pacientes com ELT-EMT, que forem submetidos à cirurgia devido à presença de epilepsia refratária. Propornos avaliar a afinidade de ligaçäo dos receptores e transmissor serotoninérgicos no hipocampo destes mesmos pacientes e correlacionar estes dados com a presença de comorbid ades psiquiátricas e outras variáveis clínicas da epilepsia indicadores de gravidadie. Para estes objetivos, nós avaliaremos as amostras de hipocampos de pacientes cirurgicamente tratados para ELT por EMT após a assinatura do Temo de Consentimento Livre e Esclarecido. A concentrapaăe de 5HT será medida através de high-performance liquid chromatography (HPLC) com detecção por fluorescéncia. Os receptores e transmissor de serotonina seräo avaliados por Westem Blot. Nossos achados podem contribuir para delinear quais mecanismos serotoninérgicas podem estar relacionados com a presença de transtomos psiquiátricos e com a gravidade da epilepsia.

Introdução:

A epilepsia do lobo temporal (ELT) é a principal causa de epilepsia refratária em adultos (Beleza 2009. Tripathi et al 2011. Veriano Jr et al 2010). A. ELT é também o protótipo da sindrome epiléptica cirurgicamente tratável (Engel et al 2012, Sagher et al 2012). Pacientes com ELT, secundárias à esclerose mesial temporal (EMT), apresentam uma maior incidència de transtornos do humor e psicose (Eriellmann RS et al 2007, DiAlessio et al 200\%, Gonçalves 8 Cendes 2011) com consequente impacto negativo nas respostas terapéuticas farmacológicas e cirúrgicas e formando fatores de risco independentes para uma pior qualidade de vida entre os pacientes com epilepsia (Änhoury et al 2000. Aydemir et al 2004, Pugh et al 2005). 1. 1. ELT e Transtomos Psiquiatricos

A etiologia das comorbidades psiquiátricas em pacientes com epilepsia é multifatorial, enwolvendo fatores neurobiológicos e psicos sociais (revisăo em Kanner 2005, revisăo em Kanner 2000). Os determinantes neurobiológicos em potencial incluem idade de inicio da epilepsia, frequência e

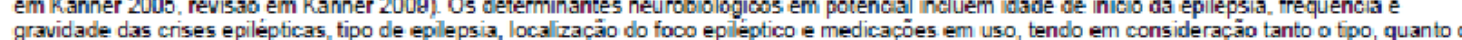

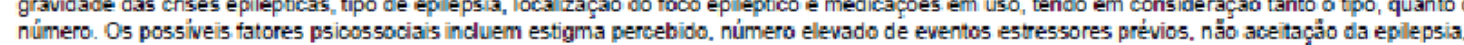
estresse financeiro, problemas profissionais e inicio precoce da epilepsia (revisäo em Kanner 2008, revisão em Kanner 2009). Os estudos mais recentes demonstram uma relaçäo bidirecional entre epilepsia e os transtornos psiquiátricos (revisäo em Kanner 2005 , revisăo em Kanner 2011, revisăo em Pineda et al 20 10). Os transtomos depressivos näo são restritos a pacientes com crises epilépticas fámaco-resistentes e. frequentemente, precedem a inicio das crises (Forsgren \& Nyström 1090, Hersdoffer et al 2000). Além disto, não somente pessoas com epilepsia tếm maior risco de desenvolver transtomos depressivos, mas pacientes com transtomos depressivos tém chances 3 a 7 vezes maiores de desenvolver epilepsia (Forsgren \&. Nyström 1090, Hersdoffer et al 2006, Hersdoffer et al 2000).

Estudios com modelos animais e com neuroimagem funcional e pós-mortem em humanos sugerem a existéncia de um mecanismo patogénico operante comum entre estas condiçóes (Cheetam et al 1990, Lothe et al 2008, Sawic et al 2004, Stockmeir et al 1998, Toczek et al 20003). Os mecanismos patológicos comuns incluem anormalidades no potencial de ligaçăo de receptores de diversos neunotransmissores do sistema nervoso central, especialmente os de serotonina e anormalidades funcionais nos lobos temporais e frontais, incluindo diminuição de receptores de serotonin nas estruturas mesiäs, núcleo da rafe, tálamo e giro cíngulo (Drevets et al. 1090, Hasler et al 2007, revisäo em Kanner 2005, revisảo em Kanner 2009, revisäo em Kanner 2011, Sargent et al. 2000)

1.2. Serotonina

Monoaminas, como a serotonina, produzem seus efeitos induzindo mudanças bioquímicas complexas nos neurơnios pós-sinápticos do sistema nervoso central, através da intera ção com proteínas sinalizadoras - proteína $\mathbf{G}$ - dentro da membrana celular pós-sináptica. Existe uma correlap̧ão consistente entre efe ito medicamentoso tendo como alvo as monoaminas e os estados afetivos e comportamentais (Kalia, 2005).

Madelos monoaminérgicos de depressáo advêm da observaçäo de que pacientes com história de depressão e exposição a altas doses de reserpina droga que causa depleçăo das reservas monoaminérgicas, apresentavam recorréncia dos sintomas depressivos (revisåo 


\section{APÊNDICE 1. INFORMAÇÕES BÁSICAS DE SUBMISSÃO NA PLATAFORMA BRASIL}

Garcia-Morales et al 2008, Kanner 2005, revisão em Hrjove et al em Ettinger and Kanner 2001)

Já foi demonstrado que a serotonina suprime crises epilepticas general izadas em modelos animais (Albano 2006. Favale et al 1995, Jobe and Browning 2005, Merril et al 2007) e diminui a gravidade das crises epiépticas em estudos (Dailey et al 1005, Yan et al 1005) com ratos geneticamente predisposto à epilepsia (GEPR). A depleçảo de serotonina, com consequente, aumento da regulaçáo do receptor pós-sináptico já foi rellacionado a uma maior gravidade da epilepsia. Estudos com GEPR, demonstraram que estes ratos possuem una reduçäo generalizada das concentraçóes de serotonina (Dailey et al 1922, Jobe and Dailey 2000) e, quando administradas medicaçóes que diminuiam ainda mais estas concentrap̧óes, aumentava-se a gravidade das crises epilépticas nestes ratos (Dailey, 1902).

Além disto, a depleçấo de serotonina está associadala à depressa. Pacientes que cometeram suicidio demonstram reservas diminuidas de serotonina, bem como um aumento no autoreceptor supressor 5HT1A nos núcleos dorsais da rafe, em tecidos cerebrais. (Cheetam et al 1890, Stockmeir et al 1988).

Stackmeir et al 1988).
1.2.1. Receptores de serotonina

1.2.1. Receptores de serotonina Os receptores serotoninérgicos são 05 mais numerosos e diversos do sistema de receptores de transmissao monoaminergica. Aproximadamente
a $80 \%$ dos neurônios do núcleo da rafe sintetizam serotonina (revisäo em Hecimove et al em Ettinger and Kanner 2001). 0 hipocampo recebe aferências serotoninérgicas de neurốnios localizados ne núcleo da rafe medial e dorsal. As vias serotoninérgicas da ráe-hipocampo desempenham um importante pappel na regulação do humor e estäo comprometid as com a depressăo (Carr \& Lucki 2011). A liberaçäo da serotonina ou 5 hidrohixitriptamina (5-HT) pelos neurốnios da rafe é regulada por mecanismos intrinsecos e extrinsecos. O mecanismo mais eficiente consiste na alça curta (feedback) autoin ibitória que envolve receptores somatodendritioos $5 \mathrm{HTT} 1 \mathrm{~A}$. A ativaçäa dos autoreceptores $5 \mathrm{HTT} 1 \mathrm{~A}$ da rafe pela liberação local de serotonina inibe a descarga de neurónios serotoninérgicos e posterior liberaçắo de neurotransmissor.

Atualmente, sete familias distintas de receptores serotoninérgicos jä foram identificadas. (5HT1, 5HT2,5HT3,5HT4, 5HT5, 5HT6 e 5HT7) e inúmeras

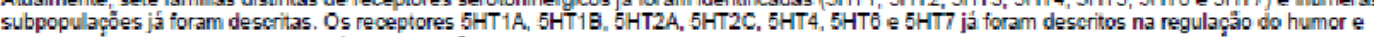
correlacionados a transtomos psiquiátricos (revis.äo em Ptyak et al 2011)

Os receptores 5HT1 são sulbolivididos em 5 subgrupos: 5HT1A, 5HT1B. 5HT1D. 5HT1E e 5HT 1F. Eles săo, em sua maioria, porém năo exclusivamente, associados com proténas GiVGo e inibem a produção de AMPc (nevisão em Ptlyak et al 2011).

Qs receptores 5HT1A sáo os mais amplamente distribuidos de todos os receptores serotoninérgicos. No sistema nervoso central (SNC) ele está presente en maior densidade no córtex cerebral, hipocampo, septo, amigdala e núcleo da rafe. No SNC, eles agem como autoreceptores e receptores polissinápticos. No córtex, estes agem como autoreceptores, bem como receptores polissinápticos. Estes receptores estáo envolvidos nal inibição da descarga de neurónios, regulaçäo da produçăo de ACTH e regulação do comportamento e fome (Wang et al. 2008), sendo que inibiçäo da descarga de neurónios, regulaçäo da produçäo de ACTH e regulaçäo do comportamento fome (Wang et al. 2009), sendo que
possivelmente desempenham um papel importante no desenvolvimento da ansiedade (Klemenhagen et al. 2006). corroborado pelo uso de
antagonistas $5 \mathrm{HT} 1 \mathrm{~A}$ no tratamento da ansied ade e depressáo.

Qs receptores 5HT1B estäo presentes no SNC, onde eles induzem inibição pós-sináptica e efeitos comportamentais. Sua maior concentração pode ser achada nos núdeos da base, estriado e córtex frontal. Sua funçäo depende de sua localizaçäo: no córtex pré-frontal acredita-se agir como receptor terminal, inibindo a liberaçăo de dopamina. No estriado e nos gânglios da base acredita-se que ajam como autoreceptores, in bindo a liberaçäa de serotonina (revisäo em Ptlyak et al 2011).

Qs receptores 5HT2 săo subdivididos em 3 classes: 5HT2A, $5 \mathrm{HT} 2 \mathrm{~B}$ e $5 \mathrm{H} T 2 \mathrm{C}$. Estes sắo os principais subtipos de receptores excitatỏrios entre os receptores acoplados a prote ina $G$ para serotonina. Entretanto. o receptor $5 \mathrm{HT} 2 \mathrm{~A}$ pode ter um efeito inibitónio em certas áreas, como 0 córtex visual e orbitofirontal (revisẵo em Ptlyak et al 2011).

Os receptores 5 HT2A säo expressos em muitos tecidos centrais e periféricos. No SNC, receptores 5 HT2A estäo presentes principalmente no córtex, elaustro e gánglios da base. (Ptliyak, 2011). Sua ativaçăa no córtex pré-frontal, regiảo cujo metabolismo está alterado em pacientes com esquizofrenia, modula a liberação de dopamina e GABA (Bortolozzi et al 2005. Feng et al 2001). Antagonistas. 5HT2A. com diferentes sitios de afinidade (come risperidona, seroquel, olanzapina), são utilizados ne tratamento da esquizofrenia, e já foram relacionados com a presença de sintomas obsessivos compulsivos nestes pacientes (Kim et al. 2008).

Sete variantes dos receptores $5 \mathrm{HT} 4(5 \mathrm{HT} 4 \mathrm{~A}-\mathrm{H})$, que diferem em si na sequëncia do segmento $\mathrm{C}$-terminal, foram identificados. Entretanto, todas as variantes diferem apresentam uma farmacologia semelhante e estäo associadas com ativid ade da adenil-ciclase. No SNC, estes receptores modulam a liberaçá de neurotransmissores (acetileolina, dopamina, serotonina e ácido gama amino butírico - GABA), reforcando a trans missẵo sináptica, a que pode afetar o desenvolvimento da memónia (Ciranna 2006). Um estudo experimental de Lucas et al (2007) com um regime de 3

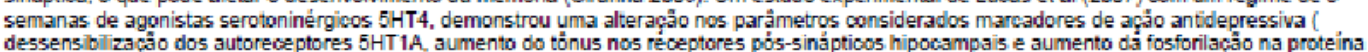
CREB e neurogénese no hipocampo', sugerindo um potencial antidepressivo dos agonistas dos receptores 5HT4, de rápida açáo.

O receptor 5HT6 está localizado predominantemente no encéfalo, onde está acoplado ao estimulo de uma adenill ciclase (Carr \& Lucki 2011). Duas variantes do receptor $5 \mathrm{HTT}$ jẩ foram descritas. A variante completa é composta por 440 aminoácidos é predomina nas áneas límbicas e nas zonas cerebrais extrapiramidais. A segunda variante possivelmente resulta de uma deleçäo da primeira. contendo 288 aminoácidos e predominando no eaudado e subståncia negra. A importáncia clínica exata dos receptores $5 \mathrm{HT}$ 0 permanece ainda ineerta (Ptyak et al 2011). Existem evidéneias que este receptor regula a liberaçăo de inúmenos neurotranmissores, como a acetilcolina, norepinefrina, ácido gaba-aminobutinco e dopamina, que provêm um mecanisme adicional para sua possivel efetividade no tratamento de transtornos psiquiátricos. Inúmeros antidepressivos (amitriptilina, imipramina, doxepina) e alguns antipsicóticos atipicos (olanzapina, quetiapina, clozapina) agem como antagonistas dos neceptores $5 \mathrm{HT} 6$, embora sem seletividade, sugerinda uma possivel associacão entre estes receptores e certos transtomos psiquiátricas.

Os receptores $5 \mathrm{HTT}$ sấ compostos por 445 aminoácidos e aumentam a ativaçăo da adenil ciclase via proteina Gs. Ele também ativa a AMP quinase. Existem 5 isoformas de receptor (5HT7A-D), que diferem entre si peló seu terminal C (Pytliak, M et al. 2011). Très destas variantes foram identificadas em humanos, designadas como 5-HTT, 5-HThb e 5-HT70 (Leopoldo et al. 2011). Todos exibem as mesmas propriedades farmacológicas e são expressos em vasios, músculos lísos extranasculares e SNC. Antipsicóticos atipicos, como a clozapina, e antidepressivos possuem grande afinidade por receptores, 5HT7. Antagonistas dos receptores.5HT7 mimetizam efeitos dos inibidores seletvos de recaptacia da realizado com ratos deficientes de receptor $5 \mathrm{HTT}$, 0 s autores, demonstraram que estes ratos, possuiam uma reduçálo do limiar para crises eplepticas, quando comparados à ratos selvagens.

Diversos estudos clínicos e experimenta is já demonstraram que na depressäo ocome um aumento na reguląăo dos receptores 5HT1.A da rafe, com consequente autoinibiçäo aumentada da liberaçäo de 5-HT. Este mecanismo também pode estar envolvido em pacientes com depressäo associado com epilepsia. Em pacientes com eplepsia do lobo temporal e depressäo associada. um estudo com tomografia por emisstio de positrons (PET) demonstrou que $\mathbf{a}$ afinidade de ligaçäo dos receptores $5 \mathrm{HT}$ da rafe estava aumentada e positivamente correlacionada cm a gravidade dos sintomas depressivios (Lothe et al 2008).

Outros estudos em humanos com neuroimagem funcional, utilizando PET, tendo como alvo os receptores serotoninérgicos 5 HT1 A, sugerem um papel fisiopatológico comum da serotonina na depressáo e epilepsia (Hasler et al 2007). Nestes estudos, foi demonstrada uma diminuiģăo da ligą̣ắc de serotonina em estruturas comuns das duas patologias: nas regiöes temporais mesiais, giro do cingulo e núcleo da rafe (Lothe et al 2008). Usando modelos animais de estado de mal induzido por lítio e pilocarpina (modelo animal de eplepsia temporal). Mazaratt et al. (2008) encontraram sintomas de depressão nos ratos pós estado de mal. Este estudo demonstrou uma transmissäo interictal seroton inérgica rafe-hipocampal diminuida em ratos pós estado de mal-induzido (Mazarati, 2008). Estudos posteriores evidenciaram 


\section{APÊNDICE 1. INFORMAÇÕES BÁSICAS DE SUBMISSÃO NA PLATAFORMA BRASIL}

que a depressăo associada com a eppilepsia é acompanhada por hipersensibilizaçäo dos receptores $5 H T 1 A$, em ratos pós-estado de mal induzido, quando comparados a controles saudáveis (Fineda 2010)

1.2.2. Transmissäo serotoninérgica

Após a serotonina ser liberada na sinapse, ela é inativada primariamente pela recaptaçăo do transmissor por um transportador serotoninérgico de membrana plasmática: o tran sportador da serotonina (SERT). Ele se localiza perisinapticamente nos temminais pré-sinapticos de ó́lulas do SNC sertoninérgicas, bem come em axönios e corpos celulares de células serotoninérgicas da rafe. No SNC, o SERT é o mecanismo controlador predominante da intensidade e duracaso da neurotransmissäo serotoninergica (Daws \& Gold 2011). Os antidepressivos triciclicos e os inibidones de predominante da intensidade e duraçáa da neurotransmissäo serotoninergica (Daws \& Gold 2011). Os antidepressivas triciclicos e os inibid ones de restudaçam PET em pacientes com transtomo depressivo maior (Lundberg et al 2012).

estuda com PET em pacientes

1.3. Estudo em tecido humano

1.3.1. Cromatografia liquida de alta eficiëncia (HPLC)
A. quantificaģás da serotonina e seus metaboblitos em homogenatos de cérebro é uma importanta estratégia comumente utilizada em estudos neurofisiológicos ou fisiopatológicos em modelos animais (Alvarez et al 1989, Nogushi et al 2000, Parrot et al 2007, Umeda et al 2005). Atualmente a cromatografia líquida de alta eficiäncia (HFLC) é o método analítice mais amplamente utilizado. No entanto, existem poucos estudos em tecido de cérebro humano. No presente estudo foi desenvolvido um método de quantificação de 5-hidroxitriptamina (serotonina) por cromatografia liquid a de alta eficiéneia com deteç̧ăo por fluonescéncia em tecido de hipocampo dos seres humanos.

a HPLC é, basicamente, uma técnica de separaçăo de moléculas de uma soluçäo. Esta técnica emprega pequenas colunas, recheadas de materiais especialmente preparados e uma fase móvel qué é eluida sob altas pres sỏes. E capaz de realizar separacốes quantitativas em poucos minutos, com alta resolucão, eficięncia e sensiblidade (Talib et al.2011). A aparelhagem para HPLC é, fundamentalmente, composta por bombas de injecäo, uma col una por onde passa a fase móvel e um detector de particulas ao final do processo. Um detector pode ser seletivo ou universal, ou seja pode ser especifico para uma amostra ou ser útil para todos os tipos de amostra. Dois tipos de detectores sajo muito utilizados: absorbancia no ultravioleta por fuore scéncia (Talib et al 2011).

por fuore scéncia (Ta lib et al 2011 ). é idefectores por fluorescencia sajo os ideais para compostos fluorescentes, devido a sua alta sensibilidade. Uma alta inten sid ade de fluarescencia

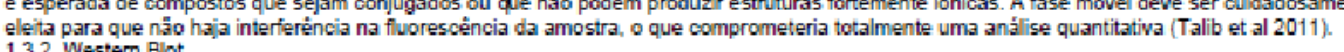
1.3.2. Western Blot

Western blot é um método utilizado para deteç̧ăo de proteínas em uma mistura de extrato de tecido biológico. Ele age separando estas proteinas desnaturadas, de acordo com sua massa molecular. durante eletroforese em gel de poliacrilamida. Teminada a eletroforese, coloca-se o gel em

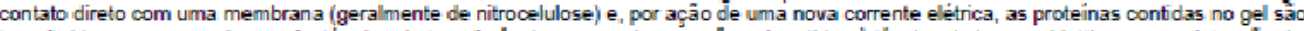
transferidas para a membrana. Ao témino da transferëneia. as membranas säo submetidas à técnica de immunoblotting para a deteç̧ấo das proteinas a partir da utilizaçăa de anticorpos específicos. Em seguida, as membranas săo incubadas com anticorpos primários e secundários en

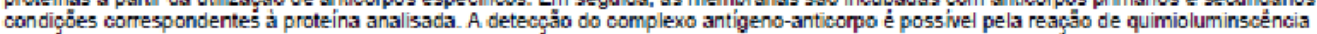
amplificada, no caso do anticorpo secundário não ser conjugado à peroxidase, deve ser realizada uma terceira incubação com um composto que permita a ligaçäo ao reagente quimioluminescente, A partir da revelaçäo da membrana , faz-se uma densitometria com auxilio de software apropriado (Talb et al.2011). A detecpä́o dos receptores e transportador de serotonina pode ser realizada através da técnica de Western Blot (Huang et al 2012. Xiacying et al 2004).

Hipótese:

A. hipótese do estudo atual é a de que nos pacientes com epilepsia do lobo temporal causada por esclenose mesial temporal (ELT-EMT). há uma redução da atividade serotoninérgica hipocampal, seja através dos niveis de serotonina, ou de receptones ou de transportadores e que esta reduçăo possa estar relacionada à presença de comerbidades psiquiátricas elou à maior gravidade da epilepsia. Este será o primeiro estudo medindo a cancentraçäo de serotonina e avaliando niveis de receptores e transmis sores em tecido humano de pacientes com epilepsia, bem como comparando grupos de epilepsia por esclerose mesial temporal com e sem transtomo psiquiátrico. Esperamos, com nossos achados, contribuir para comparando grupos de epilepsia por esclerose mesial temporal com é sem transtomo psiqulatinco. Esperamos, com nossos achados, Contribur para como. com a gravidade da epilepsia.

Objetivo Primário:

Este estudo tem come objetivo primário avaliar se a concentração de serotonina e seus metabólitos, receptores de serotonina e transportadores de serotonina no hipocampo de pacientes com epilepsia do lobo temporal causada por esclerose mesial temporal (ELT-EMT) e distúrbios psiquiátricos. estăo diminuidos em comparą̧ão com es niveis de serotonina no tecido do hipocampo de pacientes com ELT-EMT sem comorbidades psiquiátricas.

Objetivo Secundário:

a objetivo secundário deste estudo é o de deteminar se existe correlaçăo entre niveis de serotonina e as variáveis nelacionadas à gravidade da eplepsia.

Metodologia Proposta:

Tecido Humano

Uma amostra do hipocampo do paciente será coletada durante procedimento cirúrgico e congelada a $-80^{\circ} \mathrm{C}$ até análise. O hipocampo será amazenado para análise no Laboratónio de Neurociéncias (LIM 27 ) no Instituto de Psiquiatria.

Metodologia ¿ HPLC

A serotonina e o 5 -metoxitriptamina seräo diluidas em uma soluçåo de fosfato de sódio da Merck (Darmstadt, Germany). Q dodecil sulfato de sódio será da Adrich-Sigma (Steinheim, Germany). Ácido Perclórico (HClO4), methanol e acetonitrila seräo obtidos da Merck (Darmstadt, Germany).

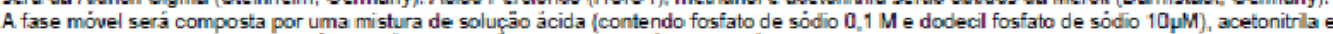
metanol $(70: 15: 15$ viviv) A. fase móvel será ajustada para $\mathrm{pH} 2.5 \mathrm{com}$ ácido perclórieo $37 \%$, filtrada com filtro de 0.45 -mm e degaseificada antes do uso. A fase móvel será usada em temperatura ambiente com fluxo de $0.8 \mathrm{~m} / \mathrm{min}$ (pressåo aproximada de 150 bar).

Serăo preparados padrōes com solucäo de fosfato de sódio, que armazenados em vials ämbar nas seguintes concentrạofes: $1 \mathrm{mg} / \mathrm{mL}, 0.1 \mathrm{mg} / \mathrm{mL}$ $0.01 \mathrm{mg} / \mathrm{mL}, 0.001 \mathrm{mg} / \mathrm{ml}$ e $0.0001 \mathrm{mg} / \mathrm{ml}$ de serotonina. O padrä́o extemo será o 5 - metoxytriptamina preparado em uma soluçáo de fiosfato de sódio $30 \mathrm{mM}, \mathrm{pH}$ 7,4 e armazenado em vial amber a $4^{\circ} \mathrm{C}$.

a tecido cerebral humano será dissecado e homogeneizado com ácido perclórico 3,4M em potter (Potter S, B. Braun da Biotech International(8) para uma concentraçäa final de $25 \mathrm{mg} / \mathrm{ml}$. Em seguida, sonicado por 30 segundos para lise de membranas (Biotech Internationale, Vir\$onic $100 \mathrm{da}$ Virtisen), centrifugado $14000 \mathrm{~g}$ a $4^{\circ} \mathrm{C}$ por 20 minutos (Centrifuga Himac CF $15 \mathrm{CC} 2$ da Hitachi $\mathrm{C}$ ) e amazenado $\mathrm{a}-80^{\circ} \mathrm{C}$ ate uso. A cromatografia será realizada pelo sistema Shimadzu. A coluna $(250 \times 4.0 \mathrm{~mm}$ i.d.) Será Lichrospher $5 \mathrm{~mm} 100 \mathrm{CB}$ (Varian). A deveccálo será realizada por fluorescéncia realizada pelo sistema Shimadzu. A coluna ( $250 \times 4.0 \mathrm{~mm}$ i.d.) será Lich

Para a curva de calibrạ̧ăo serăo utilizado $200 \mathrm{C}$ L de ácido perclórico, também utilizado para homogeneizar o tecido cerebral humano e. 


\section{APÊNDICE 1. INFORMAÇÕES BÁSICAS DE SUBMISSÃO NA PLATAFORMA BRASIL}

o qual é livre de substáncias potencialmente interferentes no comportamento da serotonina. As solucbies padröes serấo preparadas semanalmente A. metodologia de quantifica ça de serotonina foi desenwolvida baseada em protocolos previamente estabelecidos pelo grupo em plaquetas humanas e em estudos prévios da literatura (Alvarez et al 1980. Baumann et al 1898. Nogushi et al 2000. Umeda et al 2004)

Metodologia ¿ Western Blot

a tecido cerebral humano, já dissecado e armazenado, serả homogeneizado em solução de líse celular para análise por Westem Blot, associado a uma soluçăo inibidora de protease, comum a concentraçäo final de tecido de $200 \mathrm{~m} g$ de tecido wtiml. A concentraçäo da proteina na amostra será determinada usando o procedimento de Bradiord. Todas as amostras serăo submetidas à eletroforese em gell. Terminando-se a eletroforese, o gel será colocado em contato direto com uma membrana de nitrocelulose e as proteínas contidas no gel serâo transferidas para a membrana. por urmi nova corrente elétrica, para que a proteína de interesse possa ser detectada após incubaçóes com anticorpos específicos e compostos

fluorescentes. As membranas seräo incubad as com os anticorpos de interesse (anticorpo anti-transportador de serotonina, anti-receptor $5 \mathrm{HT} 1 \mathrm{~A}$, ar receptor 5HT1B, anti-receptor 5HT2 A, anti-receptor 5HT4, anti-receptor 5HT6, anti-receptor 5HT7) e para b-actina.

\section{Critério de Inclusầ}

Análise de Hipocampo ressecados cirurgicamente por eplepsia do lobo temporal decorrente de esclerose mesial temporal refratária ao tratamento medicamentoso. A amostra do hipocampo será obtida dos pacientes que serăo submetidos a procedimento neurocirúrgico padrä́o com lobectomia temporal anterior.

Critério de Exclusäo:

Os critérias de exclusão săo os hipocampos de pacientes com: 1. Idade menor de 18 anos: 2. Deficiència mental e 3. Nâa consentimento na pesquisa após a apresentaģăo do termo de consentimento livre e esclarecido.

Seräo ainda excluídas as amostras de tecido humano que näo sejam suficientes para análise após o procedimento cirúrgico.

Riscos:

Nảo há riseos para o paciente.

Beneficios:

Nẫo há benefícios diretos para o paciente

Metodologia de Análise de Dados:

A correlaçäo entre $5 \mathrm{HT}$ e as variáveis contínuas será medida através da comrelaçäo de Pearson. Comparaçắo entre as variảveis de grupo (sexo.

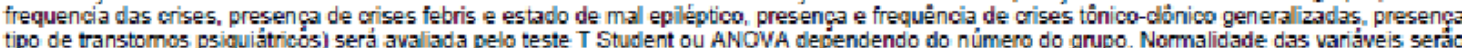
verificados por QQQ plots. Tipo I de erro foi estabelecide em $5 \%$ e todos os testes foram bieaudais. As análises serão conduzidas no SPSS v14.

Desfecho Primário:

Análise e mensuraçăo da concentrạ̧ăo de serotonina, receptores serotoninérgicos e transportador no hipocampo de pacientes com epilepsia refratária; e

Correlagăo de variáveis clínicas com a atividade serotoninérgica

Tamanho da Amostra no Brasil: 40

Paises de Recrutamento

\begin{tabular}{|c|l|c}
\hline Pais de Origem do Estudo & \multicolumn{1}{|c|}{ Pais } & NN$^{2}$ de participantes da pesquisa \\
\hline Sim & BRASIL & 40 \\
\hline
\end{tabular}




\section{APÊNDICE 1. INFORMAÇÕES BÁSICAS DE SUBMISSÃO NA PLATAFORMA BRASIL}

Outras Informaçổes

Haverả uso de fontes secundárias de dados (prontuários, dados demográficos, etc)? Nâo

Informe o número de individuos abordados pessoalmente, recrutados, ou que sofreräo algum tipo de intervenęäo neste eentro de pesquisa:

40

Grupos em que seräo divididos os participantes da pesquisa neste centro

\begin{tabular}{|l|l|l|}
\hline \multicolumn{1}{|c|}{ ID Grupo } & \multicolumn{1}{|c|}{$\mathbb{N}^{2}$ de Individuos } & \multicolumn{1}{|c|}{ Intervençóes a serem realizadas } \\
\hline $\begin{array}{l}\text { Hipocampo de Pacientes Epilepsia do Lobo } \\
\text { Temporal }\end{array}$ & 40 & Dosagem da concentraģăo de serotonina e metabólitos \\
\hline
\end{tabular}

a Estudo é Multicèntrico no Brasil?

Nลื้อ

Propöe dispensa do TCLE?

Nẫo

Haveră retenção de amos tras para armazenamento em baneo?

Nẫo

Cronograma de Execuçẳo

\begin{tabular}{|l|l|l|}
\hline \multicolumn{1}{|c|}{ Identificação da Etapa } & \multicolumn{1}{|c|}{ Início (DD/MM/AAAA) } & \multicolumn{1}{c|}{ Término (DDMMM/AAAA) } \\
\hline Pesquisa bibliográfica & $01 / 02 / 2016$ & $02 / 03 / 2016$ \\
\hline Coleta de dados e material & $01 / 03 / 2016$ & $01 / 03 / 2017$ \\
\hline Avaliaçâo de material coletado & $04 / 07 / 2016$ & $02 / 09 / 2017$ \\
\hline
\end{tabular}

Orepamento Financeiro

\begin{tabular}{|l|l|r|}
\hline \multicolumn{1}{|c|}{ Identficaçä́ de Orçamento } & \multicolumn{1}{c|}{ Tipo } & Valor em Reais (RS) \\
\hline Material de consumo + material pemanente & Capital & RS 39.243 .20 \\
\hline Total em RS
\end{tabular}

Qutras informaçöes, justificativas ou eonsideraçöes a critério do pesquisador:

a Projeto será submetido à Agéncia Finciadora de Pesquisa para subsidio após aprovação do Comitê de Ėtica desta Instituição

\section{Bibliografia:} Albano C. Cupello A, Mainardi P. Scarrone S. Favale E (2006) Successful treatment of epilepsy with serotonin reuptake inhibitors: proposed
mechanism. Neurochemical Research $31: 509$ ¿ 514 Alvarez JC. Bothua D. Collignon I, Advenier C. Spreux-Varaquaux O (1989) Simultaneous measurement of dopamine, serotonin, their metabolites and tryptophan in mouse brain homegenates by high-performance liquid chromatography with dual coulometric detection. Biomedial Chromatography 13: 293 z 298 Anhoury S. Brown RJ Krishnamoorthy ES, Trimble MR (2000) Psychiatric outcome after temporal lobectomy: a predictive study. Epilepsia 41:1808 ¿ 1815 . Aydemir N. Ozzara C.. Canbeyli R. Tekcan A (2004) Changes in quality of life and self-perspective related to surgery in patients with temporal lobe ep ilepsy. Epilepsy and Behavior $5(5)$ ) 735 i 742 Bagdy $G$, Kecskemeti V. Riba P. Jakus R (2007) Serotonin and epllepsy. Journal of Neurochemistry. 100: 857 - 873. Baumann MH, Ayestas MA, Rothman RB (1988) Functional Consequences of Central Serotonin Depletion Produced by Repeated Fenfluramine Administration in Rats. The Journal of Neuroscience 18(21):0009; 9077 Beleza P (2000) Refrastory epilepsy: a clinically oriented review. European Neurology 62: 65 i 71 Bortolozzi A. Diaz-Mataix L, Scorza MC. Artigas PCF (2005) The activation of $5 \mathrm{HT} 2$ A receptors in prefrontal obrtex enhances dopaminergic activity. Joumal of Neurochemistry 95: 1597 \& 1807 Briellmann R. Hopwood MJ. Jackson GD (2007) Major depression in temporal lobe epilepsy with hippocampal sclerosis: clinical and imaging correlates. Joumal of Neunology and Neurossurgical Psychiatry 78 : 1226 i 1230 Cam $G$, Lucki II (2011) The role of serotonin receptor subtypes in treating depression: a review of animal studies. Psychophamacology 213: 265 \& 287 Cheetam SC. Crompton MR. Katona CL. Horton RW (1980) brain $5 \mathrm{HT} 1$ binding of $3 \mathrm{H}$-imipramine in brain and platelets and its relevance to the biochemistry of affective disorders. Life Sciences $29: 211$; 220 Ciranna L (2006) Serotonin as a modulator of glutamate- and GABA-mediated neurotransmission: implications in physiological functions and in pathology. Currmts in Neurophamacology 4: 101-114 Clough RW. Peterson BR. Steenbergen JL. Jobe PC. Fells JB, Browning RA, Mishra PK 8 198B) Neurite extension of developing neuroadrenergic neurons is impained in genetical y epilepsy-prone rats (GEPR-3s): an in vitro study in locus coeruleus. Epilepsy Rese arch 28: 135 i 146 Dailey JW, Mishra PK, Ko KH, Penny JE, Jabe PC (1982) Serotoninergic abnormalities in the central nervous system of seizure-naive genetically epilepsy prone rats. Life Sciences 50: $319 \dot{z} 328$ Dailey JW, Yan Q-S, Adams -Gurtis LE, Ryu JR, Ko KH, Mishra PK, Jobe PG (1995) Neurochemical correlates of antiepileptic dings in the genetically epilepsy-prone rat (GEPR). Life Sciences 58(4):259 ¿266 Daws LC, Gould GG (2011) Ontogeny and regulation of the serotonin transporter. Prowiding insights into human disorders. Phamacology \& Therapeutics 131: 11 , 79 DeAlessio L, giagante B, Papayannis C. Qddo S, Silva W. Solis P, Donnoli V, Kauttiman M Consalvo D. Zieher LM. Kochen S (2000) Psychotic disorders in Argentine patients with refractory temporal lobe epilepsy: a case-control study. Eplepsy and Behavior 14(4): 604 ¿ 609 Drevets WC, Frank. E, Price J, Kupfer DJ, Holt D, Greer PJ, Huang Y, Gautier C, Mathis C (19.9e) Biological Psychiatry 40: 1375 c 1387 Engel JJ, McDermott MP, Wiebe S, Langitt لJT, Stern JM, Dewar S, Gardiner I, Ertba G, Fried L, Jacobs M, Vinters HV, Minzer S. Kieburtz K. (20 12) Early surgical therapy for ding-resistant temporal lobe epilepsy: a 


\section{APÊNDICE 1. INFORMAÇÕES BÁSICAS DE SUBMISSÃO NA PLATAFORMA BRASIL}

randemized trial. The Joumal of American Medical Association 307 (9): 922 ¿ 930 Favale E, Rubino V, Mainardi P. Lunardi G. Albano C (1905) Anticonvulsivant effect of fluoxetin in humans. Neurology 45(10): 1928 ¿ 1927 Feng J, Cai X, Zhao J, Yan Z (2001) Serotonin receptors modulate GABA A receptor channels through activation of anchored protein kinase $\mathrm{C}$ in prefrontal cortical neurons. The Journal of Neuroscience 21(17): 6502 26511 Fors gren L. Nyström L. (1990) An incident case-referent study of epileptic seizunes in adults. Epilepsy Research 8(1)r66-81 Garcia-Morales I,

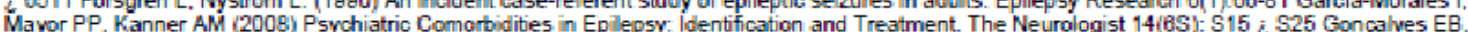
Cendes F (2011) Depression in pacients with refractory temporal lobe epilepsy. Arquivos de Neuropsiquiatria 69 (5): 775 C 777 Hasler $\mathbf{G}$, Bonwetsch R, Giowachinni G, Toczek MT, Bagic A, Luckenbaugh DA, Drevets WC, Theodore WH (2007) 5HT1A Receptor bindind in temporal lobe epilepsy patients with and without major depression. Biological Psychiatry 02: 1258; 1.264 Hesdorffer DC, Hauser WA, Olafs:son E, Olatsson E, Ludvigsson F Kiartassion $\mathrm{O}(2006)$ Depression and suicidal attempt as risk factor for incidental unprowoked seizures. Annals of Neunology $59: 35$ i 41 . Hesdorffer DC. Hauser WA, Annegers JF, Cascine 6 (2000) Major depression is a risk factor for seizures in older adults. Annals of Neurology 47:246, 249 Hrjove Hecimovic, Santos J, Giliam F. Kanner AM. Neuroanatomical and Nourobiological Bases of Psychiatrie Disorders em Ettinger, AB, Kanner, A (2001) Psychiatric Issues in Epilepsy: A Practical Guide to Diagnosis and Treatment Editora Lippincott: 93 ¿ 118 Huang Y, Xu H, Li H, Yang H, Chen Y, Shi $X$ (2012) Pre-gestational stress reduces the ratio of 5-HIAA to 5-HT and the express ion of 5-HT1A receptor and serotonin transporter in the
foetal rat. Neuroscience 13(22) Jobe PC. Browning RA (2005) the serotoninergic and noradrenergic effects of antidepressant drugs are foetal rat. Neuroscience 13(22) Jobe PC. Browning RA (2005) the serotoninergic and noradrenergic effects of antidepressant drugs are
anticonvulsivant, not proconvulsant. Epilepsy and Behavior 7: 602 ¿ 619 Jobe PC. Dailey JW (2000) Genetically Epileppsy-Prone Rats (GEPRs) in Drug Research. CNS Drug Reviews B(3): 241 ¿2 260 Kalia M (2005) Neurobiological basis of depression: an update. Metabolism 54(5.51)-24.7 Kanner AM (2005) Depression in Epilepsy. a neurobilogic perspective. Epilepsy Currents. $5(1): 21$ ¿ 27 Kanner $A$ (200B) Depression in epilepsy: a complex relation with unexpected consequences. Current Opinion in Neurology 21: 190 \& 184 Kanner A (2009) Depression and epilepsy. a review of multiple facets of their close relation. Neurologic Clinies 27: 865 i.880 Kanner AM (2011) Depression and epilepsy. a bidirectional relation? Epilepsia 52(S1); 21 2 27 Kim SW, Shin IS, KIm JM. Youn T, Yang S.J, hwang MY, Yoon JS (2009) The 5HT2 receptor profles of antipsychotics in pathogenesis of obscessive-compulsive symptoms in schizophrenia. Clinical Neuropharmalogical $32(4)=224$ ¿226 Klemenhagen KC, GondonN JA, David DJ. Hen R. Gross. CT (2006) Increased fear response to contextual cues in mice lacking the 5-HT1A receptor. Neuropsychophamacology 31 101-111 Leopoldo M. Lacivita E. Berardi F. Perrone R. Hedlund PB (2011) Serotonin 5-HT7 receptor agents: structure-activity relation ships and potential therapeutic application in central nervous system disorders. Phamacology \&. Therapeutics 120: 120 i 148 Lothe A, Didelot A, hammers A. Costes $N_{1}$, Saoud M, Gilliam F, Ryvin P (2008) Comorbidity between temporal lobe epilepsy and depression: a [18F] MPPF PET study. Brain 131: 2765 i 2782 Lucas G, Rymar W, Du J, Mnie-Filali O, Bisgaard C, Manta S, Lambars-Senas, L, Wiborg O, Haddjerj N, Piñeyro G, Sadikot AF, Debonnel G (2007) Serotonin 4 (5HT4) receptor agonists are putative antidepressants with a rapid onset of action. Neuron $55: 712$ i 725 Lunoberg J. Tiger M, Lande $\mathrm{c}$ M, Halldin C. Farde L (2012) Serotonin transporter occupancy with TCAs and SSRls: a PET study in patients with major depressive

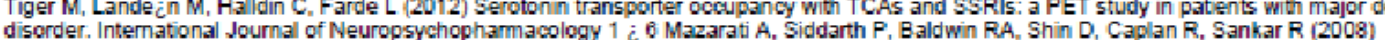
Depression after status epilepticus: behavioural and biochemical deficits and effects of fluoxetine. Brain 131(Pt 8):2071-83. Merrill MA, Clough RW, Dailey JW, Jobe PC. Browning RA (2007) Localization of the serotonergic teminal fields modulating seizures in the genetically eplepsy-prone rat. Epilepsy Research 76: 93 i 102 Mnie-Filali 0 . Lambás-Serias L. Zimmer L. Haddjeri (2007) N: 5-HT7 receptor antagon ists as a new class of antidepressants. Drug News Perspect 20: 613-618 Nogushi K, Watanabe T, Higushi S, Chiba K (2000) Determination of YMod2, a novel selective serotonin reuptake inhibitor, in rat and dog plasma by high-performanoe liquid chromatography with fluorescence detection. Biomedical Chromatography 14:208 ¿ 273 Parrot S, Lamás-Senas L. Sentenac S, Denoroy L. Renaud B (2007) Highly sensitive assay for the measurement of serotonin in micnodialysates using capillary high-performance liquid chromatography with electrochemical detection. Joumal of Chromatography $B$ 850: 303 - 300 Pineda E Shin D. Raman Sankar R. Mazarati MA (2010) Comorbidity between epilepsy and depression: Experimental evidence for 850: 303 - 309 Pineda E, Shin D, Raman Sankar R, Mazarati MA (2010) Comorbidity between epilepsy and depression: Experimental evidence for
the involvement of serotenergic, glucecorticoid, and neuroinflammatory mechanisms Epilepsia, $51(\mathrm{~S} .3)=110 \mathrm{C} 114$ Pugh MJV. Copeland LA, Zeber $\mathrm{JE}$, Cramer JA, Amuan ME (2005) The impact of epilepsy on health status among Younger and Older Adults. Epilepsia, 46(11):1820 i 1827 Pytliak M, Vargová V. Mechírová V. Fels̆öci M (2009) Serotonin Receptors ¿ From molecular biology to clinical applications. Physiologic Research 80 : 15 ¿ 25. Ryul JR, Jobe PC. Mibrandt JC. Mishra PK, Clough RW. Browning RA., Dailey JW. Seo DO. Ko KH (19ee) Morphological deficits in noradrenergic neurons in GEPR-9s stem from abnomalities in both the locus coeruleus and its target tissues. Experimental Neurology 156: 84 ¿ 91 Sagher $Q$. Thawani JO, Etame AB, Gomez-hassan DM (20 12) Seizure outcomes and mesial resection volumes followin selective amygdalohippocampectomy and temporal lobectomy. Neurosurgical Focus 32(3). EB Sargent PA Kjaer KH, Bench C.J, Rabiner EA, Messa C, Meyer J, Gunn RN, Grasby PM, Cowen PJ (200D) Brain serotonin 1A receptor binding measured by positron emission tomography with [1 1C]WAY-100635 Archives. Gen Psychiatry 57: 174 i 180 Savic I, Lindstrom P, Gulyas B, Haldin C, Andree B, Farde L (2004) Limbic reductions of BHT îA receptor binding in human temporal lobe epilepsy. Neurology 62: 1343 ¿ 1351 Stockmeier CA, Shapiro LA, Dilley GE, Kolli TN, Friedman L, Rajkowska $G$ (1998) Increase in serotonin $1^{3}$ autoreceptors in the midbrain of suicide victims with major depression- post mortem evidence for deacresed serotonin activity. Journal of Neuroscience 18: 7394 i 7401 Talib LL. Joaquim HPG. de Paula WJR (2011) Metodologia em Neuroquimica in Clínica Psiquiátrica. Editora Manole volume 2: 2048-2058 Toczek MT. Cars on RE Lang L. Ma Y. Spanali MV. Der MG. Faz lat S. Herscovitch P. Eckelman WC. Theodore WH (2003) Pet imaging of 5HT1A receptor binding in patients with temporal lobe epilepsy. Neurology 60(5): 740 ¿ 758 Tripathi M, Uma PP, Vibha D, Bhatia R, Srivastana MVP Singh MB, Kameshwar P Chandra SP (2011) Predictors of refractory epilepsy in North Indiar a case control study. Seizure 20: 779

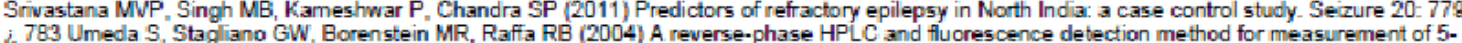
is 783 Umeda S, Stagliano GW, Borenstein MR, Raffa RB (2004) A neverse-phase HPLC and fluorescence detection method for measurement of 5 Franco V, Gambardella A, Guertini R., La Briola F, Ladogana M, Rosati E, Spechio LM, Striano S, Perucea E (2010) Characteristics of a large population of patients with refractory epilepsy attending tertiary referral centers in Italy. Epilepsia 51(5): 021 ¿ 925 Xiagying W, Baumann MH, Xu Heng, Rathman RB (2004) 3,4 Methylenedioxymethamphetamine (MDMA) administration to rat decreases brain tissue senotonin but not serotonin transporter prote in and glial fibrillary acidic prote in. Symapse 53: 240 \& 248 Wang HT. HanF. Shi $\gamma \times(2009)$. Activity of the 5-HT1A receptor is involved in the alteration of lucocorticoid receptor in hippocampus and corticotropin-releasing factor in hypothalamus in SPS rats. International Joumal Molecular Medicine 24: 227-231, Witkin JM, Baez M, Yu J, Barton ME, Shannon HE ( 2007) Constitutive deletion of the serotonin -7 (5HT7) receptor decreases electrical and chemical seizure thresholds. Epilepsy Reseanch 75: 39 ¿ 45 Yan Q-S. Jobe PC. Dailey JW (1985) Further evidence of anticonvulsivant role of 5-hydroxytryptamine in genetically eplepsy-prone rats. British Joumal of Phamacology $115(7): 1314-1318$

Upload de Documentos

Arquivo Anexros:

\begin{tabular}{|l|l|}
\hline \multicolumn{1}{|c|}{ Tipo } & \\
\hline Folha de Rosto & Follha_de_Rosto_13456.pdf \\
\hline Projeto Detalhado / Brochura Investigador & Projeto didoc \\
\hline Outros & Anuencia.pdf \\
\hline Orçamento & Orcamento.xls \\
\hline Outros & Formulario.potf \\
\hline
\end{tabular}

Dats an exukmikeso de Projatto: 19092016

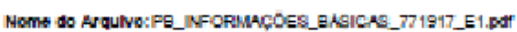

Yorress do Projetter 2 


\section{APÊNDICE 1. INFORMAÇÕES BÁSICAS DE SUBMISSÃO NA PLATAFORMA} BRASIL

\begin{tabular}{|l|l|}
$\begin{array}{l}\text { TCLE / Termos de Assentimento / Justificativa de } \\
\text { AUséncia }\end{array}$ & TCLE_doc \\
\hline Declaraçäa de Pesquisadores & Carta_Pesquisadora_Responsavel.pdf \\
\hline Outros & Formulario_Emenda_Folha1.pdf \\
\hline Outros & Formulario_Emenda_Folha2. pdf \\
\hline Outros & Formulario_Emenda_Folha3.pdf \\
\hline
\end{tabular}

\section{Finalizar}

Manter sigilo da integra do projeto de pesquisa:

Nă은

Justificativa da Emenda:

Adiçăo de pesquisador membro nas informaçốes preliminares do projetos. O pesquisador já havia sido

referido como pesquisadar membro executante no formulário on-line. Não foi modificada o termo de

também nâto oferecendo nenhum risco adicional ao paciente. Anexado Garta do pesquisador responsável e

formulârio de emenda da CAPPESQ (esta última em 3 folhas em separado). 


\section{APÊNDICE 2. PARECER DE APRECIAÇÃO DO CEP}

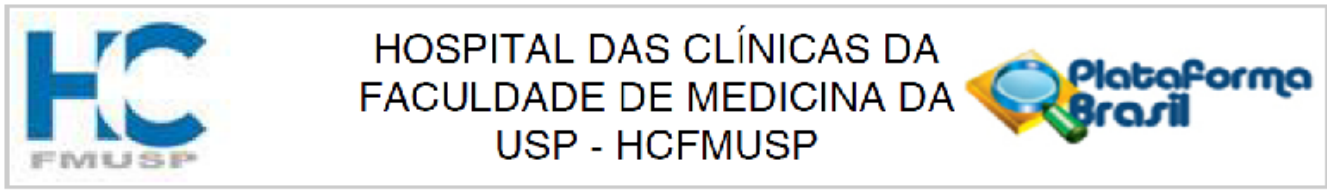

\section{PARECER CONSUBSTANCIADO DO CEP}

\section{DADOS DO PROJETO DE PESQUISA}

Titulo da Pesqulsa: Atividade serotoninérgica no hipocampo de pacientes com epilepsia de lobo temporal

Pesqulsador: Kette Dualibi Ramos Valente

Área Temática:

Versão: 1

CAAE: 56797513.4 .0000 .0068

Instituição Proponente: HOSPITAL DAS CLINICAS DA FACULDADE DE MEDICINA DA U S P

Patrocinador Principal: Financiamento Próprio

DADOS DO PARECER

Número do Parecer: 1.633 .093

\section{Apresentação do Projeto:}

Entre os indivíduos com epilepsia do lobo temporal (ELT) causada por esclerose mesial temporal (EMT), a incidência de depressão é maior do que entre aqueles com epilepsia do lobo temporal por outras causas. Estudos usando modelos animais e imagem funcional em humanos sugerem a existência de um mecanismo serotoninérgico comum.

Esse estudo objetiva a avaliaçåo da concentraçăo de serotonina (5HT) no hipocampo dos pacientes com ELT-EMT, que forem submetidos à cirurgia devido à presença de epilepsia refratária. Os pesquisadores se porpóe a avaliar a afinidade de ligação dos receptores e transmissor serotoninérgicos no hipocampo destes mesmos pacientes e correlacionar estes dados com a presença de comorbidades psiquiátricas e outras variáveis clínicas da epilepsia indicadores de gravidade. Para estes objetivos, serăo avaliadas as amostras de hipocampos de pacientes cirurgicamente tratados para ELT por EMT após a assinatura do Termo de Consentimento Livre e Esclarecido. A concentraçăo de $5 \mathrm{HT}$ será medida através de high-performance liquid chromatography (HPLC) com detecção por fluorescência. Os receptores e transmissor de serotonina serão avaliados por Western Blot.

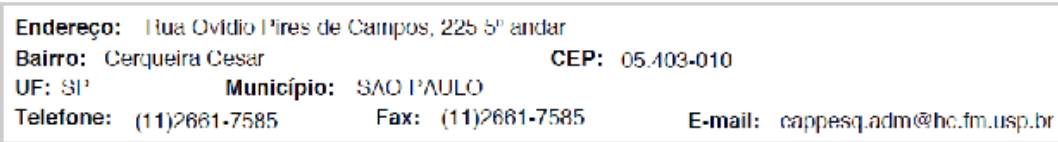




\section{APÊNDICE 2. PARECER DE APRECIAÇÃO DO CEP}

HOSPITAL DAS CLINICAS DA
FACULDADE DE MEDICINA DA Q Pratoforma
USP - HCFMUSP

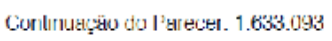

\section{Objetlvo da Pesqulsa:}

Objetivo Primário:

Este estudo tem como objetivo primário avaliar se a concentraçåo de serotonina e seus metabólitos, receptores de serotonina e transportadores de serotonina no hipocampo de pacientes com epilepsia do lobo temporal causada por esclerose mesial temporal (ELT-EMT) e distúrbios psiquiátricos estão diminuídos em comparação com os niveis de serotonina no tecido do hipocampo de pacientes com ELT-EMT sem comorbidades psiquiátricas.

Objetivo Secundário:

O objetivo secundário deste estudo é o de determinar se existe correlação entre niveis de serotonina e as variáveis relacionadas à gravidade da epilepsia.

\section{Avaliação dos Riscos e Beneficios:}

o presente estudo utilizará amostra biológica coletada durante ato cirúrgico já programado para tratamento de paciente epilepsia refrataria. Análise de Hipocampo ressecados cirurgicamente por epilepsia do lobo temporal decorrente de esclerose mesial temporal refratária ao tratamento medicamentoso. A amostra do hipocampo será obtida dos pacientes que serão submetidos a procedimento neurocirúrgico padrão com lobectomia temporal anterior. Segundo o protocolo a indicação cirurgica será clinica e independente do estudo em questão.

\section{Comentárlos e Considerações sobre a Pesqulsa:}

Projeto com objetivos bem definidos e metodologia adequadas aos objetivos propostos. O material biologico ficara armazenado no LIM27 onde sera feita as analises propostas.

\section{Conslderações sobre os Termos de apresentação obrigatórla:}

TCLE escrito em linguagem clara e compreensivel.

\section{Conclusões ou Pendências e Lista de Inadequações:}

sem pendencias

\section{Consideraçōes Finais a critério do CEP:}

Em conformidade com a Resoluçăo CNS n'466/12 - cabe ao pesquisador: a) desenvolver o projeto conforme delineado; b) elaborar e apresentar relatórios parciais e final; c)apresentar dados solicitados pelo CEP, a qualquer momento; d) manter em arquivo sob sua guarda, por 5 anos da pesquisa, contendo fichas individuais e todos os demais documentos recomendados pelo CEP; e) encaminhar os resultados para publicaçåo, com os devidos créditos aos pesquisadores associados e ao pessoal técnico participante do projeto; f) justificar perante ao CEP interrupção do projeto ou a não publicação dos resultados.

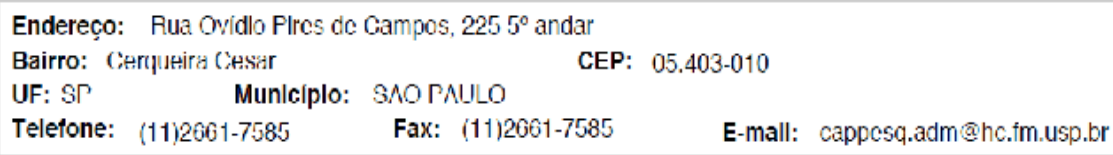




\section{APÊNDICE 2. PARECER DE APRECIAÇÃO DO CEP}

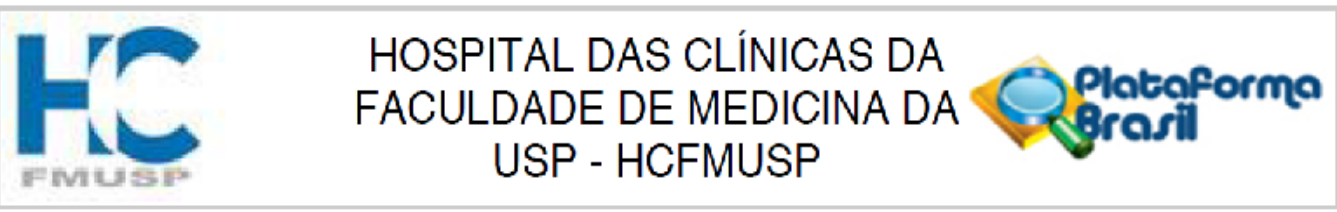

Continuaça do Farecer 1633093

Este parecer foi elaborado baseado nos documentos abaixo relacionados:

\begin{tabular}{|c|c|c|c|c|}
\hline Tipo Documento & Arquivo & Postagem & Autor & Situação \\
\hline $\begin{array}{l}\text { Informaçôes Básicas } \\
\text { do Projeto }\end{array}$ & $\begin{array}{l}\text { PB INFORMAÇÕES BÁSICAS DO P } \\
\text { ROJETO 189437.pdf }\end{array}$ & $\begin{array}{c}07 / 06 / 2016 \\
12: 30: 32\end{array}$ & & Aceito \\
\hline $\begin{array}{l}\text { TCLE / Termos de } \\
\text { Assentimento / } \\
\text { Justificativa de } \\
\text { Ausência }\end{array}$ & TCLE.dOC & $\begin{array}{c}07 / 06 / 2016 \\
12: 29: 08\end{array}$ & $\begin{array}{l}\text { Kette Dualibi Ramos } \\
\text { Valente }\end{array}$ & Aceito \\
\hline Outros & Formulario.pdf & $\begin{array}{c}30 / 03 / 2016 \\
12: 01: 51\end{array}$ & $\begin{array}{l}\text { Kette Dualibi Ramos } \\
\text { Valente }\end{array}$ & Aceito \\
\hline Orçamento & Orcamento.xIs & $\begin{array}{c}29 / 01 / 2016 \\
12: 59: 37\end{array}$ & $\begin{array}{l}\text { Kette Dualibi Ramos } \\
\text { Valente }\end{array}$ & Aceito \\
\hline Outros & Anuencia.pdf & $\begin{array}{c}29 / 01 / 2016 \\
12: 58: 47\end{array}$ & $\begin{array}{l}\text { Kette Dualibi Ramos } \\
\text { Valente }\end{array}$ & Aceito \\
\hline $\begin{array}{l}\text { Projeto Detalhado / } \\
\text { Brochura } \\
\text { Investigador }\end{array}$ & Projeto.doc & $\begin{array}{c}08 / 01 / 2016 \\
09: 39: 29\end{array}$ & $\begin{array}{l}\text { Kette Dualibi Ramos } \\
\text { Valente }\end{array}$ & Aceito \\
\hline Folha de Rosto & Folha_de_Rosto_13456.pdf & $\begin{array}{c}08 / 01 / 2016 \\
09: 34: 58 \\
\end{array}$ & $\begin{array}{l}\text { Kette Dualibi Ramos } \\
\text { Valente }\end{array}$ & Aceito \\
\hline
\end{tabular}

Situação do Parecer:

Aprovado

Necessita Apreciação da CONEP:

Não

SAO PAULO, 12 de Julho de 2016

Assinado por:

Joel Faintuch

(Coordenador)

Endereço: Rua Ovidlo Plrcs do Campos, $2255^{\circ}$ andar

Balrro: Cerquelra Cesar

CEP: $\quad 05.40 \% 3 \cdot 010$

UF: SP

Municipio: SAO PAIIIO

Telefone: (11)2661-7585

Fax: (11)2061-7585

E-mall: cappesq.adm@hc.fm.usp.br 